\author{
UNIVERSIDADE DE SÃO PAULO \\ ESCOLA DE ENGENHARIA DE SÃO CARLOS \\ DEPARTAMENTO DE ENGENHARIA DE ESTRUTURAS
}

LINCOLN GRASS VIAPIANA

Influência do confinamento na resistência e ductilidade de pilares curtos de concreto de ultra alta resistência submetidos à compressão centrada 



\title{
Influência do confinamento na resistência e ductilidade de pilares curtos de concreto de ultra alta resistência submetidos à compressão centrada
}

\begin{abstract}
VERSÃO CORRIGIDA
A versão original encontra-se na escola de Engenharia de São Carlos

Dissertação apresentada ao Departamento de Engenharia de Estruturas da EESC-USP como parte integrante dos requisitos para obtenção do título de Mestre em Ciências, Programa de Engenharia Civil (Estruturas).
\end{abstract}

Orientador:

Prof. Dr. Ricardo Carrazedo 
AUTORIZO A REPRODUÇÃO TOTAL OU PARCIAL DESTE TRABALHO, POR QUALQUER MEIO CONVENCIONAL OU ELETRÔNICO, PARA FINS DE ESTUDO E PESQUISA, DESDE QUE CITADA A FONTE.

VIAPIANA, LINCOLN GRASS

V735i Influência do confinamento na resistência e ductilidade de pilares curtos de concreto de ultra alta resistência submetidos à compressão centrada / LINCOLN GRASS VIAPIANA; orientador Ricardo Carrazedo. São Carlos, 2016.

Dissertação (Mestrado) - Programa de Pós-Graduação em Engenharia de Estruturas -- Escola de Engenharia de São Carlos da Universidade de São Paulo, 2016.

1. Concreto de ultra alta resistência. 2. Confinamento. 3. Armadura transversal. 4. Pilares. 5. Compressão axial. 6. Ductilidade. I. Título. 


\section{FOLHA DE JULGAMENTO}

Candidato: Engenheiro LINCOLN GRASS VIAPIANA.

Título da dissertação: "Influência do confinamento na resistência e ductilidade de pilares curtos de concreto de ultra alta resistência submetidos à compressāo centrada".

Data da defesa: 17/03/2016

\section{Comissão Julgadora:}

Prof. Dr. Ricardo Carrazedo (Orientador)

(Escola de Engenharia de São Carlos/EESC)

Prof. Dr. Llbânio Miranda Pinheiro

(Escola de Engenharia de São Carlos/EESC)

Prof. Dr. Fernando Menezes de Almeida Filho (Universidade Federal de São Carlos/UFSCar)

\section{Resultado:}
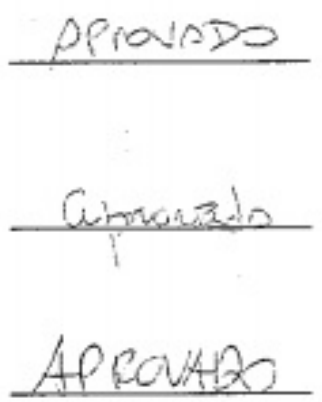

Coordenador do Programa de Pós-Graduaçăo em Engenheira Civil (Engenharia de Estruturas):

Prof. Titular Humberto Breves Coda

Presidente da Comissão de Pós-Graduação:

Prof. Associado Paulo Sergio Lima Segantine 



\section{AGRADECIMENTOS}

A Deus por ter me dado saúde e força para superar as dificuldades.

A minha mãe Sonia Regina Grass Colling, pelo amor, incentivo e por ser meu porto seguro.

A minha família, pelo amor e atenção com que sempre me acolheram, em especial aos meus avós Ely Grass e José Aroldo Grass.

Ao Prof. Dr. Ricardo Carrazedo, pela orientação, dedicação e amizade desenvolvida ao longo deste trabalho.

Aos professores do Departamento de Engenharia de Estruturas pela contribuição em minha formação acadêmica e pessoal, especialmente aos professores José Samuel Giongo e Libânio Miranda Pinheiro, pelas contribuições feitas no exame de qualificação.

A todos os funcionários do Laboratório de Estruturas, do Departamento de Engenharia de Estruturas da Escola de Engenharia de São Carlos - USP, pela colaboração na realização dos ensaios experimentais.

Ao Professor Nelson Seidler, pelos sábios ensinamentos transmitidos e pelas orientações no desenvolvimento de pesquisas científicas durante minha graduação.

Às empresas: Belgo Bekaert Arames Ltda., Cimento TUPI, Mineração Jundu Ltda., GRACE Brasil Ltda. e Cimento Novo Atacadista Ltda., pela doação dos materiais utilizados na pesquisa.

Ao Laboratório de Ensaios Tecnológicos da Construção Civil - LETCC, da Universidade Regional Integrada do Alto Uruguai e Missões-URI, campus de Santo Ângelo, por contribuir em uma das etapas essenciais para o desenvolvimento da pesquisa.

À CAPES e ao CNPQ, pelas bolsas de estudo concedidas. 

"Por mais longa que seja a caminhada o mais importante é dar o primeiro passo" Vinícius de Moraes 



\section{RESUMO}

VIAPIANA, L.G. Influência do confinamento na resistência e ductilidade de pilares curtos de concreto de ultra alta resistência submetidos à compressão centrada. 2016. 172 p. Dissertação de Mestrado em Engenharia Civil (Estruturas) Escola de Engenharia de São Carlos, Universidade de São Paulo, São Carlos, 2016.

Neste estudo foram analisados experimentalmente o comportamento de 24 pilares curtos de Concreto de Ultra Alta Resistência - CUAR, confinados por armaduras helicoidais, avaliando especificamente os acréscimos de resistência e ductilidade obtidos com diferentes níveis de pressão lateral de confinamento. $\mathrm{Na}$ etapa experimental foram realizados ensaios de pilares curtos de CUAR com as seguintes características: - seção circular de $7,2 \mathrm{~cm}$ de diâmetro e comprimento de $23 \mathrm{~cm}$, e quatro níveis de resistência à compressão do concreto sendo eles, 165, 175, 200 e $229 \mathrm{MPa}$, dosados sem e com adição de fibras metálicas; - diferentes espaçamentos das armaduras helicoidais, de modo que fossem obtidas situações com baixo, médio e alto índice de confinamento e taxa de armadura longitudinal fixa. Os ensaios de compressão centrada foram realizados com controle de deslocamento, de modo que foram obtidas as curvas força $x$ deslocamento completas. Constatou-se que a seção resistente dos pilares de CUAR é a formada pelo núcleo de concreto confinado, área delimitada pelo eixo da armadura transversal. Observou-se que o CUAR com fibras metálicas apresenta maior deformação do núcleo de concreto confinado em relação ao núcleo de concreto confinado de CUAR sem adição de fibras metálicas, indicando dessa forma, que os pilares de CUAR com fibras metálicas apresentam comportamento mais dúctil. Para as situações de alto confinamento foram gerados ao concreto do núcleo confinado significativos acréscimos de resistência e deformação axial, aumentando a resistência do concreto confinado em relação a resistência do concreto não confinado em: $82,26 \%, 75,34 \%, 90,46 \%$ e $70,51 \%$, respectivamente, e as deformações axiais do concreto confinado em relação a deformação axial do concreto não confinado em: $433 \%, 474 \%, 647 \%$ e 550\%. Finalmente, acredita-se que os resultados obtidos poderão trazer subsídios para aplicações futuras desta técnica de confinamento na construção de novos elementos estruturais e no reforço de pilares submetidos a elevados níveis de solicitação axial.

Palavras-chave: Concreto de ultra alta resistência. Confinamento. Armadura transversal. Pilares. Compressão axial. Ductilidade. 



\begin{abstract}
VIAPIANA, L.G. Influence of confinement on strength and ductility of short ultra high strength concrete columns subjected to compressive force. 2016. $172 \mathrm{p}$. Master's Thesis in Civil Engineering (Structures) - Escola de Engenharia de São Carlos, Universidade de São Paulo, São Carlos, 2016.

This study evaluated experimentally the behavior of 24 short columns of Ultra High Strength Concrete - UHSC confined by helical transverse reinforcement, specifically evaluating strength increases and ductility obtained with different levels of lateral pressure of confinement. In the experimental phase short UHSC columns with the following characteristics were tested: - circular cross section of $7.2 \mathrm{~cm}$ diameter and $23 \mathrm{~cm}$ length, four levels of concrete strength $(165,175,200$ and $229 \mathrm{MPa})$, with and without addition of metallic fibers; - different spacing of transverse reinforcement, so that situations were obtained with low, medium and high level of confinement, while the longitudinal reinforcement ratio was fixed. The centered compression tests were conducted with displacement control, so that complete force $\mathrm{x}$ displacement curves were obtained. It was found that the resistant section of UHSC columns is formed by the confined concrete core delimited by the axis of the transverse reinforcement. It was observed that the axial displacement reached in columns with steel fibers was higher than without fibers, indicating that columns with steel fibers exhibit more ductile behavior. For high confinement levels significant axial strength and displacement increases were observed. Increases of axial strength of confined concrete in comparison to unconfined concrete were $82.26 \%, 75.34 \%, 90,46 \%$ and $70.51 \%$. Axial displacements were increased by $433 \%, 474 \%, 647 \%$ and $550 \%$. Finally, it is believed that the results could provide information for future applications of this technique in construction of a new type of columns or in strengthening of columns subjected to high levels of axial force.
\end{abstract}

Keywords: Ultra-high strength concrete. Confinement. Transverse reinforcement. Columns. Axial compression. Ductility. 



\section{SUMÁRIO}

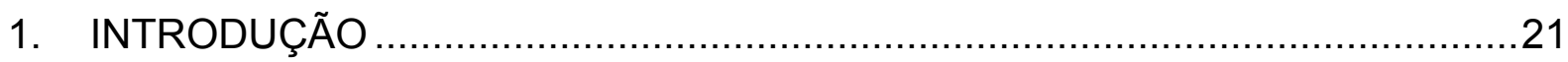

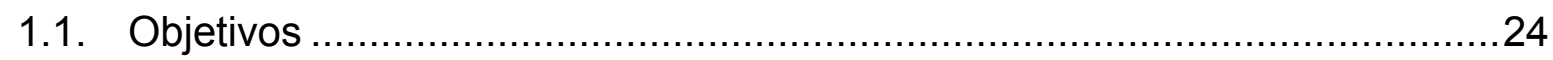

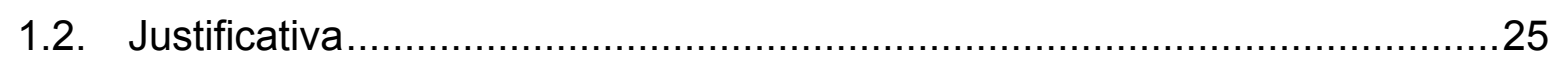

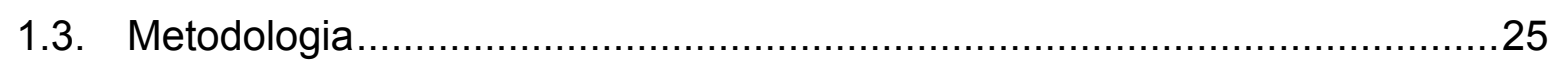

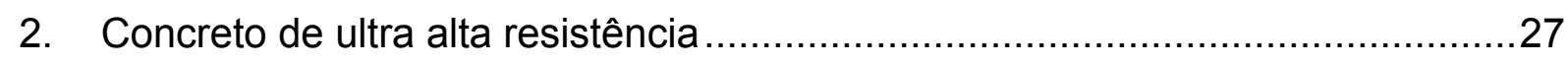

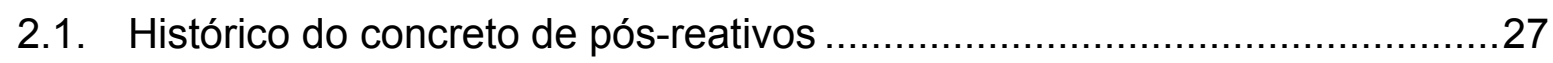

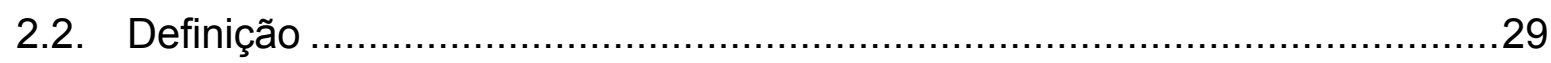

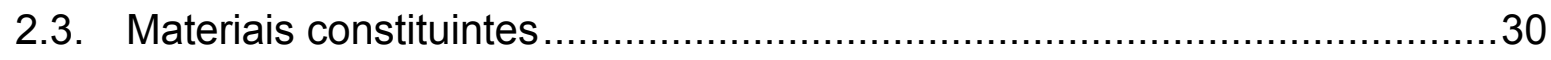

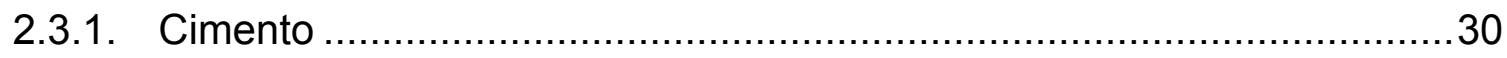

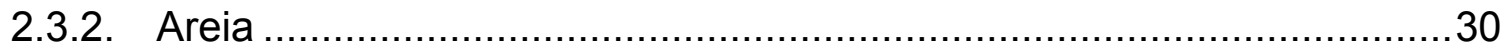

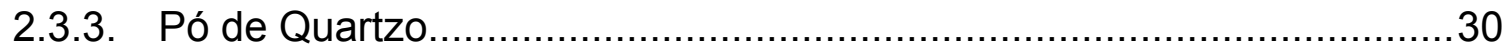

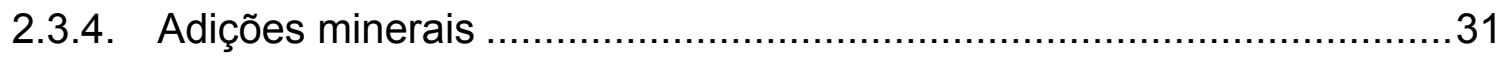

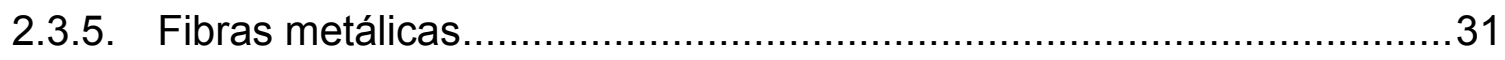

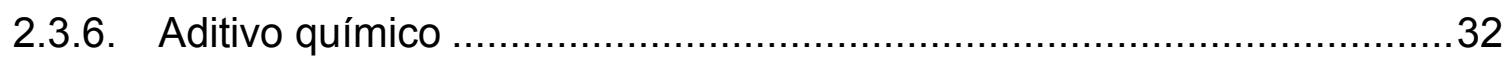

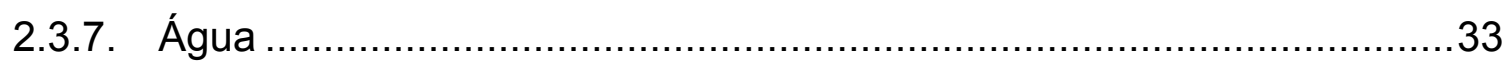

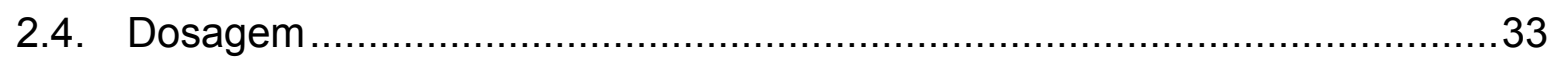

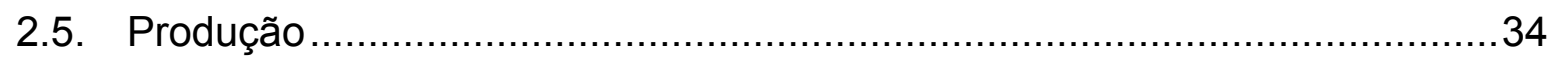

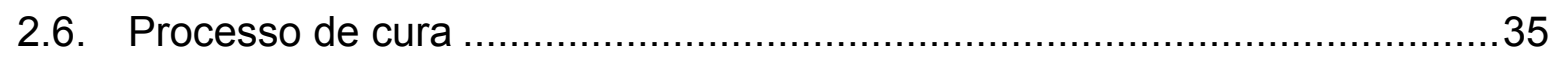

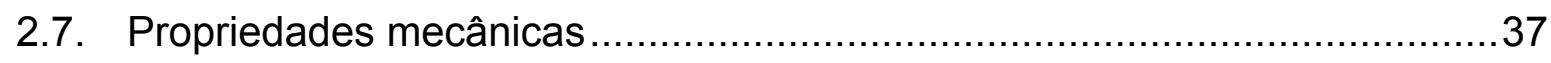

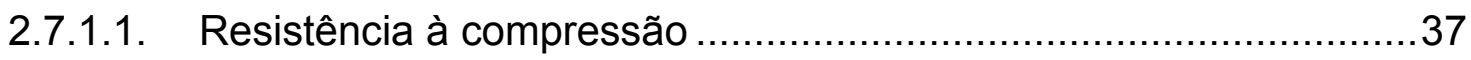

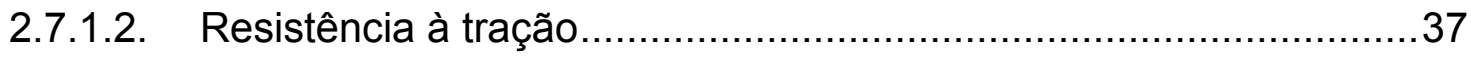

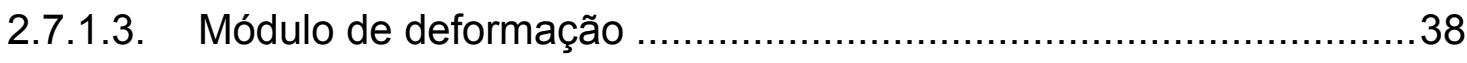

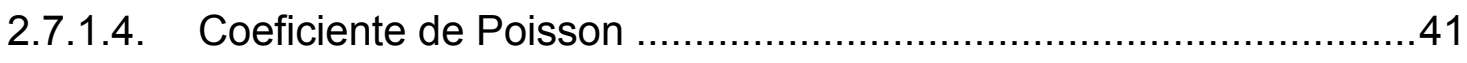

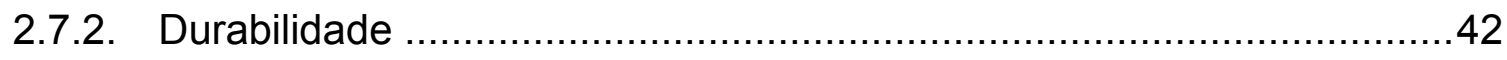

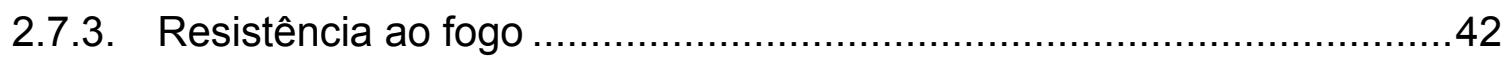

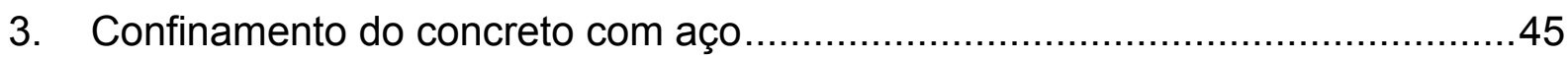

3.1. Efeitos do confinamento com aço no concreto........................................45 
3.2. Determinação da pressão lateral de confinamento com aço em pilares circulares

3.3. Principais variáveis influentes no confinamento 50

3.3.1. Resistência à compressão do concreto .50

3.3.2. Resistência do aço da armadura transversal. 50

3.3.3. Taxa de armadura transversal 51

3.3.4. Taxa de armadura longitudinal 52

3.3.5. Arranjo da armadura transversal na seção transversal 53

3.4. Modelos teóricos de confinamento com aço .54

3.4.1. Modelo de RICHART et al. (1929) .54

3.4.2. Modelo de MANDER et al. (1988) 55

3.4.3. Modelo de CUSSON \& PAULTRE (1995) 58

3.4.4. Modelo de RAZVI \&SAATCIOGLU (1999). 59

3.5. Diagrama força-deformação idealizado para pilares curtos de concreto armado proposto por GRAYBEAL \& PESSIKI (2000) 60

3.6. Índices de ductilidade 62

4. Metodologia e Resultados .65

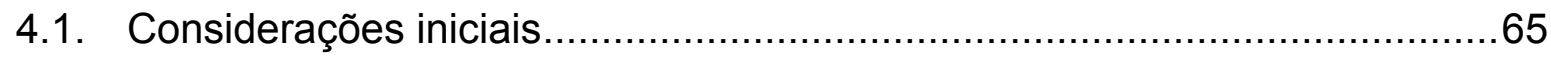

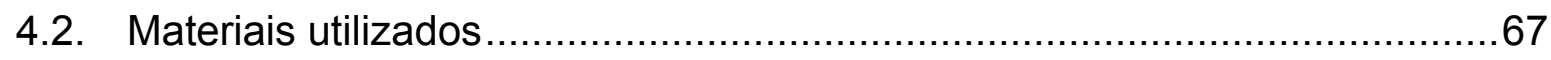

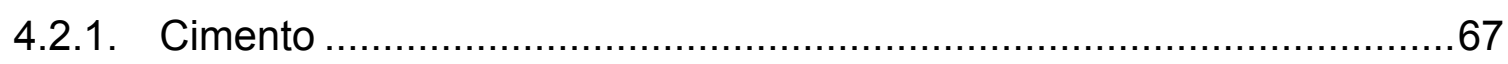

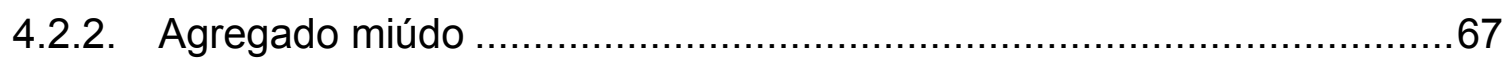

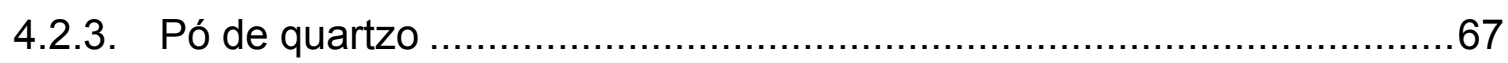

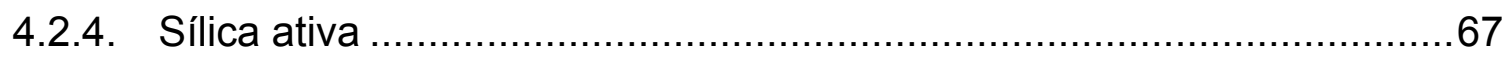

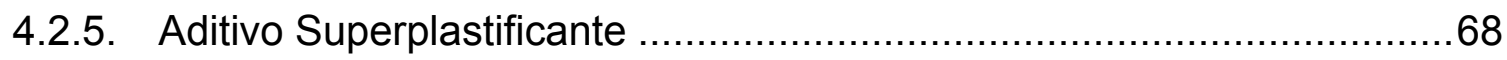

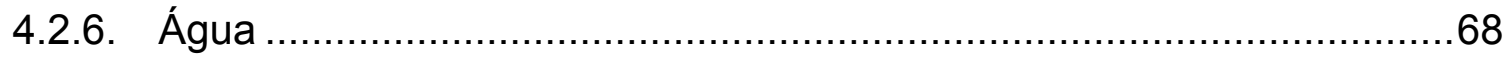

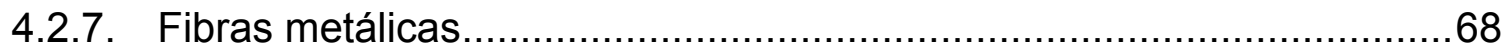

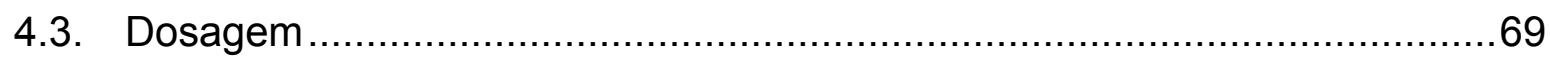

4.3.1. Determinação dos teores ideais dos materiais constituintes do CPR....69 


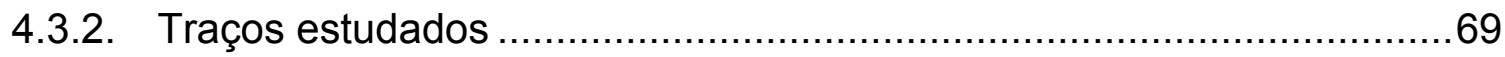

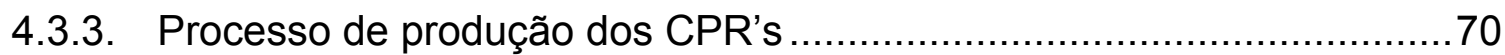

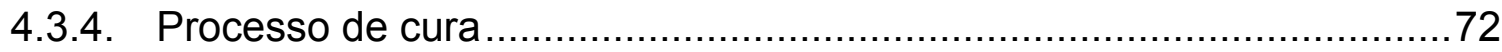

4.3.5. Resistência à compressão.............................................................

4.3.5.1. Resultados dos ensaios de resistência à compressão.....................73

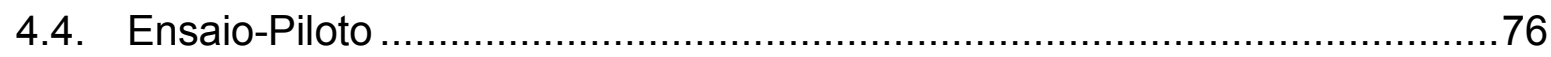

4.4.1. Características geométricas dos modelos-pilotos................................76

4.4.2. Resistência à compressão............................................................

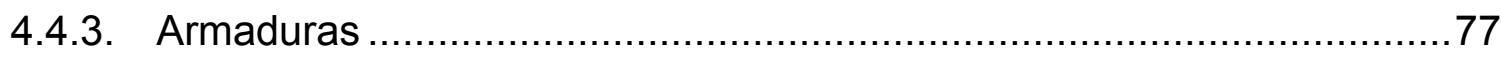

4.4.4. Retífica das extremidades dos modelos ..........................................77

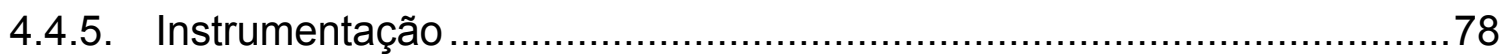

4.4.6. Velocidade de carregamento ........................................................

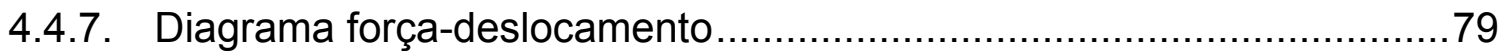

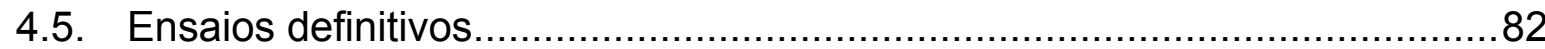

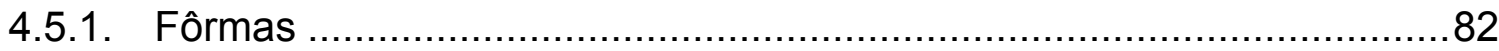

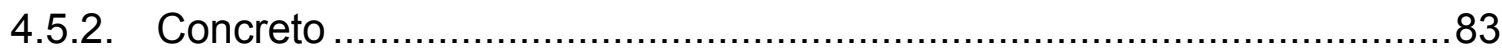

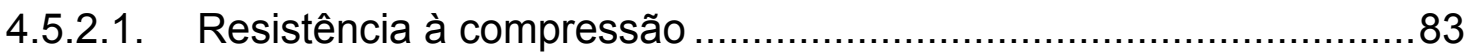

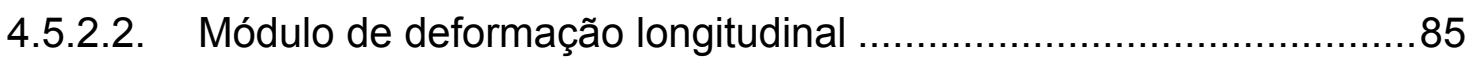

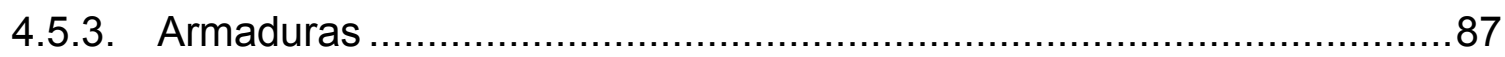

4.5.3.1. Caracterização das armaduras ..................................................90

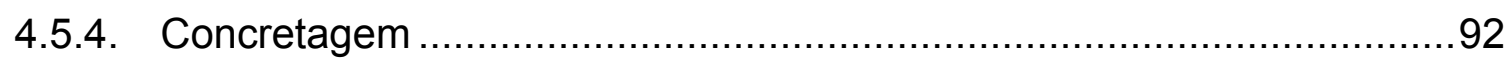

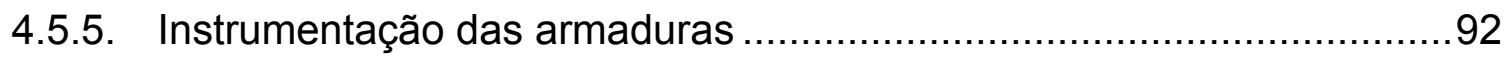

4.5.6. Reforço das extremidades dos pilares...............................................94

4.5.7. Instrumentação na máquina de ensaio ...............................................95

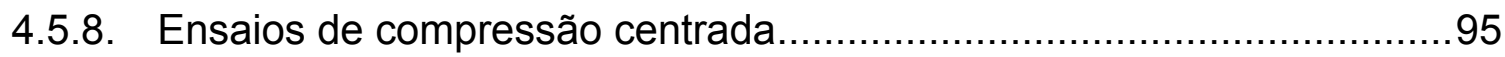

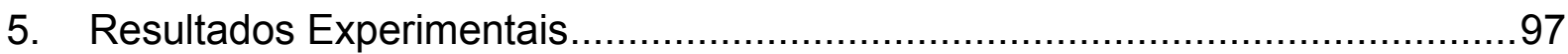

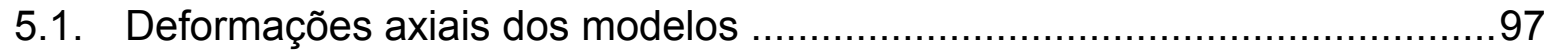

5.1.1. Correção da acomodação inicial de ensaio ........................................97 
5.1.2. Correção da deformação axial do pilar para a deformação da armadura longitudinal

5.1.3. Diagrama força-deformação axial para os pilares das séries estudadas 102

5.1.3.1. Considerações iniciais 102

5.1.3.2. Série TCF 103

5.1.3.3. Série TSF 106

5.1.3.4. Série ICF 109

5.1.3.5. Série ISF 112

5.2. Influência da dosagem e cura do CUAR ….........................................115

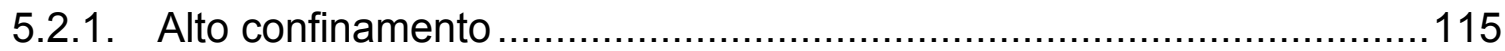

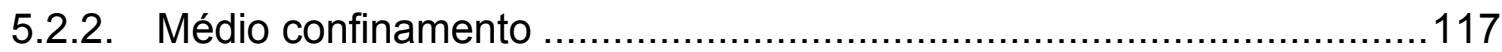

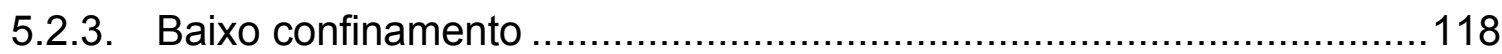

5.3. Deformações máximas nas armaduras longitudinais e transversais..........119

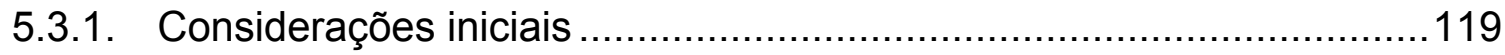

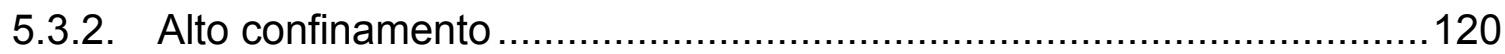

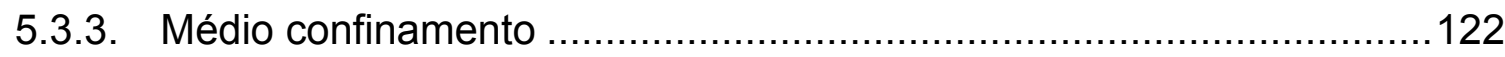

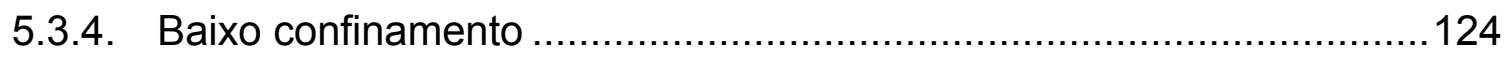

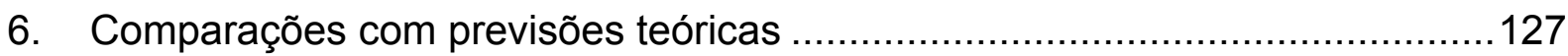

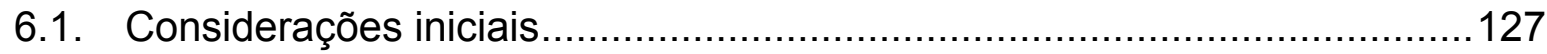

6.1.1. Consideração da flambagem das armaduras longitudinais na capacidade

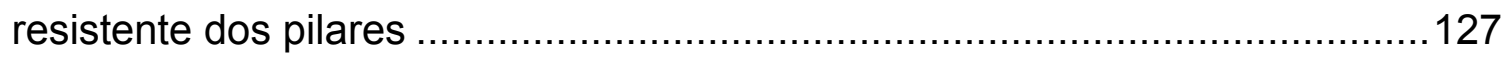

6.1.1.1. Simulação numérica da flambagem ......................................128

6.2. Estimativa da força normal teórica $\left(F_{1, t e o}\right)$ no ponto $\left(F_{1}, \varepsilon_{1}\right)$, para as séries

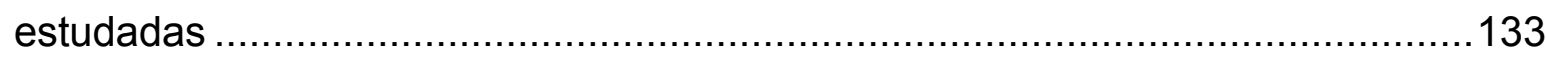

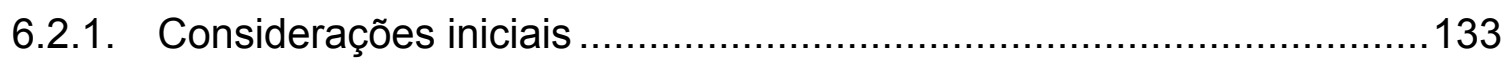

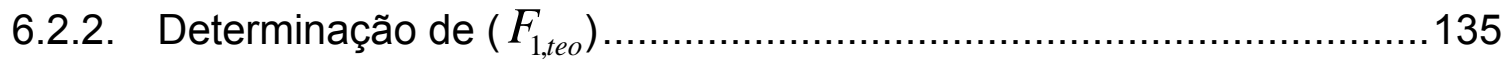

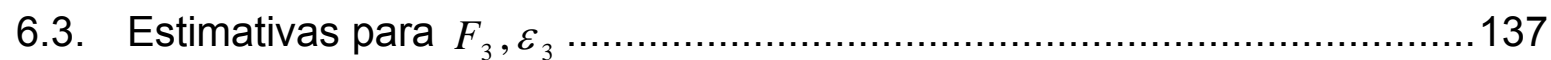

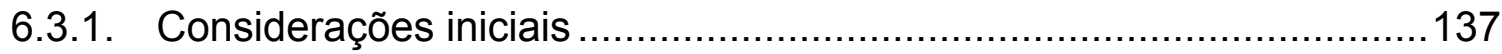


6.3.2. Série TCF

6.3.3. Série TSF

6.3.4. Série ICF 143

6.3.5. Série ISF 146

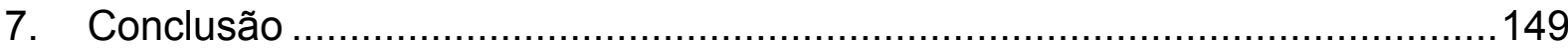

7.1. Sugestão para continuação da pesquisa .........................................151

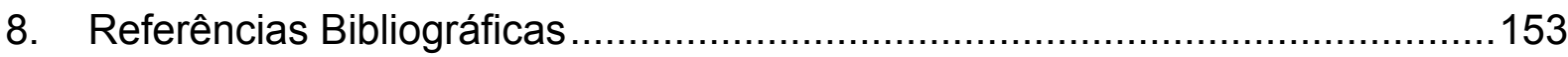

9. Apêndice $A-$ Fotos dos ensaios definitivos ......................................... 157

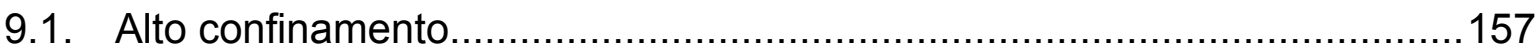

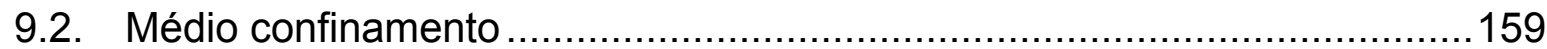

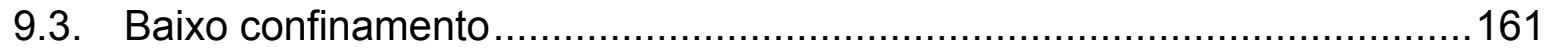

10. Apêndice B - Diagramas força-deformação dos ensaios definitivos................165

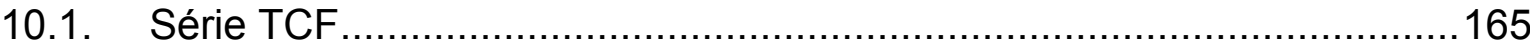

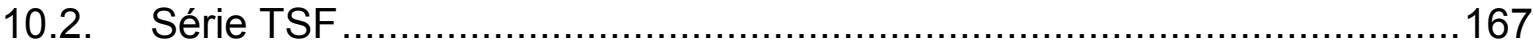

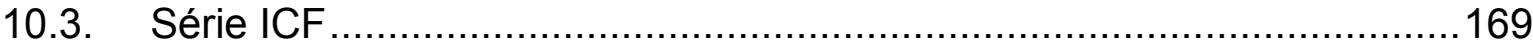

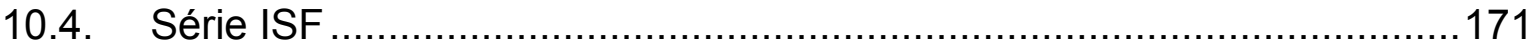





\section{INTRODUÇÃO}

As transformações que vem ocorrendo em todo o setor da construção civil, pelo mundo inteiro, levam a constantes buscas por novas tecnologias para a solução de grandes problemas oriundos das exigências impostas pela constante evolução da sociedade e do meio em que habita. Nos últimos 20 anos, o estabelecimento de novas metodologias de dosagem, a evolução dos aditivos químicos e a associação de minerais ultrafinos (pós-reativos) proporcionaram, aos engenheiros tecnologistas do concreto, avanços tecnológicos em suas propriedades mecânicas, dando origem a uma nova classe de concretos, a dos concretos de ultra alta resistência (CUAR), com propriedades mecânicas superiores às das classes de concretos existentes.

De acordo com METHA \& MONTEIRO (2008), o surgimento dessa nova classe de concretos originou-se da otimização dos seguintes parâmetros de dosagem e condições de cura: eliminação do agregado graúdo, melhoria no empacotamento do material granular, aplicação de pressão no concreto fresco, aplicação de tratamento térmico e uso de fibras metálicas com fração volumétrica máxima de 2,5\%. Essa nova classe de concretos pode alcançar resistências à compressão acima de $200 \mathrm{MPa}$, quando curados em água quente até $90^{\circ} \mathrm{C}$ por três dias, e de $800 \mathrm{MPa}$ quando curados a $400^{\circ} \mathrm{C}$. WELDON et al. (2010) citam o concreto de pós reativos (CPR), ou como é conhecido internacionalmente (Reactive Powder Concrete - RPC), como o principal representante dessa nova classe de concretos de ultra alta resistência CUAR.

Esses avanços nas propriedades mecânicas dos concretos proporcionam aos engenheiros projetistas a otimização de projetos estruturais, reduzindo seções dos elementos, utilizando de forma mais eficaz a área da edificação e proporcionando uma estrutura mais leve, quando comparada com as que se obteriam com concreto convencional. MAROLIYA (2012) cita o crescente interesse ao longo dos últimos anos na obtenção de concretos de alta resistência, principalmente por indústrias de elementos pré-fabricados protendidos, onde se deseja diminuir o peso próprio dos elementos pré-fabricados e consequentemente a redução dos custos com a estrutura. 
Essa redução das seções dos elementos estruturais implica diretamente sobre as cargas a serem transmitidas às fundações, reduzindo os custos com elas, obtendo menores custos com fôrmas, entre tantas outras vantagens que se apresentam na utilização de concretos com níveis elevados de resistência à compressão.

A necessidade de novas tecnologias se faz diariamente, pois o mercado da construção civil está cada vez mais exigindo novos produtos com custos menores e de fácil aplicação. O presente trabalho pretende abordar o estudo do confinamento em pilares curtos de concreto de ultra alta resistência (CUAR), confinados pela aplicação da técnica do dimensionamento de armaduras transversais no formato de espirais de aço de alta resistência.

De acordo com MENDES (1993), à medida que a resistência à compressão do concreto é elevada, o material tem como consequência imediata o aumento de sua fragilidade. Esse aumento na fragilidade do concreto e perda de ductilidade estão relacionados diretamente ao modo de propagação de fissuras quando o material está sob a ação de carregamento.

A ductilidade dos elementos pode ser significativamente incrementada com a utilização de arranjos de armaduras de confinamento, e inclusive nos dias atuais é de suma importância, principalmente em regiões sujeitas a solicitações de abalos sísmicos, que as estruturas de concreto armado suportem solicitações dinâmicas, dissipando essa energia através do comportamento dúctil dos elementos estruturais. São apresentadas na figura 1.1 comparações de diferentes comportamentos tensãodeformação para: concretos de baixa resistência (CBR), alta resistência (CAR), concreto de pós reativos com fibras metálicas (CPR), CPR sem fibras metálicas e confinado por tubo metálico, CPR com fibras metálicas e confinado por tubo metálico, CPR sem fibras metálicas prensado e confinado por tubo metálico e CPR com fibras metálicas prensado e confinado por tubo metálico, evidenciando os acréscimos de resistência e ductilidade gerados aos CUAR pelo confinamento. 


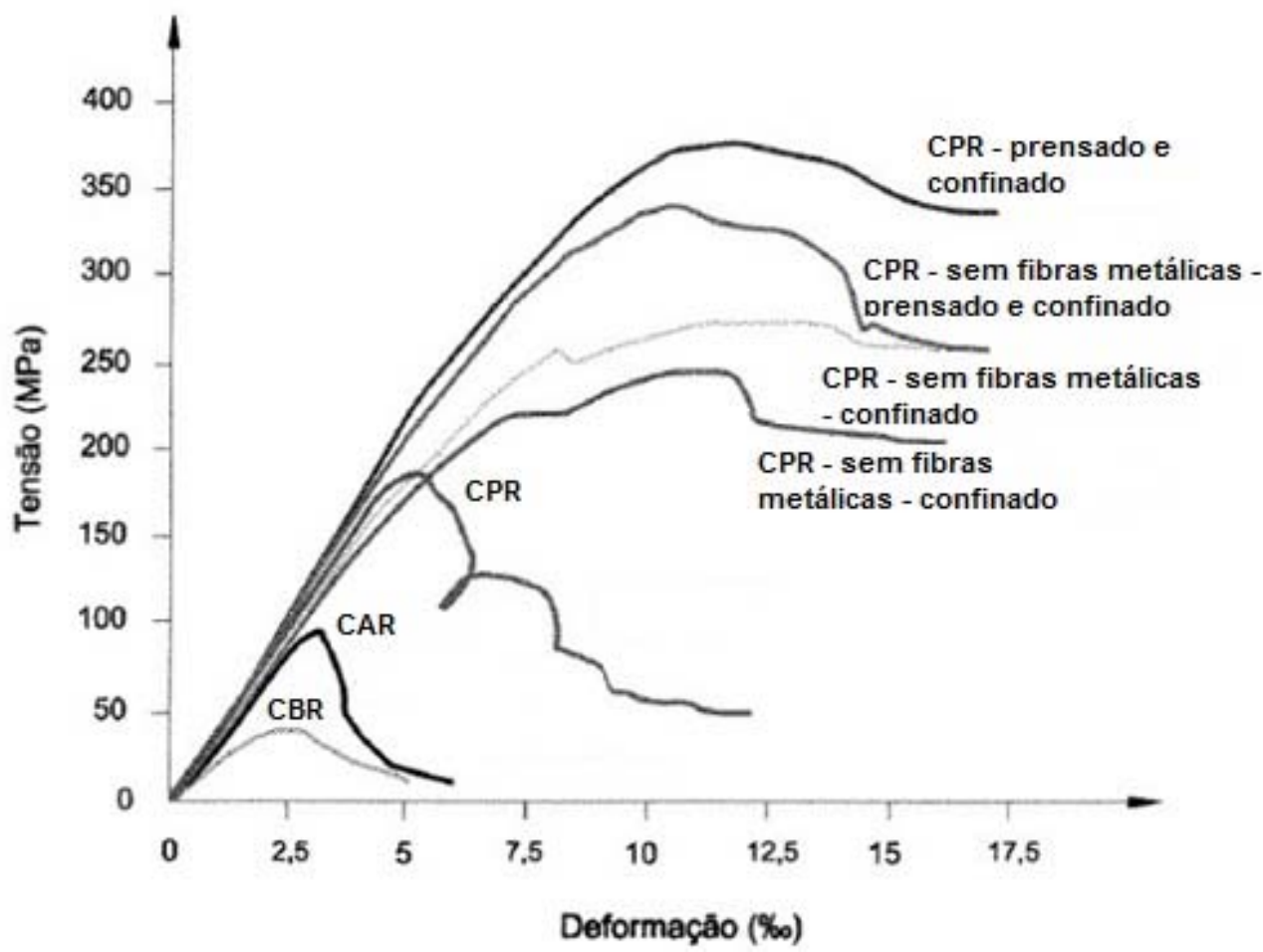

Figura 1.1- Diagramas tensão-deformação para diferentes tipos de concretos (BLAIS \& COUTURE,1999)

Sabe-se que o comportamento frágil apresentado pelo concreto de alta resistência espanta muito os engenheiros projetistas, principalmente pelo medo de suas construções apresentarem o modo de ruptura frágil desse material. $E$ este pensamento limita de certa forma a utilização desses concretos em obras civis. $\mathrm{O}$ elemento mais importante em uma estrutura de concreto armado é o pilar, pois este recebe as cargas provenientes das lajes e vigas e as transmitem para os elementos de fundação. Consequentemente é de grande valia que esses elementos sejam capazes de se comportarem de forma dúctil. Sabe-se que a maneira mais eficiente de se melhorar a ductilidade desses elementos é através do confinamento, principalmente por aumentar consideravelmente a deformação última do concreto. Pretende-se nesse trabalho abordar o estudo do confinamento em pilares curtos de concreto de ultra alta resistência (CUAR), pela aplicação de armaduras transversais no formato de espirais de aço de alta resistência. Visa-se estudar a contribuição do confinamento sobre a resistência e ductilidade. As principais variáveis a serem analisadas serão a capacidade resistente, a deformação última e o comportamento tensão-deformação dos modelos reforçados. A avaliação dos efeitos de confinamento 
será por meio de análise experimental e simulações teóricas com modelos teóricos de confinamento. A análise experimental constituirá no ensaio de pilares curtos de seção circular submetidos à compressão centrada, devidamente instrumentados para a observação da capacidade resistente, ductilidade e efeitos de confinamento.

\subsection{Objetivos}

O presente trabalho aborda o estudo do confinamento em pilares curtos de concreto de ultra alta resistência (CUAR), pela aplicação de armaduras transversais no formato de espirais de aço de alta resistência. Visa-se obter informações através da análise experimental sobre a influência do confinamento na resistência e na ductilidade de pilares curtos de CUAR, submetidos à compressão centrada, executados com quatro níveis de resistência média à compressão, 160, 175, 200 e $229 \mathrm{MPa}$, dosados com e sem a adição de fibras metálicas, fazendo com que desta forma se tenham quatro tipos diferentes de respostas nos diagramas tensãodeformação, para os concretos confinados. Pretende-se verificar os tipos de rupturas apresentadas para as situações de baixo, médio e alto confinamento e quais irão garantir ruptura dúctil aos pilares. Dessa forma, visa-se contribuir para futuras aplicações do CUAR em pilares curtos solicitados a compressão centrada, fornecendo orientações sobre as seguintes influências:

I. Diferentes pressões laterais efetivas de confinamento;

II. Diferentes níveis de resistência à compressão do concreto;

III. Adição de fibras metálicas ao concreto;

IV. Diferentes condições de cura do concreto (térmica e ambiente);

V. Aços de alta resistência para utilização nas armaduras longitudinais e transversais;

VI. Taxas mínimas transversais para garantir ruptura dúctil de pilares curtos, em função da resistência do concreto não confinado. 


\subsection{Justificativa}

O confinamento do concreto convencional é conhecido por melhorar a sua resistência última e sua ductilidade. Consequentemente, vários modelos foram desenvolvidos nos últimos anos para prever sua resposta tensão-deformação no confinamento. Ao contrário do confinamento no $\mathrm{CBR}$, o confinamento no $\mathrm{CAR}$ não leva a melhorias significativas na sua resistência última e na ductilidade, justamente por este concreto apresentar baixa capacidade de deformação. Por outro lado, devido à elevada capacidade de deformação apresentada pelo CUAR, espera-se que seu comportamento no confinamento seja superior ao apresentado pelo CAR.

São poucas pesquisas encontradas na literatura sobre os efeitos do confinamento no CUAR, apesar dos grandes benefícios que podem ser obtidos em incrementos de resistência, deformação de pico e ductilidade dos elementos confinados. O CUAR sem adição de fibras metálicas apresenta um diagrama tensãodeformação praticamente elástico linear até a ruptura, e esta fragilidade espanta os engenheiros projetistas, pois esta fragilidade não é uma característica desejável em estruturas que necessitam de ductilidade. $O$ estudo de alternativas que aumentem a ductilidade desse material, como a adição de fibras metálicas e os efeitos do confinamento, é altamente desejável e possibilitará incrementar a sua aplicação na construção civil.

Por conseguinte, o desenvolvimento de recomendações sobre as influências dos índices de confinamento nos ganhos de resistência, deformação última e ductilidade torna-se de fundamental importância para projetos de pilares curtos de CUAR, bem como orientações sobre quais níveis irão garantir uma ruptura dúctil aos pilares.

\subsection{Metodologia}

Para a busca dos objetivos propostos nesta pesquisa, a metodologia experimental foi fragmentada em três etapas: a primeira relacionada à obtenção dos 
concretos de ultra alta resistência (CUAR's), a segunda relativa ao ensaio piloto e a terceira pertencente aos ensaios definitivos.

Para a obtenção dos CUAR's, partiu-se da utilização de um traço de referência de CPR, proposto por GRASS \& SEIDLER (2010), realizando-se a verificação de sua máxima resistência à compressão, e posteriormente a execução de seis traços auxiliares para o seu aprimoramento, estudando-se as influências nos teores de adição de: sílica ativa, pó de quartzo e fibras metálicas.

A etapa do ensaio piloto compreendeu a avaliação do emprego da instrumentação inicialmente proposta para avaliação: das deformações nas armaduras longitudinais e transversais e do deslocamento axial do modelo. Esses ensaios tiveram a intenção de constatar a eficiência da instrumentação inicialmente proposta, verificando todas as possíveis variáveis que pudessem comprometer a aquisição dos dados de ensaio.

Na última etapa, referente à série dos modelos definitivos, foi realizada a avaliação da influência do confinamento por meio da análise experimental de 24 pilares. A análise experimental constituiu no ensaio de 24 pilares curtos de CUAR, com seção circular, submetidos a compressão centrada, devidamente instrumentados para observação da capacidade resistente e ductilidade. Para tanto, o programa experimental envolveu a análise de modelos confinados por armadura transversal de aço de alta resistência, com diferentes taxas volumétricas de armadura transversal, taxa de armadura longitudinal fixa e quatro níveis de resistência à compressão do concreto.

A partir da análise dos resultados do programa experimental, verificou-se a eficiência de alguns modelos teóricos existentes de previsão do confinamento com aço, para a estimativa da capacidade resistente e da deformação última do CUAR. 


\section{Concreto de ultra alta resistência}

\subsection{Histórico do concreto de pós-reativos}

Segundo GRAYBEAL (2006), a classe dos concretos de ultra alta resistência (CUAR) surgiu nas últimas décadas, possuindo propriedades superiores às das classes dos concretos de baixa resistência (CBR) e dos concretos de alta resistência (CAR), e essas superioridades referem-se a resistência à compressão, módulo de elasticidade, resistência à abrasão, resistência ao impacto, menor fluência, menor retração e menor penetração de íons cloreto. DUGAT et al. (1996), na tabela 2.1 apresentam algumas dessas superioridades.

Tabela 2.1-Propriedades mecânicas comparadas ao concreto convencional e ao de alta resistência (DUGAT et al., 1996)

\begin{tabular}{lccc}
\hline \multicolumn{1}{c}{ Propriedades } & CBR & CAR & CPR \\
\hline $\begin{array}{l}\text { Resistência à Compressão } \\
\text { (MPa) }\end{array}$ & $\mathbf{2 0 ~ - ~ 5 0}$ & $\mathbf{6 0 - 8 0}$ & $200-800$ \\
\hline $\begin{array}{l}\text { Resistência à tração na Flexão } \\
(\mathrm{MPa})\end{array}$ & $\mathbf{4 - \mathbf { 8 }}$ & $\mathbf{6 - 1 0}$ & $15-140$ \\
\hline Energia de Fratura $\left(\mathrm{J} / \mathrm{m}^{2}\right)$ & $\mathbf{1 3 0}$ & $\mathbf{1 4 0}$ & $1000-40000$ \\
\hline Deformação Última $\left(10^{-6}\right)$ & $100-150$ & $100-150$ & $2000-8000$ \\
\hline
\end{tabular}

DUGAT et al. (1996) classificam o CPR em duas famílias: CPR 200 e CPR 800. Essa divisão baseia-se principalmente na máxima resistência alcançada para cada composição. A tabela 2.2 apresenta a composição típica de cada família.

Tabela 2.2 - Composição típica do CPR original (DUGAT et al., 1996)

\begin{tabular}{lcc}
\hline \multicolumn{1}{c}{ Material $\left(\mathrm{kg} / \mathrm{m}^{3}\right)$} & CPR 200 & CPR 800 \\
\hline $\begin{array}{l}\text { Cimento Portland Comum Tipo } \\
\text { I (ASTM) }\end{array}$ & $\mathbf{9 5 0}$ & 980 \\
\hline Sílica Ativa & $\mathbf{2 3 7}$ & 225 \\
\hline Pó de Quartzo & - & 382 \\
\hline Areia & $\mathbf{9 9 7}$ & 490 \\
\hline Fibras de aço 13 mm & $\mathbf{1 4 6}$ & - \\
\hline Fibras de aço 3 mm & - & 617 \\
\hline Superplastificante & $\mathbf{1 7}$ & 18 \\
\hline Água & $\mathbf{1 8 0}$ & 186 \\
\hline Relação (água/cimento+sílica) & 0,15 & 0,14 \\
\hline
\end{tabular}


De acordo com LIU et al. (2012), o concreto de pós reativos (CPR), ou como é conhecido internacionalmente (Reactive Powder Concrete - RPC), é o principal representante dessa classe de concretos de ultra alta resistência (CUAR). WELDON et al. (2010) citam que o CPR foi desenvolvido na década de 1990 por Richard e Cheyrezy no laboratório da Bouygues na França, baseado no princípio da formação de um material com o mínimo defeitos, obtido pelo aprimoramento de sua microestrutura. MAROLIYA (2012) cita que esse aprimoramento foi fundamentado nos seguintes parâmetros: eliminação do agregado graúdo, baixa relação água/materiais cimentícios, adição de material com propriedades pozolânicas, utilização de superplastificantes de última geração para baixar a relação água/cimento e garantir trabalhabilidade a mistura, aplicação de pressão durante ou posterior ao processo de moldagem, tratamento térmico e adição de fibras metálicas.

FEHLING et al. (2014) ressaltam a importância das partículas ultrafinas e reativas, presentes no cimento, pó de quartzo e sílica ativa, nessa composição, as quais contribuem de forma significativa para o aprimoramento do empacotamento de partículas nessa mistura, garantindo uma microestrutura densa, praticamente isenta de poros capilares, e que combinada com a baixa relação água/cimento proporciona ao material níveis de resistência à compressão superiores às das classes de concretos existentes. A figura 2.1 apresenta, para uma típica composição de CBR, CAR e CUAR, as frações volumétricas ocupadas por seus materiais constituintes.

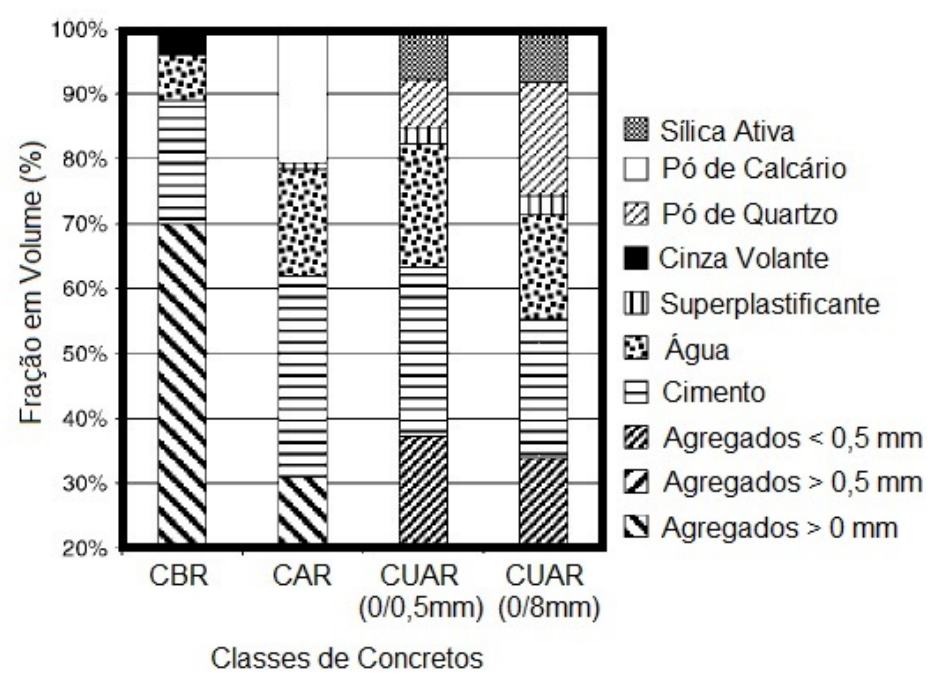

Figura 2.1 -Comparação dos volumes ocupados pelos agregados nos CBR, CAR e CUAR, modificado de (FEHLING et. al.,2014) 
Pode-se afirmar, sem sombra de dúvidas, que o CPR é fruto do avanço da engenharia de microestrutura, principalmente por ser um compósito constituído de partículas com granulometria muito fina e baixa relação água/cimento (a/c), apresentando uma matriz densa obtida a partir da otimização do empacotamento dos materiais granulares, com a trabalhabilidade alcançada por meio de aditivos químicos de altíssima eficiência. A superioridade nas propriedades mecânicas do CPR em relação às demais classes de concretos existentes vem possibilitando a conquista gradual de um mercado que antes era ocupado somente pelas estruturas metálicas, com a vantagem de adaptação às mais variadas formas arquitetônicas, possibilitando, desta forma, uma vasta aplicação na indústria da construção civil.

\subsection{Definição}

Segundo MAROLIYA (2012), o concreto de pós-reativos (CPR) é composto basicamente por: cimento, areia, pó de quartzo, sílica ativa, superplastificante e fibras metálicas, classificando a importância da contribuição de cada material constituinte em suas propriedades finais:

I. Cimento - material ligante e produção de hidratos primários;

II. Areia - dureza do agregado;

III. Pó de Quartzo - intensificar a atividade pozolânica;

IV. Sílica Ativa - produção de hidratos secundários e efeito microfíller;

V. Superplastificante - redução do fator água/cimento e dar plasticidade à mistura;

VI. Fibras metálicas - melhorar a ductilidade. 


\subsection{Materiais constituintes}

\subsubsection{Cimento}

De acordo com RICHARD e CHEYREZY (1995), a escolha do tipo de cimento exige a verificação da compatibilidade entre cimento e aditivo superplastificante, pois cimentos com baixos teores de aluminato tricálcico hidratado $\left(\mathrm{C}_{3} \mathrm{~A}\right)$ produzem melhores espalhamentos. Segundo inúmeros pesquisadores, $\mathrm{o}$ melhor cimento a ser utilizado para a produção de CPR seria o cimento com alto teor de sílica, em virtude das suas características mecânicas e reológicas, entretanto, este cimento apresenta uma taxa lenta de pega e por isso comprometeria a sua aplicação em algumas situações. FEHLING et al. (2014) citam que o consumo de cimento no CPR varia entre $700 \mathrm{~kg} / \mathrm{m}^{3}$ e $850 \mathrm{~kg} / \mathrm{m}^{3}$.

\subsubsection{Areia}

Segundo VANDERLEI (2004), a escolha da areia é influenciada pelos seguintes parâmetros: composição mineral, diâmetro médio e forma das partículas, composição granulométrica e sua fração volumétrica na mistura. Conforme citado pelo autor a areia mais indicada é a do tipo quartoza, por ser um material de elevada dureza, apresentar excelente interface pasta/agregado, aliada à boa disponibilidade e baixo custo, com tamanho das partículas limitados a: diâmetro máximo $\leq 600 \mu \mathrm{m}$ e mínimo $\geq 150 \mu \mathrm{m}$, evitando-se valores inferiores a $150 \mu \mathrm{m}$.

\subsubsection{Pó de Quartzo}

A utilização do pó de quartzo no CPR é fundamental para intensificar as reações pozolânicas, quando o CPR é submetido a tratamento térmico, e contribuição para o fechamento do pacote granulométrico, preenchendo os vazios deixados pela areia. Segundo VANDERLEI (2004), para que se tenha uma máxima reatividade na cura térmica, a dimensão máxima característica do pó quartzo deve estar entre $5 \mu \mathrm{m}$ e $25 \mu \mathrm{m}$, classe granular muito próxima à do cimento. 


\subsubsection{Adições minerais}

A utilização de adições minerais foi bastante difundida com o surgimento dos CAR, pois elas são bastante eficientes no aumento da resistência, principalmente por apresentarem efeito químico, densificando a matriz e a zona de transição. A adição mineral que mais tem se destacado mundialmente na produção de concretos especiais é sem dúvida a sílica ativa, principalmente por apresentar efeito fíller, preenchendo os vazios das partículas de cimento, melhorar a reologia da mistura e pela sua reação pozolânica com a cal resultante da hidratação primária. De acordo com MEHTA \& MONTEIRO (2008), a sílica ativa é altamente pozolânica, possuindo diâmetro médio da ordem de $0,1 \mu \mathrm{m}$ e área superficial específica entre 15 e $25 \mathrm{~m}^{2} / \mathrm{kg}$.

VANDERLEI (2004) cita que a taxa de utilização de sílica ativa no CPR é normalmente de $25 \%$, a qual corresponderia à dosagem requerida para consumir a cal resultante da total hidratação do cimento, e por corresponder a um empacotamento ótimo. Porém, devido ao CPR apresentar uma baixa quantidade de água na mistura, a hidratação do cimento é incompleta e a quantidade de sílica ativa torna-se maior que a requerida para a reação pozolânica, consequentemente este excesso atuará com a função de micro-fíller, contribuindo para um melhor empacotamento dos sólidos constituintes do CPR.

\subsubsection{Fibras metálicas}

De acordo com VANDERLEI (2004), o CPR sem fibras metálicas apresenta comportamento elástico-linear, apresentando baixa energia de fratura, e a única forma de corrigir este comportamento frágil seria pela inserção de fibras metálicas ao material. Conforme GRAYBEAL (2006), as fibras mais utilizadas no CPR 200 são metálicas com diâmetro de $0,2 \mathrm{~mm}$ e comprimento de aproximadamente $13 \mathrm{~mm}$, resistência mínima à tração de $2600 \mathrm{MPa}$ e módulo de elasticidade superior a 205 GPa. FEHLING et. al. (2014) citam como mais favorável a utilização de um fator de forma (relação comprimento da fibra/diâmetro) de no mínimo 65. 
METHA \& MONTEIRO (2008) classificam o concreto com fibras em função das frações volumétricas:

I. Baixa fração volumétrica (<1\%): utilização das fibras apenas para controle da fissuração por retração;

II. Moderada fração volumétrica (entre 1 e $2 \%$ ): aumentam o módulo de elasticidade, tenacidade e a resistência ao impacto;

III. Alta fração volumétrica (maior $2 \%$ ): as fibras utilizadas neste nível levam ao endurecimento por deformação dos compósitos e são chamados de compósitos de alto desempenho. O CPR é considerado como um compósito ainda melhor que os desenvolvidos nesta faixa de adição de fibras metálicas.

GRAYBEAL (2006) cita como usual a utilização de 2\% em relação ao volume, para o teor de adição de fibras metálicas ao CPR. Segundo FEHLING et al. (2014), a adição de fibras metálicas ao CUAR traz uma nítida melhoria no seu comportamento tensão x deformação, principalmente no trecho pós-pico, trecho descendente do diagrama, sendo este influenciado pelos seguintes parâmetros: tipo da fibra, geometria (comprimento e diâmetro), sua orientação na mistura, aderência entre a fibra e a matriz cimentícia e a rigidez das fibras, especialmente quando são utilizadas combinações diferentes na composição do CUAR.

\subsubsection{Aditivo químico}

Para a produção do CPR é imprescindível a utilização de aditivos químicos de última geração, para garantir a baixa relação $(a / c)$ desejada e principalmente garantir plasticidade à mistura. De acordo com CHEYREZY et. al. (1995), a utilização do superplastificante no CPR é justificada por promover um aumento da trabalhabilidade sem mudança na composição da mistura, diminuição da quantidade de água, redução da relação água/aglomerante e consequentemente aumento da resistência e durabilidade. Existem algumas discordâncias no meio técnico entre o 
teor ideal de adição de superplastificante ao CPR. Algumas das taxas mais utilizadas são: $1,0 \% ; 1,5 \%$ e $2,0 \%$ de adição em função do teor de cimento. Cabe a ressalva que estes teores são tomados em relação aos teores de sólidos presentes no superplastificante utilizado. FEHLING et. al. (2014) citam que os superplastificantes mais eficazes para a produção de CPR são os baseados em cadeias de policarboxilatos, com a trabalhabilidade diretamente correlacionada com a quantidade de sólidos presentes nesse aditivo, recomendando a utilização de superplastificantes com teores de sólidos superiores a $30 \%$.

\subsection{7. Água}

No caso do CPR, a água geralmente é substituída por gelo, com a intenção de diminuir o calor de hidratação gerado no processo de hidratação do cimento, minimizando os efeitos de retração térmica, uma vez que o CPR utiliza altíssimos teores de cimento.

\subsection{Dosagem}

RICHARD \& CHEYREZY (1995) desenvolveram o CPR baseados no princípio da formação de um material isento de microfissuras e poros capilares, obtido pelo aumento da compacidade, juntamente com a alta resistência dos materiais constituintes da matriz, permitindo com que, desta forma, maiores níveis de tensão sejam alcançados pelo material.

A dosagem do CPR é diferente das dosagens utilizadas para a produção de CBR e CAR, principalmente pelo fato da eliminação do agregado graúdo neste material e por ser extremamente criteriosa na seleção dos materiais e processo de produção do concreto. Durante a realização da pesquisa bibliográfica constatou-se que não há um método de dosagem desenvolvido especificamente para o CPR, entretanto, alguns pesquisadores citam o método de empacotamento de partículas como utilizável para esta finalidade. A tabela 2.3 apresenta a composição de CPR desenvolvida por RICHARD \& CHEYREZY (1995). 
Tabela 2.3 - Típica composição do CPR (RICHARD \& CHEYREZY, 1995)

\begin{tabular}{c|c}
\hline Materiais & $\left(\mathbf{k g} / \mathbf{m}^{\mathbf{3}}\right)$ \\
\hline Cimento & 705 \\
Sílica Ativa & 230 \\
Pó de Quartzo & 210 \\
Areia & 1010 \\
Superplastificante & 17 \\
Fibras de aço $(12 \mathrm{~mm})$ & 195 \\
Água & 195 \\
\hline Densidade & $\mathbf{2 5 5 7}$ \\
\hline
\end{tabular}

VANDERLEI (2004) ressalta que para se alcançar uma alta compacidade é necessário que se tenha uma distribuição granulométrica otimizada dos grãos, com os espaços vazios deixados pelas partículas maiores sendo preenchidos pelas partículas menores, e assim sucessivamente, formando o chamado empacotamento de partículas.

\subsection{Produção}

A produção do CPR se diferencia das relativas ao CBR e ao CAR pela necessidade da utilização de um misturador forçado, importante dispersor de pós, uma vez que a mistura é praticamente composta por materiais finos. Devem ser ainda tomados alguns cuidados em sua produção, principalmente nas etapas relativas: ao amassamento do concreto, ao tempo de duração do processo e à dosagem da água, a qual deve ser executada com precisão, para que seja garantido o baixo fator água/cimento, conferindo, desta forma, as altas resistências apresentadas pelo material.

PARK et al. (2008) citam que para a produção de CPR devem-se obedecer aos seguintes parâmetros: colocação dos materiais constituintes, tempos de mistura e velocidades de rotação no misturador. Essas etapas são baseadas na seguinte sequência, tempos e velocidades:

I. Homogeneização do material seco (cimento, areia, sílica e pó de quartzo), velocidade de 40 rpm e tempo de mistura de $10 \mathrm{mim}$; 
II. Fluidificação da pasta pela adição da água e do aditivo químico, velocidade de $70 \mathrm{rpm}$ e tempo de mistura de $10 \mathrm{mim}$;

III. Adição de fibras metálicas após a homogeneização da pasta fluída, velocidade de $40 \mathrm{rpm}$ e tempo de mistura de $5 \mathrm{mim}$.

\subsection{Processo de cura}

A cura do concreto, independentemente da classe de resistência, pode ser definida como um conjunto de medidas para evitar a evaporação da água de amassamento da mistura, e assim promover melhor hidratação do cimento. $O$ procedimento de cura do CPR está relacionado diretamente com a sua destinação final e com as condições técnicas do local de sua produção. Segundo

RUSSEL \& GRAYBEAL (2013), o processo de cura do CPR ocorre em duas fases, a primeira correspondente ao início da pega, onde as propriedades mecânicas desse material encontram-se em desenvolvimento, e por isso deve-se garantir que a água da mistura não seja perdida ao ambiente, e a segunda relativa à aplicação de cura úmida ou térmica, afim de que todo o processo de reação química se complete.

De acordo com VANDERLEI (2004), a temperatura de cura térmica afeta de forma significante a resistência à compressão do CPR, pois sob condições térmicas (temperaturas inferiores a $90^{\circ} \mathrm{C}$ ), ocorre a formação de cristais como "tobermorite", resultantes da reação da cal com a sílica ativa, e dos cristais "truscottite, gyrolite, xonotlite e hillebrandite" para temperaturas acima de $200^{\circ} \mathrm{C}$. De acordo com o pesquisador, a formação desses cristais tem efeito vantajoso no ganho de resistência.

No decorrer da pesquisa bibliográfica, constatou-se que as temperaturas mais utilizadas para aplicação de tratamento térmico para a família CPR 200 é de $90^{\circ} \mathrm{C}$. CHEYREZY et al. (1995) concluíram que o comprimento da cadeia de C-S-H é altamente proporcional à temperatura de cura, e que períodos mais longos de aplicação de cura térmica conduzem a cadeias mais compridas de $\mathrm{C}-\mathrm{S}-\mathrm{H}$, devido ao aumento da atividade pozolânica, ao passo que, quando curados à temperatura ambiente, as atividades pozolânicas são menores e pouco melhoradas pela presença 
de sílica ativa e pelo tamanho dos cristais de C-S-H. De acordo com JUNGWIRTH (2002), as diferenças de temperatura para o processo de cura do CPR conduzem a diferenças consideráveis na resistência do concreto à compressão, e consequentemente na resposta de seu comportamento tensão-deformação. A figura 2.2 ilustra essas diferenças aos 28 dias, para um traço de CPR com adição de fibras metálicas e duas aplicações diferentes de cura.

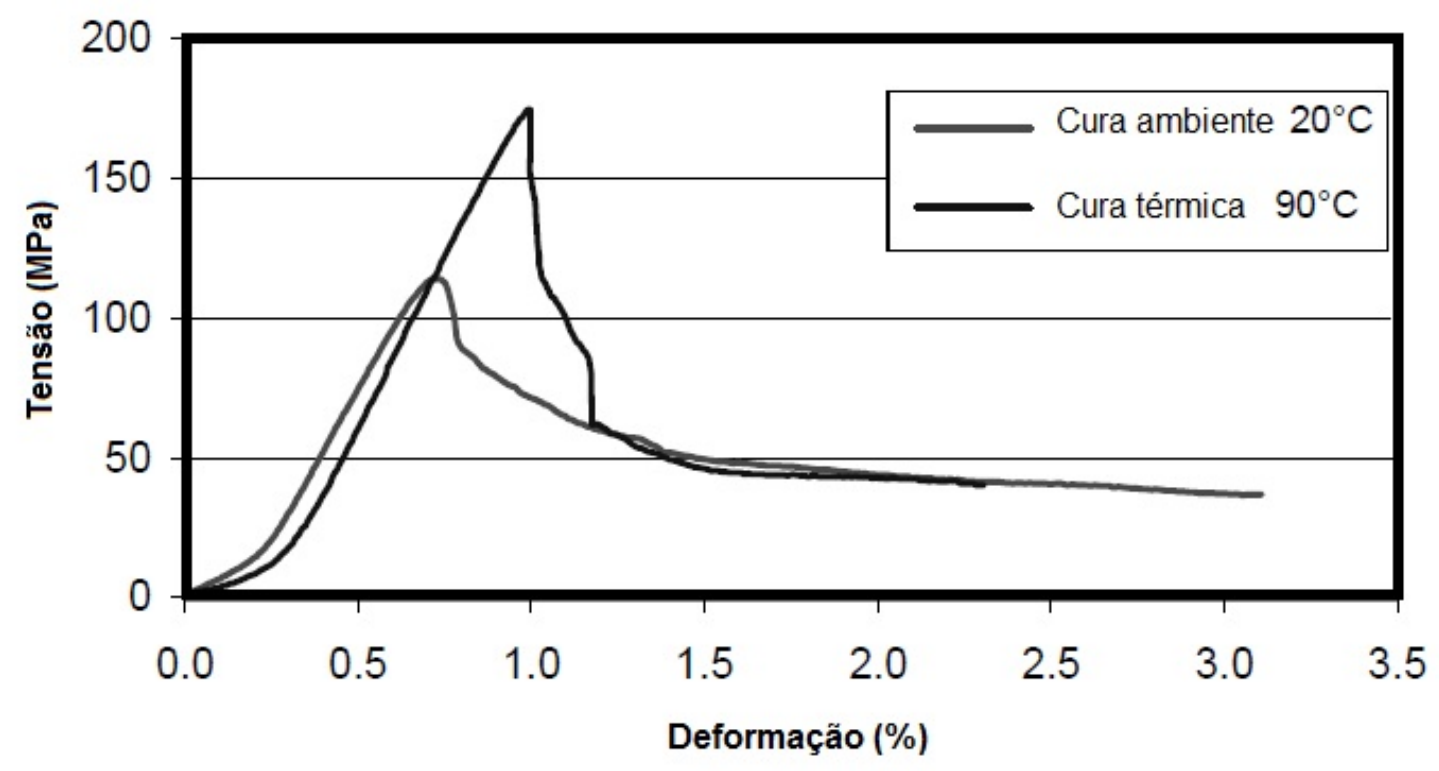

Figura 2.2 - Comportamento tensão-deformação do CPR para dois tipos diferentes de cura (JUNGWIRTH, 2002)

RUSSEL \& GRAYBEAL (2013) relatam a diferença obtida na resistência média à compressão do CPR, na idade de 28 dias, medida em seis corpos de provas, para quatro aplicações diferentes de cura:

I. $24 \mathrm{~h}$ após a concretagem, aplicação de cura térmica a $90^{\circ} \mathrm{C}$, pelo período de 48 h, combinada com cura imersa, pelo período de 48 h;

II. $\quad 24 \mathrm{~h}$ após a concretagem, aplicação de cura térmica a $60^{\circ} \mathrm{C}$, pelo período de $48 \mathrm{~h}$;

III. Após 15 dias da concretagem, aplicação de cura térmica a $90^{\circ} \mathrm{C}$, pelo período de $48 \mathrm{~h}$;

IV. Sem aplicação de cura. 
Os resultados obtidos foram respectivamente: $193 \mathrm{MPa}, 171 \mathrm{MPa}, 171$ $\mathrm{MPa}$ e $126 \mathrm{MPa}$. A partir dos resultados obtidos pelos autores citados pode-se presumir que o primeiro processo de cura produz maiores resistências à compressão, parecendo ser o método de cura mais eficaz.

\subsection{Propriedades mecânicas}

\subsubsection{Resistência à compressão}

De acordo com RUSSEL \& GRAYBEAL (2013), a resistência do concreto à compressão é a propriedade mecânica frequentemente utilizada como método de controle para a qualidade do concreto estrutural, servindo muitas vezes de referência para os engenheiros correlacionarem outras propriedades mecânicas em função desse parâmetro, e o CPR não foge dessa regra. LIU et al. (2012) citam que a resistência à compressão do CUAR é principalmente dependente da: relação água/materiais cimentícios, composição mineral dos materiais constituintes da mistura, adição de sílica ativa e adição de fibras metálicas. De acordo com RICHARD e CHEYREZY (1995), a resistência à compressão do CPR é afetada diretamente pela densidade do concreto, consequentemente, quanto maior for a sua densidade, maior será a sua resistência à compressão.

\subsubsection{Resistência à tração}

De acordo com GRAYBEAL (2006), frequentemente a resistência à tração é estimada como uma porcentagem da resistência à compressão, e para o CPR, essa relação está situada entre os valores de 5 a $7 \%$ da resistência à compressão. FEHLING et al. (2014) citam como valores típicos de resistência à tração do CPR valores entre $7 \mathrm{MPa}$ e $11 \mathrm{MPa}$, ressaltando que essa propriedade mecânica é influenciada principalmente pelo teor de adição de sílica ativa a mistura. 


\subsubsection{Módulo de deformação}

GRAYBEAL (2006) estudou o módulo de elasticidade e a deformação última para uma dosagem de CPR, com duas aplicações diferentes de cura, com resistências à compressão de $193 \mathrm{MPa}$ e $126 \mathrm{MPa}$, e obteve respectivamente 52,7 GPa e 42,7 GPa, para os módulos de elasticidade, e 4,1\% e 3,5\%, para as deformações máximas desses concretos $\left(\varepsilon_{C}\right)$. Esses resultados foram obtidos com a seguinte metodologia de cura: aplicação de cura térmica a $90^{\circ} \mathrm{C}$ pelo período de 48 horas e após mantidos em condições normais dentro de um laboratório, para o primeiro nível de resistência, e no segundo, após a desmoldagem, os corpos de prova foram mantidos em temperatura ambiente de laboratório até as idades de ensaio.

Já BONNEAU et al. (1996), em seu estudo de CPR com resistências à compressão variando entre $160 \mathrm{MPa}$ e $220 \mathrm{MPa}$, sem e com adição de fibras metálicas, encontraram os seguintes valores de módulo de elasticidade, respectivamente: $46 \mathrm{GPa}$ e 49GPa.

LIU et al. (2012) observaram a influência do teor de fibras metálicas em dois traços de CPR, com taxas volumétricas de fibras de $0,5 \%$ e $2 \%$, para duas situações de taxas de carregamento, e dois níveis de resistência à compressão, 133,9 MPa e 178,2 MPa. A figura 2.3 ilustra as diferentes respostas obtidas no diagrama tensão-deformação dos concretos estudados pelos autores citados.

Os resultados obtidos comprovaram o aumento da deformação na compressão para o CPR e uma melhoria não muito significativa para seu módulo de elasticidade, em comparação aos valores apresentados pelo CBR e CAR. De acordo com os autores, a deformação última do CPR é sempre maior que 3\%o, a figura 2.4 apresenta a resposta do diagrama tensão-deformação para as três classes de concretos.

Segundo FEHLING et al. (2014) quando comparado ao CBR e ao CAR em ensaios de compressão, o CPR é caracterizado por apresentar um comportamento elástico-linear até a iminência de sua ruptura, sendo este efeito observado 
independentemente do tamanho máximo dos agregados utilizados, com módulo de elasticidade situando-se geralmente entre $45 \mathrm{GPa}$ e $55 \mathrm{GPa}$. De acordo com os pesquisadores, uma forma de aumentar significativamente o módulo de elasticidade do CPR seria a utilização de agregados de Bauxita.

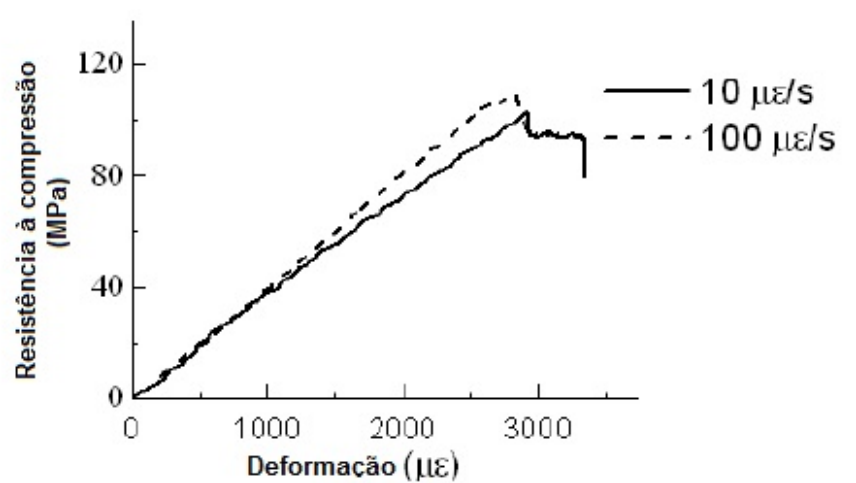

CPR - 2

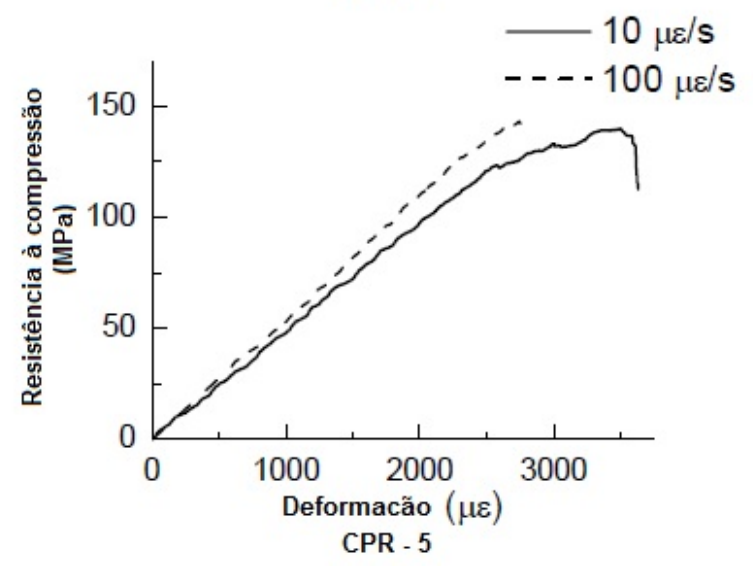

Figura 2.3 - Influência da taxa volumétrica de fibras metálicas no diagrama tensão-deformação de dois traços de CPR para diferentes velocidades de carregamento (LIU et al., 2012) 


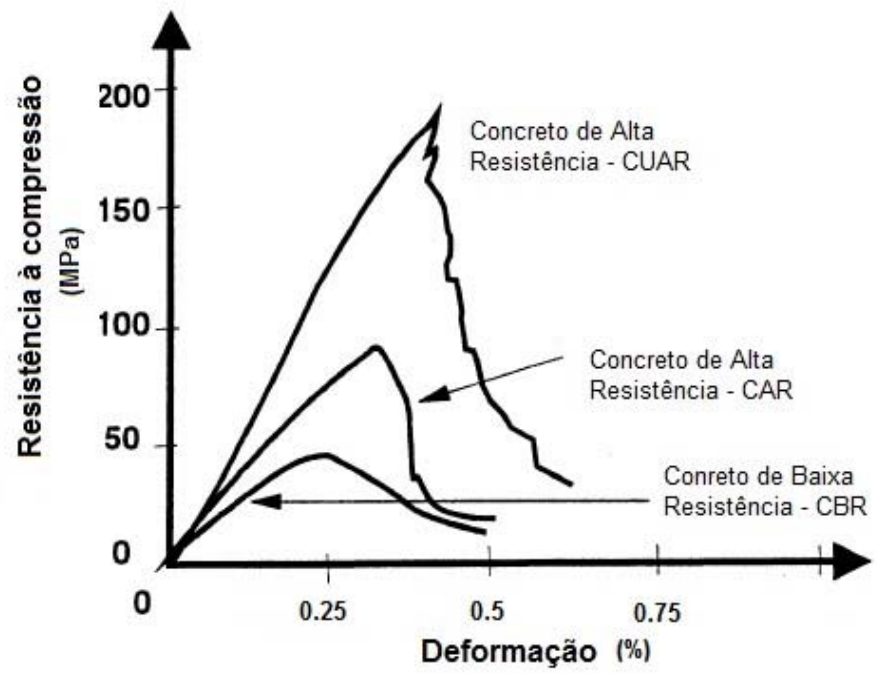

Figura 2.4 - Diagramas tensão-deformação para as classes de concretos CBR, CAR e CUAR (SAHAH \& WEISS, 1998)

Segundo FEHLING et al. (2014) quando comparado ao CBR e ao CAR em ensaios de compressão, o CPR é caracterizado por apresentar um comportamento elástico-linear por um período longo de tempo, até momentos antes de sua ruptura, e alcance da máxima tensão de compressão, sendo este efeito observado independentemente do tamanho máximo dos agregados utilizados, com módulo de elasticidade situando-se geralmente entre $45 \mathrm{GPa}$ e $55 \mathrm{GPa}$. De acordo com os pesquisadores, uma forma de aumentar significativamente o módulo de elasticidade do CPR seria a utilização de agregados de Bauxita.

FEHLING et al. (2014) alertam que a utilização das expressões presentes nas normas DIN 1045-1 e CEB-FIP código modelo 90, para estimar o valor do módulo de elasticidade em função da resistência à compressão do concreto, subestimam os valores de módulo de elasticidade apresentados pelo CPR, sendo mais apropriada a utilização das seguintes expressões para a determinação do módulo de elasticidade do CPR com agregados menores que $0,5 \mathrm{~mm}$ e do CPR com agregados menores que $8 \mathrm{~mm}$, respectivamente: 


$$
\begin{aligned}
& E_{c}=8800 \cdot f_{c}^{1 / 3} \\
& E_{c}=10200 \cdot f_{c}^{1 / 3}
\end{aligned}
$$

Onde:

- $E_{C}$ e $f_{c}$ são dados em megapascais (MPa).

RUSSEL \& GRAYBEAL (2013) recomendam a utilização da seguinte expressão para a determinação do valor do módulo de elasticidade do CPR:

$$
E_{c}=49000 \cdot \sqrt{f_{c}}
$$

Onde:

- $E_{C}$ e $f_{C}$ são dados em psi.

- $1 \mathrm{MPa}=0,006895$ psi.

\subsubsection{Coeficiente de Poisson}

De acordo com DUGAT et. al. (1996), as classes CPR 200 e CPR 800 apresentam valores de coeficientes de Poisson de 0,23 e 0,28, respectivamente. FEHLING et al. (2014) abordam para a fase elástica do CUAR com agregados menores que 0,5 mm valores de coeficientes de Poisson situados entre 0,18 e 0,19, e 0,21 para CUAR com agregados menores que $8 \mathrm{~mm}$. A figura 2.5 ilustra a variação do coeficiente de Poisson para o CUAR com agregados menores que $8 \mathrm{~mm}$, CBR e CAR no ensaio de compressão axial. 


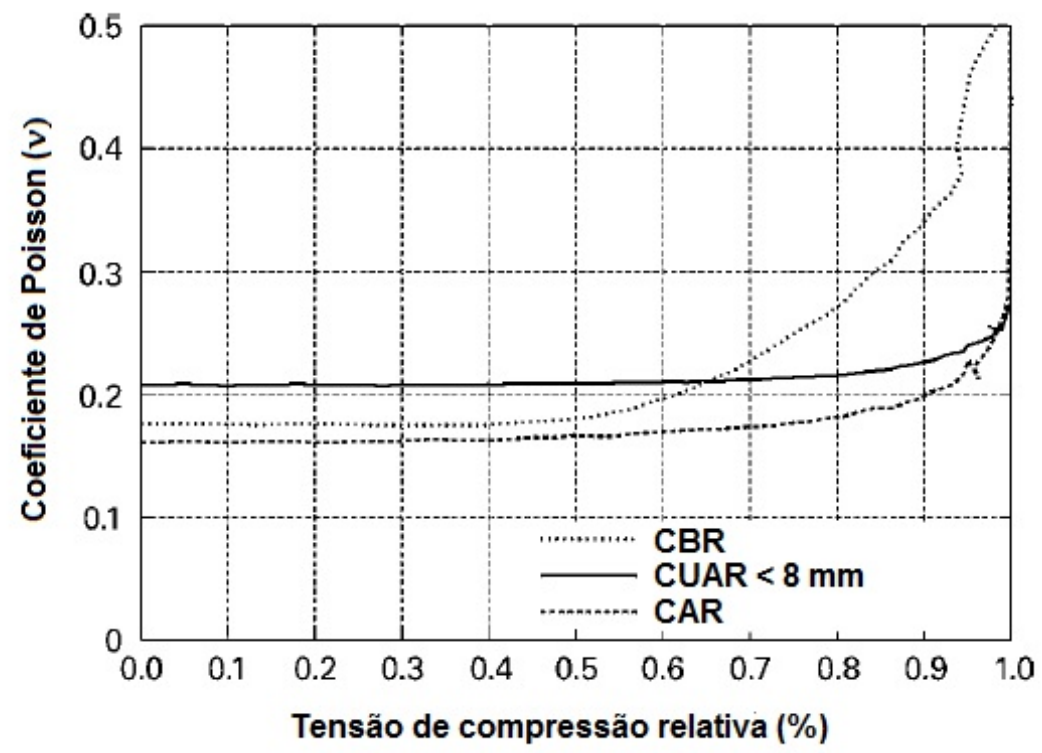

Figura 2.5 - Evolução do coeficiente de Poisson com o aumento da resistência à compressão para o CBR, CAR e CUAR (FEHLING et al., 2014)

\subsubsection{Durabilidade}

Por apresentar uma microestrutura completamente densa, o CUAR é praticamente impermeável, apresentando dessa forma alta resistência ao ataque de agentes agressivos. Com relação ao risco da reação álcali-sílica, pode-se afirmar que o CUAR é resistente, por apresentar um baixo fator água/cimento (a/c), lembrando que a presença de água é fundamental para a ocorrência desta reação. De acordo com RESPLENDINO (2004), o CUAR apresenta uma clara melhoria de durabilidade perante os CBR e CAR, como mostra os resultados da tabela 2.4.

Tabela 2.4 - Comparação de durabilidade entre concretos (RESPLENDINO, 2004)

\begin{tabular}{l|ccc}
\hline \multicolumn{1}{c}{ Indicadores de durabilidade } & CBR & CAR & CUAR \\
\hline Porosidade (\%) & $14-20$ & $10-13$ & $1,5-5$ \\
\hline Permeabilidade ao Oxigênio $\left(\mathbf{m}^{2}\right)$ & $10^{-16}$ & $10^{-17}$ & $\leq 10^{-19}$ \\
\hline Fator de difusão de Íons Cloreto ( $\left.\mathbf{m}^{2} / \mathbf{s}\right)$ & & & \\
& $2.10^{-11}$ & $2.10^{-12}$ & $2.10^{-14}$ \\
\hline
\end{tabular}

\subsubsection{Resistência ao fogo}

Segundo FEHLING et al. (2014), o CAR apresenta lascamento sob efeitos de alta temperatura, mesmo em estágios iniciais de um incêndio, porque sua microestrutura densa impede a dissipação da pressão de vapor causada pelas 
elevadas temperaturas, e este comportamento motivou investigações sobre o comportamento do CUAR sob efeitos de altas temperaturas, ou seja, ação do fogo. Tais estudos comprovaram que temperaturas acima de $573^{\circ} \mathrm{C}$ acarretam um aumento de volume, devido à inversão do quartzo, sendo este efeito controlado pela adição de fibras de polipropileno ou pela substituição da areia de quartzo pela de basalto. $O$ CUAR apresenta uma perda prematura de resistência a temperaturas inferiores a $200^{\circ} \mathrm{C}$, a qual é muito mais baixa a altas temperaturas, conforme ilustra a figura 2.6.

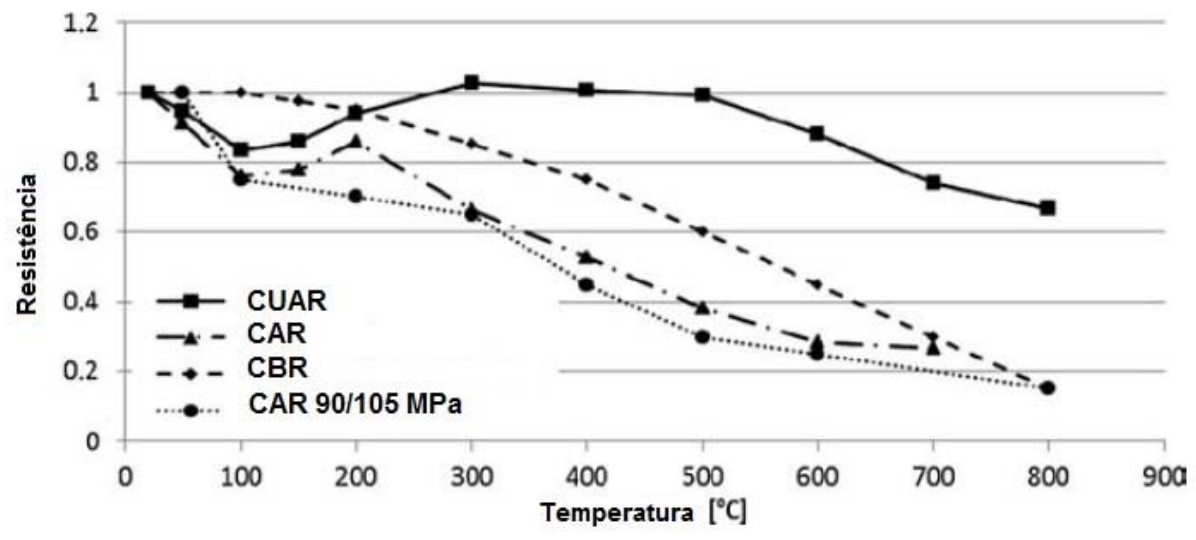

Figura 2.6 - Resistência à compressão em função da temperatura para o CBR, CAR e CUAR (FEHLING et al., 2014) 


\section{Confinamento do concreto com aço}

\subsection{Efeitos do confinamento com aço no concreto}

Segundo LEONHARDT \& MÖNNIG (1977), a capacidade de carga de pilares de concreto armado com seção circular, com pequena excentricidade e esbeltez reduzida, pode ser aumentada através de uma armadura de confinamento.

De acordo com AGUIAR (2000), quando pilares são submetidos à compressão axial, o concreto sofre um encurtamento longitudinal, e pelo efeito de Poisson, expande-se lateralmente. Esta expansão passa a ser contida pelas armaduras transversais, que restringem a deformação lateral do concreto do núcleo.

O impedimento da expansão lateral, gerado pela restrição da deformação imposta pelas armaduras transversais ao concreto do núcleo confinado, produz um estado triaxial de tensões de compressão $\left(\sigma_{1} ; \sigma_{2}=\sigma_{3}\right)$, onde: $\left(\sigma_{1}\right)$ é a tensão de compressão axial, que provoca o encurtamento longitudinal do elemento estrutural, e $\left(\sigma_{2}=\sigma_{3}\right)$, a pressão lateral de confinamento exercida sobre o núcleo de concreto, promovida pelo surgimento de tensões de tração na armadura transversal, devido à restrição de deformação lateral, imposta ao concreto do núcleo. A figura 3.1, ilustra o efeito do confinamento em pilares curtos circulares com armadura transversal de confinamento em formato de espiral contínua, onde: (a) representa um pilar curto de concreto armado submetido a esforços de compressão axial, (b) a formação da área de concreto do núcleo e a área bruta da seção de concreto do pilar circular, (c) o núcleo de concreto confinado em estado triaxial de tensões (acréscimos de resistência e deformação axial ao elemento estrutural) e, (d) e (e) a representação da distribuição da pressão lateral de confinamento oriunda da resistência da armadura à expansão lateral do concreto. 


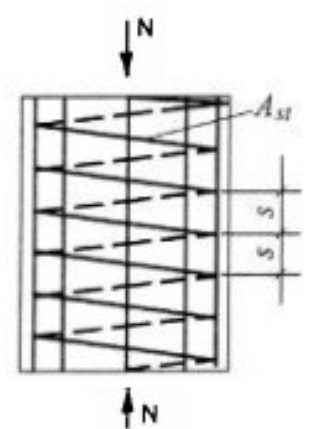

(a)

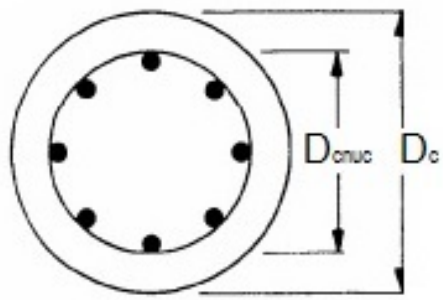

(b)

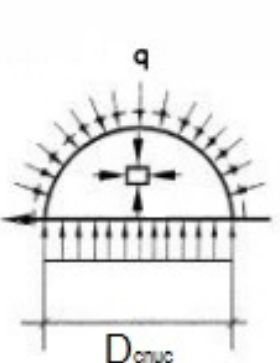

$\sigma_{2}=\sigma_{3}=q$

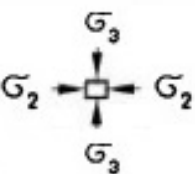

(c)

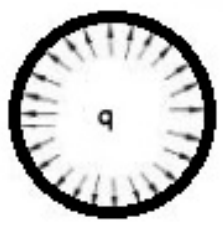

(d)

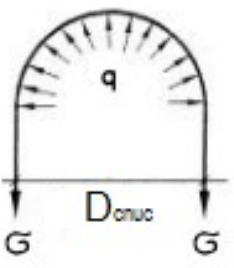

(e)

Figura 3.1 - Representação dos efeitos do confinamento com aço sobre o concreto para pilares com seção circular (Modificada de GUO,2014)

Portanto, o emprego adequado de uma taxa de armadura transversal produzirá acréscimos de resistência à compressão e de deformação axial ao concreto do núcleo, promovendo ao elemento estrutural uma ruptura gradual e do tipo dúctil.

O princípio fundamental de atuação do confinamento sobre o concreto é de que toda expansão lateral provoca uma tensão de tração na armadura transversal, aplicando uma força lateral de confinamento ao concreto do núcleo $\left(\sigma_{2}=\sigma_{3}\right)$, promovendo dois efeitos benéficos no comportamento de pilares de concreto armado confinados: acréscimo de resistência do concreto do núcleo e maior deformação axial.

Segundo MENDES (1993), o principal efeito do confinamento é diminuir a inclinação da parte descendente do diagrama tensão-deformação do concreto confinado, consequentemente, quanto maior for a taxa de armadura transversal empregada, melhor será o comportamento do pilar no trecho descendente do 
diagrama força-deformação, proporcionando uma ruptura do tipo dúctil ao elemento estrutural.

Segundo CUSSON \& PAULTRE (1994), à medida que a resistência à compressão do concreto aumenta, a sua eficiência no confinamento decai, tanto em acréscimos de resistência à compressão, como em acréscimos de deformação axial, e esses decréscimos estão diretamente associados à menor expansão lateral apresentada por esses concretos.

De acordo com AGUIAR (2000), muitos pesquisadores acreditam que a utilização de aços de alta resistência para a armadura transversal produzirá maiores benefícios aos elementos estruturais pelo confinamento, pois são gerados maiores níveis de pressão lateral de confinamento ao núcleo de concreto.

De acordo com CARRAZEDO (2002), a eficiência do confinamento é diretamente proporcional à expansão lateral do concreto não confinado, uma vez que se necessita que a expansão lateral seja suficientemente alta para que seja atingida a capacidade máxima da armadura transversal. Desta forma, pilares com concreto de baixa resistência são os mais beneficiados pelos efeitos do confinamento.

Segundo QUEIROGA (1999), o diagrama força-deformação para pilares de concreto de alta resistência confinados, submetidos a compressão simples e pequenas excentricidades, possuem três tipos diferentes de rupturas esperadas, conforme ilustra a figura 3.2, em função da classe de confinamento adotada.

O autor descreve o trecho $\mathrm{AO}$ do diagrama força-deformação como praticamente linear até o início da ruptura do concreto do cobrimento, próximo do alcance do ponto $A$, onde se inicia uma leve curvatura no diagrama força-deformação até a sua obtenção do ponto A. Quando este ponto é alcançado todo o cobrimento já está destacado do núcleo de concreto confinado, definido pelos eixos centrais da armadura transversal. $O$ trecho $A B$, apresenta uma queda de capacidade resistente do pilar, devido a perda da parcela colaboram-te do concreto do cobrimento na resistência da seção transversal, e a partir do ponto $B$, pode-se ter três respostas 
diferentes no comportamento do diagrama força-deformação do elemento estrutural, em função da eficácia da armadura transversal.

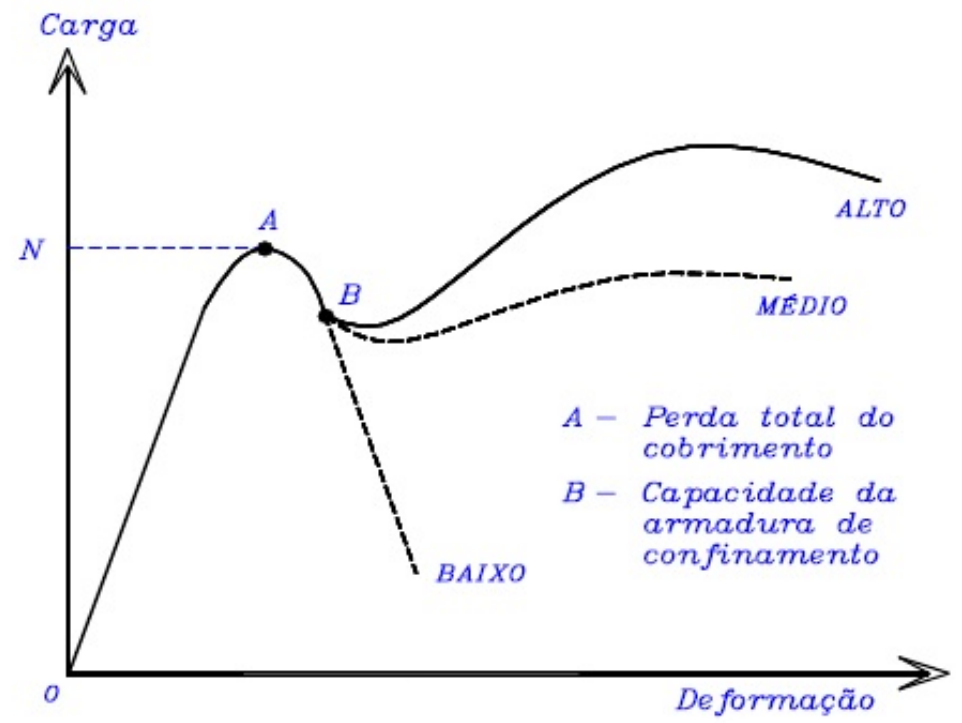

Figura 3.2 - Diagrama típico de força-deformação apresentado por pilares com CAR e os modos de rupturas esperados em função da classe de confinamento empregada

(AGUIAR,2000)

Segundo QUEIROGA (1999), as três respostas esperadas no diagrama força-deformação são: baixo, médio e alto confinamento.

Nas situações de baixo confinamento, a armadura transversal não atinge sua tensão de escoamento $\left(f_{y w}\right)$, e o elemento estrutural irá apresentar ruptura do tipo frágil, pois a taxa volumétrica de armadura transversal empregada na seção não promove acréscimos de resistência e ductilidade ao concreto do núcleo.

Para situações de médio confinamento, o elemento estrutural irá apresentar acréscimos de ductilidade e seu modo de ruptura será do tipo dúctil, gradual, pois a armadura transversal alcança seu patamar de escoamento.

Já em situações de alto confinamento, o pilar pode apresentar forças superiores à força máxima obtida no ponto A do diagrama força-deformação, pois acréscimos substanciais de resistência e deformação são obtidos. 


\subsection{Determinação da pressão lateral de confinamento com aço em pilares circulares}

CARRAZEDO (2002) cita que a taxa volumétrica de armadura transversal $\left(\rho_{w}\right)$ é o fator mais importante sobre o confinamento.

Segundo GRAYBEAL \& PESSIKI (2000), a determinação da pressão lateral de confinamento aplicada ao núcleo de concreto confinado pelo emprego de armadura transversal de confinamento em formato de espiral contínua é dada por:

$$
f_{l}=0,5 \cdot \rho_{w} \cdot f_{y w}
$$

onde:

- $\rho_{w}$-Taxa volumétrica de armadura transversal;

- $f_{y w}$ - Tensão de escoamento da armadura transversal.

A taxa volumétrica de armadura transversal $\left(\rho_{w}\right)$ é definida por:

$$
\rho_{w}=\frac{4 \cdot A_{s w}}{D_{\text {cnuc }} \cdot s}
$$

onde:

- $A_{s w}$ - Área da seção transversal de uma barra da armadura transversal;

- $D_{\text {cnuc }}$ - Diâmetro do núcleo de concreto confinado, formado pelos centros das barras da armadura da espiral;

- $S$ - Espaçamento da armadura transversal de confinamento, medido de centro a centro das barras transversais. 


\subsection{Principais variáveis influentes no confinamento}

De acordo com CUSSON \& PAULTRE (1994), as variáveis mais influentes no comportamento do concreto confinado são:

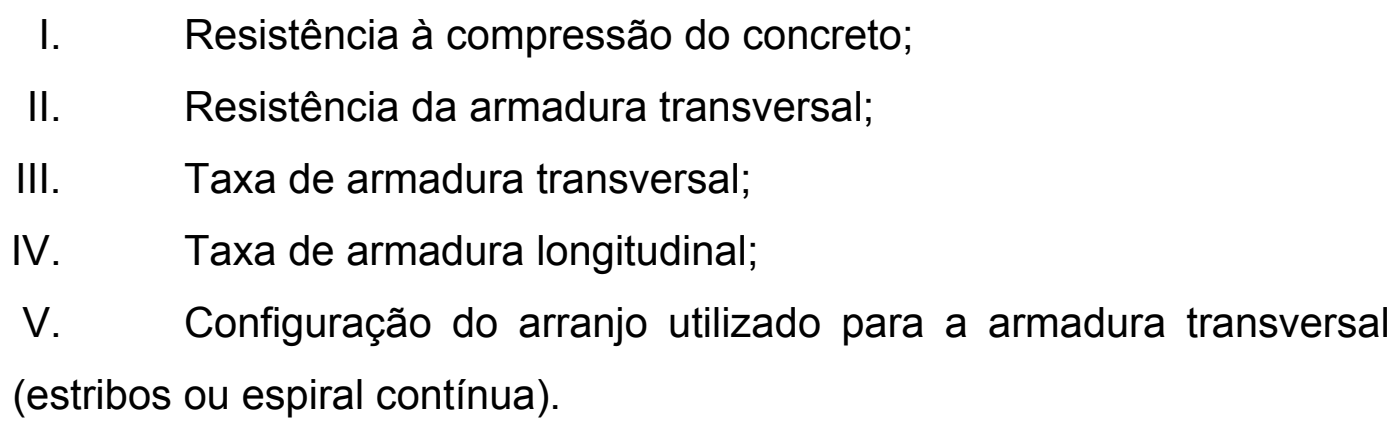

\subsubsection{Resistência à compressão do concreto}

Segundo Li et al. (2001), a resistência à compressão do concreto é um fator relevante a ser considerado no comportamento do concreto confinado, pois concretos de alta resistência possuem uma dilatação lateral menor que a apresentada pelo concreto de baixa resistência, consequentemente, a eficácia do confinamento em pilares de concreto armado com mesma taxa volumétrica de armadura transversal é menor com o aumento da resistência à compressão do concreto.

CARRAZEDO (2002) cita que o comportamento do concreto confinado varia significativamente com a resistência do concreto não confinado, pois concretos de baixa resistência apresentam maior expansão lateral e mobilizam mais facilmente a armadura transversal de confinamento.

\subsubsection{Resistência do aço da armadura transversal}

A pressão lateral de confinamento $\left(f_{l}\right)$ é gerada a partir das deformações desenvolvidas no aço da armadura transversal. Todavia, espera-se que aços de alta resistência exerçam maiores pressões laterais sobre o concreto do núcleo. No entanto, o desenvolvimento desta tensão é diretamente proporcional à expansão 
lateral do concreto. Se esta expansão não for suficiente para solicitar a armadura a níveis de tensões mais elevadas, não será utilizado o potencial do aço de alta resistência, e consequentemente, as pressões laterais de projeto não serão alcançadas.

CUSSON \& PAULTRE (2008) afirmam que pilares de concreto de alta resistência apresentando baixo índice efetivo de confinamento, não se beneficiariam pelo emprego do aço de alta resistência para a armadura transversal, sendo este emprego mais indicado para as situações de médio e alto índice de confinamento, onde as altas taxas volumétricas de armadura transversal conduziriam o pilar a maiores níveis de deformação e, em contrapartida, maiores solicitações de tração seriam desenvolvidas na armadura transversal, atingindo assim a sua tensão de escoamento.

MENDES (1993) afirma que a resistência do aço da armadura de confinamento lateral não altera a parte ascendente do diagrama força-deformação de pilares de concretos de alta resistência confinados, consequentemente, nenhum aumento de resistência é proporcionado pelo emprego de um aço com maior resistência. No entanto, após o ponto de obtenção da tensão máxima de compressão do concreto, a alta resistência do aço da armadura transversal influenciaria no trecho descendente do diagrama força-deformação, em função do crescimento da expansão lateral, fazendo com que a tensão de escoamento do aço seja alcançada.

\subsubsection{Taxa de armadura transversal}

A taxa de armadura transversal $\left(\rho_{w}\right)$ é definida como a razão entre o volume de estribos e o volume de concreto do pilar. Consequentemente quanto maior for esse volume maior será a pressão lateral de confinamento imposta ao núcleo do pilar e maiores serão os ganhos de resistência à compressão e de deformação axial desse elemento estrutural. Em contrapartida, quanto menor for esse volume, menor será a pressão lateral de confinamento, e como consequência direta, menores serão esses acréscimos, respectivamente. 
A importância do espaçamento da armadura transversal pode ser fracionada em duas parcelas de contribuição, a primeira referente à forma de distribuição da pressão lateral de confinamento na seção do pilar, e a segunda alusiva à garantia de estabilidade das barras da armadura longitudinal. A utilização de menores espaçamentos conduz, respectivamente, a uma maior uniformidade da pressão lateral e uma melhor eficiência da armadura longitudinal.

Li et al. (2001) recomendam para que seja evitada uma perda relativamente precoce de capacidade de carga em pilares de concreto de alta resistência, limitar o espaçamento máximo, para a armadura transversal em: quatro e cinco vezes o diâmetro da armadura longitudinal, respectivamente.

\subsubsection{Taxa de armadura longitudinal}

A taxa de armadura longitudinal $\left(\rho_{l}\right)$ pode ser definida como a razão entre a área da seção transversal total das armaduras longitudinais e a área da seção transversal do pilar. A influência da taxa de armadura longitudinal no confinamento ocorre principalmente pela melhor distribuição das barras na seção transversal do pilar do que pelo aumento da taxa de aço.

Li et al. (2001) informam que a eficácia do confinamento está mais relacionada ao espaçamento adotado para a armadura transversal do que com a quantidade de armadura longitudinal presente na seção do pilar, embora a adoção de maiores taxas geométricas para esta armadura possa conduzir a melhorias no trecho descendente do diagrama força-deformação de pilares confinados. Esta melhoria, por sua vez, não é tão significativa quanto a que se obteria com a redução do espaçamento da armadura transversal de confinamento ou pela modificação em sua configuração. Os pesquisadores citam que a distribuição da armadura longitudinal na seção do pilar é mais interessante para a eficácia do confinamento do que a adoção de uma determinada taxa geométrica para este reforço, embora não haja um limite de utilização necessária para a quantidade deste reforço gerar um comportamento dúctil a pilares de concreto de alta resistência confinados. Os pesquisadores sugerem para 
pilares de concreto de alta resistência confinados o emprego de oitos barras distribuídas ao longo do perímetro de sua seção para a armadura longitudinal.

\subsubsection{Arranjo da armadura transversal na seção transversal}

AGUIAR (2000) cita que a configuração do arranjo adotado para a armadura transversal determina a área efetivamente confinada de concreto, que aumenta com uma melhor distribuição da armadura longitudinal ao redor do núcleo do pilar, consequentemente, quanto maior for a área efetivamente confinada, maior será a eficácia do confinamento.

Segundo MENDES (1993), os tipos de armadura de confinamento mais empregados em pilares com seção quadrada e retangular são os estribos, e a armadura em forma de espiral contínua, para os pilares circulares. No caso do emprego de estribos para a armadura de confinamento, a distribuição das tensões de confinamento dependem diretamente da configuração adotada para o arranjo dos estribos e da distribuição da armadura longitudinal na seção transversal do pilar. Normalmente, o confinamento devido aos estribos não é tão efetivo quanto ao proporcionado pela armadura transversal em forma de espiral contínua, que por ser contínua ao longo do pilar distribui de maneira mais efetiva as tensões de confinamento.

CARRAZEDO (2002) aponta que a utilização de estribos retilíneos apresenta tensões não uniformes, com concentrações de tensões nos pontos de encontro entre as barras das armaduras longitudinais e transversais, e devido aos efeitos do arqueamento apresentam considerável redução da pressão lateral. $O$ autor destaca que a adoção de arranjos adequados para os estribos e uma distribuição efetiva da armadura longitudinal na seção do pilar podem atingir níveis de confinamento semelhantes aos obtidos por pilares circulares com armadura em forma de espiral contínua. 


\subsection{Modelos teóricos de confinamento com aço}

\subsubsection{Modelo de RICHART et al. (1929)}

Trata-se de um modelo com base em resultados de uma análise experimental de pilares confinados com armaduras em formato helicoidal (espiral) e carregamento por pressão hidrostática de fluidos, que permite a determinação de uma envoltória de ruptura linear, ou seja, a obtenção da resistência última do concreto confinado $\left(f_{c c}\right)$ e a deformação última para o concreto confinado $\left(\varepsilon_{c c}\right)$. A determinação da envoltória de ruptura linear proposta pelos pesquisadores pode ser calculada pela expressão:

$$
f_{c c}=f_{c o}+4,1 \cdot f_{l}
$$

onde:

- $f_{c c}$ - Resistência do concreto confinado;

- $f_{C C}$ - Resistência do concreto não confinado;

- $f_{l}$ - Força lateral ou pressão lateral.

Obs: Os autores adotaram para $\left(k_{1}\right)$ um valor constante e igual a 4,1.

A equação proposta pelos pesquisadores para prever a deformação última do concreto confinado é:

$$
\varepsilon_{c c}=\varepsilon_{c o} \cdot\left(1+20,5 \cdot \frac{f_{l}}{f_{c o}}\right)
$$

onde:

- $\varepsilon_{c c}$ - Deformação última do concreto confinado;

- $\varepsilon_{c o}$ - Deformação última do Concreto não confinado. 
Obs: $k_{2}$ igual a 20,5, produto da expressão: $k_{2}=5 \cdot k_{1}$

\subsubsection{Modelo de MANDER et al. (1988)}

O modelo de MANDER et al. (1988) tem como principal característica a consideração dos efeitos de arqueamento na determinação da pressão efetiva de confinamento $\left(f_{l e}\right)$, ou seja, leva em consideração a penalização da área de concreto do núcleo, para a determinação da área efetiva confinada do núcleo, obtida pela eliminação das áreas de concreto não confinadas, provenientes do efeito de arqueamento. Esse efeito é considerado pela subtração das parábolas de concreto não confinado, formadas nos encontros com as barras longitudinais ou transversais (nós rígidos). CARRAZEDO (2002) cita que os efeitos de arqueamento se desenvolvem na forma de uma parábola de segundo grau, com inclinação inicial de $45^{\circ}$, e possui comportamentos distintos, de acordo com a forma da seção crítica do pilar, podendo ocorrer tanto no sentido transversal como no longitudinal, no caso de pilares retangulares e quadrados, e somente no sentido longitudinal, para pilares com seção circular, conforme ilustra a figura 3.3.

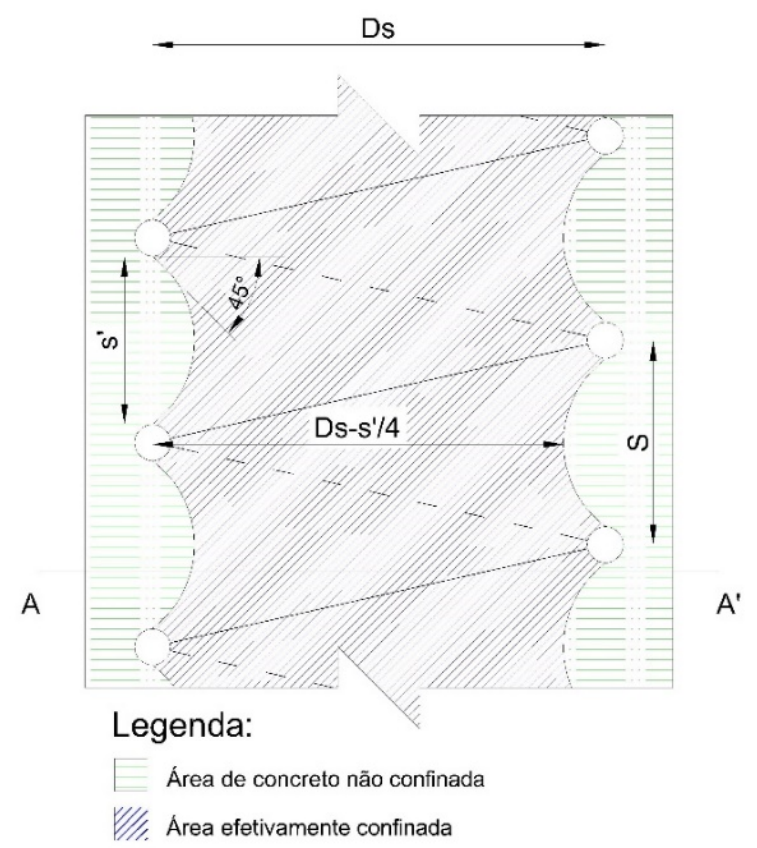

Figura 3.3 - Efeitos do arqueamento em pilares na direção longitudinal (Modificada de Carrazedo, 2002) 
Essa delimitação para a área de concreto efetivamente confinada indica que parte da seção do elemento estrutural não participa no cálculo da resistência à compressão do concreto confinado. Embora ocorra esta perda, o estado multiaxial de tensões desenvolvido pelo efeito do confinamento proporciona acréscimos de resistência e até mesmo ductilidade ao elemento estrutural, quando comparado ao elemento estrutural sem efeito do confinamento. A figura 3.4 apresenta de forma mais clara a influência do espaçamento, em pilares circulares com a armadura transversal em forma de espiral contínua, na delimitação da área de concreto efetivamente confinada, comprovando que a utilização de espaçamentos maiores conduz a maiores áreas de concreto não confinado, diminuindo diretamente a área de concreto efetivamente confinada.

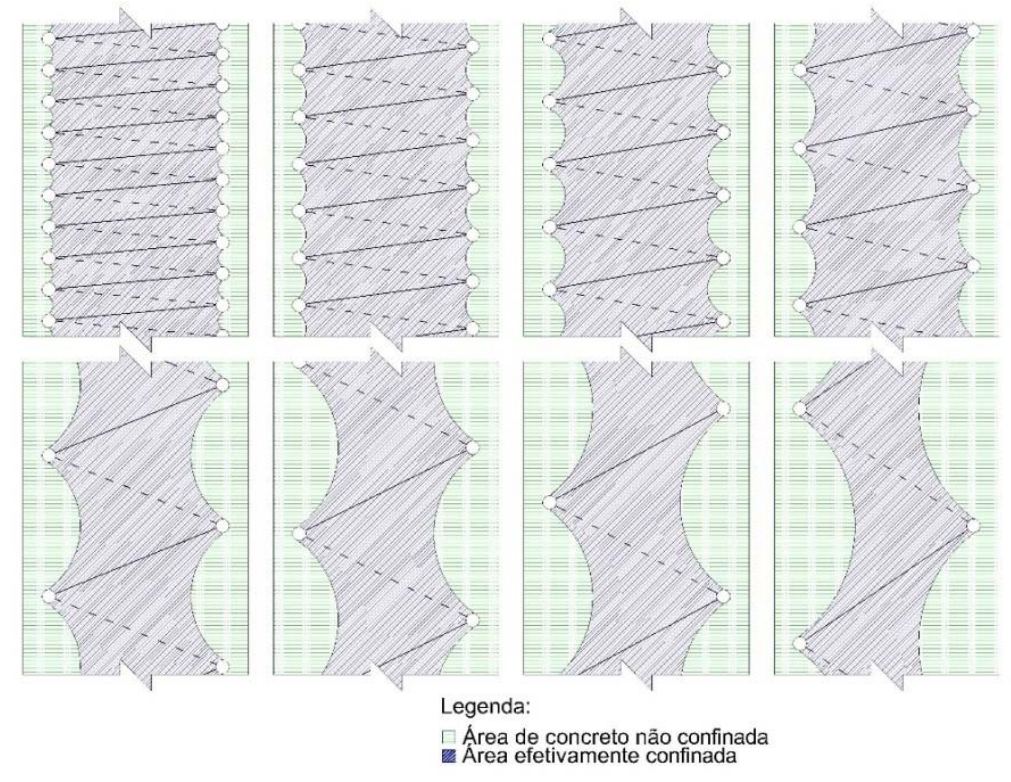

Figura 3.4 - Efeitos do arqueamento em pilares circulares na direção longitudinal

$\mathrm{A}$ área de concreto do núcleo $\left(A_{\text {cnuc }}\right)$ é delimitada pelos eixos centrais da armadura transversal, seja no formato de espiral contínua ou estribo circular, determinada pela expressão:

$$
A_{\text {спис }}=\frac{\pi}{4} \cdot D_{s}^{2} \cdot\left(1-\rho_{\text {sl, пuс }}\right)
$$


onde:

- $\rho_{s l, n u c}$ - Taxa de armadura longitudinal em relação a área de concreto do núcleo;

A área de concreto efetivamente confinada, para armadura transversal em forma de espiral contínua, é determinada pela expressão:

$$
A_{e}=\frac{\pi}{4} \cdot D_{s}^{2} \cdot\left(1-\frac{s^{\prime}}{2 \cdot D_{s}}\right)
$$

A consideração da perda de efetividade da área confinada do núcleo, para a armadura transversal em forma de espiral contínua, é realizada pela adoção do coeficiente penalizador de efetividade $\left(k_{e}\right)$, obtido conforme a expressão:

$$
k_{e}=\frac{\left(1-\frac{s^{\prime}}{2 \cdot D_{s}}\right)}{\left(1-\rho_{s l, n u c}\right)}
$$

onde:

- $D_{s}$ - Diâmetro formato entre os centros das barras da espiral;

- $s^{\prime}$ - Espaçamento interno das espirais.

Logo, a pressão lateral efetiva de confinamento $\left(f_{l e}\right)$ é expressa por:

$$
f_{l e}=f_{l} \cdot k_{e}
$$

MANDER et al. (1988) sugerem, para a determinação da resistência última do concreto confinado, a seguinte expressão:

$$
f_{c c}=f_{c o}+\left(-1,254+2,254 \cdot \sqrt{1+\frac{7,94 \cdot f_{l e}}{f_{c o}}}-2 \cdot \frac{f_{l e}}{f_{c o}}\right)
$$


A deformação do concreto confinado correspondente à resistência máxima do concreto confinado é dada pela expressão:

$$
\varepsilon_{c c}=\varepsilon_{c o} \cdot\left[1+5 \cdot\left(\frac{f_{c c}}{f_{c o}}-1\right)\right]
$$

\subsubsection{Modelo de CUSSON \& PAULTRE (1995)}

Modelo desenvolvido a partir de uma análise experimental de pilares de concreto de alta resistência em escala real, tendo como principais características: a utilização da pressão lateral efetiva $\left(f_{l e}\right)$, consideração da não linearidade da envoltória na ruptura multiaxial e adoção de um processo iterativo para o cálculo da tensão na armadura transversal para o nível de tensão de pico no concreto confinado. Os pesquisadores propuseram uma relação para o ganho de resistência e a pressão lateral para a determinação da envoltória de ruptura, conforme a expressão:

$$
f_{c c}=\left[1+2,1 \cdot\left(\frac{f_{l e}}{f_{c o}}\right)^{0,7}\right] \cdot f_{c o}
$$

A deformação máxima no ponto de pico pode ser estimada por:

$$
\varepsilon_{c c}=\varepsilon_{c o}+0,21 \cdot\left(\frac{f_{l e}}{f_{c o}}\right)^{1,7}
$$

De acordo com os pesquisadores, a tensão na armadura transversal para o nível de resistência de pico do concreto confinado pode ser obtida em função da deformação radial $\left(\varepsilon_{r}\right)$, calculada pela expressão:

$$
\varepsilon_{r}=0,5 . \varepsilon_{c c} \cdot\left[1-\left(\frac{f_{l e}}{f_{c c}}\right)\right]
$$


De acordo com CARRAZEDO (2002), esta equação pode ser aplicada para todos os índices de confinamento, diferenciando-se principalmente no caso de alto índice de confinamento por apresentar valores de tensão maiores que os reais, indicando, neste caso, que as armaduras já escoaram. A determinação da tensão na armadura transversal é realizada por um processo iterativo de cálculo onde se deve seguir os seguintes passos:

I. Calcular a pressão lateral efetiva supondo que $f_{s}=f_{y w}$;

II. Determinar $f_{c c} \mathrm{e}_{\varepsilon_{c c}}$;

III. Estimar a $\varepsilon_{r}$;

IV. Encontrar, no diagrama tensão-deformação do aço utilizado para a armadura transversal, a tensão correspondente à deformação obtida no passo anterior.

V. Se $f_{s} \leq f_{y w}$, repete-se o processo de cálculo até que a convergência seja satisfeita.

\subsubsection{Modelo de RAZVI \&SAATCIOGLU (1999)}

O modelo de confinamento para concreto de alta resistência de

RAZVI \& SAATCIOGLU (1999) é aplicável a concretos de baixa e alta resistência, com resistência à compressão variando de $30 \mathrm{MPa}$ a $130 \mathrm{MPa}$. O modelo foi desenvolvido tendo como base o conceito de pressão uniforme equivalente, conceito utilizado por RAZVI \& SAATCIOGLU (1992) na formulação do modelo de confinamento para concretos de baixa resistência.

De acordo com os autores a resistência do concreto confinado é expressa por:

$$
f_{c c}=f_{c o}+k_{1} \cdot f_{l e}
$$


onde:

- $k_{1}=6,7 \cdot\left(f_{l e}\right)^{-0,17}$, sendo $k_{1}$ um coeficiente que varia com a pressão lateral.

- $f_{l e}=k_{2} \cdot f_{l}$, sendo $k_{2}$ o coeficiente que reflete a eficácia da pressão lateral atuante na seção, de acordo com o proposto por MANDER et al. (1988).

A deformação máxima no ponto de pico pode ser estimada por:

$$
\varepsilon_{c c}=\varepsilon_{c o} \cdot\left(1+5 k_{3} \cdot K\right)
$$

onde:

- $k_{3}=\frac{40}{f_{c o}} \leq 1$

- $K=\frac{k_{1} f_{l e}}{f_{c o}}$

\subsection{Diagrama força-deformação idealizado para pilares curtos de concreto armado proposto por GRAYBEAL \& PESSIKI (2000)}

De acordo com GRAYBEAL \& PESSIKI (2000), o comportamento do diagrama força-deformação de pilares curtos de concreto armado confinados por armadura transversal em forma de espiral contínua, submetidos à compressão centrada, apresenta comportamento similar ao diagrama idealizado de forçadeformação proposto pelos autores, ilustrado na figura 3.5. 


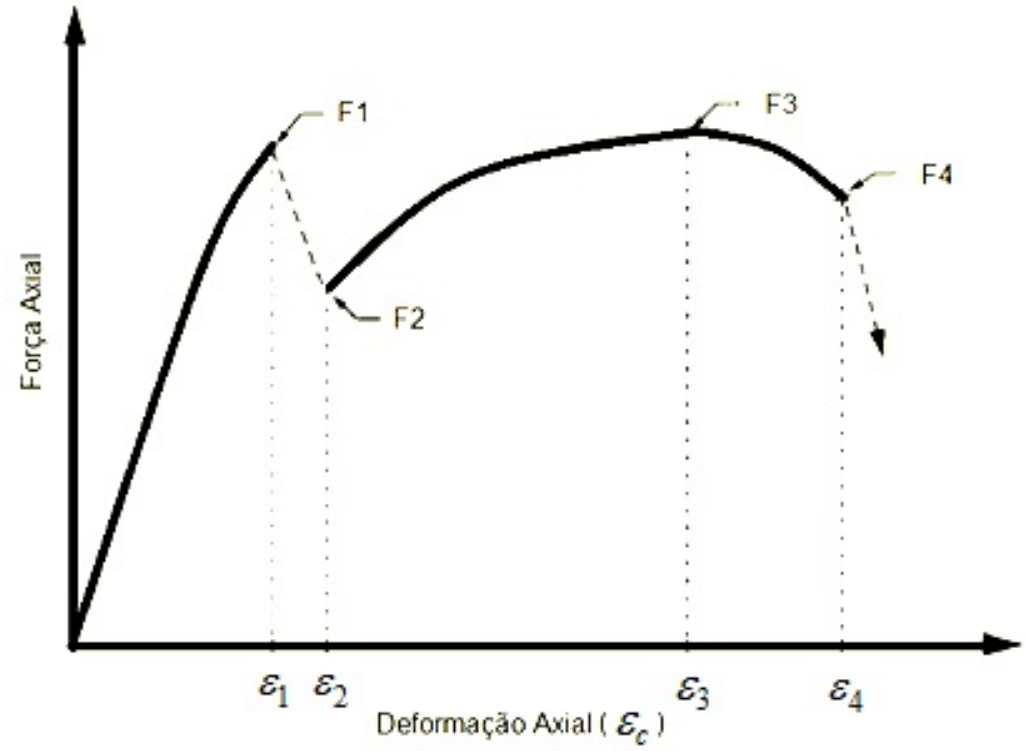

Figura 3.5 - Diagrama força-deformação idealizado para pilares confinados por armadura transversal na forma de espiral contínua, proposto por GRAYBEAL \& PESSIKI (2000)

Segundo os autores existem quatro pontos principais no diagrama idealizado de força-deformação e cada um corresponde a:

- Primeiro ponto $\left(F_{1}, \varepsilon_{1}\right)$ - Ponto que indica a força normal e a deformação axial do concreto correspondente ao início do destacamento do concreto do cobrimento;

- Segundo ponto $\left(F_{2}, \varepsilon_{2}\right)$ - Ponto que indica a força normal e a deformação axial do concreto, correspondente, à perda total do concreto do cobrimento. Esse ponto é caracterizado por uma queda na capacidade resistente do pilar, devido à perda da parcela colaboram-te do concreto do cobrimento;

- Terceiro ponto $\left(F_{3}, \varepsilon_{3}\right)$ - Ponto que indica a força normal e a deformação axial do concreto do núcleo confinado;

- Quarto ponto $\left(F_{4}, \varepsilon_{4}\right)$ - Ponto que indica a força normal e a deformação axial do concreto correspondente à ruptura da espiral. Esse ponto é caracterizado pela queda de capacidade resistente do núcleo de concreto confinado, devido à perda da pressão lateral confinante . 


\section{6. Índices de ductilidade}

Quando um pilar de concreto armado está submetido a esforços de compressão, sem restrição lateral (sem confinamento), apresentará uma ruptura do tipo frágil, todavia, quando sua deformação lateral for restringida por uma armadura transversal adequada (efeitos do confinamento com aço), poderão ser obtidos acréscimos de resistência à compressão e deformações no concreto do núcleo, alterando a forma de ruptura para uma do tipo dúctil.

Portanto, a ductilidade pode ser definida como a capacidade de deformação apresentada pelo elemento estrutural sem a ocorrência de uma perda significativa de sua resistência.

Conforme CARRAZEDO (2000), a ductilidade de pilares de concreto armado é influenciada pela resistência do concreto e pela forma de seu diagrama tensão-deformação.

SHIN et al. (2014) quantificaram numericamente a ductilidade, dos resultados de seus ensaios experimentais, pela utilização dos índices de ductilidade:

$$
\begin{aligned}
& I D_{1}=\frac{\varepsilon_{1}}{\varepsilon_{c o}} \\
& I D_{2}=\frac{\varepsilon_{3}}{\varepsilon_{c o}}
\end{aligned}
$$

onde:

- $\varepsilon_{1}$ - Deformação do concreto referente à obtenção da força normal $\left(F_{1}\right)$, atuante no ponto $\left(F_{1}, \varepsilon_{1}\right)$ do diagrama idealizado proposto por GRAYBEAL \& PESSIKI (2000);

- $\varepsilon_{c o}$ - Deformação do concreto não confinado;

- $\varepsilon_{3}$ - Deformação última do concreto confinado $\left(\varepsilon_{c c}\right)$. 
Os dois índices de ductilidade utilizados pelos pesquisadores correspondem a duas situações distintas no diagrama força-deformação do concreto confinado. O primeiro índice $\left(I D_{1}\right)$ relaciona a deformação axial registrada na obtenção da força máxima no trecho ascendente do diagrama força-deformação com a deformação do concreto não confinado, já o segundo índice $\left(I D_{2}\right)$ correlaciona a deformação última do concreto confinado, trecho descendente do diagrama forçadeformação, com a deformação do concreto não confinado.

MENDES (1993) sugere, para quantificar a ductilidade do concreto confinado no trecho descendente do diagrama força-deformação, o índice:

$$
I D_{3}=\frac{\varepsilon_{0,85}}{\varepsilon_{3}}
$$

onde:

- $\varepsilon_{0,85}$ - Deformação correspondente a $0,85 \cdot f_{c c}$, no trecho descendente do diagrama força-deformação

- $\varepsilon_{3}$ - Deformação última do concreto confinado $\left(\varepsilon_{c c}\right)$.

CUSSON \& PALTRE (1993) propuseram a análise mais importante no estudo do confinamento, a qual sugere um estimador de eficiência para o confinamento, denominado Índice de eficiência do confinamento (I.E.C ), dado por:

$$
\text { I.E.C }=\frac{f_{l e}}{f_{c o}}
$$

Esse índice é determinado pela relação entre pressão lateral efetiva $\left(f_{l e}\right) \mathrm{e}$ a resistência à compressão do concreto não confinado $\left(f_{c o}\right)$. Desse modo, quanto maior for a pressão lateral de confinamento e menor for a resistência do concreto não confinado, maiores índices de confinamento serão obtidos, e vice-versa. A 
classificação desses índices de eficiência do confinamento é dividida em três níveis de eficiência, sendo estes apresentados na tabela 3.1.

Tabela 3.1 - Classificação dos índices efetivos de confinamento (CUSSON \& PAULTRE, 1993)

\begin{tabular}{cc}
\hline Classificação & Índice de Eficiência (\%) \\
\hline CLASSE 1 - Baixo confinamento & $0 \%<$ I.E.C $\leq 5 \%$ \\
\hline CLASSE 2 - Médio confinamento & $5 \%<$ I.E.C $\leq 20 \%$ \\
\hline CLASSE 3 - Alto confinamento & I.E.C $>20 \%$ \\
\hline
\end{tabular}

A classificação do índice efetivo de confinamento fornece diretrizes para a aplicação dos pilares confinados, sobre ganhos de resistência, ductilidade e aplicações, e essas aplicações são realizadas em função da classe a que o pilar pertence:

- CLASSE 1: Pilares com poucos ganhos de ductilidade e nenhum ganho de resistência pelo efeito do confinamento, podendo serem aplicados em regiões onde não ocorram efeitos sísmicos;

- CLASSE 2: Pilares com ganhos moderados de resistência e comportamento dúctil após o trecho de pós-pico, podendo serem aplicados em regiões sujeitas a efeitos sísmicos;

- CLASSE 3: Pilares com elevados acréscimos de resistência e grande ductilidade, sendo a classe mais recomendada para aplicações em regiões sujeitas a abalos sísmicos elevados. 


\section{Metodologia e Resultados}

\subsection{Considerações iniciais}

Este capítulo relata a metodologia empregada no desenvolvimento experimental desta pesquisa, a qual foi fragmentada em três etapas: a primeira relacionada à obtenção dos concretos de pós-reativos (CPR's), a segunda relativa ao ensaio piloto e a terceira pertencente aos ensaios definitivos. Neste capítulo cada uma dessas etapas terão os seus procedimentos descritos, como apresentado a seguir, de forma resumida.

a) Obtenção dos CPR's

- Utilização de um traço de referência de CPR desenvolvido por GRASS \& SEIDLER (2010);

- Execução do traço de referência para a verificação da máxima resistência à compressão;

- Execução de seis traços auxiliares para o aprimoramento do traço de referência, sendo estudados os teores ideais de adição de: sílica ativa, pó de quartzo e fibras metálicas;

- Execução de ensaios de compressão axial em corpos de prova cilíndricos de $5 \mathrm{~cm} \times 10 \mathrm{~cm}$, nas idades de 3, 7, 14 e 28 dias.

b) Ensaio Piloto

- Projeto dos modelos pilotos;

- Montagem das armaduras, instrumentação dos fios das armaduras longitudinais e transversais;

- Moldagem, adensamento, desmoldagem e aplicação de cura.

- Preparação das extremidades dos modelos;

- Preparação da instrumentação na máquina de ensaio e realização dos ensaios de compressão centrada, com controle de deslocamento. 
c) Ensaios definitivos

- Projeto dos modelos definitivos;

- Montagem das armaduras, instrumentação dos fios das armaduras longitudinais e transversais e posicionamento da armação nas fôrmas;

- Moldagem, adensamento, desmoldagem e aplicação de cura;

- Preparação das extremidades dos modelos;

- Aplicação de reforço estrutural por meio de aplicação de polímero reforçado com fibras de carbono (PRFC) nas extremidades dos modelos;

- Execução de retífica nas extremidades dos modelos e verificação da planicidade dos topos dos modelos;

- Execução de ensaios de tração nas amostras dos fios de aço que foram utilizados como armaduras longitudinais e transversais;

- Execução de ensaios de compressão axial em corpos de prova cilíndricos de $5 \mathrm{~cm} \times 10 \mathrm{~cm}$, nas idades de rompimento dos pilares, para controle da resistência à compressão do concreto e do módulo de elasticidade;

- Preparação da instrumentação na máquina de ensaio;

- Ensaios de compressão centrada nos pilares, com deformação controlada para a obtenção do comportamento pós pico do concreto confinado, sendo 4 séries com 6 modelos cada, totalizando 24 modelos.

Praticamente todo o desenvolvimento do programa experimental foi realizado no Laboratório de Estruturas do Departamento de Engenharia de Estruturas da EESC/USP, ficando apenas exclusos a este universo o dobramento das armaduras transversais e uma etapa da aplicação de cura térmica. O dobramento das armaduras transversais, em formato de espiral, foi realizado pela empresa INCOMOL, situada na cidade de Ribeirão Preto - SP. Parte do processo de aplicação de cura térmica a $90^{\circ} \mathrm{C}$ foi realizado na Universidade Regional Integrada do Alto Uruguai e das Missões - URI, campus Santo Ângelo - RS, no laboratório de Ensaios Tecnológicos da Construção Civil - LETCC. 


\subsection{Materiais utilizados}

\subsubsection{Cimento}

$\mathrm{O}$ cimento utilizado na pesquisa foi o $\mathrm{CP} V-\mathrm{ARI}$, doado pela empresa Cimento TUPI, por intermédio da empresa Cimento Novo, situada na cidade de São Carlos -SP, e em conformidade com a NBR 5733:1994. A empresa forneceu os valores de: massa específica $3,12 \mathrm{~kg} / \mathrm{dm}^{3}$; superfície específica Blaine de $5690 \mathrm{~cm}^{2} / \mathrm{g}$, e resistência à compressão aos 28 dias de 48,6 MPa.

\subsubsection{Agregado miúdo}

A areia utilizada na pesquisa foi doada pela empresa Mineração Jundu, comercializada como areia industrial. A empresa forneceu os valores de: diâmetro médio dos grãos de 0,28 mm; diâmetro máximo de 0,6 mm; módulo de finura 1,287 e massa específica de 2,64 kg/dm³ . De acordo com a NBR 7211:1983, esta areia é classificada como muito fina. De acordo com o fabricante, a composição química dessa areia apresenta valores de $99,42 \%$ de quartzo $\left(\mathrm{SiO}_{2}\right)$, classificada como uma areia quartoza.

\subsubsection{Pó de quartzo}

O pó de quartzo utilizado na pesquisa foi doado pela Mineração Jundu, comercializado como sílica moída 325. A empresa forneceu os valores de: dimensão máxima característica de 0,045 mm e composição química de 99,73\% de quartzo $\left(\mathrm{SiO}_{2}\right)$.

\subsubsection{Sílica ativa}

A sílica ativa utilizada na pesquisa foi doada pela empresa Tecnosil - Sílica Ativa, a qual forneceu os valores de: massa especifica de $2220 \mathrm{~kg} / \mathrm{m}^{3}$, superfície específica aproximada de $19.000 \mathrm{~m}^{2} / \mathrm{kg}$ e diâmetro médio de $0,20 \mu \mathrm{m}$. 


\subsubsection{Aditivo Superplastificante}

O aditivo superplastificante utilizado na pesquisa foi doado pela empresa GRACE, comercializado com o nome de ADVA CAST $675^{\circledR}$, sendo classificado como um aditivo superplastificante de última geração, com densidade específica de 1,075 $\mathrm{kg} / \mathrm{L}$ a $20^{\circ} \mathrm{C}$ e teor de sólidos de $38,5 \%$.

\subsection{6. Água}

A água utilizada na pesquisa para o amassamento dos concretos é potável. Cabe a ressalva que nesta etapa toda a água da mistura foi substituída por gelo triturado.

\subsubsection{Fibras metálicas}

As fibras metálicas utilizadas na pesquisa foram importadas da China, fabricadas pela empresa Ganzhou Daye Metallic Fibers Co., Ltda, sediada na cidade de Ganzhou, província de Jiangxi, com características e propriedades descritas na tabela 4.1.

Tabela 4.1 - Características e propriedade mecânica da fibra metálica utilizada

\begin{tabular}{ccc}
\hline $\begin{array}{c}\text { Comprimento } \\
(\mathbf{m m})\end{array}$ & $\begin{array}{c}\text { Diâmetro } \\
(\mathbf{m m})\end{array}$ & $\begin{array}{c}\text { Resistência à tração } \\
(\mathbf{M P a})\end{array}$ \\
\hline 13 & 0,2 & 2850 \\
\hline
\end{tabular}

A fibra metálica apresenta comprimento reto, relação de aspecto (L/d) de 65 , sendo a mais utilizada internacionalmente na produção de CPR. As variações de fibras metálicas em volume utilizadas no estudo de dosagem variaram de $0,38 \%$, $1,53 \%$ e $2,23 \%$. 


\subsection{Dosagem}

\subsubsection{Determinação dos teores ideais dos materiais constituintes do CPR}

A fim de estudar as proporções ideais de: adição de sílica ativa, pó de quartzo e dos teores de adição de fibras metálicas ao CPR, foram estudadas seis variações de traços diferentes, tendo como base um traço de CPR desenvolvido por GRASS \& SEIDLER (2010), apresentado na tabela 4.2.

\begin{tabular}{cc} 
Tabela 4.2 - Traço de CUAR proposto por GRASS \& SEIDLER (2010) \\
\hline Materiais & $\mathbf{k g} / \mathbf{m}^{\mathbf{3}}$ \\
\hline Cimento & 700 \\
Sílica Ativa & 300 \\
Pó de Quartzo & 300 \\
Areia & 1000 \\
Superplastificante & 64,5 \\
Água & 138 \\
\hline
\end{tabular}

Nesta etapa, foram então fixadas as variações nos teores de adição de: sílica ativa, pó de quartzo e fibras metálicas. Os teores estudados foram: 25 e $30 \%$ para a adição de sílica ativa; 30\% e 40\% para o teor de pó de quartzo; e 3\%, 12,5\% e $17,5 \%$ para a adição de fibras metálicas. Todas as adições foram realizadas em função da massa de cimento. As misturas foram classificadas por séries como mostra a tabela 4.3.

Tabela 4.3 - Classificação e descrição dos teores variáveis das misturas estudadas

\begin{tabular}{lccc} 
& \multicolumn{3}{c}{ Materiais constituintes variáveis } \\
\cline { 2 - 4 } Nomenclatura das misturas & $\begin{array}{c}\text { Sílica Ativa } \\
\text { (SA) } \\
\text { (\%) }\end{array}$ & $\begin{array}{c}\text { Pó de } \\
\text { Quartzo } \\
\text { (PQ) } \\
(\%)\end{array}$ & $\begin{array}{c}\text { Fibras } \\
\text { Metálicas } \\
\text { (FM) } \\
\text { (\%) }\end{array}$ \\
\hline M1-SA25/PQ30 & 25 & 30 & - \\
\hline M2-SA30/PQ30 & 30 & 30 & - \\
\hline M4-SA30/PQ40 & 30 & 40 & - \\
\hline M5-SA30/PQ30/FM12 & 30 & 30 & 3 \\
\hline M6-SA30/PQ30/FM17,5 & 30 & 30 & 12 \\
\hline
\end{tabular}

\subsubsection{Traços estudados}

Os traços estudados foram estipulados em função dos materiais constituintes variáveis, com os outros materiais constituintes fixados em função do 
traço de CPR de referência. A tabela 4.4, apresenta o desdobramento dos traços de concretos estudados na pesquisa.

Tabela 4.4 - Traços de CPR utilizados

\begin{tabular}{|c|c|c|c|c|c|c|}
\hline \multirow[b]{2}{*}{$\begin{array}{l}\text { Materiais } \\
\text { Constituintes }\end{array}$} & \multicolumn{6}{|c|}{ Misturas } \\
\hline & $\begin{array}{c}\text { M1 } \\
\text { SA25 } \\
\text { PQ30 }\end{array}$ & $\begin{array}{c}\text { M2 } \\
\text { SA30 } \\
\text { PQ30 }\end{array}$ & $\begin{array}{c}\text { M3 } \\
\text { SA30 } \\
\text { PQ40 }\end{array}$ & $\begin{array}{c}\text { M4 } \\
\text { SA30 } \\
\text { PQ30 } \\
\text { FM3 }\end{array}$ & $\begin{array}{c}\text { M5 } \\
\text { SA30 } \\
\text { PQ30 } \\
\text { FM12 }\end{array}$ & $\begin{array}{c}\text { M6 } \\
\text { SA30 } \\
\text { PQ30 } \\
\text { FM17,5 }\end{array}$ \\
\hline Cimento $\left(\mathrm{kg} / \mathrm{m}^{3}\right)$ & 750 & 700 & 700 & 700 & 700 & 700 \\
\hline Sílica Ativa $\left(\mathrm{kg} / \mathrm{m}^{3}\right)$ & 250 & 300 & 300 & 300 & 300 & 300 \\
\hline $\begin{array}{l}\text { Pó de Quartzo } \\
\left(\mathrm{kg} / \mathrm{m}^{3}\right)\end{array}$ & 300 & 300 & 400 & 300 & 300 & 300 \\
\hline Areia $\left(\mathrm{kg} / \mathrm{m}^{3}\right)$ & 1000 & 1000 & 1000 & 1000 & 1000 & 1000 \\
\hline $\begin{array}{l}\text { Superplastificante } \\
\left(\mathrm{kg} / \mathrm{m}^{3}\right)\end{array}$ & 64,5 & 64,5 & 64,5 & 64,5 & 64,5 & 64,5 \\
\hline Água $\left(\mathrm{kg} / \mathrm{m}^{3}\right)$ & 138 & 138 & 138 & 138 & 138 & 138 \\
\hline $\begin{array}{l}\text { Fibras Metálicas } \\
\left(\mathrm{kg} / \mathrm{m}^{3}\right)\end{array}$ & - & - & - & 30 & 120 & 175 \\
\hline
\end{tabular}

\subsubsection{Processo de produção dos CPR's}

O processo de amassamento dos concretos foi realizado em uma argamassadeira planetária elétrica com cuba de $20 \mathrm{~L}$ e seis velocidades de rotação, conforme a sequência detalhada a seguir:

I. Pesagem dos materiais secos do concreto;

II. Colocação dos materiais na cuba da argamassadeira planetária, pré-mistura dos materiais secos com o auxílio de espátula metálica e mistura em baixa rotação por dois minutos;

III. Lançamento da água de amassamento e do superplastificante;

IV. Processo de mistura em baixa rotação, com limpezas intercaladas do material aderido à cuba da argamassadeira e colocação das fibras metálicas;

V. Processo de mistura em alta rotação por 15 minutos ou até o material apresentar a fluidez desejada;

VI. Pré-vibração do concreto com vibrador de imersão dentro da cuba por 2 minutos;

VII. Moldagem dos corpos de provas com auxílio de mesa vibratória e vibrador de imersão; 
VIII. Após a moldagem dos corpos de provas, foi executado o nivelamento das suas superfícies dos topos dos corpos de prova com o auxílio de uma espátula metálica e proteção de seus topos com sacos plásticos;

IX. Desmoldagem dos corpos de prova com $24 \mathrm{~h}$;

X. Aplicação dos processos de cura aos concretos.

As figuras $4.1,4.2,4.3,4.4$ e 4.5 ilustram algumas das etapas anteriormente descritas para a produção dos concretos.

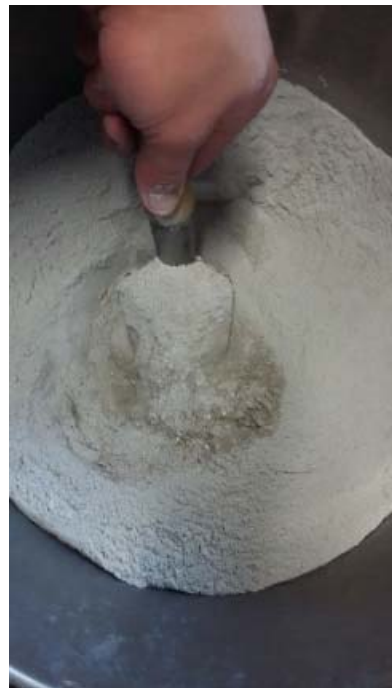

Figura 4.1 - Pré-mistura

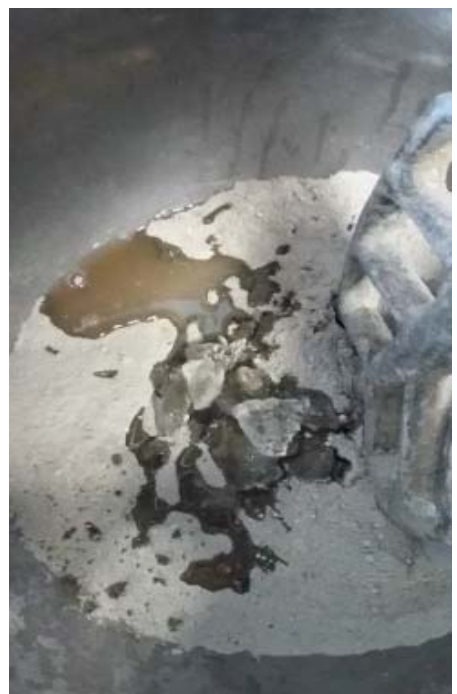

Figura 4.2 - Colocação do superplastificante

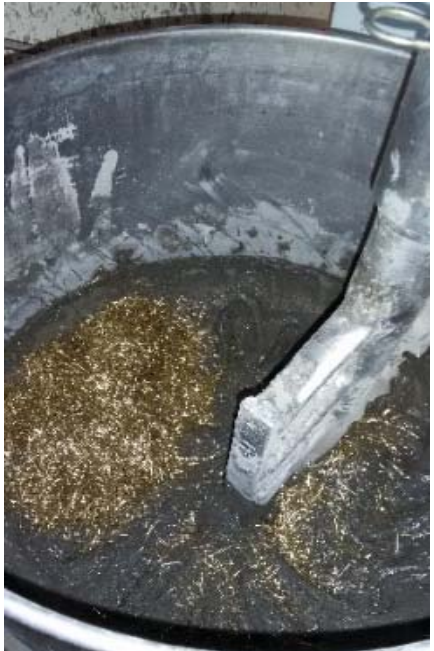

Figura 4.3 - Colocação das fibras metálicas 


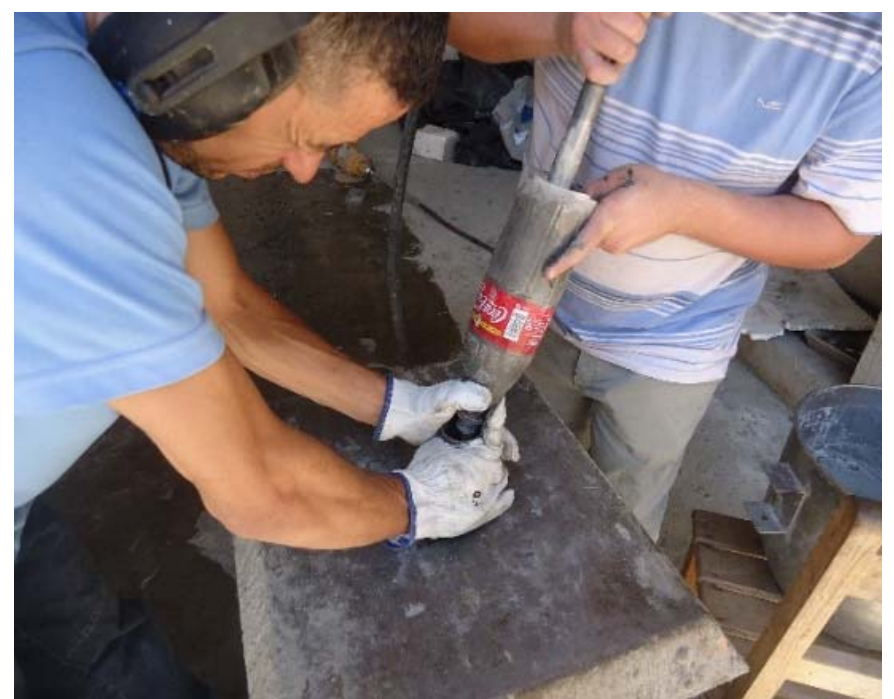

Figura 4.4 - Processo de moldagem utilizado para os corpos de prova de concretos

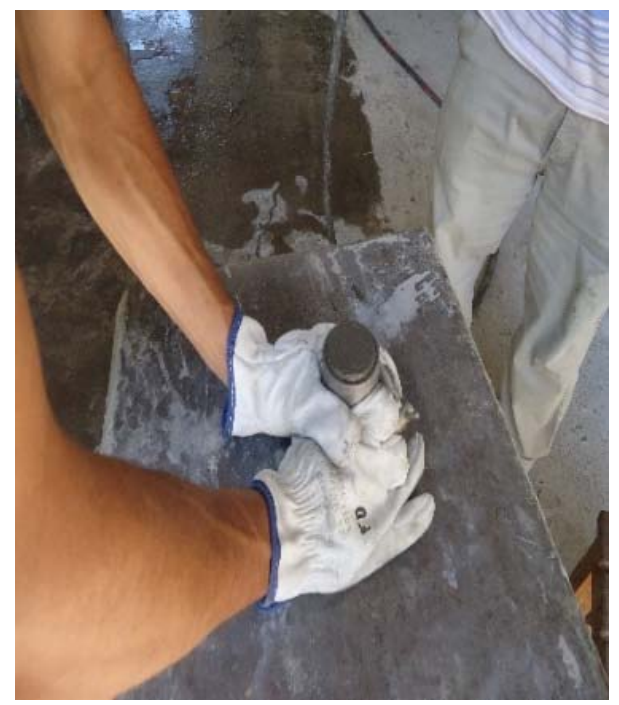

Figura 4.5 - Vibração dos corpos de prova

\subsubsection{Processo de cura}

Os corpos de provas de concreto foram todos desformados após $24 \mathrm{~h}$ da concretagem e imersos em um tanque com água em temperatura ambiente pelo período de sete dias. Posteriormente a este período foram levados para a aplicação de cura térmica a $90^{\circ} \mathrm{C}$, permanecendo nesse tratamento até as idades de rompimento à compressão fixadas na pesquisa. Os corpos de provas de concreto eram retirados sempre nas idades de rompimento pelo período da manhã, tinham suas faces retificadas e ensaiados pelo período da tarde. 


\subsubsection{Resistência à compressão}

Para a realização dos ensaios de resistência à compressão optou-se por moldar quatro corpos de prova para serem rompidos aos 3, 7, 14 e 28 dias, nas dimensões de $5 \mathrm{~cm}$ de diâmetro por $10 \mathrm{~cm}$ de altura, totalizando 96 amostras, com os procedimentos laboratoriais adotados conforme prescreve a NBR 5739:1994.

\subsubsection{Resultados dos ensaios de resistência à compressão}

Os ensaios de resistência à compressão foram executados com a intenção de verificar o comportamento da resistência à compressão do traço de referência de CPR, em função das variações nos teores de adições estudadas, bem como para comprovar sua eficiência. Os resultados obtidos são apresentados na tabela 4.5, em função da resistência média à compressão $\left(f_{c m}\right)$, tomada como a média entre as quatro leituras de resistência à compressão nas idades estudadas na pesquisa.

Tabela 4.5 - Resistência média à compressão para os traços de CPR estudados

\begin{tabular}{lcccc}
\hline \multirow{2}{*}{ Misturas } & \multicolumn{4}{c}{$\begin{array}{c}\text { Resistência média à compressão } \\
(\end{array}$} \\
& \multicolumn{4}{c}{$\begin{array}{c}\text { Idade em (dias) } \\
\text { Idac }\end{array}$} \\
\cline { 2 - 5 } & $\mathbf{3}$ & $\mathbf{7}$ & $\mathbf{1 4}$ & $\mathbf{2 8}$ \\
\hline M1-SA25/PQ30 & 85,6 & 114,9 & 212 & 229,3 \\
\hline M2-SA30/PQ30 & 88,1 & 119,2 & 220,5 & 242,5 \\
\hline M3-SA30/PQ40 & 58,4 & 110,9 & 200,15 & 200,2 \\
\hline M4-SA30/PQ30/FM3 & 92 & 130,1 & 210,4 & 223,1 \\
\hline M5-SA30/PQ30/FM12 & 90,8 & 109,5 & 212,4 & 214,2 \\
\hline M6-SA30/PQ30/FM17,5 & 89 & 119,6 & 208,9 & 215,1 \\
\hline
\end{tabular}

Os resultados de resistências média à compressão aos 28 dias, apresentados pelas misturas com variação nos teores de adição de sílica ativa e pó de quartzo, mostram que para o teor de adição de $30 \%$ obteve-se a máxima resistência à compressão. A resistência média à compressão aos 28 dias, para a mistura $\mathrm{M} 2$, é superior à máxima resistência à compressão apresentada pelo traço de referência proposto por GRASS \& SEIDLER (2010), que é de 240,34 MPa, comprovando a eficiência do traço de CPR utilizado na pesquisa. Para as misturas com variação nos teores de adição de fibras metálicas, os resultados de resistências média à compressão aos 28 dias mostram que a máxima resistência à compressão 
foi obtida com o teor de adição de $3 \%$. Notou-se que a incorporação de fibras metálicas nos teores estudados na pesquisa (3\%,12\% e 17,5\%) diminuíram a resistência à compressão média aos 28 dias do traço de referência, nos respectivos valores: 19, 28,3 e 27,4 MPa. A partir dos desdobramentos dos traços de CPR utilizados na pesquisa, apresentados na tabela 4.4, conseguiu-se determinar as frações volumétricas utilizadas na pesquisa, e compará-las de acordo com classificação proposta por MEHTA \& MONTEIRO (2008). As frações volumétricas de fibras metálicas utilizadas para as misturas M4, M5 e M6 foram, respectivamente: $0,38 \%, 1,5 \%$ e $2,2 \%$, classificadas como: baixa fração volumétrica, moderada fração volumétrica e alta fração volumétrica, respectivamente.

Nesta etapa de desenvolvimento da pesquisa ficaram evidentes os modos de ruptura apresentados pelas misturas estudadas, possibilitando distinguir o comportamento último dos concretos dosados sem e com a adição de fibras metálicas. As figuras 4.6, 4.7 e 4.8 ilustram as formas de ruptura apresentadas pelas misturas: M1, M4 e M6, respectivamente. Nota-se que para a mistura M1 sem adição de fibras metálicas o material se fragmenta em pedaços, possuindo comportamento frágil. Já para as misturas M4 e M6, dosadas com adição de fibras metálicas, o comportamento apresentado foi do tipo dúctil, com as fibras evitando a fragmentação do concreto.

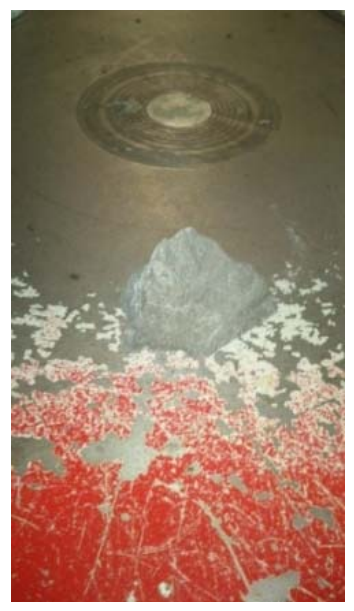

Figura 4.6 - Forma de ruptura CPR sem fibras metálicas 


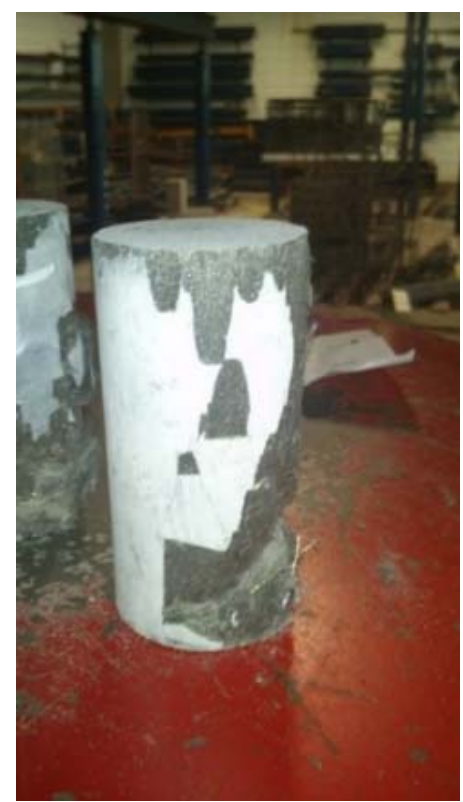

Figura 4.7 - Forma de ruptura CPR com fração volumétrica de 1,5\%

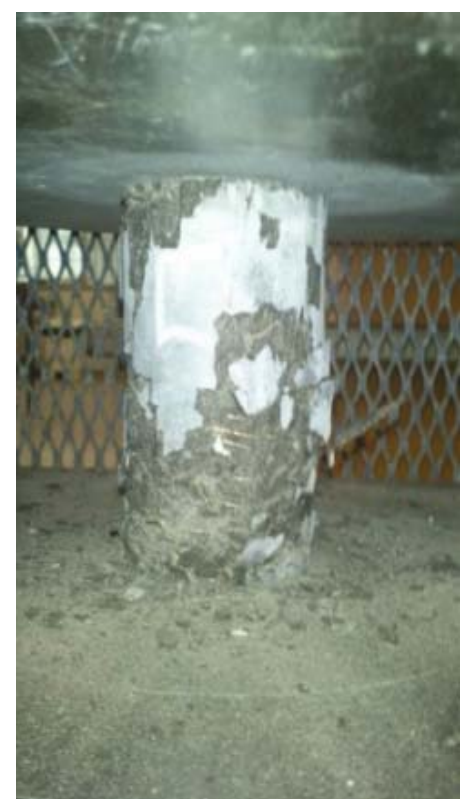

Figura 4.8 - Forma de ruptura CPR com fração volumétrica de fibras metálicas de 2,2\%

Todas as dosagens estudadas tiveram crescimento de resistência ao longo do tempo de estudo, como mostra a figura 4.9. 


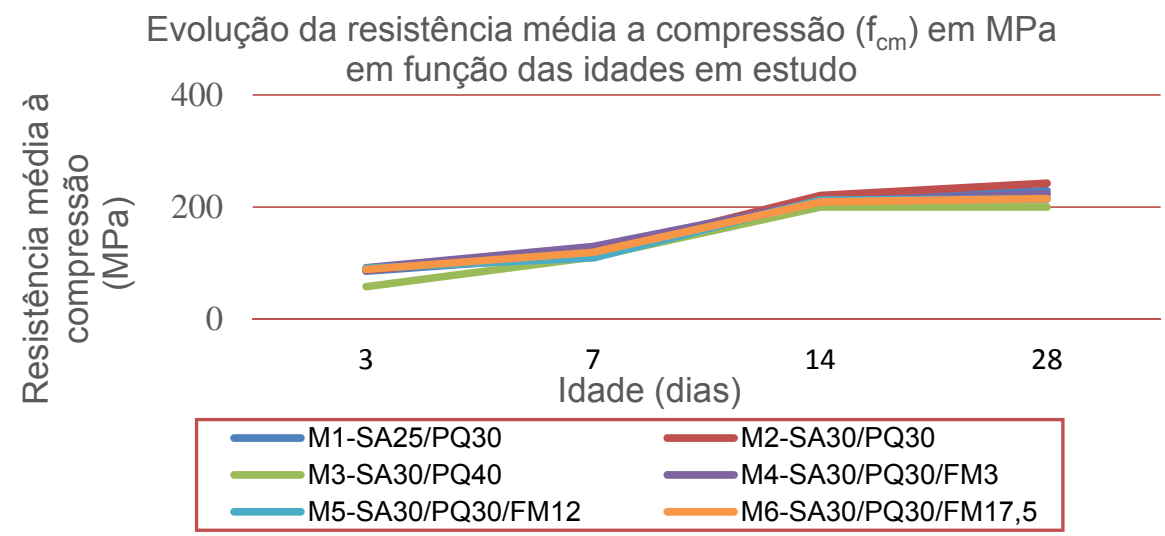

Figura 4.9 - Evolução da resistência média à compressão $\left(f_{c m}\right)$ para as misturas estudadas

\subsection{Ensaio-Piloto}

Afim de realizar a verificação da metodologia adotada para a análise experimental, foram moldados dois pilares de concreto armado, com as características apresentadas na tabela 4.6 abaixo.

Tabela 4.6 - Características do confinamento adotado para os modelos pilotos

\begin{tabular}{c|cccc}
\hline Modelo & $\begin{array}{c}\text { Pressão } \\
\text { lateral } \\
\text { efetiva } \\
\left(f_{l e}\right)\end{array}$ & $\begin{array}{c}\text { Índice de } \\
\text { Confinamento } \\
(I . E . C)\end{array}$ & $\begin{array}{c}\text { Espaçamentos } \\
\text { da espiral } \\
(\mathbf{S}) \\
\mathbf{( c m )}\end{array}$ & $\begin{array}{c}\text { Classificação em } \\
\text { função do } \\
(I . E . C)\end{array}$ \\
\hline $\mathbf{1}$ & 14,73 & 12,38 & 1 & Médio Confinamento \\
\hline $\mathbf{2}$ & 4,91 & 4,13 & 3 & Baixo Confinamento \\
\hline
\end{tabular}

\subsubsection{Características geométricas dos modelos-pilotos}

Os modelos pilotos possuíam seção circular de $7,2 \mathrm{~cm}$ de diâmetro e $23 \mathrm{~cm}$ de altura. Foram adotados cobrimento de 0,3 cm para as armaduras. 


\subsubsection{Resistência à compressão}

Os modelos foram moldados com o traço de CPR proposto por GRASS \& SEIDLER (2010), com resistência média à compressão aos 28 dias de 140 MPa. Nesta etapa optou-se por não utilizar tratamento térmico nos modelos, pois estavam sendo investigadas as especificações necessárias para os fios pertencentes à instrumentação das armaduras, em virtude da exposição a temperaturas acima de $90^{\circ} \mathrm{C}$.

\subsubsection{Armaduras}

Os modelos possuíam armaduras na seção transversal e longitudinal. Foi utilizado para as armaduras longitudinais o diâmetro de $4 \mathrm{~mm}$, e para as armaduras transversais o diâmetro de 1,65 mm. Nesse processo foram utilizados dois tipos diferentes de aço, sendo eles:

I. Armaduras transversais: Aço mola classe $\mathrm{C}$, com tensão de escoamento $\left(f_{y w}\right)$ de $2150 \mathrm{MPa}$, de acordo com a NBR 11414:1990;

II. Armaduras longitudinais: Fios de aço para protensão estabilizados (RB), com tensão de escoamento $\left(f_{y l}\right)$ de $1750 \mathrm{MPa}$, de acordo com a NBR 7482:1991.

Os espaçamentos utilizados para as armaduras transversais estão descritos na tabela 4.6.

\subsubsection{Retífica das extremidades dos modelos}

As extremidades dos modelos foram retificadas conforme ilustra a figura 4.10, afim de tornar a superfície plana e isenta de irregularidades. 


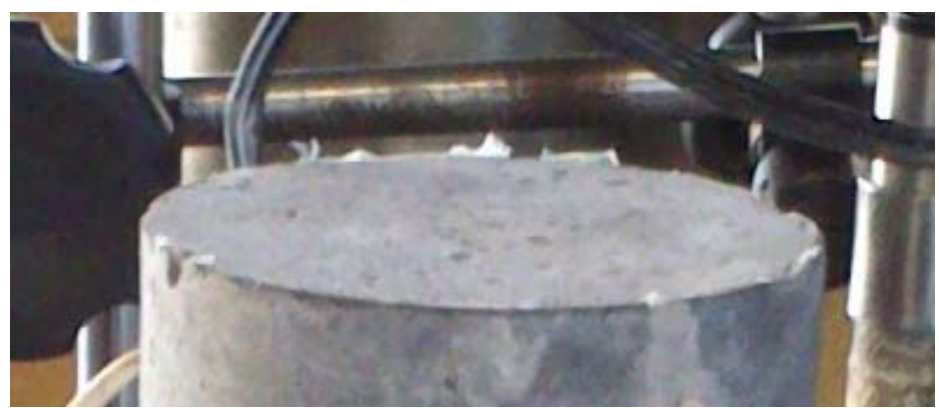

Figura 4.10 - Retificação das extremidades dos modelos-piloto

\subsubsection{Instrumentação}

Para a instrumentação das armaduras longitudinais dos modelos foram utilizados extensômetros elétricos de resistência da marca KYOWA, modelo KFG5-C1-120-11, e para as armaduras transversais, o KFG-2-C1-120-11. Foram utilizados dois extensômetros elétricos nas armaduras transversais, dois nas armaduras longitudinais e um na face do concreto. Os deslocamentos verticais foram registrados por dois transdutores de deslocamento da marca KYOWA, com curso de $30 \mathrm{~mm}$. As figuras 4.11 e 4.12 ilustram as instrumentações adotadas nesta etapa.

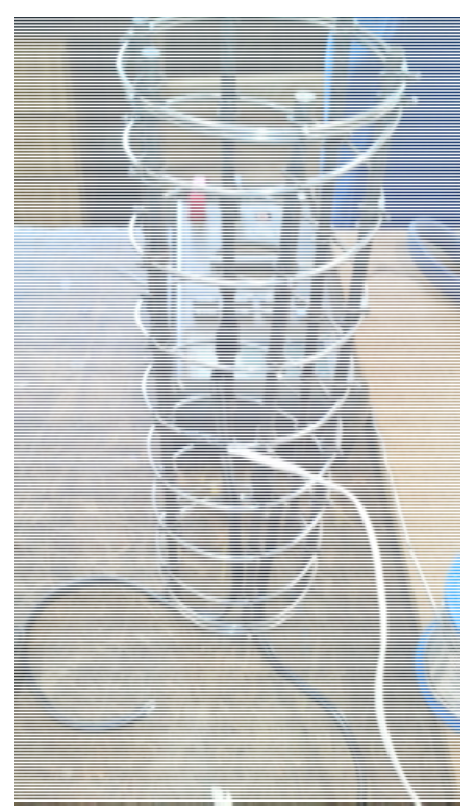

Figura 4.11 - Instrumentação nas armaduras 


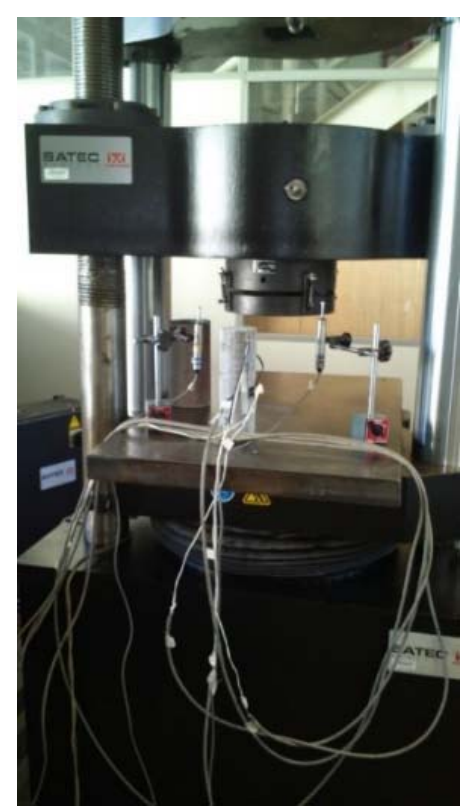

Figura 4.12 - Instrumentação na máquina de ensaio

\subsubsection{Velocidade de carregamento}

Os modelos foram ensaiados à compressão centrada aos 28 dias de idade, com uma taxa de deslocamento de $0,003 \mathrm{~mm} / \mathrm{s}$.

\subsubsection{Diagrama força-deslocamento}

Através da realização do ensaio de compressão centrada de cada modelo, foi obtido um diagrama de força-deslocamento para cada modelo, conforme apresentado na figura 4.13. 


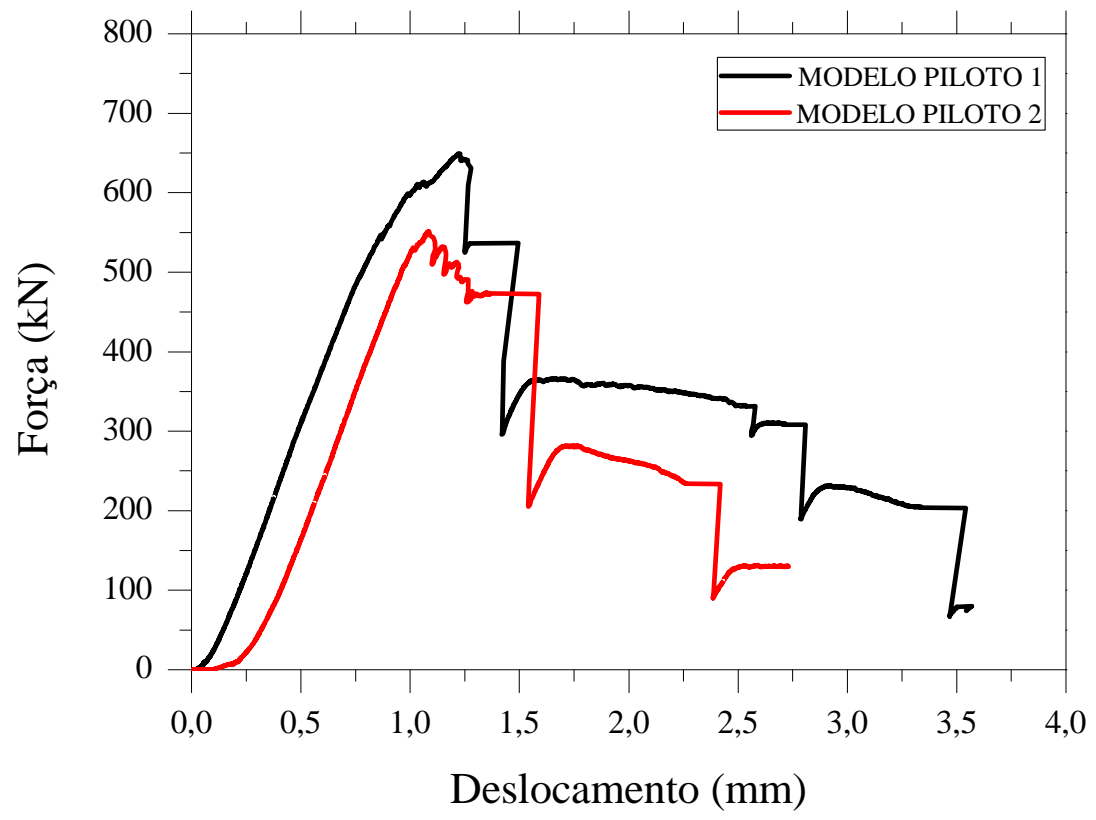

Figura 4.13 - Diagramas Força-Deslocamento (média dos transdutores) dos modelos-pilotos

Nesta etapa da pesquisa constatou-se as seguintes particularidades após a execução dos ensaios dos modelos: ruptura das espirais da armadura transversal, flambagem das armaduras longitudinais e o destacamento do concreto do cobrimento. O fenômeno do destacamento do concreto do cobrimento, ou a perda prematura do cobrimento, é uma importante característica apresentada por pilares de concreto de alta resistência. As figuras 4.14 e 4.15 ilustram as formas de ruptura apresentadas pelos modelos-piloto ensaiados.

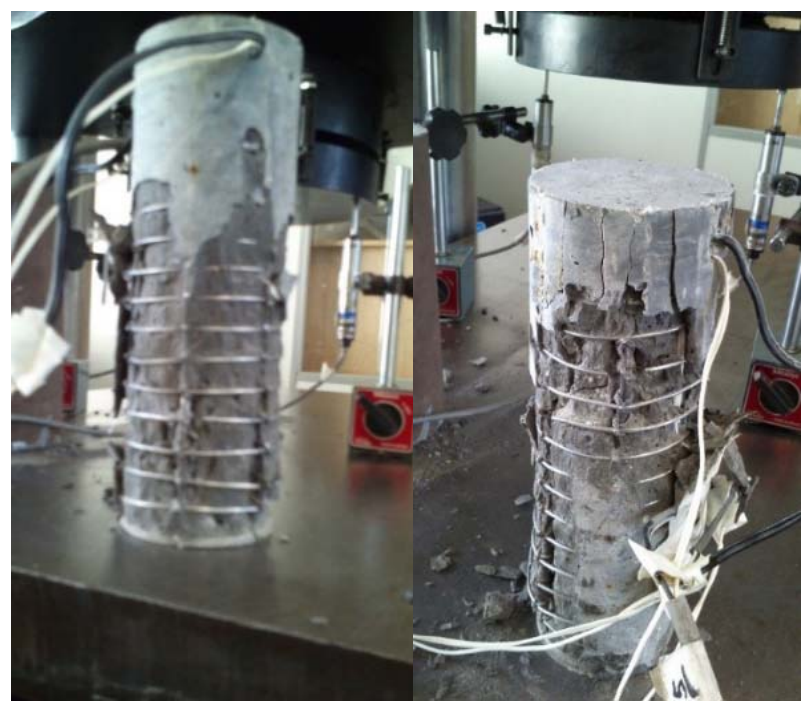

Figura 4.14 - Modelo-piloto 1 após a ruptura 


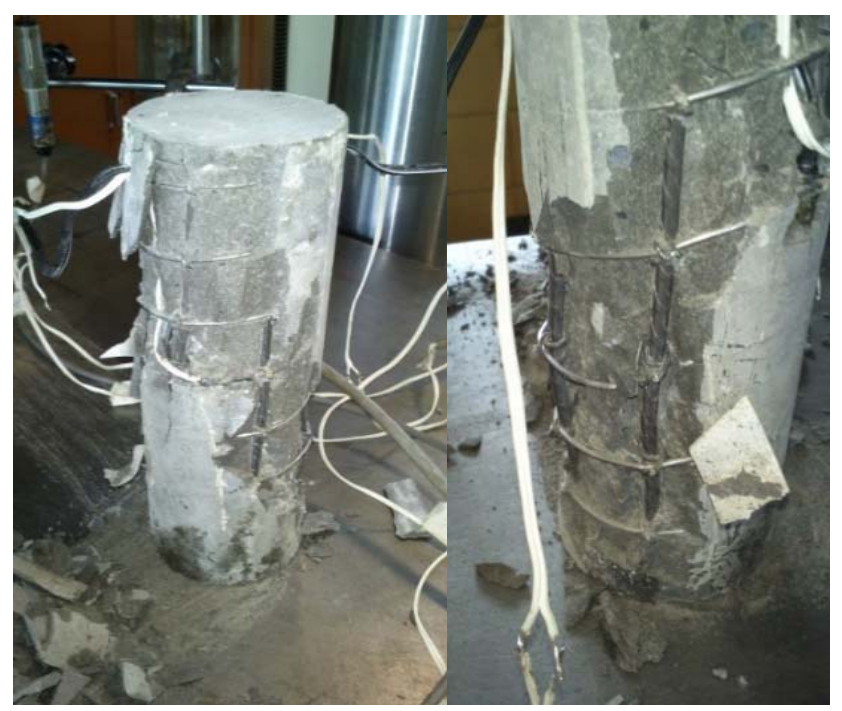

Figura 4.15-Modelo-piloto 2 após a ruptura

Analisando os diagramas obtidos nos ensaios experimentais, com o diagrama apresentado por AGUIAR (2000) para o comportamento de pilares de CAR submetidos à compressão simples, pode-se notar que ambos modelos, após a obtenção da força máxima, apresentaram uma queda acentuada na capacidade resistente, sendo essa perda associada à perda da contribuição do concreto do cobrimento na resistência do elemento estrutural, e a partir desse ponto nota-se em ambos modelos a ativação da atuação da armadura transversal, a qual conduziu os modelos a uma ruptura com maior ductilidade, em comparação aos corpos de prova de CPR sem adição de fibras metálicas.

Esta etapa da pesquisa visava a verificação da eficiência da instrumentação adotada, bem como a determinação de todos os fatores intervenientes que comprometessem a realização dos ensaios definitivos e a aquisição dos dados de ensaio. Visando uma melhor aquisição nos dados obtidos para a realização dos ensaios definitivos, constataram-se as seguintes necessidades:

I. Aumentar o número de extensômetros para a instrumentação da armadura transversal, utilizando dois extensômetros em cada lado da espiral, totalizando quatro extensômetros na armadura transversal;

II. Retirada da instrumentação na face do concreto, pois esta era perdida rapidamente devido à perda prematura do cobrimento; 
III. Aplicação de reforço nas extremidades dos modelos, a fim de impedir a ruptura prematura dos modelos, por serem regiões com elevadas concentrações de tensões.

\subsection{Ensaios definitivos}

\subsubsection{Fôrmas}

Para a série definitiva foram utilizados modelos reduzidos de pilares de concreto armado com seção transversal circular com 7,2 cm de diâmetro por $23 \mathrm{~cm}$ de altura, com relação (L/D) superior a três. A escolha dessas dimensões para a série definitiva ocorreu principalmente pelas limitações de aplicação de carga dos equipamentos de ensaio presentes no laboratório, especificamente por causa das altas resistências à compressão dos CUAR's utilizados na pesquisa. Para as fôrmas dos pilares foram utilizados tubos de papelão com espessura de $1,5 \mathrm{~mm}$, com interior revestido por alumínio e fundo metálico. O emprego desse tipo de material ocorreu principalmente pela facilidade na realização da furação para a passagem dos fios da instrumentação das armaduras longitudinais e transversais, funcionando como fôrma perdida, conforme ilustra a figura 4.16.

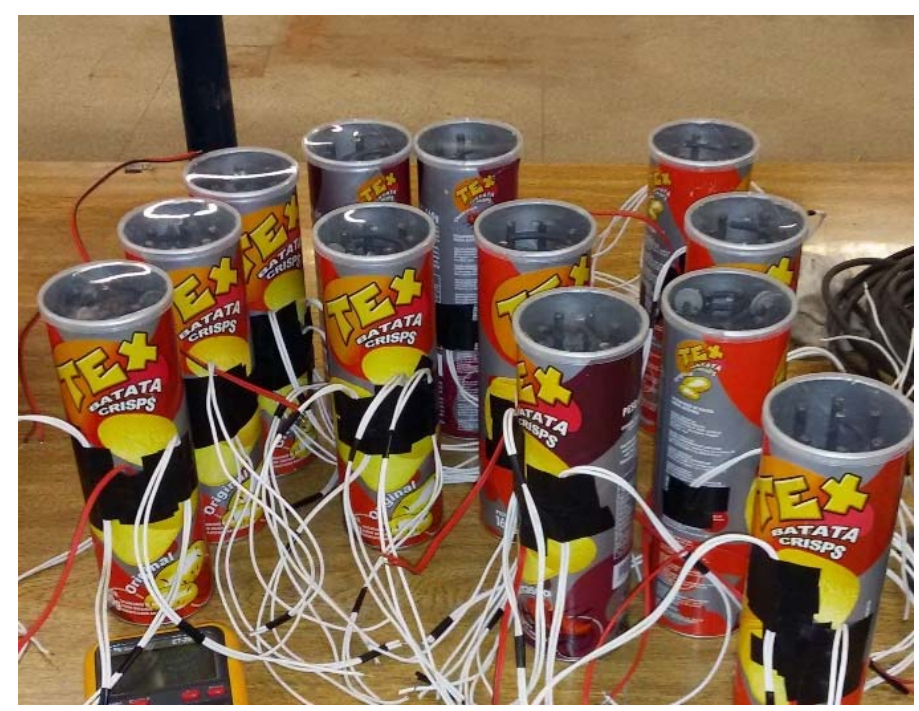

Figura 4.16 - Fôrma utilizada para os modelos 


\subsubsection{Concreto}

Nesta etapa optou-se pela utilização de dois tipos de CUAR, o dosado sem fibras metálicas e o com adição de fibras metálicas, com a utilização de duas metodologias diferentes para a aplicação de cura aos concretos, fazendo com que dessa forma fossem obtidos dois níveis de resistências à compressão, para cada dosagem, e dessa forma fosse aumentando o horizonte da pesquisa para quatro níveis de resistência à compressão.

A partir do estudo de dosagem realizado na etapa anterior, para determinar as proporções ideais de adição de sílica ativa, pó de quartzo e dos teores de adição de fibras metálicas ao CPR, decidiu-se trabalhar nos ensaios definitivos com as dosagens M2 e M6 da tabela 4.4. Optou-se pelas referidas dosagens pelo fato da dosagem M2 apresentar a maior resistência à compressão aos 28 dias e pela M6 ser a dosagem com a taxa volumétrica de adição de fibras metálicas mais próxima das encontradas na literatura técnica para a produção de CPR. A partir de agora as principais diferenças entre as dosagens foram: o método de aplicação de cura e a incorporação de fibras metálicas. A tabela 4.7 apresenta as dosagens utilizadas, a nomenclatura adotada para distingui-las, significa: TSF - Cura térmica sem fibras, ISF - Cura imersa sem fibras, TCF - Cura térmica com fibras e ICF - Cura imersa com fibras.

Tabela 4.7 - Resistência média à compressão para os traços de CPR estudados

\begin{tabular}{ccccc}
\hline & \multicolumn{4}{c}{ Dosagens } \\
\cline { 2 - 5 } & TSF & ISF & TCF & ICF \\
\hline Cimento $\left(\mathbf{k g} / \mathbf{m}^{\mathbf{3}}\right)$ & 700 & 700 & 700 & 700 \\
\hline Sílica Ativa $\left(\mathbf{k g} / \mathbf{m}^{\mathbf{3}}\right)$ & 300 & 300 & 300 & 300 \\
\hline Pó de Quartzo $\left(\mathbf{k g} / \mathbf{m}^{\mathbf{3}}\right)$ & 300 & 300 & 300 & 300 \\
\hline Areia $\left(\mathbf{k g} / \mathbf{m}^{\mathbf{3}}\right)$ & 1000 & 1000 & 1000 & 1000 \\
\hline Superplastificante $\left(\mathbf{k g} / \mathbf{m}^{\mathbf{3}}\right)$ & 64,5 & 64,5 & 64,5 & 64,5 \\
\hline Água $\left(\mathbf{k g} / \mathbf{m}^{\mathbf{3}}\right)$ & 138 & 138 & 138 & 138 \\
\hline Fibras Metálicas $\mathbf{( k g / \mathbf { m } ^ { 3 } )}$ & - & - & 175 & 175 \\
\hline
\end{tabular}

\subsubsection{Resistência à compressão}

Os corpos de provas eram desformados após 24 h e imersos em um tanque com água em temperatura ambiente pelo período de 7 dias. Após esse período, os 
concretos que seriam submetidos a tratamento térmico eram levados para a aplicação de cura térmica a $90^{\circ} \mathrm{C}$, permanecendo lá por $72 \mathrm{~h}$, retirados e retornados para a cura imersa até as idades de rompimento a compressão dos pilares, a qual foi fixada aos 28 dias.

Para a realização dos ensaios de verificação da resistência à compressão dos concretos, os corpos de prova eram retirados do processo de cura sempre nas idades de rompimento dos pilares. No período da manhã, tinham suas faces retificadas, e eram ensaiados pelo período da tarde. A figura 4.17 ilustra o equipamento utilizado para o rompimento dos corpos de provas, marca ELE, com capacidade de $2000 \mathrm{kN}$, e a tabela 4.8 apresenta as resistências à compressão obtidas para as dosagens.

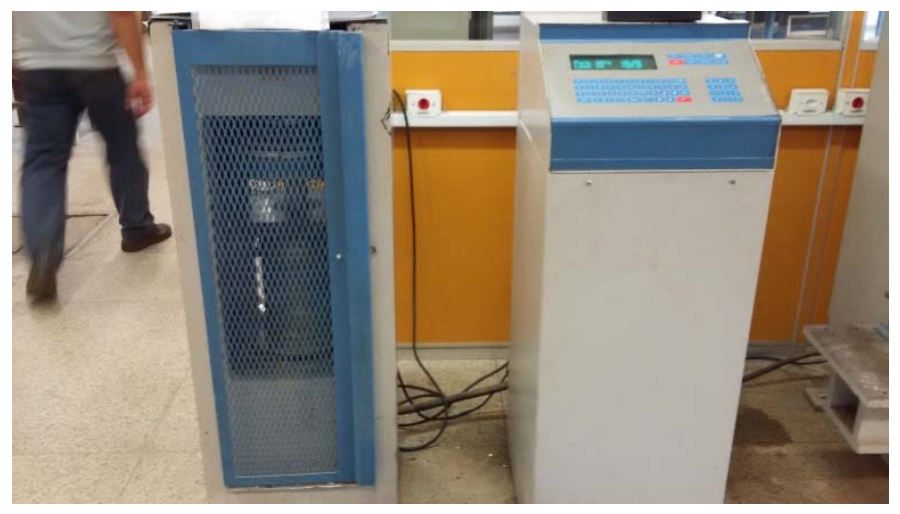

Figura 4.17 - Máquina utilizada para a realização dos ensaios de compressão

Tabela 4.8 - Resistência à compressão $\left(f_{c k}\right)$ para os traços de CPR estudados

\begin{tabular}{ccccc}
\hline Dosagem & TCF & TSF & ICF & ISF \\
\hline CP1 & 193,90 & 205,60 & 180,50 & 179,80 \\
CP2 & 236,20 & 215,00 & 181,10 & $*$ \\
CP3 & 234,70 & 183,40 & 186,60 & 151,80 \\
\hline CP4 & 225,40 & 231,60 & 175,40 & 156,80 \\
\hline CP5 & 242,50 & 174,00 & 180,90 & 154,30 \\
\hline CP6 & 171,00 & $*$ & 162,70 & 167,50 \\
\hline CP7 & 239,70 & 190,20 & 171,00 & 174,60 \\
\hline CP8 & 241,20 & 218,60 & 163,40 & 172,40 \\
\hline CP9 & 221,40 & 198,30 & 175,00 & $*$
\end{tabular}

* Amostras excluídas devido a problemas nos corpos de prova. 
A avaliação dos resultados dos ensaios de resistência à compressão foi realizada pelo critério de Chauvenet, para a verificação de possível inconsistência na amostragem, pois esse critério fornece uma base consistente para a tomada da decisão da exclusão ou não de um valor medido, em função do número de exemplares, em função da razão entre o máximo desvio aceitável e o desvio padrão. Utilizando-se desse critério, apenas a amostra CP6 da dosagem TCF foi excluída. A tabela 4.9 apresenta: a resistência média à compressão para cada dosagem, o desvio padrão e as resistências médias finais à compressão $\left(f_{c m}\right)$ adotadas para a avaliação dos pilares.

Tabela 4.9 - Resistência média à compressão $\left(f_{c m}\right)$ para os traços de CPR estudados

\begin{tabular}{ccccc}
\hline Dosagem & TCF & TSF & ICF & ISF \\
\hline Média inicial $\left(f_{c m}\right)$ & 222,89 & 202,09 & 175,18 & 165,31 \\
\hline Desvio Padrão $(\mathbf{S d})$ & 24,65 & 40,31 & 8,20 & 11,01 \\
\hline $\begin{array}{c}\text { Média Final } \\
\text { (fcm,28dias) }\end{array}$ & 229,38 & 202,09 & 175,18 & 165,31 \\
\hline
\end{tabular}

\subsubsection{Módulo de deformação longitudinal}

Para os ensaios de módulo de deformação longitudinal foram ensaiados dois corpos de prova de cada dosagem, instrumentados com extensômetros elétricos nas direções longitudinais afim de obter a curva tensão-deformação longitudinal. A figura 4.18 mostra os diagramas tensão-deformação dos concretos estudados na pesquisa.

A partir dos resultados dos diagramas tensão-deformação dos concretos estudados, foram determinados os valores de módulo de elasticidade ou módulo de deformação tangente inicial ( $E_{c i}$ ), conforme a NBR 8522:2008. A tabela 4.10 apresenta os valores obtidos paras as dosagens estudadas na pesquisa. 

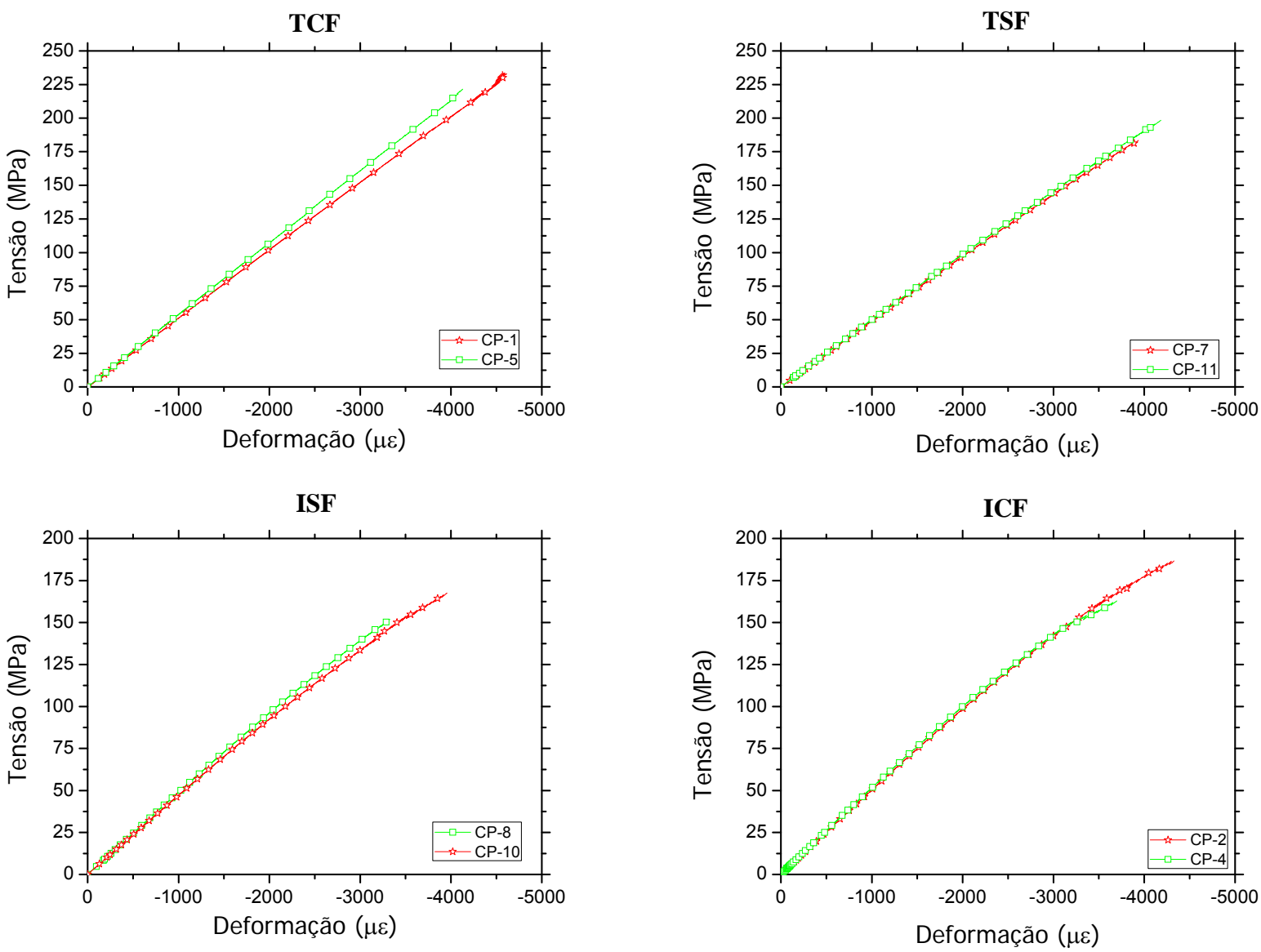

Figura 4.18 - Diagramas tensão-deformação dos concretos estudados

Tabela 4.10 - Resultados Experimentais

\begin{tabular}{ccccc}
\hline Dosagem & $\begin{array}{c}\text { Corpo de } \\
\text { prova }\end{array}$ & $\begin{array}{c}f_{C} \\
(\mathbf{M P a})\end{array}$ & $\begin{array}{c}\boldsymbol{E}_{C} \\
(\%)\end{array}$ & $\begin{array}{c}E_{c} \\
(\mathbf{M P a})\end{array}$ \\
\hline TCF & CP1 & 234,70 & 4,57 & 51264,0 \\
& CP5 & 221,40 & 4,13 & 53882,5 \\
\hline & Média & 228,05 & 4,35 & 52573,2 \\
\hline TSF & & & & \\
& CP7 & 183,40 & 3,94 & 49048,3 \\
& CP11 & 198,30 & 4,18 & 49789,0 \\
\hline ICF & Média & 190,85 & 4,06 & 49418,6 \\
& & & & \\
& CP2 & 186,60 & 4,33 & 50278,0 \\
\hline ISF & CP4 & 162,70 & 3,70 & 51828,0 \\
& Média & 174,65 & 4,01 & 51053,0 \\
\hline & & & & \\
& CP8 & 151,80 & 3,33 & 48911,0 \\
& CP10 & 167,50 & 3,96 & 46986,0 \\
\hline & Média & 159,65 & 3,64 & 47948,5 \\
\hline
\end{tabular}




\subsubsection{Armaduras}

O projeto dos pilares de concreto armado da série definitiva foi baseado na premissa da obtenção de situações de baixo, médio e alto índice de confinamento, de acordo com o proposto por CUSSON \& PAULTRE (1993), tendo como principal objetivo a verificação de quais índices de confinamento conduziriam esses elementos estruturais a uma ruptura do tipo dúctil, em função dos níveis de resistência à compressão dos concretos adotados na pesquisa. Para tal, em todos os modelos ensaiados, as armaduras longitudinais $\left(A_{s l}\right)$ e as armaduras transversais $\left(A_{s w}\right)$ tiveram seus diâmetros fixados em: $6 \mathrm{~mm}$ e $4,5 \mathrm{~mm}$, respectivamente, de modo que a variação no espaçamento da armadura transversal acarretasse em taxas volumétricas de armadura transversal $\left(\rho_{w}\right)$ crescentes, em função dos espaçamentos utilizados, conforme demonstra a tabela 4.11.

\begin{tabular}{cccccc}
\multicolumn{3}{c}{ Tabela 4.11 - Taxas volumétricas e taxa geométrica adotadas na pesquisa } \\
\hline \multicolumn{2}{c}{$\begin{array}{c}\text { Armadura Transversal } \\
\left(A_{s w}\right)\end{array}$} & \multicolumn{3}{c}{$\begin{array}{c}\text { Armadura Longitudinal } \\
\left(A_{s l}\right)\end{array}$} \\
\hline $\begin{array}{c}\text { Diâmetro } \\
(\varnothing) \\
(\mathbf{m m})\end{array}$ & $\begin{array}{c}\text { Espaç. } \\
(\mathrm{S}) \\
(\mathrm{mm})\end{array}$ & $\begin{array}{c}\text { Taxa Vol. } \\
\left(\rho_{w}\right)\end{array}$ & $\begin{array}{c}\text { Diâmetro } \\
(\boldsymbol{(}) \\
(\mathbf{m m})\end{array}$ & $\begin{array}{c}\mathrm{N}^{\circ} \\
\text { de barras }\end{array}$ & $\begin{array}{c}\text { Taxa Geo. } \\
\left(\rho_{l}\right) \\
(\%)\end{array}$ \\
\hline $\mathbf{4 , 5}$ & 10 & 11,46 & $\mathbf{6 , 0}$ & 6 & 4,17 \\
\hline $\mathbf{4 , 5}$ & 15 & 7,64 & $\mathbf{6 , 0}$ & 6 & 4,17 \\
\hline $\mathbf{4 , 5}$ & 20 & 5,73 & $\mathbf{6 , 0}$ & 6 & 4,17 \\
\hline $\mathbf{4 , 5}$ & 25 & 4,58 & $\mathbf{6 , 0}$ & 6 & 4,17 \\
\hline $\mathbf{4 , 5}$ & 45 & 2,55 & $\mathbf{6 , 0}$ & 6 & 4,17 \\
\hline $\mathbf{4 , 5}$ & 55 & 2,08 & $\mathbf{6 , 0}$ & 6 & 4,17 \\
\hline $\mathbf{4 , 5}$ & 60 & 1,91 & $\mathbf{6 , 0}$ & 6 & 4,17 \\
\hline $\mathbf{4 , 5}$ & 75 & 1,53 & $\mathbf{6 , 0}$ & 6 & 4,17 \\
\hline
\end{tabular}

O máximo espaçamento utilizado foi fixado em função da largura do modelo, sendo uma medida recomendada pela NBR 6118:2014. CUSSON \& PAULTRE (1993) recomendam a utilização de um índice de eficiência de confinamento (I.E.C ), o qual é determinado pela relação entre a pressão lateral efetiva $\left(f_{l e}\right)$ e a resistência à compressão do concreto não confinado $\left(f_{c o}\right)$, para estimar os ganhos de resistência e ductilidade dos elementos estruturais. A tabela 4.12 apresenta os índices efetivos de confinamento estudados, em função da relação 
entre as pressões laterais estudadas e a resistência média à compressão para os concretos estudados.

Tabela 4.12 - Pressão lateral efetiva e Índices efetivos de confinamento utilizados

\begin{tabular}{cccccc}
\hline & & \multicolumn{5}{c}{ Concretos } \\
\cline { 3 - 6 } $\begin{array}{c}\text { Espaçamentos } \\
(\mathbf{S})\end{array}$ & $f_{l e}$ & $\begin{array}{c}\text { TCF } \\
\text { I.E.C } \\
(\mathrm{MPa})\end{array}$ & $\begin{array}{c}\text { TSF } \\
\text { I.E.C }\end{array}$ & $\begin{array}{c}\text { ICF } \\
\text { I.E.C } \\
(\%)\end{array}$ & $\begin{array}{c}\text { ISF } \\
\text { I.E.C } \\
(\%)\end{array}$ \\
\hline $\mathbf{1 0}$ & 53,18 & 23,19 & 26,32 & 30,36 & 32,17 \\
\hline $\mathbf{1 5}$ & 34,39 & 14,99 & 17,02 & - & - \\
\hline $\mathbf{2 0}$ & 24,73 & 10,78 & 12,24 & 14,12 & 14,96 \\
\hline $\mathbf{2 5}$ & 18,72 & - & - & 10,69 & 11,32 \\
\hline $\mathbf{4 5}$ & 8,04 & 3,50 & 3,98 & - & - \\
\hline $\mathbf{5 5}$ & 5,71 & 2,49 & 2,82 & 3,26 & 3,45 \\
\hline $\mathbf{6 0}$ & 4,79 & - & - & 2,73 & 2,90 \\
\hline $\mathbf{7 5}$ & 2,77 & 1,21 & 1,37 & 1,58 & 1,67 \\
\hline
\end{tabular}

Os arranjos de armaduras utilizados são apresentados na figura 4.19, e na figura 4.20, o detalhamento em forma de gancho utilizado nas extremidades para garantir a ancoragem da armadura transversal em formato de espiral, já que a execução de voltas justapostas nas extremidades dos arranjos, como garantia de ancoragem da espiral, foi comprometida pela alta dureza do aço utilizado para compor a armadura transversal. Todas as armaduras longitudinais tinham $22 \mathrm{~cm}$ de comprimento, tal como as espirais que compunham a armadura transversal. A figura 4.21 apresenta o detalhamento das armaduras para o modelo $\mathrm{S15}$, assim como apresenta a adoção de espaçadores de plástico para garantir a posição das armaduras dentro da fôrma. 

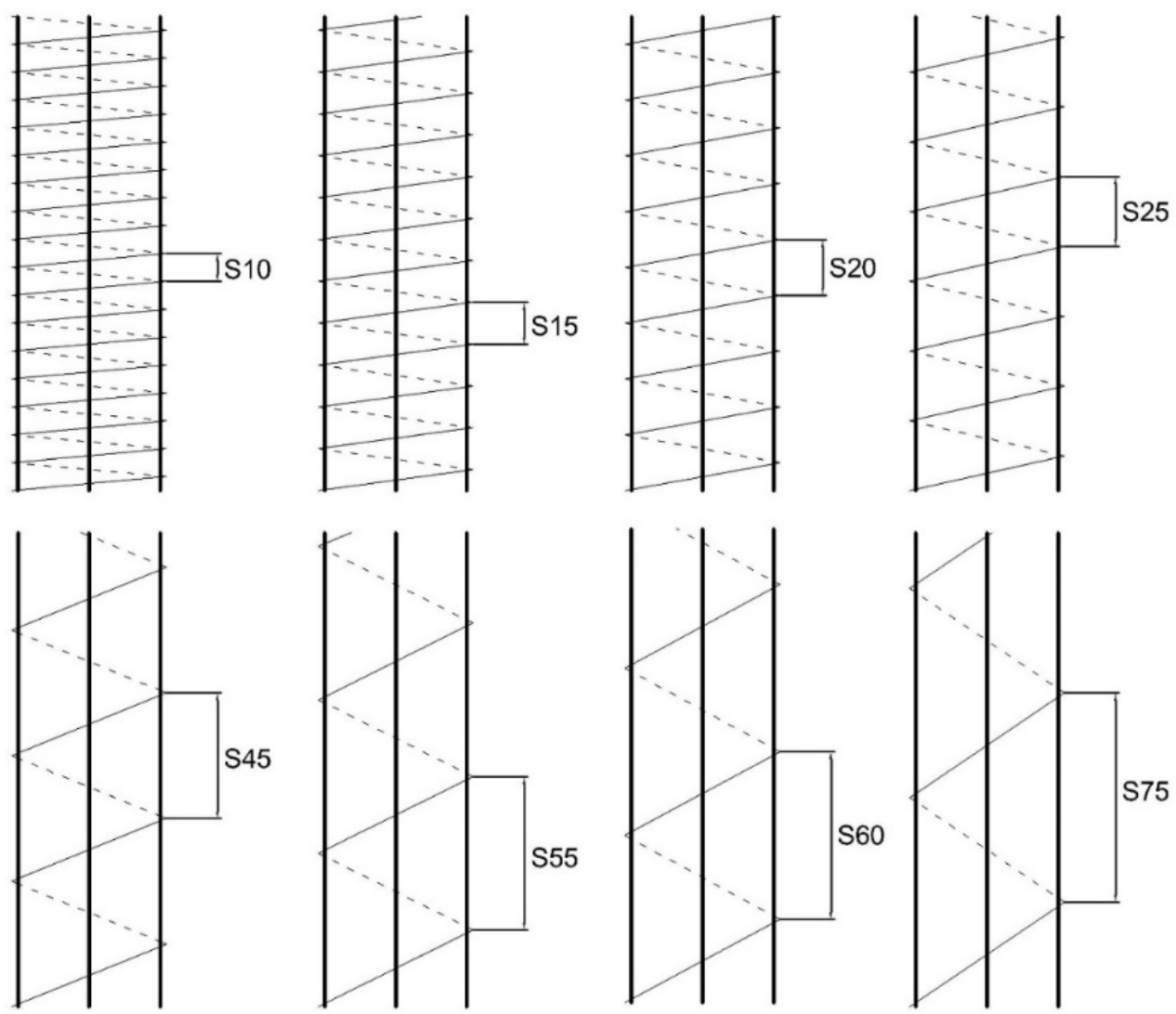

Figura 4.19 - Detalhe das armações utilizadas nos pilares da série definitiva
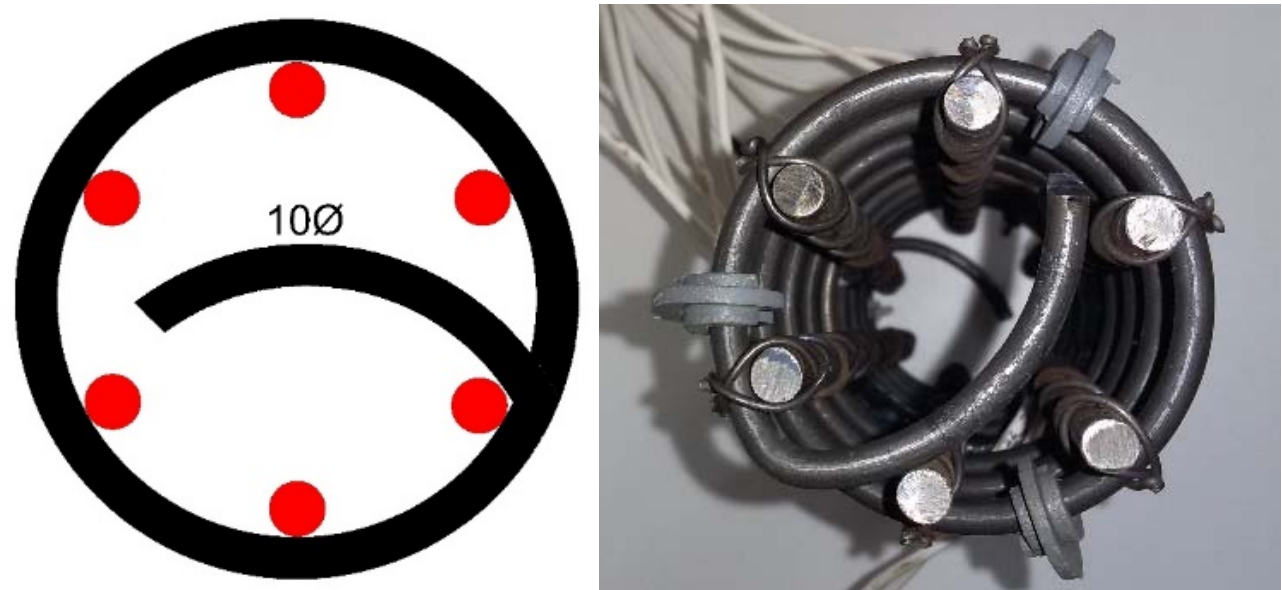

Figura 4.20 - Detalhe em forma de gancho utilizado para ancorar a armadura transversal 


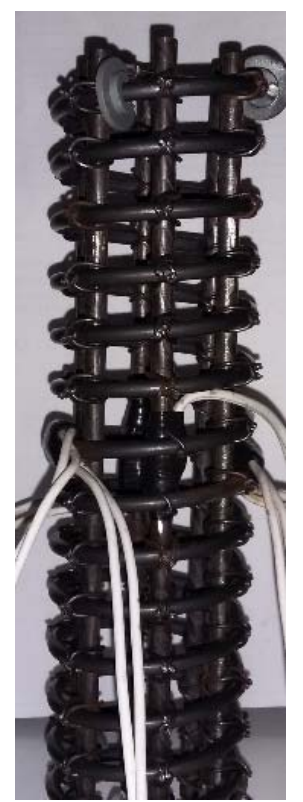

Figura 4.21 - Detalhamento das armaduras utilizado para o modelo S15

\subsubsection{Caracterização das armaduras}

A caracterização dos fios utilizados na pesquisa foi realizada a partir da execução de ensaios de tração simples em duas amostras para cada diâmetro. A figura 4.22 ilustra os diagramas tensão-deformação para os dois tipos de aço utilizados na pesquisa, e a tabela 4.13 apresenta as propriedades mecânicas determinadas a partir dos resultados dos ensaios. 
Fio $\varnothing 6 \mathrm{~mm}$

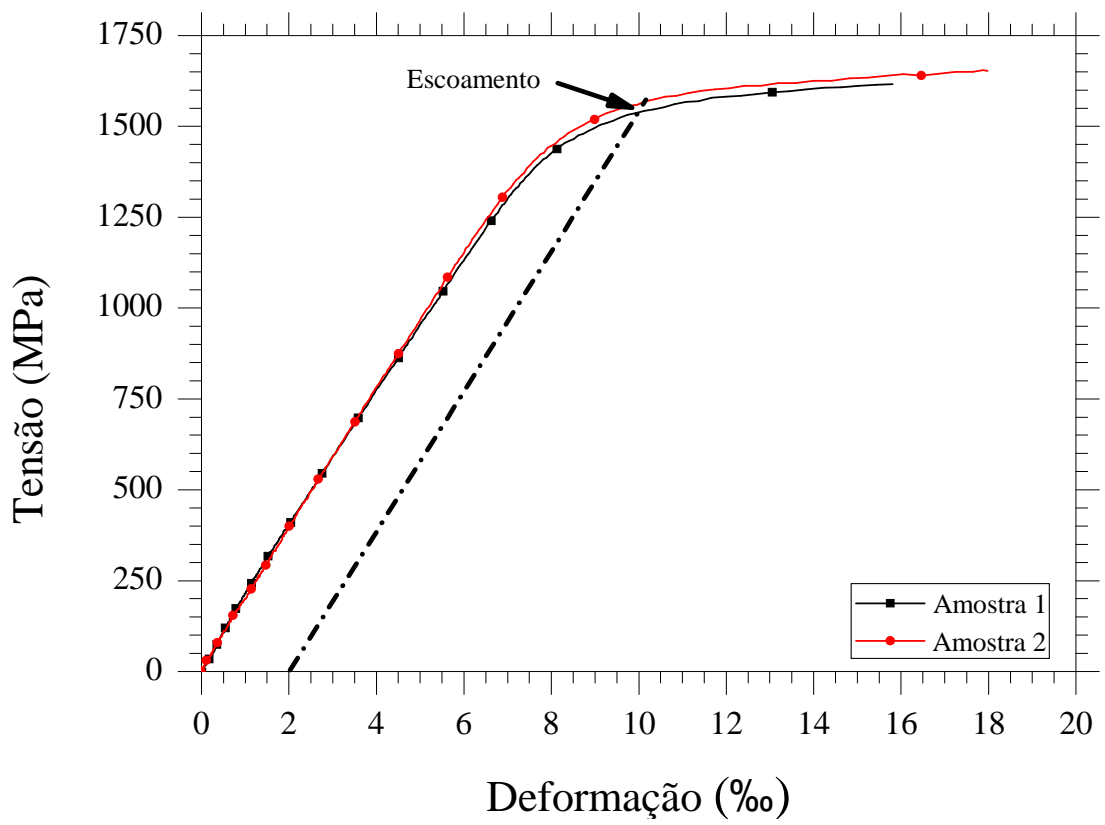

Fio $\varnothing 4,5 \mathrm{~mm}$

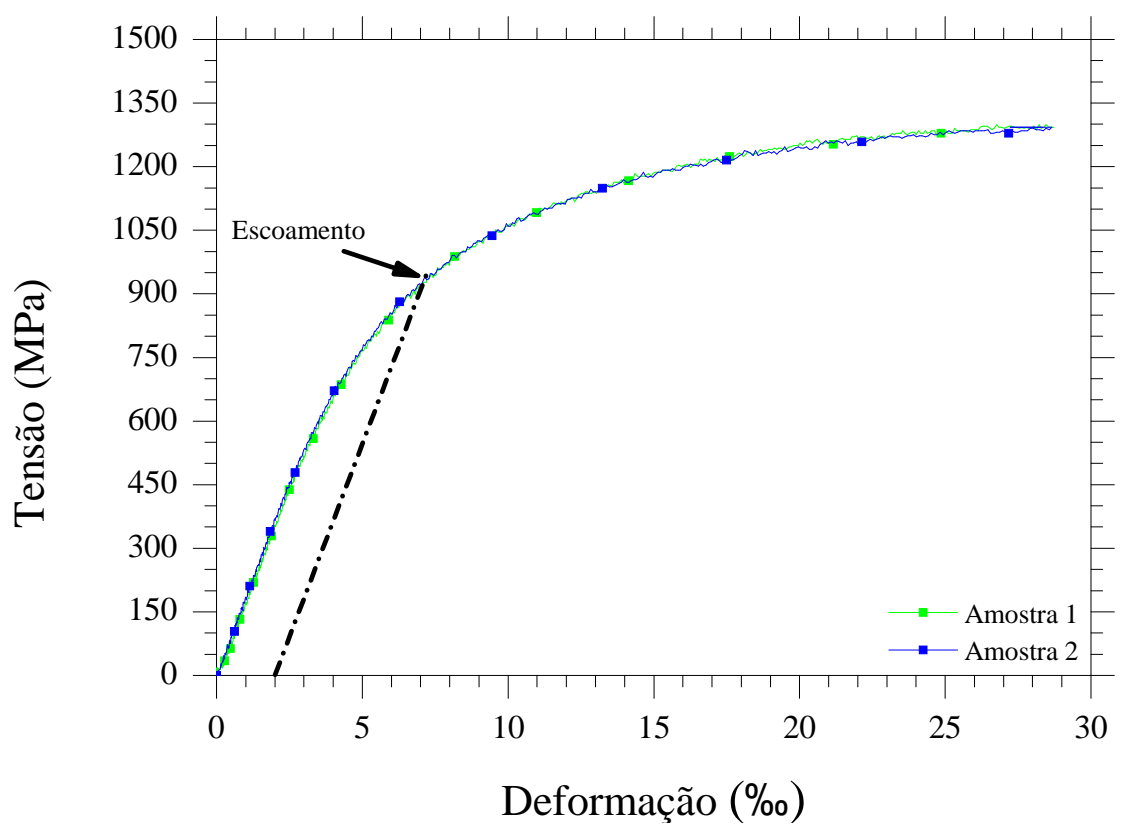

Figura 4.22 - Diagramas tensão-deformação dos aços utilizados na pesquisa 
Tabela 4.13 - Características dos aços empregados

\begin{tabular}{ccccc}
\hline \multirow{5}{*}{ Amostra } & $f_{y}(\mathrm{MPa})$ & $\varepsilon_{y}(\%)$ & $E_{s}(\mathrm{MPa})$ & $F_{\text {últ }}$ \\
\hline $\mathbf{1}$ & 1539,17 & 9,98 & 190658 & 1826,46 \\
$\mathbf{2}$ & 1569,64 & 10,14 & 194049 & 1818,36 \\
\hline Média & 1554,41 & 10,06 & 192354 & 1822,41 \\
\hline Amostra & $f_{y}(\mathrm{MPa})$ & $\boldsymbol{E}_{y}(\%)$ & $E_{s}(\mathrm{MPa})$ & $F_{\text {últ }}$ \\
\hline $\mathbf{1}$ & 925,44 & 7,08 & 182907 & 1292,83 \\
$\mathbf{2}$ & 930,92 & 7,11 & 176230 & 1310,13 \\
\hline Média & 928,18 & 7,10 & 179569 & 1301,48 \\
\hline
\end{tabular}

\subsubsection{Concretagem}

Nesta etapa, para cada dosagem moldaram-se seis pilares circulares e nove corpos de prova para verificação da resistência à compressão e módulo de elasticidade aos 28 dias. Devido esse tipo de concreto ser composto basicamente por finos, foi moldado por concretagem dois pilares circulares nas dimensões de 7,2 cm de diâmetro por $23 \mathrm{~cm}$ de altura e três corpos de provas nas dimensões de $5 \mathrm{~cm}$ de diâmetro por $10 \mathrm{~cm}$ de altura, conforme ilustra a figura 4.23.

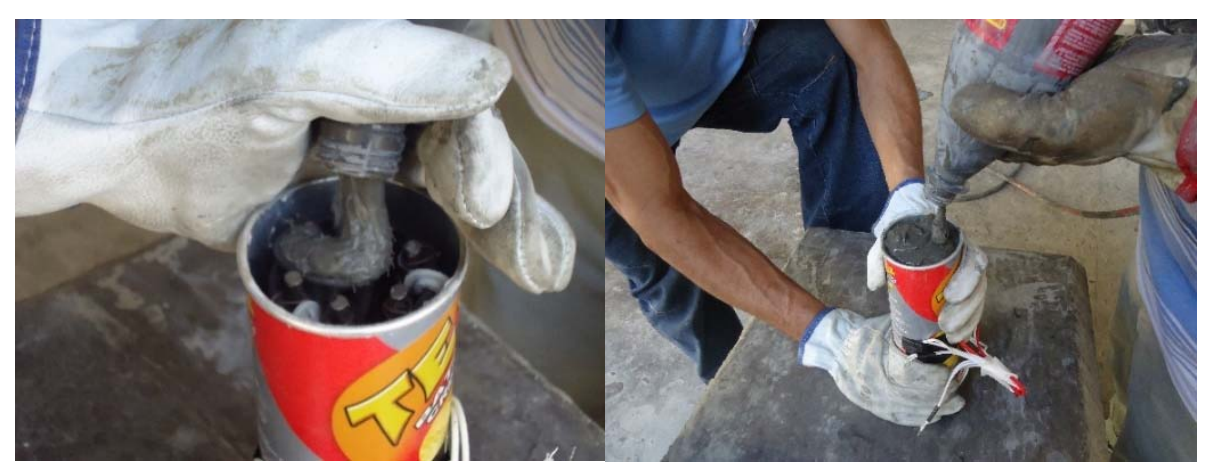

Figura 4.23-Concretagem dos pilares

\subsubsection{Instrumentação das armaduras}

As deformações nas armaduras longitudinais e transversais foram medidas por extensômetros elétricos de resistência, marca KYOWA, tipo

KLF-5-C1120-11, como mostra a figura 4.24. Foram utilizados dois extensômetros elétricos nas armaduras longitudinais, um em cada barra, e quatro extensômetros elétricos nas 
armaduras transversais, dois em cada face oposta da espiral. O posicionamento dessa instrumentação nos modelos era sempre na metade da altura do pilar. A figura 4.25 ilustra a instrumentação empregada e seu posicionamento.

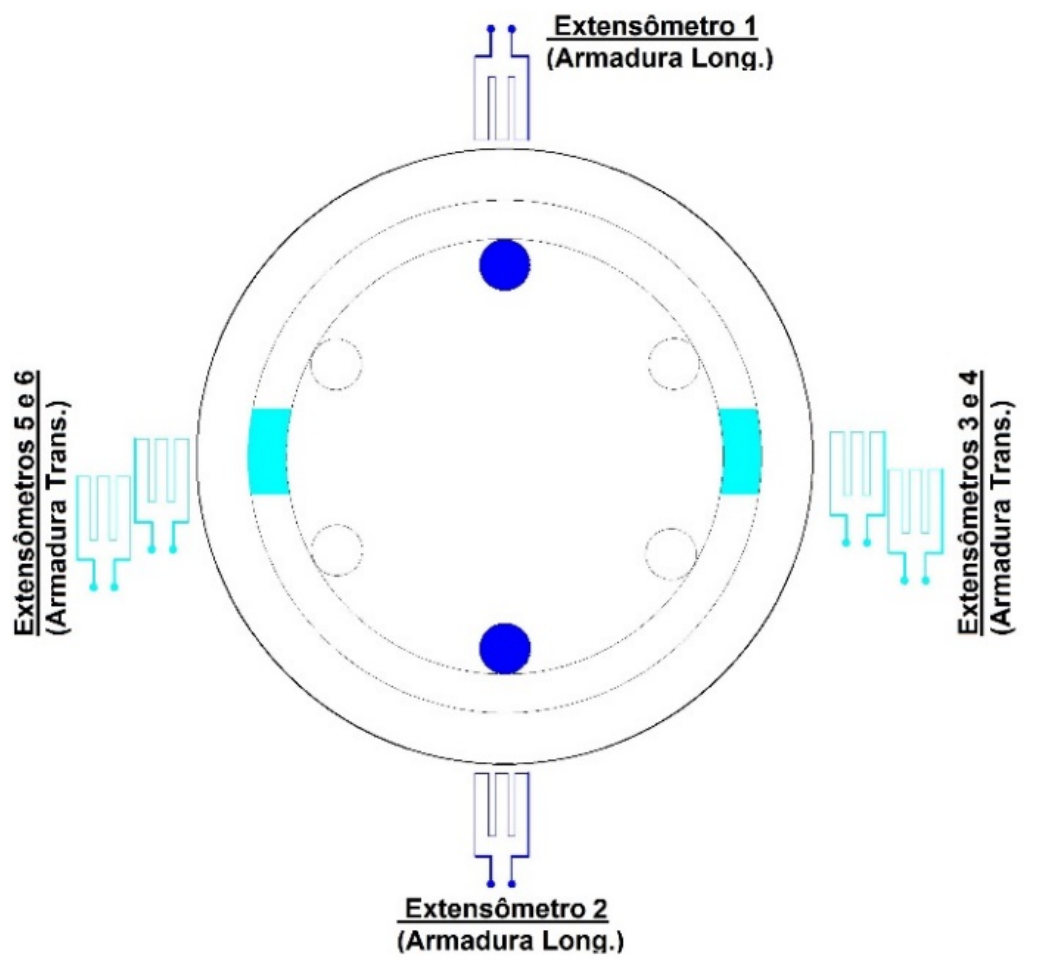

Figura 4.24 - Instrumentação utilizada nas armaduras

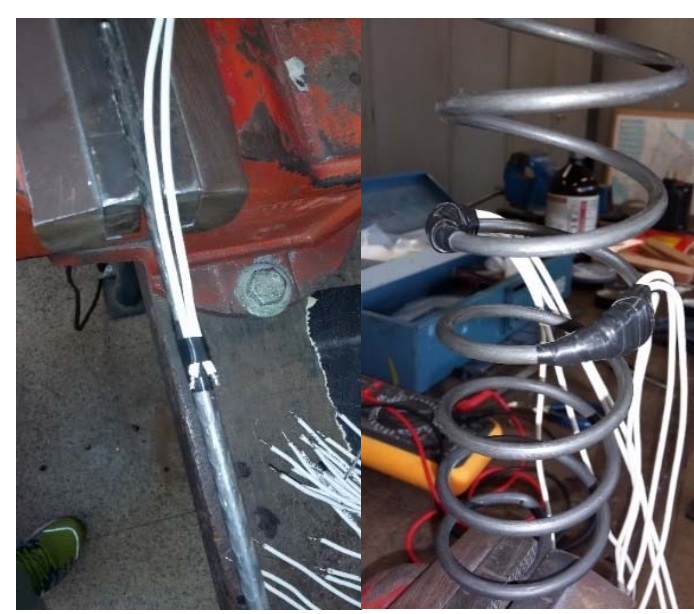

Figura 4.25-Preparação da instrumentação utilizada nas armaduras 


\subsubsection{Reforço das extremidades dos pilares}

As extremidades dos modelos, por serem regiões de altas concentrações de tensões, foram reforçadas por encamisamento com o sistema SIKAWARP ${ }^{\circledR}$, que consiste em duas etapas: a primeira relativa ao corte dos tecidos unidirecionais de fibras de carbono (SIKAWRAP HEX-230C) e a segunda alusiva à impregnação dos tecidos com a resina epóxi (SIKADUR-330), conforme ilustram as figuras 4.26 e 4.27.

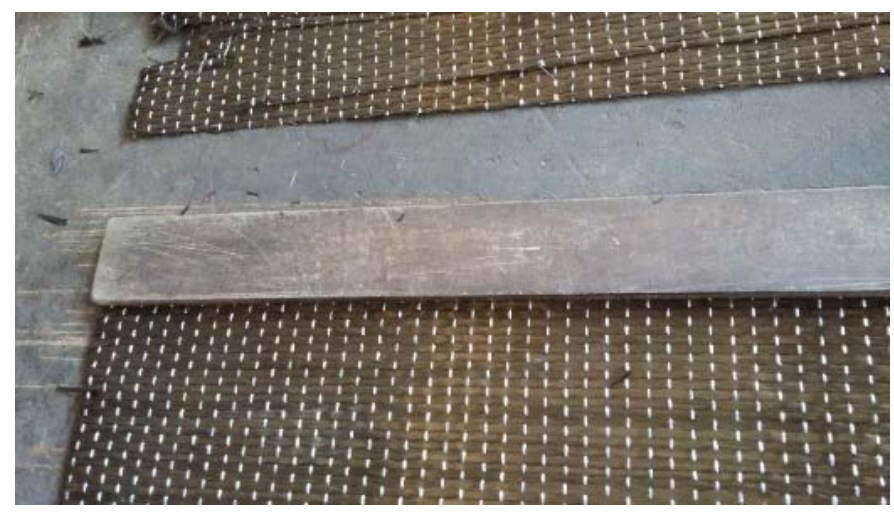

Figura 4.26 - Corte dos tecidos de fibra de carbono

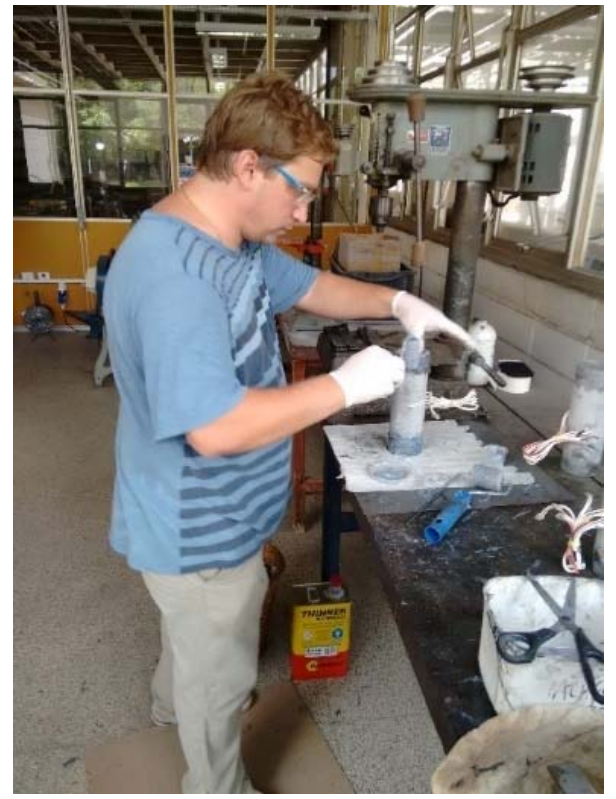

Figura 4.27 - Impregnação dos tecidos de fibras de carbono com resina epóxi 
Os reforços das extremidades foram realizados com tiras de $3 \mathrm{~cm}$ de largura de tecido unidirecional de fibras de carbono e composto por quatro camadas (quatro voltas completas na seção transversal do pilar).

\subsubsection{Instrumentação na máquina de ensaio}

Os deslocamentos verticais dos modelos foram registrados por dois transdutores de deslocamento, marca VISHAY, com curso de $30 \mathrm{~mm}$, posicionados entre os pratos da máquina de ensaio, como mostra a figura 4.28.

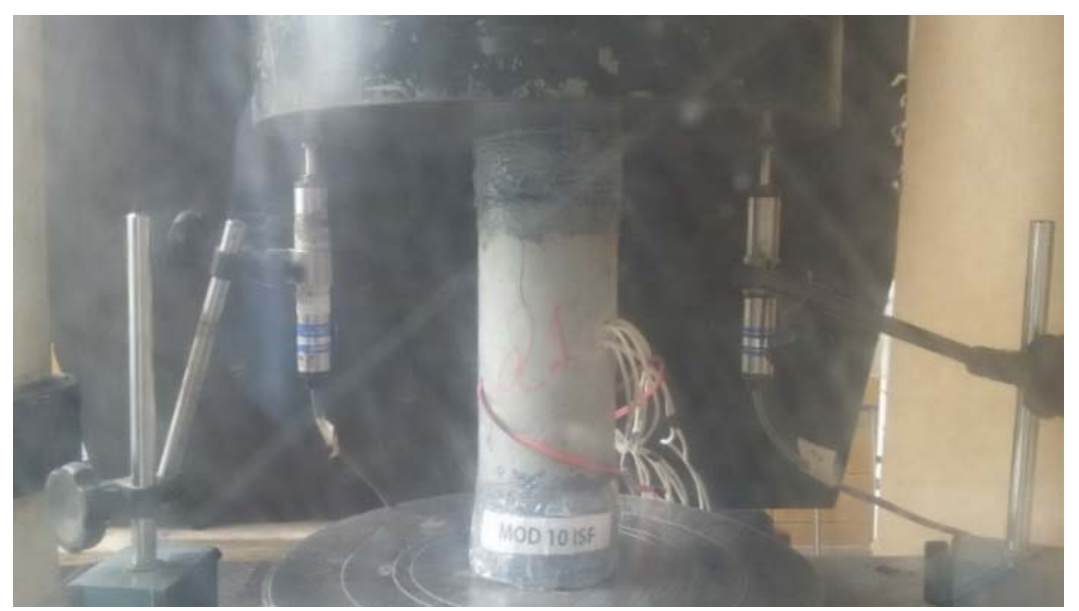

Figura 4.28 - Instrumentação utilizada para a medição dos deslocamentos verticais dos modelos

\subsubsection{Ensaios de compressão centrada}

Os modelos definitivos foram ensaiados à compressão centrada aos 28 dias de idade, com aplicação de deslocamentos com velocidade controlada $(\mathrm{mm} / \mathrm{s})$, numa máquina universal de ensaio, servo-hidráulica, marca INSTRON, modelo 8506, com capacidade de $2500 \mathrm{kN}$, indicada na figura 4.29.

A aplicação de carga aos modelos foi realizada com controle de deslocamento, a uma velocidade constante de $0,0023 \mathrm{~mm} / \mathrm{s}$, de acordo com a NBR 8522:2008. 
A aquisição de dados durante o ensaio (medidas de aplicação de força, deslocamentos e deformações) foi realizada de forma automática, na frequência de 1 $\mathrm{Hz}$, através do sistema SYSTEM 5000.

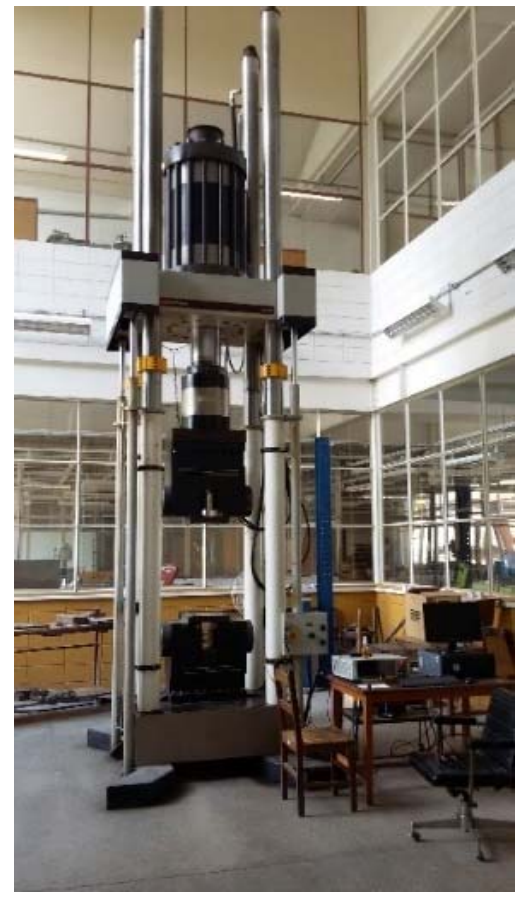

Figura 4.29 - Máquina de ensaio INSTRON 


\section{Resultados Experimentais}

\subsection{Deformações axiais dos modelos}

\subsubsection{Correção da acomodação inicial de ensaio}

A partir do ensaio de compressão centrada de cada pilar, foram obtidos diagramas força-deformação, tendo como base as leituras dos dois transdutores de deslocamento fixados entre os pratos da máquina de ensaio e do pistão da máquina de ensaio. Para fins de apresentação as deformações foram multiplicadas por mil.

Os trechos iniciais dos diagramas força-deformação obtidos pelos transdutores, média dos transdutores, e pelo pistão da máquina de ensaio exibiram uma acomodação inicial, conforme apresenta a figura 5.1, para o pilar MOD10TCF. Essa acomodação pode ser resultante da acomodação inicial da máquina de ensaio, a qual surge devido ao deslocamento total do conjunto da máquina de ensaio, ou pela acomodação de alguma imperfeição nas extremidades dos modelos.

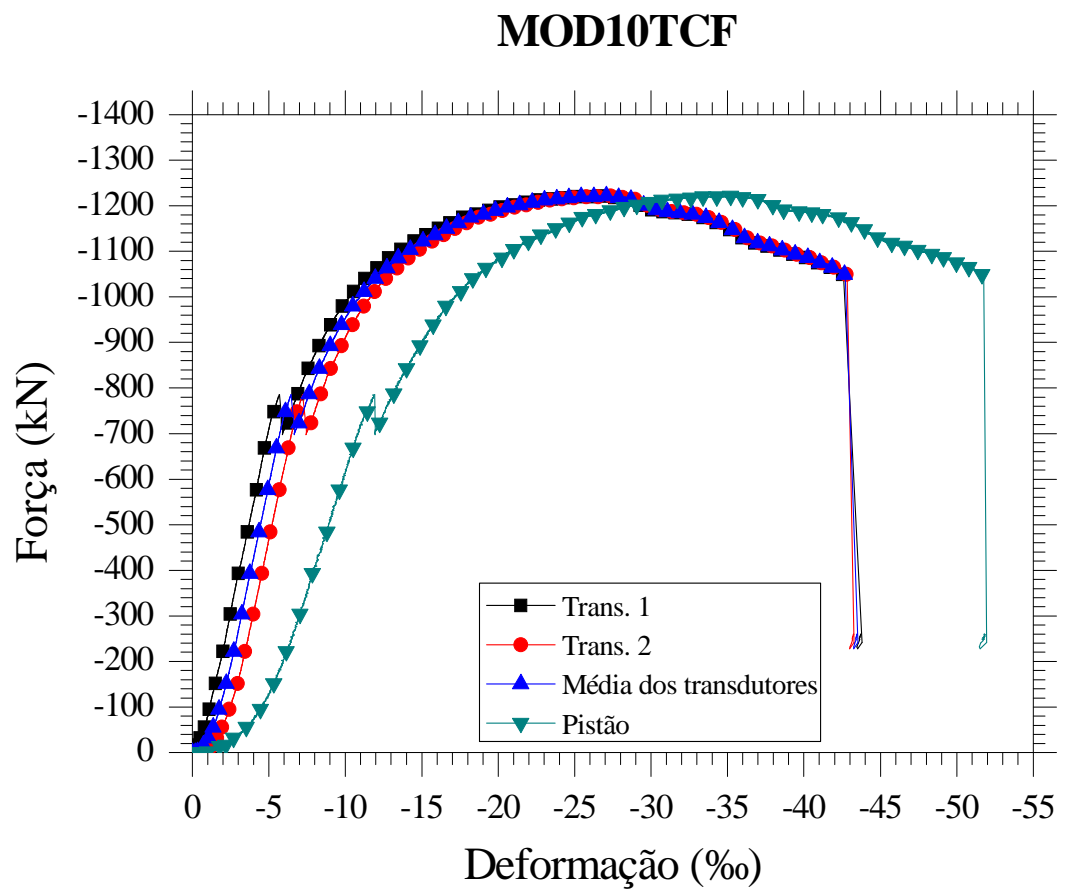

Figura 5.1 - Diagrama bruto de força-deformação do pilar MOD10TCF 
A correção dessa acomodação inicial é realizada com a adoção de uma equação de reta, isenta de acomodação, denominada de trecho de interpolação, para cada caso (média dos transdutores de deslocamento e para o pistão), de acordo com a figura 5.2 .

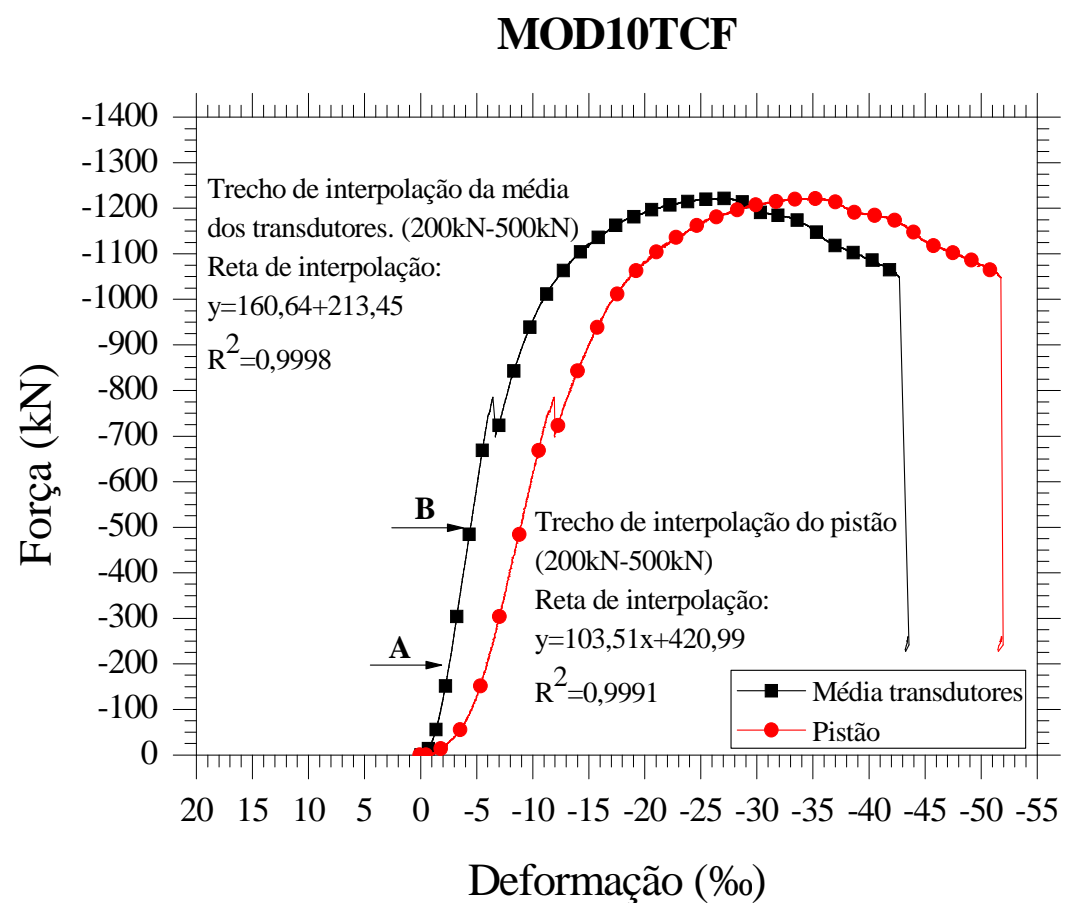

Figura 5.2 - Trechos de interpolação utilizados para correção da acomodação inicial do diagrama força-deformação do pilar MOD10TCF

O esquema de correção baseou-se na obtenção de um trecho isento de acomodação, para cada caso, determinado entre as cargas de $200 \mathrm{kN}$ e $500 \mathrm{kN}$. A correção dos trechos inicias do diagrama força-deformação, até o valor de $200 \mathrm{kN}$, é feita pela divisão da carga axial de ensaio pelo coeficiente angular da reta obtida para cada caso. Após esse trecho a correção é realizada retirando-se da leitura média dos transdutores de deslocamento e do pistão a acomodação inicial, obtida pela divisão do coeficiente linear da reta pelo coeficiente angular, respectivamente. A figura 5.3 apresenta o diagrama corrigido de força-deformação do pilar MOD10TCF. 


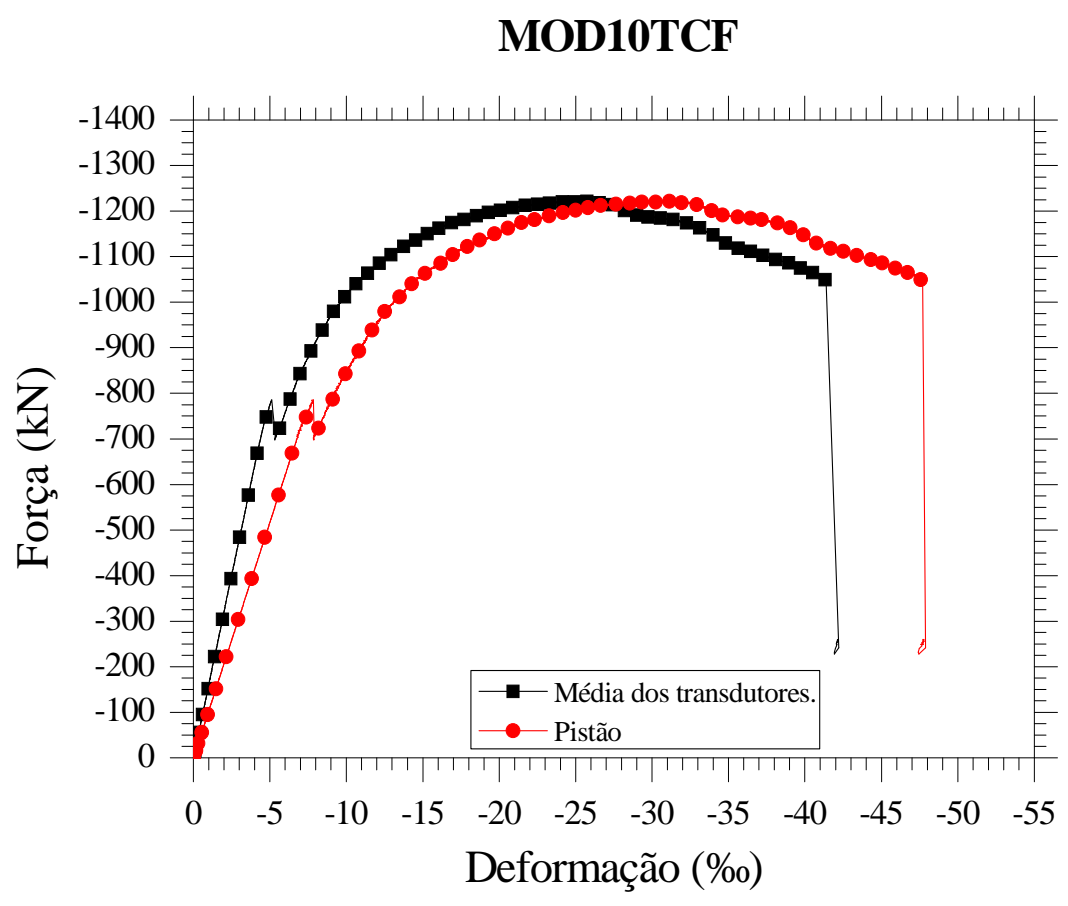

Figura 5.3 - Diagrama força-deslocamento MOD10TCF

Todos os resultados apresentados de diagrama força-deformação de agora em diante são resultantes da média dos transdutores de deslocamento e tratados como explicado anteriormente.

\subsubsection{Correção da deformação axial do pilar para a deformação da armadura longitudinal}

A figura 5.4 apresenta os diagramas força-deformação das deformações das armaduras longitudinais $A_{s l_{1}} e_{A_{s l_{2}}}$, a deformação média das armaduras (obtida entre as leituras registradas pelos extensômetros 1 e 2) e a deformação axial do pilar MOD10TCF. 


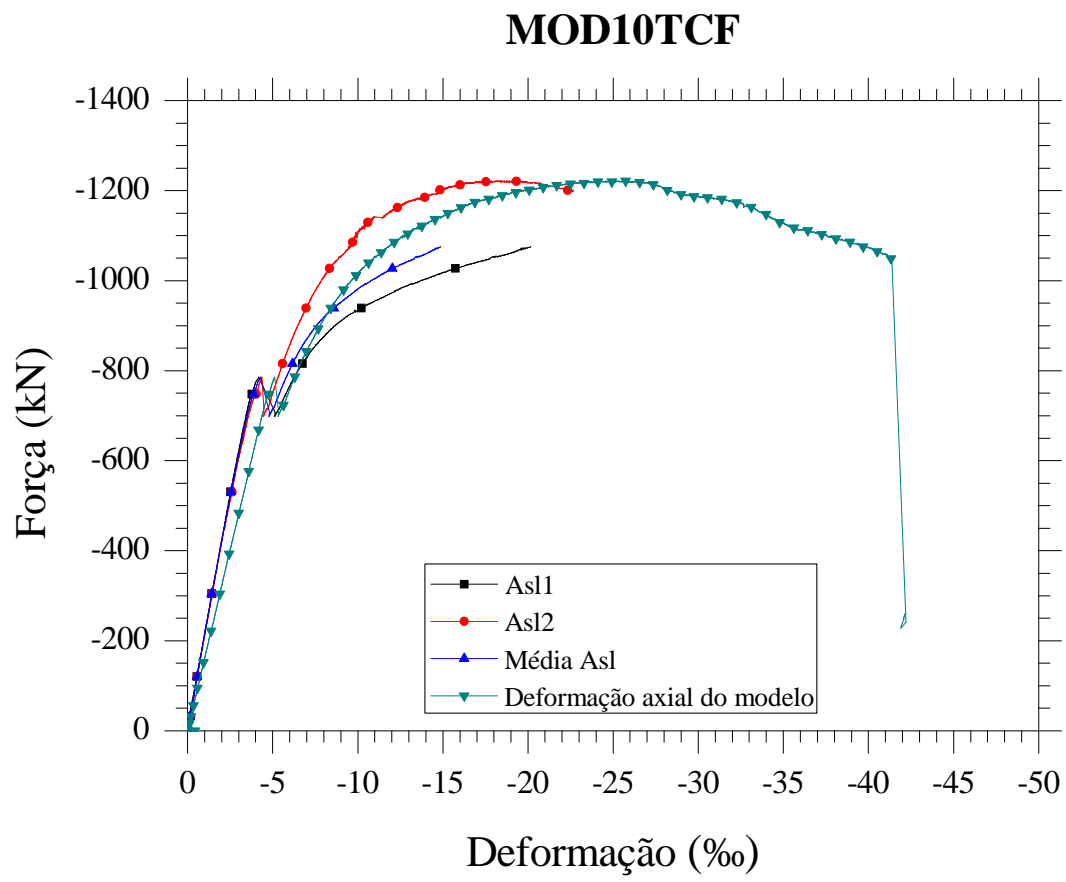

Figura 5.4-Diagrama força-deformação axial do pilar MOD10TCF e diagrama força-deformação axial das armaduras longitudinais

Observa-se uma diferença na inclinação entre os diagramas força $x$ deslocamento do pilar e o das armaduras longitudinais. Essa diferença na inclinação do diagrama força $\mathrm{x}$ deslocamento está relacionada à diferença das bases de leituras. No pilar as medidas referem-se ao trecho entre topo e base do pilar enquanto nas armaduras é uma pequena região central das barras longitudinais, isenta de acomodação. Cabe a ressalva, que este comportamento foi apresentado por todos os pilares estudados na pesquisa. Como, neste trecho inicial, as leituras registradas pelas armaduras são as mais confiáveis, decidiu-se corrigir a inclinação do diagrama força-deformação dos pilares estudados para a inclinação do diagrama forçadeformação exibido pelas armaduras longitudinais. Além disso, o rebatimento mostrou-se necessário para corrigir o módulo de elasticidade do concreto assim como, para a observação do comportamento das deformações apresentadas pelas armaduras longitudinais ao longo do ensaio, já que, muitas leituras foram perdidas em situações de elevados carregamentos durante a realização de alguns ensaios, devido os fios da instrumentação dos extensômetros elétricos serem cortados pelas fibras metálicas, presentes nos concretos. 
A correção baseou-se na obtenção de uma equação de reta, para cada caso, denominado de trecho de interpolação (média dos transdutores e média das armaduras longitudinais), determinado entre as cargas de $50 \mathrm{kN}$ e $300 \mathrm{kN}$, conforme indica a figura 5.5 .

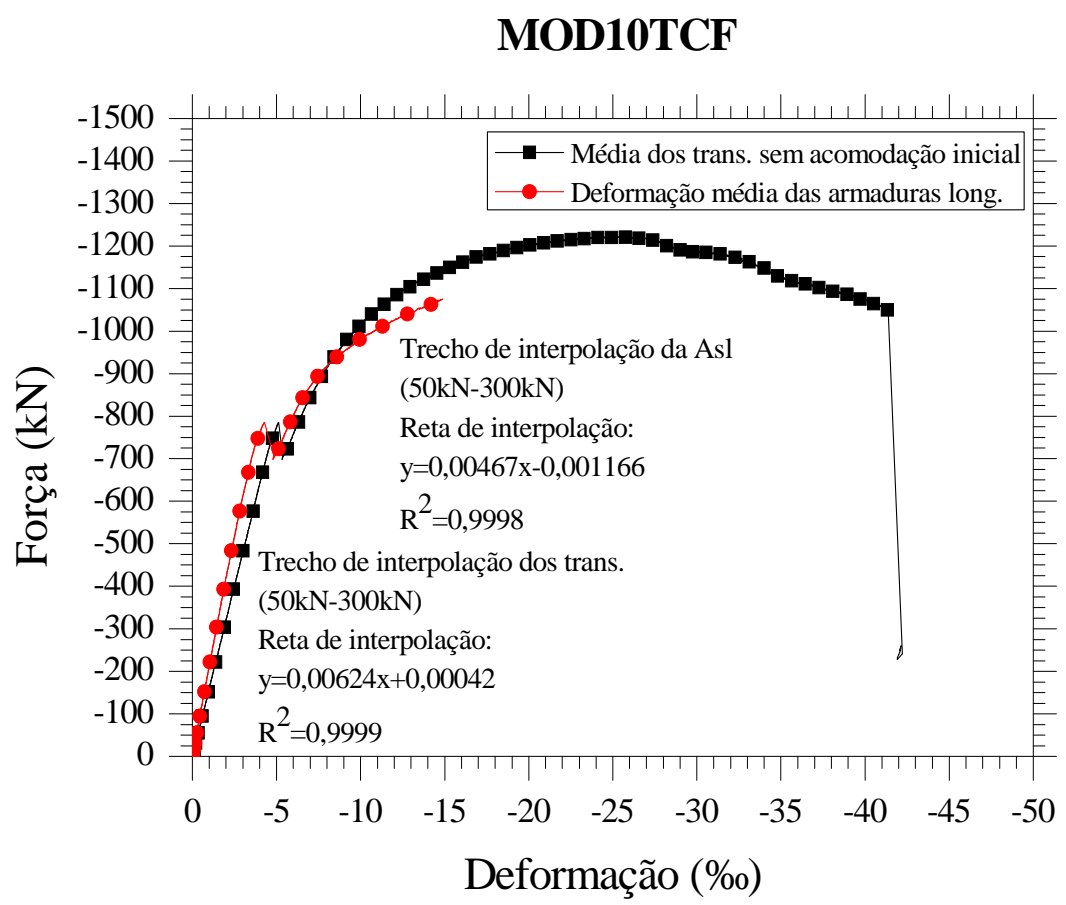

Figura 5.5 - Diagrama força-deformação MOD10TCF e diagrama força-deformação da armadura longitudinal

O processo de translação é feito da seguinte forma: retira-se da deformação axial do pilar o valor resultante entre a multiplicação da carga atuante no modelo pela diferença entre os coeficientes angulares da deformação axial do pilar e da média das armaduras longitudinais, neste caso $(0,00157)$. A figura 5.6, apresenta o resultado dessa correção para o pilar MOD10TCF. 


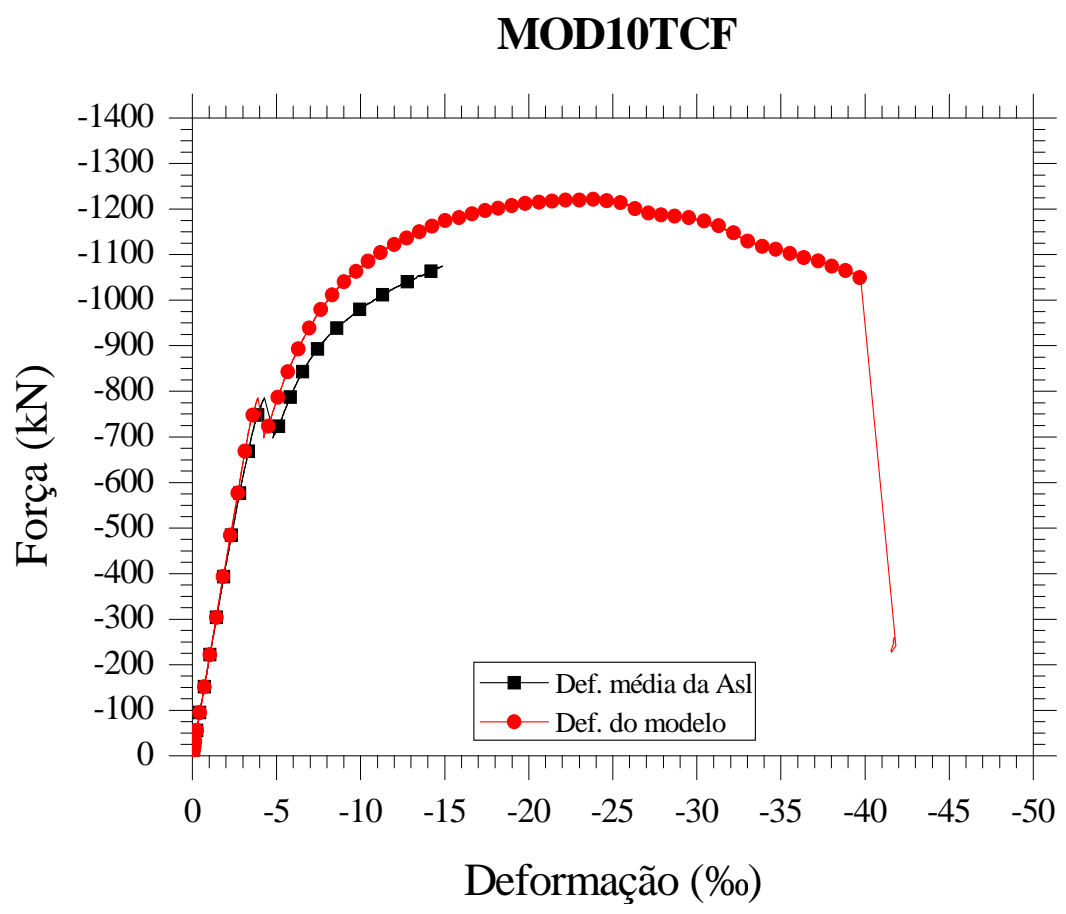

Figura 5.6 - Correção da inclinação do diagrama força-deformação axial do pilar MOD10TCF para a inclinação do diagrama força-deformação da média das armaduras longitudinais

\subsubsection{Diagrama força-deformação axial para os pilares das séries estudadas}

\subsubsection{Considerações iniciais}

Os pilares das séries TCF, TSF, ICF e ISF foram ensaiados à compressão centrada, por controle de deslocamento, com velocidade constante de $0,0023 \mathrm{~mm} / \mathrm{s}$, nas idades de: 37 dias, 35 dias, 36 dias e 36 dias, respectivamente. $O$ término do ensaio foi fixado pela primeira ocorrência do primeiro evento: ruptura da espiral ou a obtenção de $50 \%$ da força última $\left(F_{\text {ult }}\right)$. São apresentados no apêndice $A$ algumas fotos da realização dos ensaios de compressão centrada dos pilares com alto, médio e baixo confinamento.

As forças de ruína $\left(F_{\text {ruín }}\right)$ dos pilares MOD10ICF, MOD10TSF e MOD10ISF não foram alcançadas, pois os ensaios tiveram que ser abortados devido ao excessivo deslocamento horizontal do conjunto da máquina de ensaio. Por esse motivo, a última leitura de força e deformação axial será considerada como a força de ruína ( $\left.F_{\text {ruínc }}\right)$, 
correspondente ao ponto $\left(F_{4}, \varepsilon_{4}\right)$ do diagrama idealizado de força-deformação proposto por GRAYBEAL \& PESSIKI (2000).

\subsubsection{Série TCF}

A série TCF é composta pelos pilares MOD10TCF, MOD15TCF, MOD20TCF, MOD45TCF, MOD55TCF e MOD75TCF, com as seguintes taxas volumétricas de armadura transversal $\left(\rho_{w}\right)$, nesta ordem: $11,46 \%, 7,64 \%, 5,73 \%$, 2,55\%, 2,08\% e 1,53\%. A figura 5.7 apresenta os diagramas força-deformação dos pilares da série.

\section{SÉRIE TCF}

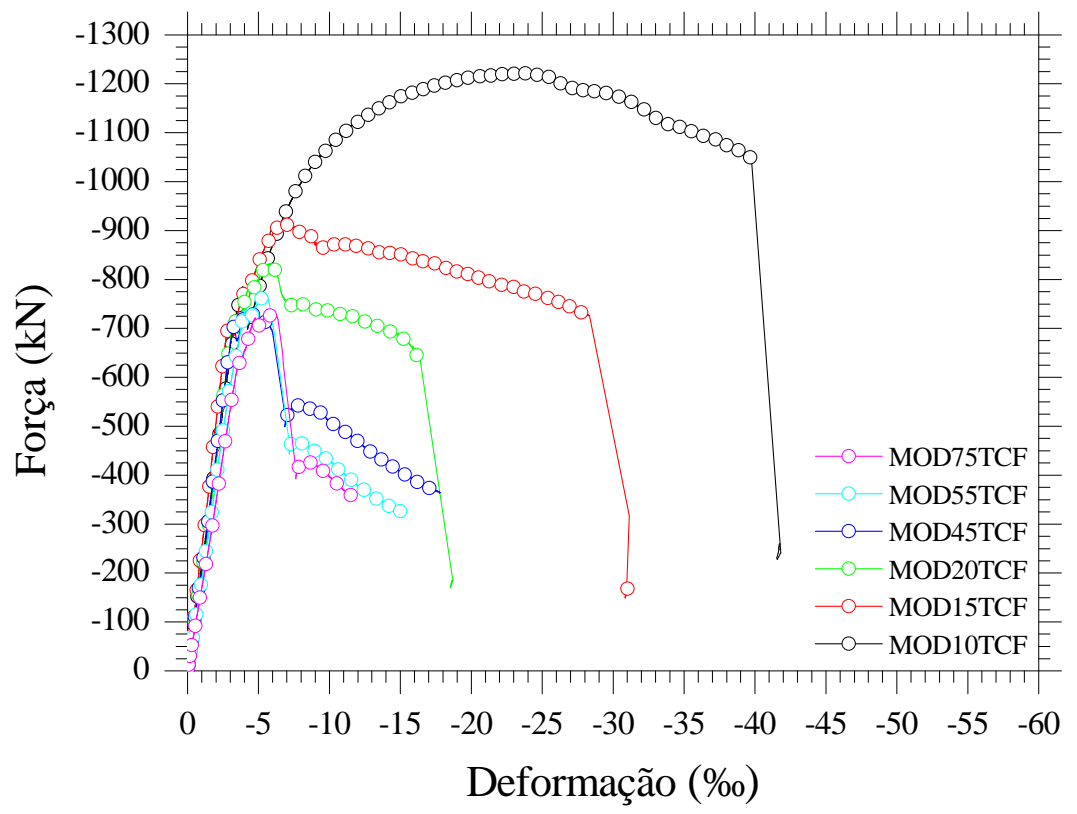

Figura 5.7 - Diagramas força-deformação axial para os pilares da série TCF

A tabela 5.1 apresenta os valores correspondentes aos quatro pontos do diagrama idealizado de força-deformação proposto por GRAYBEAL \& PESSIKI (2000). 
Tabela 5.1 - Resultados Experimentais Série TCF

\begin{tabular}{ccccccccc}
\hline & \multicolumn{4}{c}{ Força axial } & \multicolumn{5}{c}{ Deformação axial } \\
\hline \multirow{2}{*}{ Pilar } & $F_{1}$ & $F_{2}$ & $F_{3}$ & $F_{4}$ & $\varepsilon_{1}$ & $\varepsilon_{2}$ & $\mathcal{E}_{3}$ & $\varepsilon_{4}$ \\
& $(\mathrm{kN})$ & $(\mathrm{kN})$ & $(\mathrm{kN})$ & $(\mathrm{kN})$ & $(\%)$ & $(\%)$ & $(\%)$ & $(\%)$ \\
\hline MOD10TCF & $-785,39$ & $-698,25$ & $-1221,84$ & $-1047,34$ & $-3,89$ & $-4,23$ & $-23,21$ & $-39,74$ \\
MOD15TCF & $-712,21$ & $-681,31$ & $-914,34$ & $-725,95$ & $-2,91$ & $-3,21$ & $-6,90$ & $-28,33$ \\
MOD20TCF & $-711,37$ & $-688,79$ & $-832,93$ & $-645,29$ & $-3,18$ & $-3,53$ & $-5,87$ & $-16,35$ \\
MOD45TCF & $-703,36$ & $-499,56$ & $-543,20$ & $-363,81$ & $-3,29$ & $-6,85$ & $-7,83$ & $-17,75$ \\
MOD55TCF & $-739,61$ & $-442,86$ & $-472,77$ & $-324,21$ & $-4,10$ & $-7,16$ & $-7,71$ & $-15,16$ \\
MOD75TCF & $-721,52$ & $-393,04$ & $-426,76$ & $-354,81$ & $-4,78$ & $-7,67$ & $-8,29$ & $-11,50$ \\
\hline
\end{tabular}

São apresentados os valores de $I D_{1}, I D_{2}$ e $I D_{3}$ para os pilares da série nas tabelas 5.2 e 5.3 .

Tabela $5.2-I D_{1}$ e $I D_{2}$ dos pilares da série TCF

\begin{tabular}{|c|c|c|c|c|}
\hline Pilar & $\begin{array}{c}\mathcal{E}_{1} \\
(\%)\end{array}$ & $I D_{1}=\frac{\varepsilon_{1}}{\varepsilon_{c o}}$ & $\begin{array}{c}\mathcal{E}_{3} \\
(\% \circ)\end{array}$ & $I D_{2}=\frac{\varepsilon_{3}}{\varepsilon_{c o}}$ \\
\hline $\begin{array}{l}\text { MOD10TCF } \\
\text { MOD15TCF } \\
\text { MOD20TCF } \\
\text { MOD45TCF } \\
\text { MOD55TCF } \\
\text { MOD75TCF }\end{array}$ & $\begin{array}{l}-3,89 \\
-2,91 \\
-3,18 \\
-3,29 \\
-4,10 \\
-4,78 \\
\end{array}$ & $\begin{array}{l}0,89 \\
0,69 \\
0,73 \\
0,75 \\
0,94 \\
1,09 \\
\end{array}$ & $\begin{array}{l}-23,21 \\
-6,90 \\
-5,87 \\
-7,83 \\
-7,71 \\
-8,29 \\
\end{array}$ & $\begin{array}{l}5,33 \\
1,58 \\
1,35 \\
1,80 \\
1,77 \\
1,90 \\
\end{array}$ \\
\hline
\end{tabular}

Tabela $5.3-I D_{3}$ para os Série TCF

\begin{tabular}{cccccc}
\hline Pilar & $\begin{array}{c}F_{3} \\
(\mathrm{kN})\end{array}$ & $0,85 \cdot F_{3}$ & $\begin{array}{c}\varepsilon_{3} \\
(\%)\end{array}$ & $\begin{array}{c}\varepsilon_{0,85} \\
(\%)\end{array}$ & $I D_{3}=\frac{\varepsilon_{0,85}}{\varepsilon_{3}}$ \\
\hline MOD10TCF & $-1221,84$ & $-1038,56$ & $-23,21$ & $-39,74^{*}$ & 1,71 \\
MOD15TCF & $-914,34$ & $-777,19$ & $-6,90$ & $-23,23$ & 3,37 \\
MOD20TCF & $-832,93$ & $-707,99$ & $-5,87$ & $-13,16$ & 2,24 \\
MOD45TCF & $-543,20$ & $-461,72$ & $-7,83$ & $-12,29$ & 1,57 \\
MOD55TCF & $-472,77$ & $-401,85$ & $-7,71$ & $-10,94$ & 1,42 \\
MOD75TCF & $-426,76$ & $-362,75$ & $-8,29$ & $-11,31$ & 1,36 \\
\hline
\end{tabular}

Obs: $\mathrm{O}$ valor com asterisco $\left({ }^{*}\right)$ corresponde à última deformação registrada (ruptura da espiral).

Com base nos resultados obtidos dos diagramas de força e deformação axial dos pilares da série TCF, pode-se notar que: 
- Os pilares apresentaram linearidade do trecho ascendente dos diagramas força-deformação até o ponto $\left(F_{1}, \varepsilon_{1}\right)$, particularidade similar a já apresentada pelos concretos de alta resistência, de acordo com QUEIROGA (1999);

- Quando $F_{\text {ult }}$ do pilar é atingida no ponto $\left(F_{3}, \varepsilon_{3}\right)$, demonstra que o confinamento promoveu acréscimos de resistência e deformação ao concreto do núcleo confinado pelos eixos centrais da armadura transversal, benefícios verificados para os pilares MOD10TCF, MOD15TCF e MOD20TCF. Outro parâmetro que pode ser utilizado para verificar se foram gerados benéficos pelo confinamento ao concreto do núcleo é realizar a comparação entre as forças obtidas nos pontos $\left(F_{3}, \varepsilon_{3}\right)$ e $\left(F_{1}, \varepsilon_{1}\right)$ quando, $F_{3}>F_{1}$. Isto significa que o confinamento causou acréscimo de resistência e ductilidade ao núcleo de concreto confinado;

- Quando $F_{u l t}$ do pilar ocorre no ponto $\left(F_{1}, \varepsilon_{1}\right)$, confirma que a taxa de armadura transversal $\left(\rho_{\text {Asw }}\right)$ utilizada não promove acréscimos de resistência ao concreto do núcleo confinado, mas gera benefícios de deformação axial, caso comprovado pelos pilares MOD45TCF, MOD55TCF e MOD75TCF, onde a armadura transversal atua corrigindo o tipo de ruptura frágil apresentada pelo CUAR sem confinamento;

- Os valores apresentados pela comparação entre as relações das forças $F_{3} / F_{1}$ para os pilares da série são: $1,55,1,28,1,17,0,77,0,63$ e 0,59. Esses valores demonstram que foram gerados acréscimos de resistência à compressão ao concreto do núcleo para os pilares MOD10TCF, MOD15TCF e MOD20TCF, elevando a capacidade resistente desses pilares em relação à força normal $F_{1}$ em: $55 \%, 28 \%$ e $17 \%$, respectivamente;

- A perda de capacidade resistente da seção transversal foi visível nos diagramas força-deformação dos pilares MOD10TCF, MOD15TCF e MOD20TCF, indicando a perda da contribuição do concreto do cobrimento na seção resistente dos pilares; 
- Os pilares MOD45TCF, MOD55TCF e MOD75TCF apresentaram nos pontos $\left(F_{1}, \varepsilon_{1}\right)$ e $\left(F_{2}, \varepsilon_{2}\right)$ um alto valor de queda de capacidade resistente da seção transversal do pilar, sendo um indicativo da ruptura da seção transversal do pilar;

- Ocorreu a ruptura da espiral instrumentada nos pilares MOD10TCF, MOD15TCF e MOD20TCF, indicando que a armadura transversal atingiu sua força última $\left(F_{u l t, w}\right)$;

- Observou-se pela média dos valores de $I D_{1} q u e$ a perda do concreto do cobrimento (spalling) ocorre quando $0,85 \%$ da deformação do concreto não confinado é atingida;

- Os valores de $I D_{2}$ demonstraram que o confinamento promoveu acréscimos de deformação ao concreto do núcleo confinado em relação à deformação do concreto não confinado, e que quanto maior for a restrição da deformação lateral do concreto do núcleo pela armadura transversal (taxa de armadura transversal de confinamento), maiores são os ganhos de deformação do concreto confinado;

- Os valores de $I D_{3}$ indicam que os melhores resultados de ductilidade no trecho descendente do diagrama força-deformação foram para os pilares MOD15TCF e MOD20TCF. Nota-se que todos os pilares da série apresentaram comportamento dúctil, ou seja, uma ruptura do tipo gradual;

- Todos os pilares apresentaram flambagem da armadura longitudinal.

\subsubsection{Série TSF}

A série TSF, composta pelos pilares MOD10TSF, MOD15TSF, MOD20TSF, MOD45TSF, MOD55TSF e MOD75TSF, possuiam as seguintes taxas volumétricas de armadura transversal, respectivamente: $11,46 \%, 7,64 \%, 5,73 \%$, $2,55 \%, 2,08 \%$ e $1,53 \%$. A figura 5.8 apresenta os resultados dos diagramas forçadeformação obtidos para os pilares da série TSF. 


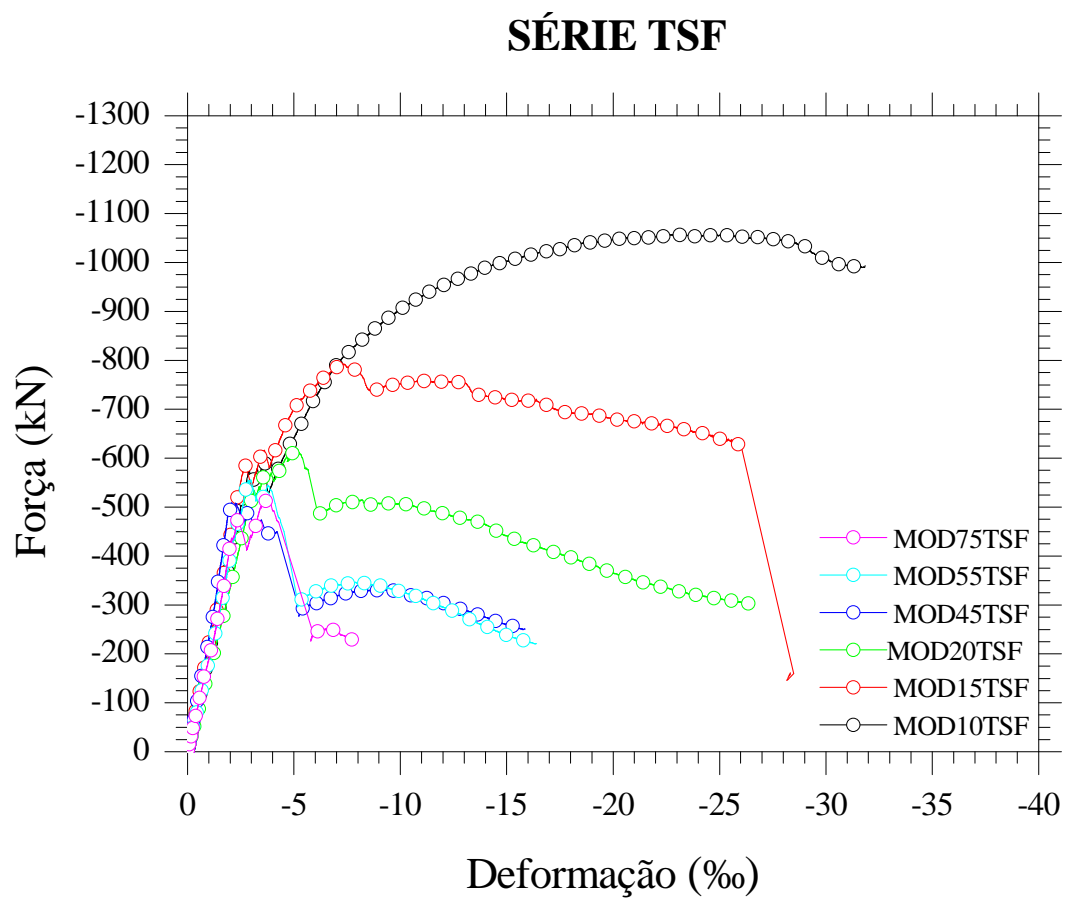

Figura 5.8 - Diagramas força-deformação axial para os pilares da série TSF

A tabela 5.4 mostra os valores correspondentes aos quatro pontos do diagrama idealizado de força-deformação proposto por GRAYBEAL \& PESSIKI (2000).

Tabela 5.4 - Resultados experimentais para os pilares da série TSF

\begin{tabular}{ccccccccc}
\hline & \multicolumn{4}{c}{ Força axial } & \multicolumn{5}{c}{ Deformação axial } \\
\hline \multirow{2}{*}{ Pilar } & $F_{1}$ & $F_{2}$ & $F_{3}$ & $F_{4}$ & $\mathcal{E}_{1}$ & $\mathcal{E}_{2}$ & $\mathcal{E}_{3}$ & $\mathcal{E}_{4}$ \\
& $(\mathrm{kN})$ & $(\mathrm{kN})$ & $(\mathrm{kN})$ & $(\mathrm{kN})$ & $(\%)$ & $(\% \circ)$ & $(\%)$ & $(\%)$ \\
\hline MOD10TSF & $-574,64$ & $-524,05$ & $-1058,40$ & $-989,73$ & $-2,91$ & $-3,75$ & $-23,29$ & $-31,79$ \\
MOD15TSF & $-584,71$ & $-581,35$ & $-791,88$ & $-625,23$ & $-2,73$ & $-3,83$ & $-7,33$ & $-25,95$ \\
MOD20TSF & $-534,50$ & $-486,43$ & $-514,51$ & $-299,87$ & $-3,12$ & $-6,05$ & $-8,20$ & $-26,61$ \\
MOD45TSF & $-508,56$ & $-279,90$ & $-331,38$ & $-249,43$ & $-2,06$ & $-5,23$ & $-9,10$ & $-15,80$ \\
MOD55TSF & $-554,80$ & $-269,06$ & $-346,80$ & $-220,44$ & $-2,86$ & $-5,17$ & $-7,90$ & $-16,37$ \\
MOD75TSF & $-473,61$ & $-226,01$ & $-251,57$ & $-227,23$ & $-2,34$ & $-5,79$ & $-6,59$ & $-7,87$ \\
\hline
\end{tabular}

São apresentados os valores de $I D_{1}, I D_{2}$ e $I D_{3}$ para os pilares da série, nas tabelas 5.5 e 5.6 . 
Tabela $5.5-I D_{1}$ e $I D_{2}$ dos pilares da série TSF

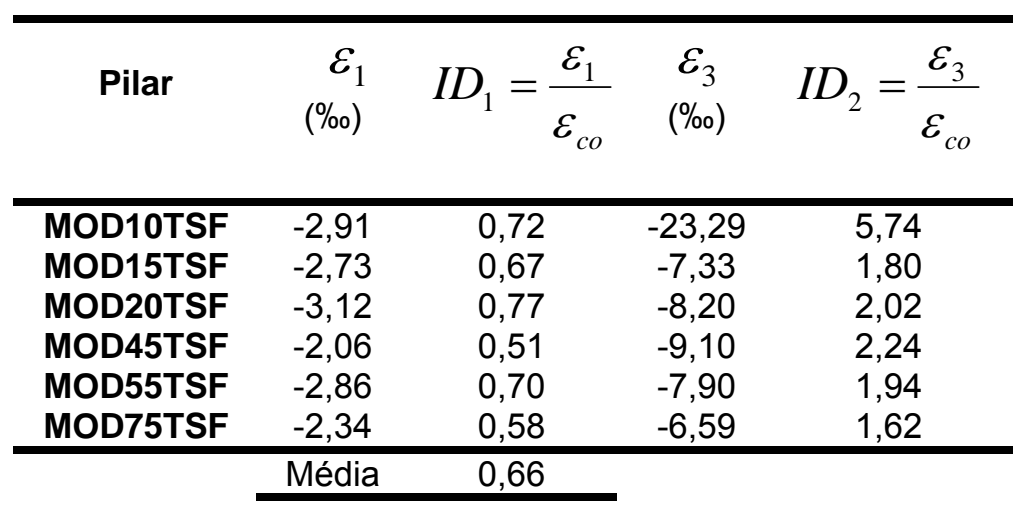

Tabela $5.6-I D_{3}$ para os Série TSF

\begin{tabular}{cccccc}
\hline Pilar & $\begin{array}{c}F_{3} \\
(\mathrm{kN})\end{array}$ & $0,85 \cdot F_{3}$ & $\begin{array}{c}\varepsilon_{3} \\
(\% \circ)\end{array}$ & $\begin{array}{c}\varepsilon_{0,85} \\
(\%)\end{array}$ & $I D_{3}=\frac{\varepsilon_{0,85}}{\varepsilon_{3}}$ \\
\hline MOD10TSF & $-1058,40$ & $-899,64$ & $-23,29$ & $-31,79^{*}$ & 1,36 \\
MOD15TSF & $-791,88$ & $-673,01$ & $-7,33$ & $-21,33$ & 2,91 \\
MOD20TSF & $-514,51$ & $-473,33$ & $-8,20$ & $-15,20$ & 1,85 \\
MOD45TSF & $-331,38$ & $-281,67$ & $-9,10$ & $-13,55$ & 1,49 \\
MOD55TSF & $-346,80$ & $-294,78$ & $-7,90$ & $-12,04$ & 1,52 \\
MOD75TSF & $-251,57$ & $-213,83$ & $-6,59$ & $-7,87^{*}$ & 1,19 \\
\hline
\end{tabular}

Obs: Os valores com asterisco $\left.{ }^{*}\right)$ não correspondem à deformação $\left(\varepsilon_{0,85}\right)$, pois esses valores não foram registrados nos ensaios. Dessa forma foram adotados para a avaliação da ductilidade os últimos valores de leitura registrados.

A partir dos resultados obtidos dos diagramas força-deformação dos pilares da série TSF, pode-se notar que:

- Os pilares apresentaram linearidade do trecho ascendente dos diagramas força-deformação até o ponto $\left(F_{1}, \varepsilon_{1}\right)$;

- A comparação entre as forças $F_{3} / F_{1}$ para os pilares da série apresentaram os seguintes valores: $1,84,1,35,0,96,0,65,0,68$ e 0,53, demonstrando que apenas os pilares MOD10TSF e MOD15TSF apresentaram acréscimos de resistência à compressão do concreto do núcleo confinado, elevando a capacidade resistente desses elementos estruturais em relação à capacidade resistente no ponto $\left(F_{1}, \varepsilon_{1}\right) \mathrm{em}$ : $84 \% \mathrm{e}$ $35 \%$, respectivamente; 
- A perda de capacidade resistente da seção transversal foi visível nos diagramas força-deformação dos pilares MOD10TSF, MOD15TSF e MOD20TSF o que indica a perda da contribuição do concreto do cobrimento na seção resistente dos pilares;

- Os pilares MOD45TSF, MOD55TSF e MOD75TSF apresentaram nos pontos $\left(F_{1}, \varepsilon_{1}\right)$ e $\left(F_{2}, \varepsilon_{2}\right)$ um alto valor de queda de capacidade resistente da seção transversal do pilar, sendo um indicativo da ruptura da seção transversal do pilar. Esse fato é um indicativo que a taxa de armadura transversal $\left(\rho_{w}\right)$ utilizada nesses pilares atuou apenas para melhorar aforma de ruptura frágil apresentada pelo CUAR;

- Observou-se pela média dos valores de $I D_{1}$ que a perda do concreto do cobrimento (spalling) ocorre quando $0,66 \%$ da deformação do concreto não confinado é atingida;

- Os valores de $I D_{2}$ demonstraram que o confinamento promoveu acréscimos de deformação ao concreto do núcleo confinado em relação à deformação do concreto não confinado;

- Os valores de $I D_{3}$ indicam que os melhores resultados de ductilidade no trecho descendente do diagrama força-deformação foram para os pilares MOD15TCF e MOD20TCF. Nota-se que todos os pilares apresentaram comportamento dúctil, ou seja, uma ruptura do tipo gradual;

- Ocorreu a ruptura da espiral instrumentada no pilar MOD15TCF;

- Todos os pilares apresentaram flambagem da armadura longitudinal.

\subsubsection{Série ICF}

A série ICF é composta pelos pilares MOD10ICF, MOD20ICF, MOD25ICF, MOD55ICF, MOD60ICF e MOD75ICF, possuíam as seguintes taxas volumétricas de armadura transversal, respectivamente: $11,46 \%, 5,73 \%, 4,58 \%, 2,08 \%, 1,91 \%$ e 1,53\%. A figura 5.9 apresenta os diagramas força-deformação para os pilares da série. 


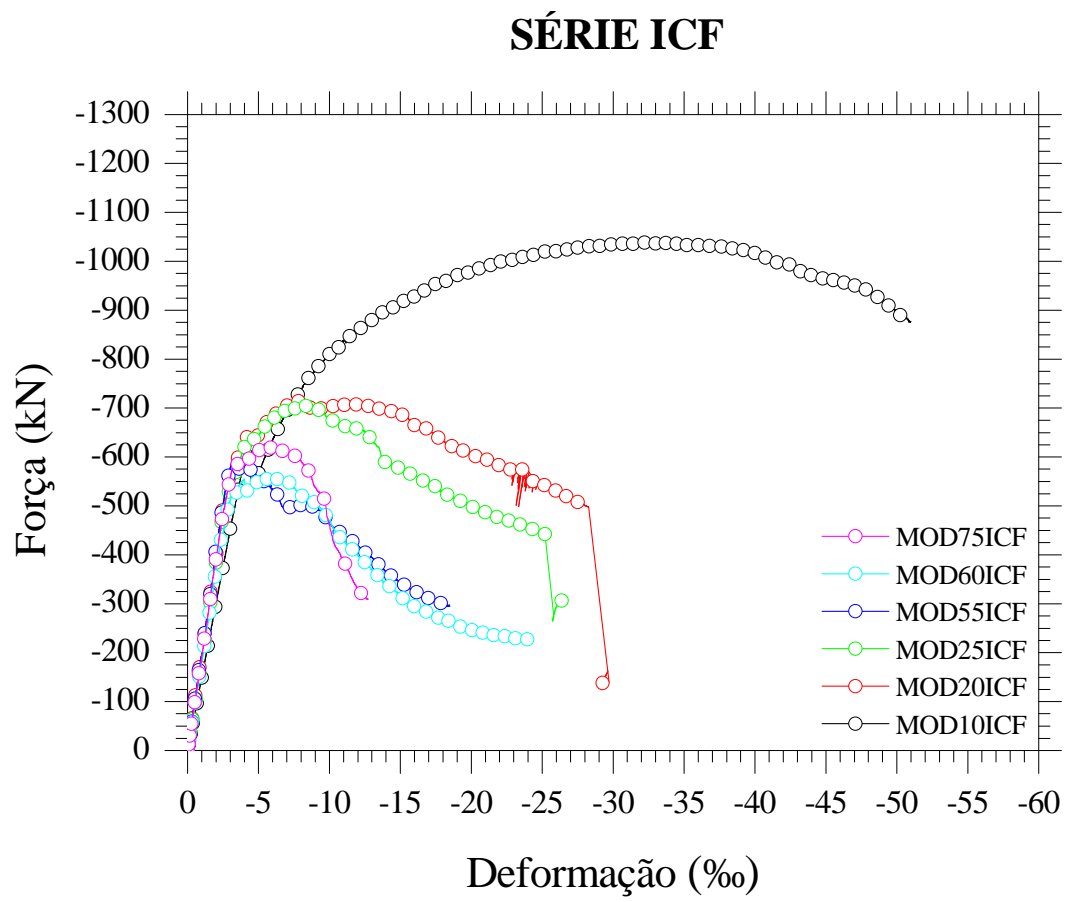

Figura 5.9 - Diagramas força-deformação axial para os pilares da série ICF

A tabela 5.7 mostra os valores correspondentes aos quatro pontos do diagrama idealizado de força-deformação proposto por GRAYBEAL \& PESSIKI (2000).

Tabela 5.7 - Resultados Experimentais Série ICF

\begin{tabular}{ccccccccc}
\hline & \multicolumn{4}{c}{ Força axial } & \multicolumn{5}{c}{ Deformação axial } \\
\hline \multirow{2}{*}{ Pilar } & $F_{1}$ & $F_{2}$ & $F_{3}$ & $F_{4}$ & $\varepsilon_{1}$ & $\varepsilon_{2}$ & $\varepsilon_{3}$ & $\varepsilon_{4}$ \\
& $(\mathrm{kN})$ & $(\mathrm{kN})$ & $(\mathrm{kN})$ & $(\mathrm{kN})$ & $(\% \circ)$ & $(\% \circ)$ & $(\%)$ & $(\%)$ \\
\hline MOD10ICF & $-618,44$ & $-532,67$ & $-1039,01$ & $-875,43$ & $-3,02$ & $-3,47$ & $-29,99$ & $-49,24$ \\
MOD20ICF & $-601,88$ & $-581,81$ & $-714,58$ & $-496,73$ & $-3,22$ & $-3,38$ & $-7,96$ & $-28,29$ \\
MOD25ICF & $-623,93$ & $-613,78$ & $-704,89$ & $-264,77$ & $-4,06$ & $-4,13$ & $-8,40$ & $-25,19$ \\
MOD55ICF & $-590,97$ & $-495,51$ & $-501,99$ & $-294,15$ & $-3,15$ & $-6,85$ & $-8,33$ & $-18,47$ \\
MOD60ICF & $-554,88$ & $-531,22$ & $-558,01$ & $-221,13$ & $-3,98$ & $-4,13$ & $-5,91$ & $-24,28$ \\
MOD75ICF & $-588,45$ & $-571,82$ & $-619,51$ & $-309,10$ & $-3,43$ & $-3,64$ & $-5,93$ & $-12,69$ \\
\hline
\end{tabular}

São apresentados os valores de $I D_{1}, I D_{2}$ e $I D_{3}$ para os pilares da série nas tabelas 5.8 e 5.9 . 
Tabela 5.8 - $I D_{1}$ e $I D_{2}$ dos pilares da série ICF

\begin{tabular}{|c|c|c|c|c|}
\hline Pilar & $\begin{array}{c}\mathcal{E}_{1} \\
(\%)\end{array}$ & $I D_{1}=\frac{\varepsilon_{1}}{\varepsilon_{c o}}$ & $\begin{array}{c}\mathcal{E}_{3} \\
(\%)\end{array}$ & $I D_{2}=\frac{\varepsilon_{3}}{\varepsilon_{c o}}$ \\
\hline MOD10ICF & $-3,02$ & 0,75 & $-29,99$ & 7,47 \\
\hline MOD20ICF & $-3,22$ & 0,80 & $-7,96$ & 1,98 \\
\hline MOD25ICF & $-4,06$ & 1,01 & $-8,40$ & 2,09 \\
\hline MOD55ICF & $-3,15$ & 0,78 & $-8,33$ & 2,08 \\
\hline MOD60ICF & $-3,98$ & 0,99 & $-5,91$ & 1,47 \\
\hline \multirow[t]{2}{*}{ MOD75ICF } & $-3,43$ & 0,85 & $-5,93$ & 1,48 \\
\hline & Média & 0,86 & & \\
\hline
\end{tabular}

Tabela $5.9-I D_{3}$ para os Série ICF

\begin{tabular}{cccccc}
\hline Pilar & $\begin{array}{c}F_{3} \\
(\mathrm{kN})\end{array}$ & $0,85 \cdot F_{3}$ & $\begin{array}{c}\varepsilon_{3} \\
(\% \circ)\end{array}$ & $\begin{array}{c}\varepsilon_{0,85} \\
(\%)\end{array}$ & $I D_{3}=\frac{\varepsilon_{0,85}}{\varepsilon_{3}}$ \\
\hline MOD10ICF & $-1039,01$ & $-883,16$ & $-29,99$ & $-48,96$ & 1,63 \\
MOD20ICF & $-714,58$ & $-607,39$ & $-7,96$ & $-19,86$ & 2,49 \\
MOD25ICF & $-704,89$ & $-599,15$ & $-8,40$ & $-13,67$ & 1,63 \\
MOD55ICF & $-501,99$ & $-426,69$ & $-8,33$ & $-11,71$ & 1,40 \\
MOD60ICF & $-558,01$ & $-474,31$ & $-5,91$ & $-9,93$ & 1,68 \\
MOD75ICF & $-619,51$ & $-526,58$ & $-5,93$ & $-9,31$ & 1,57 \\
\hline
\end{tabular}

A partir dos resultados obtidos dos diagramas força-deformação dos pilares da série ICF, pode-se notar que:

- Os pilares apresentaram linearidade do trecho ascendente dos diagramas força-deformação até o ponto $\left(F_{1}, \varepsilon_{1}\right)$;

- As relações das forças $F_{3} / F_{1}$ exibidas pelos pilares da série são: 1,68, $1,19,1,12,0,85,1,00$ e 1,05, indicando que os pilares MOD10ICF, MOD20ICF, MOD25ICF e MOD75TCF apresentaram acréscimos de resistência à compressão do concreto do núcleo confinado;

- A perda de capacidade resistente da seção transversal foi mais visível nos diagramas força-deformação dos pilares MOD10ICF, MOD20ICF e MOD25ICF, indicando a perda da contribuição do concreto do cobrimento na seção resistente dos pilares no ponto $\left(F_{1}, \varepsilon_{1}\right)$; 
- A ruptura da espiral instrumentada ocorreu nos pilares MOD20ICF e MOD25ICF, indicando que a armadura transversal atingiu sua força última $\left(F_{u l t, w}\right)$;

- Observou-se pela média dos valores de $I D_{1}$ que a perda do concreto do cobrimento (spalling) ocorre quando $0,86 \%$ da deformação do concreto não confinado é atingida;

- Os valores de $I D_{2}$ demonstraram que o confinamento promoveu acréscimos de deformação ao concreto do núcleo confinado em relação à deformação do concreto não confinado, para todos os pilares da série;

- Os valores de $I D_{3}$ no trecho descendente do diagrama força-deformação indicam que os pilares MOD10ICF, MOD20ICF, MOD25ICF e MOD60ICF apresentaram os melhores resultados de ductilidade. Nota-se que todos os pilares apresentaram comportamento dúctil;

- Todos os pilares apresentaram flambagem da armadura longitudinal.

\subsubsection{Série ISF}

A série ISF, composta pelos pilares MOD10ISF, MOD20ISF, MOD25ISF, MOD55ISF, MOD60ISF e MOD75ISF, possuíam as seguintes taxas volumétricas de armadura transversal, respectivamente: $11,46 \%, 5,73 \%, 4,58 \%, 2,08 \%, 1,91 \%$ e 1,53\%. O pilar MOD55ISF apresentou problemas na aquisição de dados da instrumentação utilizada durante o ensaio devido a problemas no cabo da instrumentação, sendo descartado da série ISF.

Os resultados dos diagramas força-deformação dos pilares da série estão apresentados na figura 5.10 . 


\section{SÉRIE ISF}

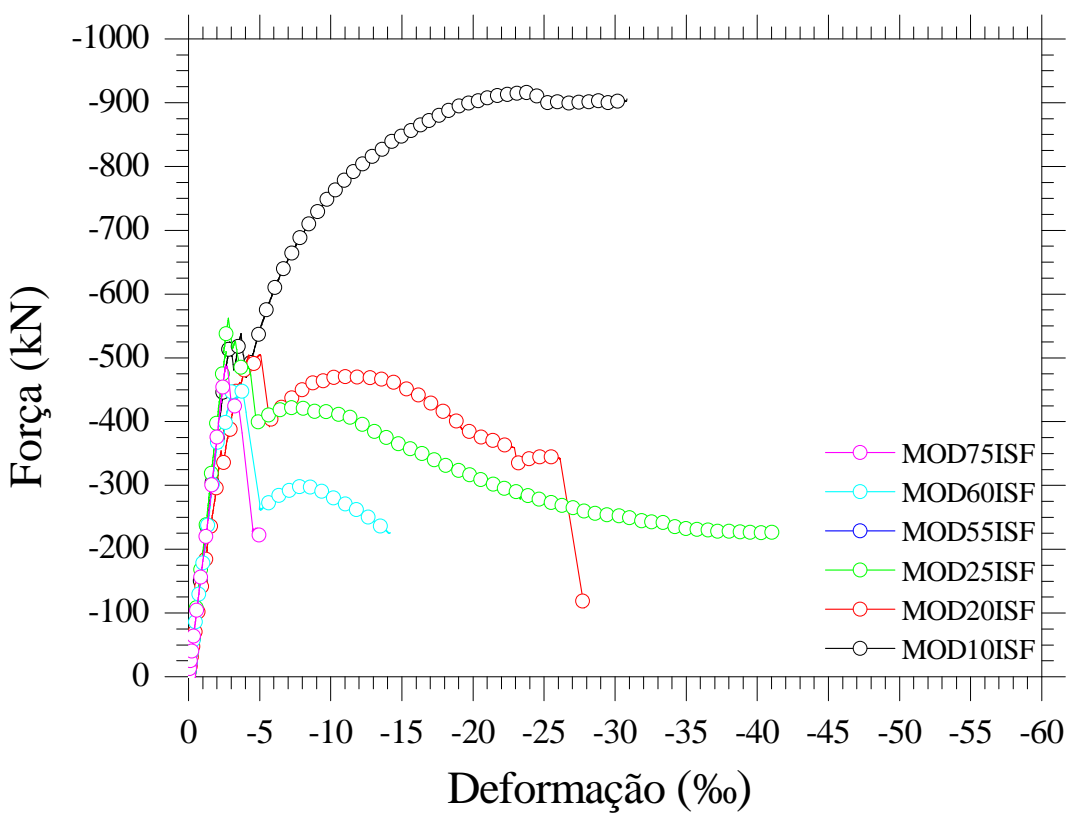

Figura 5.10 - Diagramas força-deformação axial para os pilares da série ISF

A tabela 5.10 mostra os valores correspondentes aos quatro pontos do diagrama idealizado de força-deformação proposto por GRAYBEAL \& PESSIKI (2000).

Tabela 5.10 - Resultados Experimentais Série ISF

\begin{tabular}{ccccccccc}
\hline & \multicolumn{4}{c}{ Força axial } & \multicolumn{4}{c}{ Deformação axial } \\
\hline \multirow{2}{*}{ Pilar } & $F_{1}$ & $F_{2}$ & $F_{3}$ & $F_{4}$ & $\varepsilon_{1}$ & $\mathcal{E}_{2}$ & $\varepsilon_{3}$ & $\varepsilon_{4}$ \\
& $(\mathrm{kN})$ & $(\mathrm{kN})$ & $(\mathrm{kN})$ & $(\mathrm{kN})$ & $(\% \circ)$ & $(\%)$ & $(\% \circ)$ & $(\%)$ \\
\hline MOD10ISF & $-525,04$ & $-470,33$ & $-916,02$ & $-902,06$ & $-2,91$ & $-4,04$ & $-23,69$ & $-30,78$ \\
MOD20ISF & $-504,29$ & $-391,81$ & $-471,32$ & $-341,38$ & $-4,23$ & $-5,69$ & $-11,31$ & $-26,10$ \\
MOD25ISF & $-562,58$ & $-399,37$ & $-423,56$ & $-224,56$ & $-2,81$ & $-4,89$ & $-7,47$ & $-41,38$ \\
MOD60ISF & $-447,06$ & $-261,87$ & $-298,96$ & $-225,02$ & $-3,06$ & $-4,99$ & $-8,31$ & $-14,14$ \\
MOD75ISF & $-489,10$ & $-227,54$ & $-232,88$ & $-222,50$ & $-2,60$ & $-4,49$ & $-4,82$ & $-4,96$ \\
\hline
\end{tabular}

As tabelas 5.11 e 5.12 apresentam os valores dos índices de ductilidade $I D_{1}, I D_{2}$ e $I D_{3}$ para os pilares da série. 
Tabela 5.11 - ID $1 D_{2}$ dos pilares da série ISF

\begin{tabular}{|c|c|c|c|c|}
\hline Pilar & $\begin{array}{c}\varepsilon_{1} \\
(\% \circ)\end{array}$ & $I D_{1}=\frac{\varepsilon_{1}}{\varepsilon_{c o}}$ & $\begin{array}{l}\mathcal{E}_{3} \\
(\%)\end{array}$ & $I D_{2}=\frac{\varepsilon_{3}}{\varepsilon_{c o}}$ \\
\hline $\begin{array}{l}\text { MOD10ISF } \\
\text { MOD20ISF } \\
\text { MOD25ISF } \\
\text { MOD60ISF } \\
\text { MOD75ISF }\end{array}$ & $\begin{array}{l}-2,91 \\
-4,23 \\
-2,81 \\
-3,06 \\
-2,60\end{array}$ & $\begin{array}{l}0,80 \\
1,16 \\
0,77 \\
0,84 \\
0,71\end{array}$ & $\begin{array}{c}-23,69 \\
-11,31 \\
-7,47 \\
-8,31 \\
-4,82\end{array}$ & $\begin{array}{l}6,50 \\
3,10 \\
2,05 \\
2,28 \\
1,32 \\
\end{array}$ \\
\hline & Média & 0,86 & & \\
\hline
\end{tabular}

\begin{tabular}{cccccc}
\hline Pilar & $\begin{array}{c}F_{3} \\
(\mathrm{kN})\end{array}$ & $0,85 \cdot F_{3}$ & $\begin{array}{c}\varepsilon_{3} \\
(\%)\end{array}$ & $\begin{array}{c}\varepsilon_{0,85} \\
(\%)\end{array}$ & $I D_{3}=\frac{\varepsilon_{0,85}}{\varepsilon_{3}}$ \\
\hline MOD10ISF & $-916,02$ & $-778,62$ & $-23,69$ & $-30,78^{*}$ & 1,30 \\
MOD20ISF & $-471,32$ & $-400,62$ & $-11,31$ & $-18,83$ & 1,66 \\
MOD25ISF & $-423,56$ & $-360,03$ & $-7,47$ & $-15,32$ & 2,05 \\
MOD60ISF & $-298,96$ & $-254,12$ & $-8,31$ & $-12,32$ & 1,48 \\
MOD75ISF & $-232,88$ & $-197,95$ & $-4,82$ & $-4,96^{*}$ & 1,02 \\
\hline
\end{tabular}

Obs: os valores com asterisco $\left(^{*}\right)$ não correspondem à deformação $\left(\varepsilon_{0,85}\right)$, pois esses valores não foram registrados nos ensaios. Dessa forma foram adotados para a avaliação da ductilidade os últimos valores de leitura registrados.

A partir dos resultados obtidos dos diagramas força-deformação dos pilares da série ISF, pode-se notar que:

- Os pilares apresentaram linearidade do trecho ascendente dos diagramas força-deformação até o ponto $\left(F_{1}, \varepsilon_{1}\right)$;

- Os valores da relação entre as forças $F_{3} / F_{1}$ exibidas pelos pilares da série são, respectivamente: 1,74, 0,93, 0,75, 0,66 e 0,48. Esses valores demonstram que apenas o pilar MOD10ISF, apresentou acréscimos de resistência à compressão do concreto do núcleo confinado;

- A perda de capacidade resistente da seção transversal foi mais visível nos diagramas força-deformação dos pilares MOD25ISF, MOD60ISF e MOD75ISF, dando indícios da ocorrência de ruptura da seção de concreto dos pilares;

- A ruptura da espiral instrumentada ocorreu no pilar MOD20ISF; 
- Os pilares MOD10ISF, MOD20ISF, MOD25ISF e MOD60ISF apresentaram flambagem das armaduras longitudinais;

- Nota-se graficamente que todos os pilares apresentaram comportamento dúctil, ou seja, uma ruptura do tipo gradual;

- Observou-se pela média dos valores de $I D_{1} q u e$ a perda do concreto do cobrimento (spalling) ocorre quando $0,86 \%$ da deformação do concreto não confinado é atingida;

- Os valores de $I D_{2}$ demonstraram que o confinamento promoveu acréscimos de deformação ao concreto do núcleo confinado em relação à deformação do concreto não confinado, para todos os pilares da série;

- Os valores de $I D_{3}$ no trecho descendente do diagrama força-deformação indicam que apenas o pilar MOD75ISF não apresentou ductilidade após a obtenção da deformação última do concreto confinado, apresentando uma ruptura do tipo frágil.

\subsection{Influência da dosagem e cura do CUAR}

\subsubsection{Alto confinamento}

A partir dos resultados obtidos dos diagramas força-deformação dos pilares MOD10TCF, MOD10TSF, MOD10ICF e MOD10ISF, observou-se que foram gerados ao concreto do núcleo confinado, significativos acréscimos de resistência e deformação. A resistência à compressão do concreto confinado apresentou valores de: 418,07 MPa, 354,36 MPa, 333,65 MPa e 281,87 MPa, respectivamente, enquanto que as deformações do concreto confinado foram: $23,21 \%, 23,29 \%, 29,99 \%$ e 23,69\%. Em relação à resistência do concreto não confinado, a resistência do concreto confinado teve incrementos de: $82,26 \%, 75,34 \%, 90,46 \%$ e $70,51 \%$, ao passo que as deformações apresentaram: $433 \%, 474 \%, 647 \%$ e $550 \%$, valores comprovados pelo índice de ductilidade $I D_{2}$.

A figura 5.11 apresenta os diagramas força-deformação dos pilares com alto confinamento, para as dosagens TCF, TSF, ICF e ISF. 
S10

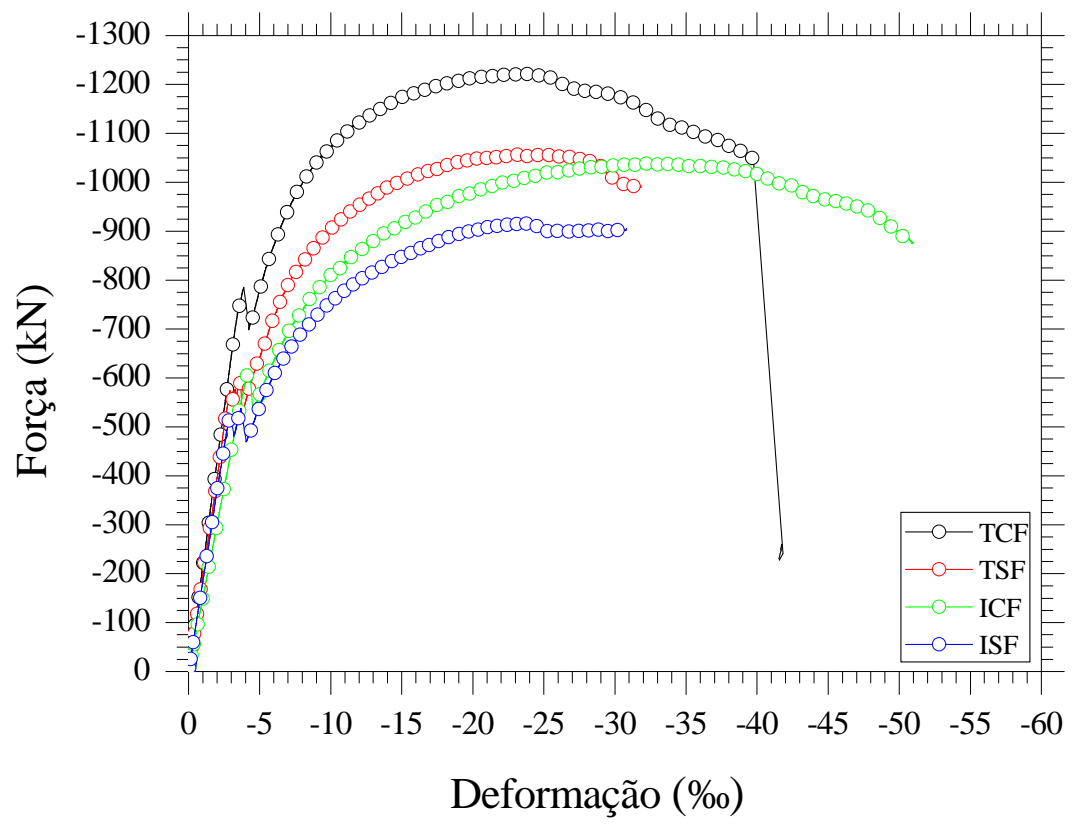

Figura 5.11 - Influência da resistência à compressão do CUAR para a situação de alto confinamento

Em comparação à obtenção da força normal $F_{1}$, no ponto $\left(F_{1}, \varepsilon_{1}\right)$, pode-se notar que as dosagens contendo fibras metálicas apresentaram maiores valores que as dosagens sem adição de fibras metálicas. Os valores obtidos de $F_{1}$ para os pilares MOD10TCF, MOD10TSF, MOD10ICF e MOD10ISF foram de: 785,39 kN, $574,64 \mathrm{kN}$, 618,44 kN e 525,04 kN, respectivamente.

A partir dos valores de $\mathrm{ID}_{3}$ apresentados pelos pilares, pode-se notar que as dosagens com adição de fibras metálicas (TCF e TSF) apresentaram maior ductilidade no trecho descendente do diagrama força-deformação, após a obtenção da resistência e deformação do concreto confinado em relação às dosagens sem adição de fibras metálicas (TSF e ISF), ao passo que o tipo de cura aplicada aos concretos forneceu melhores valores de $I D_{2}$ para as dosagens com cura imersa. 


\subsubsection{Médio confinamento}

A figura 5.12 apresenta os diagramas força-deformação dos pilares MOD20TCF, MOD20TSF, MOD20ICF e MOD20ISF, com médio confinamento, concretados com as dosagens TCF, TSF, ICF e ISF.

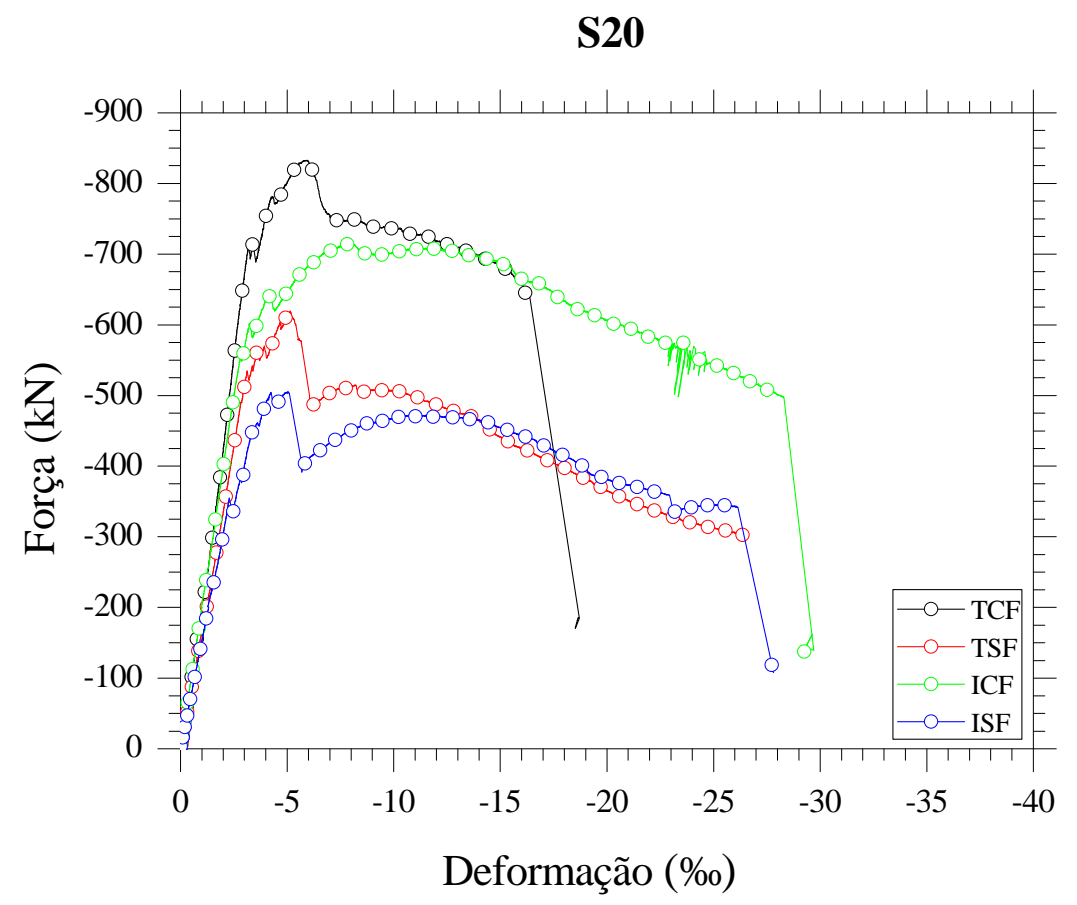

Figura 5.12 - Influência da resistência do CUAR para a situação de médio confinamento

A partir dos resultados obtidos dos diagramas força-deformação dos pilares MOD20TCF, MOD20TSF, MOD20ICF e MOD20ISF, observou-se que apenas os pilares que tinham dosagens com fibras metálicas (MOD20TCF e MOD20ICF) apresentaram acréscimos de resistência à compressão do concreto confinado, apresentando resistência à compressão do concreto confinado nos valores de: 284,79 MPa e 201,70 MPa. Os pilares MOD20TSF e MOD20ISF apresentaram perda de resistência à compressão do concreto do núcleo. Essa perda pode estar relacionada ao modo de fissuração apresentado pelo CUAR sem adição de fibras metálicas, no entanto, as deformações do concreto confinado para os pilares foram de: $5,87 \%$, $8,20 \%, 15,14 \%$ e $11,31 \%$. 
Em comparação à obtenção da força normal $F_{1}$, no ponto $\left(F_{1}, \varepsilon_{1}\right)$, pode-se notar o mesmo comportamento apresentado pelos pilares com alto confinamento, onde os maiores resultados de força normal $F_{1}$ foram atingidos pelos pilares com concreto dosado com adição de fibras metálicas.

A partir dos valores de $I D_{3}$ apresentados pelos pilares MOD20TCF, MOD20TSF, MOD20ICF e MOD20ISF, pode-se notar que as dosagens com adição de fibras metálicas (TCF e TSF) apresentam maiores valores de ductilidade em relação às dosagens sem adição de fibras metálicas (TSF e ISF), ao mesmo tempo que a cura imersa aplicada aos concretos forneceu os maiores valores de $I D_{3}$, para as dosagens estudadas.

\subsubsection{Baixo confinamento}

Em comparação à obtenção da força normal $F_{1}$, no ponto $\left(F_{1}, \varepsilon_{1}\right)$, pode-se notar o mesmo comportamento apresentado pelos pilares com alto e médio confinamento, onde os maiores resultados de força normal $F_{1}$ foram atingidos pelos pilares com concreto dosado com adição de fibras metálicas.

A partir dos valores de $I D_{3}$ apresentados pelos pilares MOD75TCF, MOD75TSF, MOD75ICF e MOD75ISF, pode-se notar que as dosagens com adição de fibras metálicas (TCF e TSF) apresentam maiores valores de ductilidade no trecho descendente do diagrama força-deformação após a obtenção da resistência e deformação última do concreto confinado, em relação às dosagens sem adição de fibras metálicas (TSF e ISF). Mesmo com uma baixa taxa de armadura transversal, os pilares MOD75TCF, MOD75TSF e MOD75ICF apresentaram uma ruptura do tipo dúctil, enquanto que o pilar MOD75ISF apresentou uma ruptura do tipo frágil.

A figura 5.13 apresenta os diagramas força-deformação dos pilares MOD75TCF, MOD75TSF, MOD75ICF e MOD75ISF, com baixo confinamento, concretados com as dosagens TCF, TSF, ICF e ISF. 


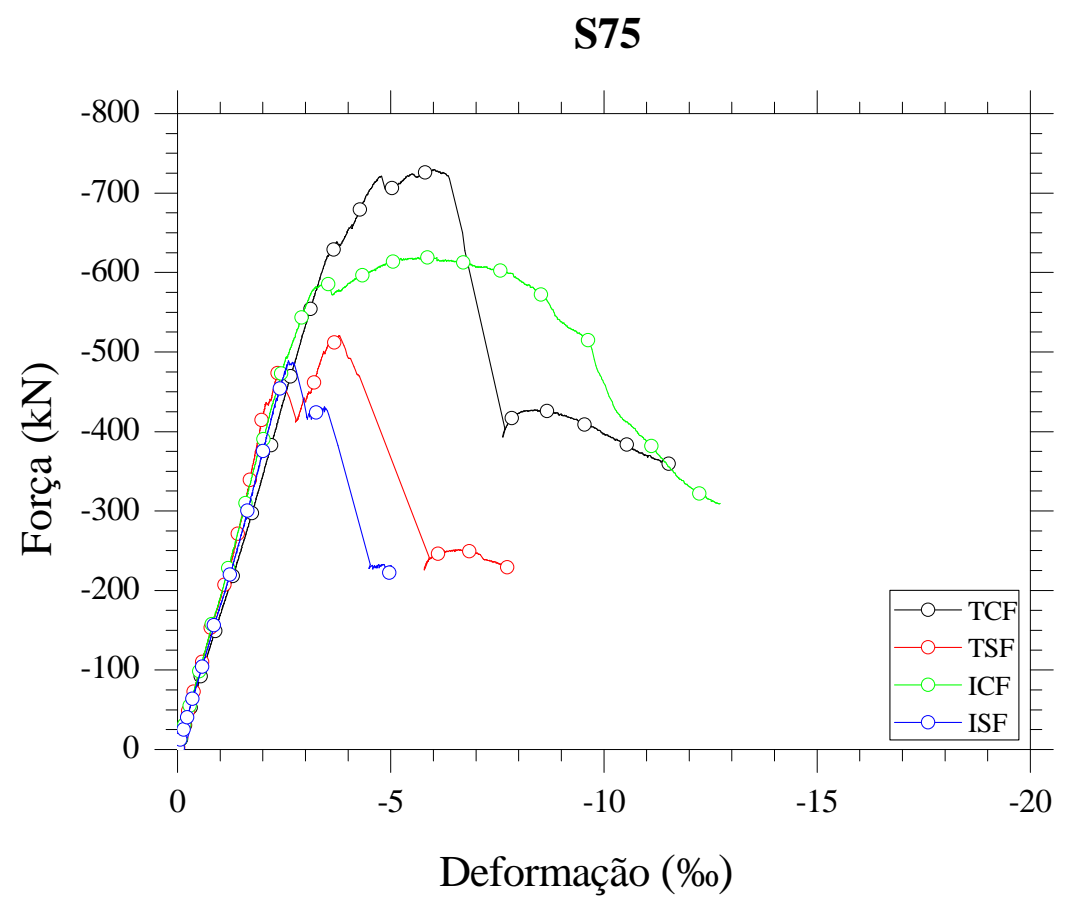

Figura 5.13 - Influência da resistência à compressão do CUAR para situações de baixo confinamento

\subsection{Deformações máximas nas armaduras longitudinais e transversais}

\subsubsection{Considerações iniciais}

Será apresentado o diagrama força-deformação das armaduras longitudinais e transversais para um pilar de cada série estudada na pesquisa, correspondente às situações de alto, médio e baixo confinamento. Os diagramas força-deformação das armaduras longitudinais e transversais de todos os pilares das séries estudadas estão disponíveis no Apêndice B. As deformações máximas nas armaduras longitudinais e transversais, correspondentes aos quatro pontos do diagrama idealizado de força-deformação proposto por GRAYBEAL \& PESSIKI (2000), foram determinadas pelo máximo valor registrado pelos extensômetros elétricos, posicionados nas armaduras, conforme a figura 4.24. 


\subsubsection{Alto confinamento}

A figura 5.14 apresenta os diagramas de força-deformação para as armaduras longitudinais e transversais dos pilares MOD10TCF, MOD10TSF, MOD10ICF e MOD10ISF, com índice de eficiência do confinamento (I.E.C) nos valores de: $23,19 \%, 26,32 \%, 30,36 \%$ e $32,17 \%$.

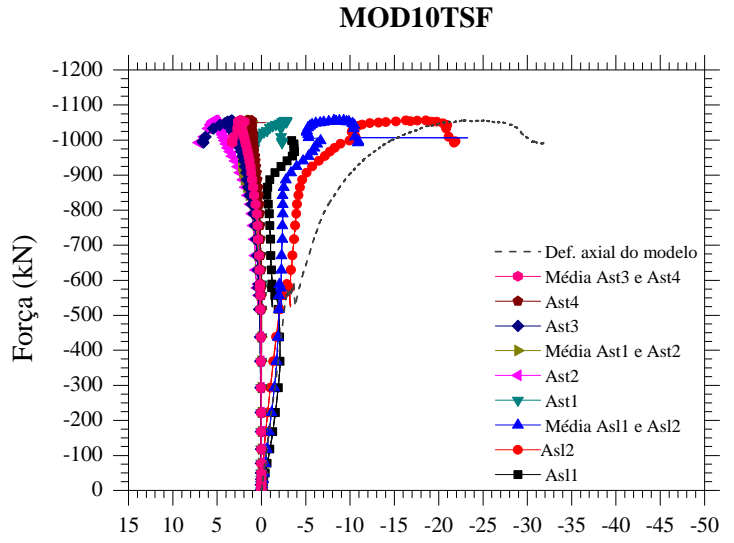

Def. Transversal (\%)

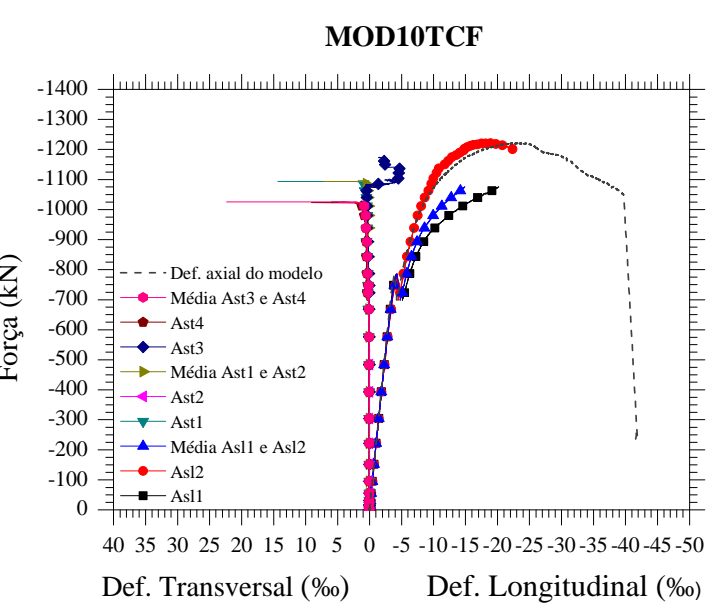

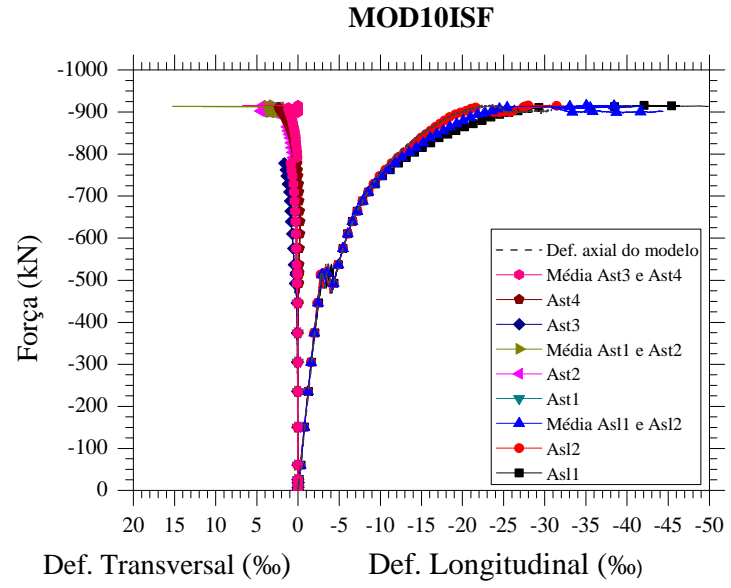

MOD10ICF

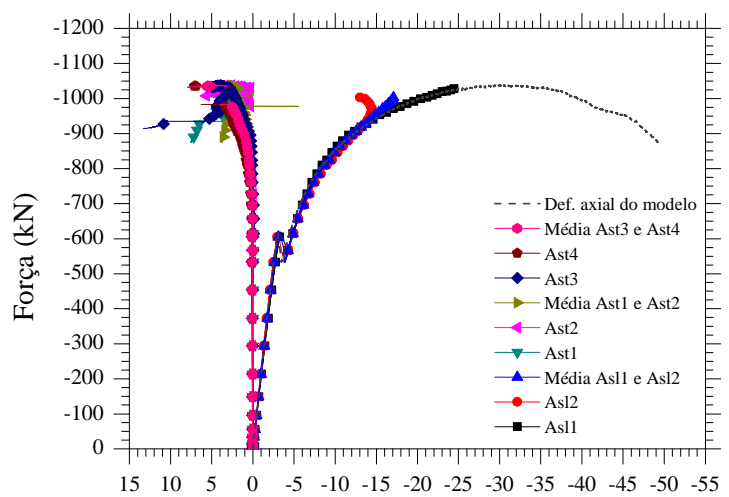

Def. Transversal (\%) Def. Longitudinal (\%)

Figura 5.14 - Pilares com alto confinamento

A tabela 5.13 mostra os valores das deformações máximas nas armaduras longitudinais e transversais, correspondentes aos quatro pontos do diagrama idealizado de força-deformação proposto por GRAYBEAL \& PESSIKI (2000). 
Tabela 5.13 - Deformações máximas nas armaduras longitudinais e transversais

\begin{tabular}{|c|c|c|c|c|c|c|c|}
\hline Pilar & Pontos & $\begin{array}{l}\varepsilon_{\text {Asl }} \\
(\% \circ)\end{array}$ & $\begin{array}{l}\varepsilon_{\text {Asw }} \\
(\% \circ)\end{array}$ & Pilar & Pontos & $\begin{array}{l}\varepsilon_{\text {Asl }} \\
\text { (\%o) }\end{array}$ & $\begin{array}{l}\varepsilon_{\text {Asw }} \\
(\% \circ)\end{array}$ \\
\hline \multirow{4}{*}{ MOD10TCF } & $F_{1}, \varepsilon_{1}$ & $-4,37$ & 0,28 & \multirow{4}{*}{ M0D10TSF } & $F_{1}, \varepsilon_{1}$ & $-2,33$ & 0,24 \\
\hline & $F_{2}, \varepsilon_{2}$ & $-5,11$ & 0,38 & & $F_{2}, \varepsilon_{2}$ & $-3,24$ & 0,39 \\
\hline & $F_{3}, \varepsilon_{3}$ & $-18,41$ & - & & $F_{3}, \varepsilon_{3}$ & $-16,45$ & 5,19 \\
\hline & $F_{4}, \varepsilon_{4}$ & - & - & & $F_{4}, \varepsilon_{4}$ & $-21,72$ & 7,22 \\
\hline \multirow{4}{*}{ MOD10ICF } & $F_{1}, \varepsilon_{1}$ & $-3,37$ & 0,10 & \multirow{4}{*}{ MOD10ISF } & $F_{1}, \varepsilon_{1}$ & $-3,17$ & 0,27 \\
\hline & $F_{2}, \varepsilon_{2}$ & $-3,91$ & 0,08 & & $F_{2}, \varepsilon_{2}$ & $-4,11$ & 0,34 \\
\hline & $F_{3}, \varepsilon_{3}$ & - & 4,46 & & $F_{3}, \varepsilon_{3}$ & $-42,48$ & 3,82 \\
\hline & $F_{4}, \varepsilon_{4}$ & - & 7,51 & & $F_{4}, \varepsilon_{4}$ & $-26,37$ & 4,75 \\
\hline
\end{tabular}

A partir da observação dos gráficos das deformações apresentadas pelas armaduras longitudinais dos pilares e pelos valores registrados pelos extensômetros posicionados nas armaduras, pode-se notar que, quando os pilares atingem a força última $\left(F_{u l t}\right)$ no ponto $\left(F_{3}, \varepsilon_{3}\right)$, as armaduras longitudinais já se encontravam em escoamento.

Comparando as deformações apresentadas pelas armaduras longitudinais e a deformação axial do pilar no ponto $\left(F_{1}, \varepsilon_{1}\right)$, dos diagramas de força-deformação dos pilares, comprova-se a similaridade entre as leituras das deformações registradas, demonstrando que o comportamento da armadura longitudinal é igual ou muito próximo do apresentado pela deformação axial do pilar.

Observando o comportamento das deformações apresentadas pelas armaduras transversais dos pilares MOD10TSF e MOD10ISF, pode-se notar que as armaduras transversais não atingiram seu limite de escoamento, na obtenção da força última $\left(F_{\text {ult }}\right)$ pelos pilares, ocorrida no ponto $\left(F_{3}, \varepsilon_{3}\right)$, consequentemente, 
as pressões laterais aplicadas ao concreto do núcleo foram inferiores à adotada em projeto.

\subsubsection{Médio confinamento}

Os diagramas de força-deformação para as armaduras longitudinais e transversais dos pilares MOD15TCF, MOD15TSF, MOD20ICF e MOD20ISF, com índice de eficiência do confinamento (I.E.C) nos valores de: 15,46\%, 17,54\%, $15,18 \%$ e $16,09 \%$, são apresentados na figura 5.15 .
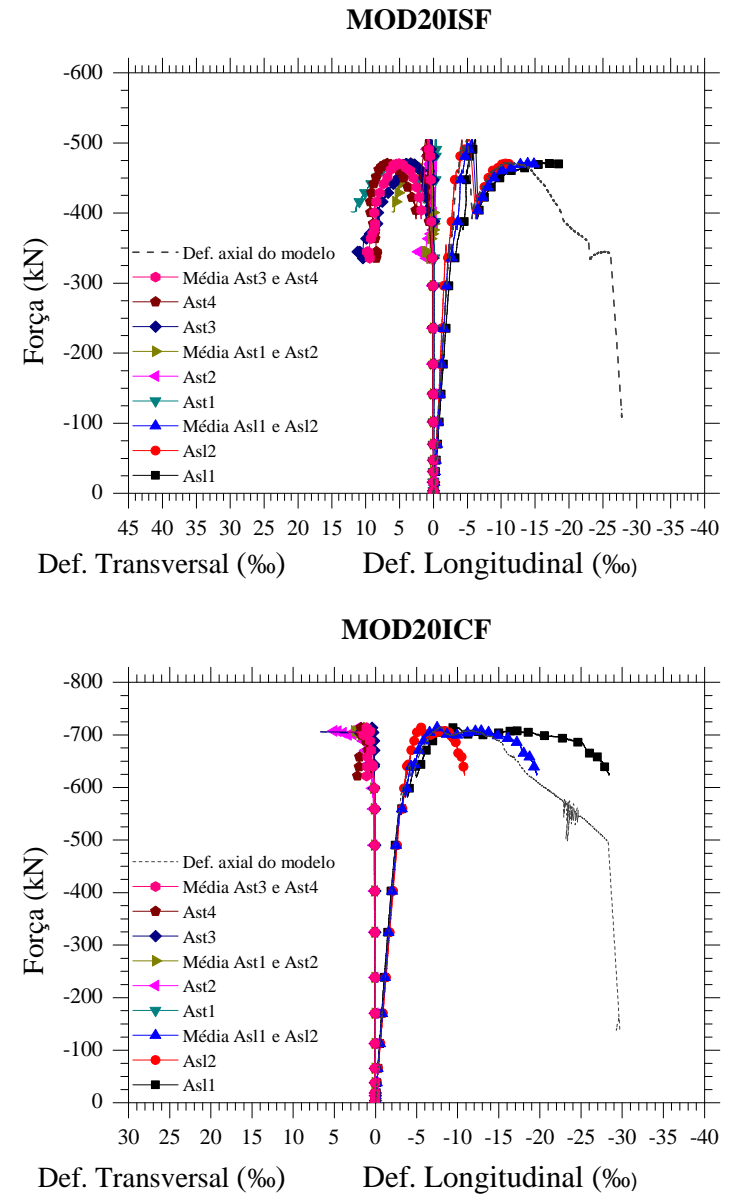

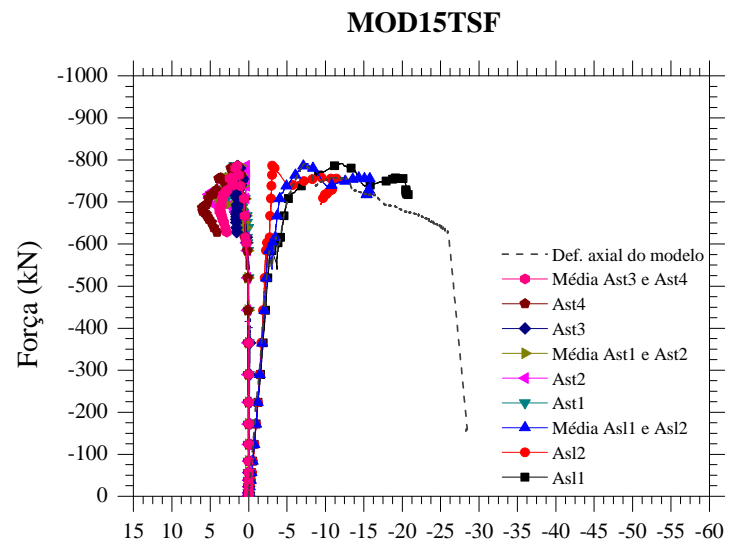

Def. Transversal (\%) Def. Longitudinal (\%)

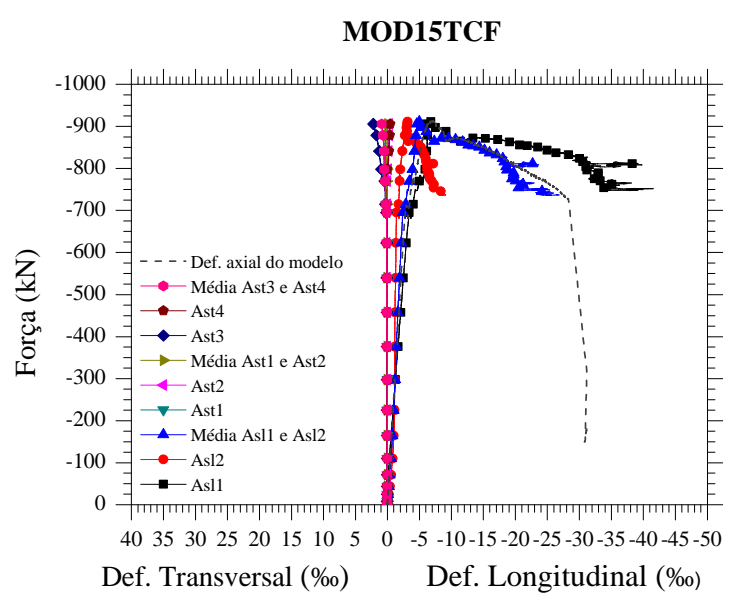

Figura 5.15 - Pilares com médio confinamento

A tabela 5.14 mostra os valores das deformações máximas nas armaduras longitudinais e transversais, correspondentes aos quatro pontos do 
diagrama idealizado de força-deformação proposto por GRAYBEAL \& PESSIKI (2000).

Tabela 5.14- Deformações máximas nas armaduras longitudinais e transversais

\begin{tabular}{|c|c|c|c|c|c|c|c|}
\hline Pilar & Pontos & $\begin{array}{c}\mathcal{E}_{\text {Asl }} \\
(\% \circ)\end{array}$ & $\begin{array}{c}\varepsilon_{\text {Asw }} \\
\text { (\%o) }\end{array}$ & Pilar & Pontos & $\begin{array}{l}\varepsilon_{A s l} \\
(\% o)\end{array}$ & $\begin{array}{c}\mathcal{E}_{\text {Asw }} \\
(\% \mathbf{0})\end{array}$ \\
\hline \multirow{4}{*}{ MOD15TCF } & $F_{1}, \varepsilon_{1}$ & $-3,61$ & 0,14 & \multirow{4}{*}{ MoD20ICF } & $F_{1}, \varepsilon_{1}$ & $-3,60$ & 0,29 \\
\hline & $F_{2}, \varepsilon_{2}$ & $-3,68$ & 0,26 & & $F_{2}, \varepsilon_{2}$ & $-3,91$ & 0,34 \\
\hline & $F_{3}, \varepsilon_{3}$ & $-6,31$ & - & & $F_{3}, \varepsilon_{3}$ & $-9,74$ & 2,24 \\
\hline & $F_{4}, \varepsilon_{4}$ & - & - & & $F_{4}, \varepsilon_{4}$ & - & - \\
\hline \multirow{4}{*}{ MOD15TSF } & $F_{1}, \varepsilon_{1}$ & $-3,00$ & 0,20 & \multirow{4}{*}{ MOD20ISF } & $F_{1}, \varepsilon_{1}$ & $-5,76$ & 0,39 \\
\hline & $F_{2}, \varepsilon_{2}$ & $-3,76$ & 0,32 & & $F_{2}, \varepsilon_{2}$ & $-6,52$ & 2,58 \\
\hline & $F_{3}, \varepsilon_{3}$ & $-12,10$ & 1,94 & & $F_{3}, \varepsilon_{3}$ & $-17,67$ & 6,96 \\
\hline & $F_{4}, \varepsilon_{4}$ & - & 4,07 & & $F_{4}, \varepsilon_{4}$ & - & 11,46 \\
\hline
\end{tabular}

Pode-se notar pelas deformações nas armaduras longitudinais nos gráficos da figura 5.15, e pelos valores registrados dos extensômetros posicionados nas armaduras dos pilares MOD15TSF e MOD20ISF, que as armaduras longitudinais já tinham alcançado seu limite de escoamento antes de atingirem a força última $\left(F_{u l t}\right)$ no ponto $\left(F_{3}, \varepsilon_{3}\right)$. Comparando as deformações apresentadas pelas armaduras longitudinais e a deformação axial do pilar no ponto $\left(F_{1}, \varepsilon_{1}\right)$, dos diagramas de força-deformação dos pilares MOD15TCF, MOD20ICF e MOD15TSF, comprova-se a similaridade entre as leituras das deformações registradas, demonstrando que o comportamento da armadura longitudinal é igual ou muito próximo do apresentado pela deformação axial do pilar. O pilar MOD20ISF apresentou maiores deformações nas armaduras longitudinais em comparação às apresentadas pela deformação axial do modelo. Esse comportamento foi notado a partir de um trecho do diagrama força-deformação, comportamento parecido ao dos pilares MOD10TSF, MOD55TSF e MOD75TSF.

Observando o comportamento das deformações apresentadas pelas armaduras transversais, constata-se que apenas o pilar MOD20ISF atinge $o$ 
limite de escoamento da armadura transversal, na obtenção da força última $\left(F_{u l t}\right)$, ocorrida no ponto $\left(F_{3}, \varepsilon_{3}\right)$, consequentemente, menores pressões laterais foram aplicadas ao concreto do núcleo do que as estipuladas em projeto.

\subsubsection{Baixo confinamento}

A figura 5.16 apresenta os diagramas de força-deformação para as armaduras longitudinais e transversais dos pilares MOD75TCF, MOD75TSF, MOD75ICF e MOD75ISF, com índice de eficiência do confinamento ( $I$.E.C ) nos valores de: $3,09 \%, 3,51 \%, 4,05 \%$ e $4,29 \%$.

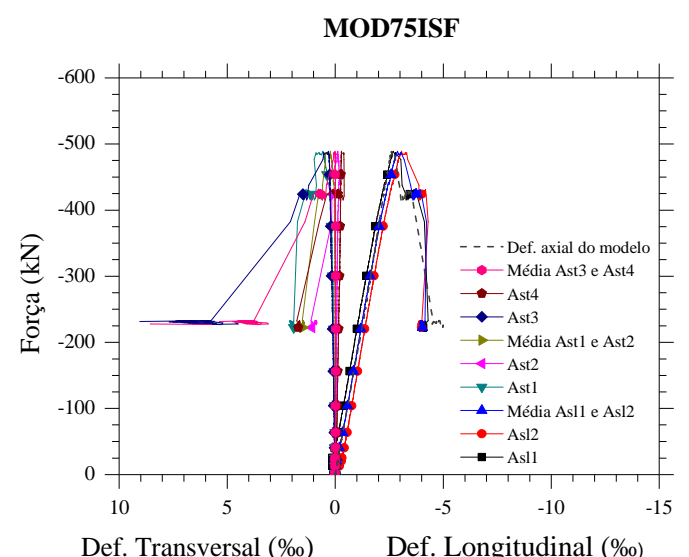

MOD75TSF

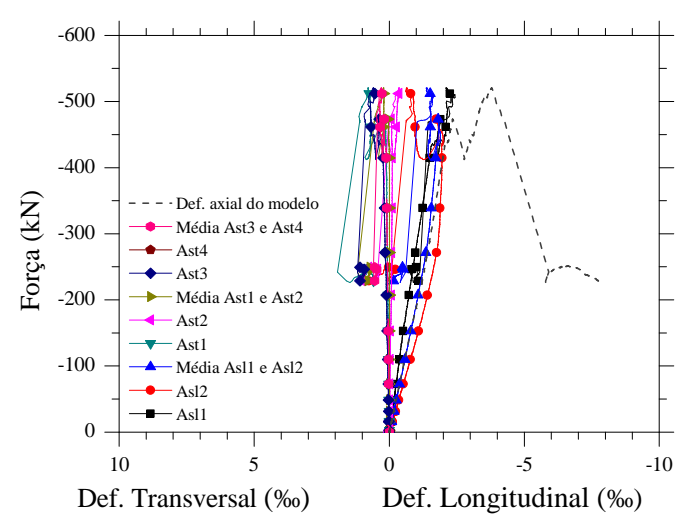

MOD75ICF
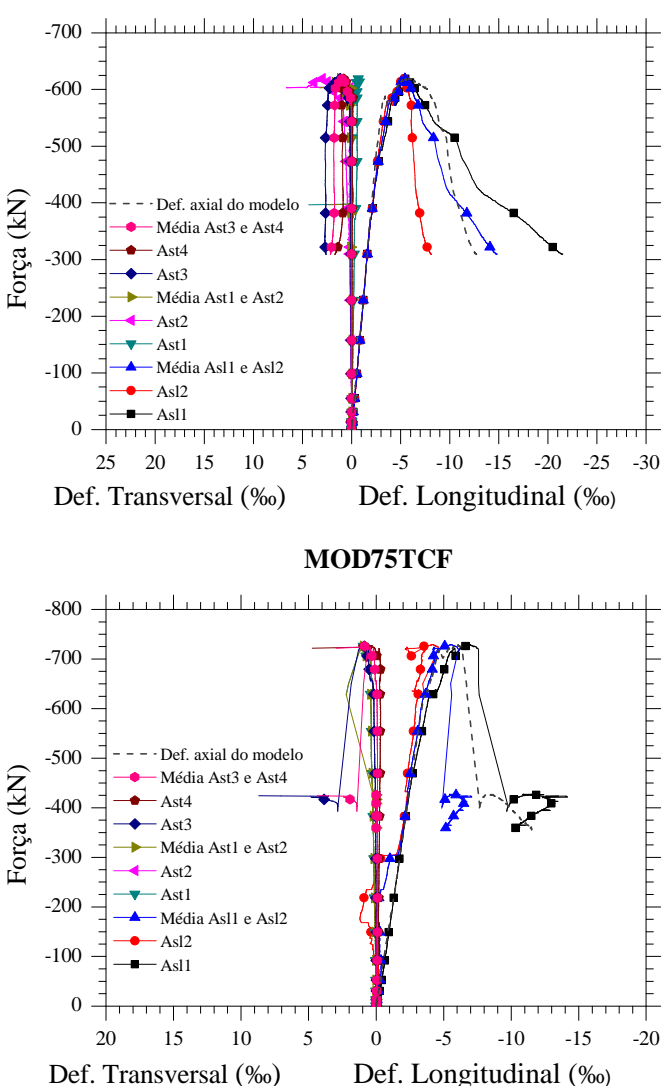

Figura 5.16 - Pilares com baixo confinamento 
A tabela 5.15 mostra os valores das deformações máximas nas armaduras longitudinais e transversais, correspondentes aos quatro pontos do diagrama idealizado de força-deformação proposto por GRAYBEAL \& PESSIKI (2000).

Tabela 5.15 - Deformações máximas nas armaduras longitudinais e transversais

\begin{tabular}{|c|c|c|c|c|c|c|c|}
\hline Pilar & Pontos & $\begin{array}{l}\varepsilon_{\text {Asl }} \\
(\% \circ)\end{array}$ & $\begin{array}{c}\varepsilon_{\text {Asw }} \\
(\% \circ)\end{array}$ & Pilar & Pontos & $\begin{array}{l}\varepsilon_{\text {Asl }} \\
(\%)\end{array}$ & $\begin{array}{l}\varepsilon_{\text {Asw }} \\
(\% \circ)\end{array}$ \\
\hline \multirow{4}{*}{ MOD75TCF } & $F_{1}, \varepsilon_{1}$ & $-5,81$ & 0,62 & \multirow{4}{*}{ M0D75ICF } & $F_{1}, \varepsilon_{1}$ & $-4,34$ & 1,07 \\
\hline & $F_{2}, \varepsilon_{2}$ & $-9,67$ & 2,85 & & $F_{2}, \varepsilon_{2}$ & $-4,49$ & 1,17 \\
\hline & $F_{3}, \varepsilon_{3}$ & $-11,83$ & - & & $F_{3}, \varepsilon_{3}$ & $-5,53$ & 3,03 \\
\hline & $F_{4}, \varepsilon_{4}$ & $-10,27$ & - & & $F_{4}, \varepsilon_{4}$ & $-21,44$ & 2,59 \\
\hline \multirow{4}{*}{ MOD75TSF } & $\overline{F_{1}, \varepsilon_{1}}$ & $-1,90$ & 0,37 & \multirow{4}{*}{ MOD75ISF } & $F_{1}, \varepsilon_{1}$ & $-3,07$ & 0,57 \\
\hline & $F_{2}, \varepsilon_{2}$ & $-0,88$ & 1,45 & & $F_{2}, \varepsilon_{2}$ & $-4,13$ & 5,21 \\
\hline & $F_{3}, \varepsilon_{3}$ & $-0,99$ & 1,02 & & $F_{3}, \varepsilon_{3}$ & $-4,02$ & 5,79 \\
\hline & $F_{4}, \varepsilon_{4}$ & $-1,21$ & 1,14 & & $F_{4}, \varepsilon_{4}$ & $-4,07$ & 1,92 \\
\hline
\end{tabular}

Pode-se notar, pelas deformações apresentadas nas armaduras longitudinais do pilar MOD75TCF, que altas deformações foram registradas pelos extensômetros posicionados nas armaduras, dando indícios que as armaduras atingiram seu limite de escoamento. Segundo BAE et al. (2005), quando a relação, $L / \phi_{A s l} \leq 4$, o comportamento do aço comprimido é similar ao seu comportamento em ensaio de tração, sendo atingida sua tensão de escoamento e grandes deformações elásticas, sendo $L$ o espaçamento entre os estribos e $\phi_{\text {Asl }}$, o diâmetro da barra da armadura longitudinal. Os autores alertam que relações $L / \phi_{\text {Asl }}>6$ devem ser evitadas para elementos estruturais que necessitam de ductilidade, pois nesta relação mudam-se as tensões e deformações elásticas alcançadas no aço da armadura, devido à ocorrência do fenômeno da flambagem. Por esse motivo, após a realização dos ensaios e constatação do fenômeno da flambagem nos pilares estudados, decidiu-se considerar na avaliação da capacidade resistente dos pilares o efeito da flambagem, desse modo, 0 comportamento do aço de alta resistência utilizado para compor a armadura longitudinal foi simulado com as relações $L / \phi_{A s l}$, utilizadas na pesquisa, com a utilização de um programa de elementos finitos. 
Observando o comportamento das deformações apresentadas pelas armaduras transversais dos pilares, pode-se notar que as armaduras transversais não atingiram seu limite de escoamento, na obtenção da força última $\left(F_{\text {ult }}\right)$ pelos pilares. 


\section{Comparações com previsões teóricas}

\subsection{Considerações iniciais}

A partir dos resultados experimentais obtidos e baseado no diagrama de força-deformação idealizado, para pilares curtos de concreto armado confinados por armadura transversal em forma de espiral contínua, proposto por GRAYBEAL \& PESSIKI (2000), serão investigados neste capítulo os seguintes parâmetros:

I. Comparativo entre as forças normais teóricas e as forças normais experimentais no ponto $\left(F_{1}, \varepsilon_{1}\right)$, considerando como seção resistente do pilar a seção bruta de concreto e o núcleo de concreto confinado;

II. Estimativa da força normal no ponto $\left(F_{3}, \varepsilon_{3}\right)$, com base nas resistências à compressão do concreto confinado pelos modelos de previsões teóricos de confinamento com aço e comparação com as forças experimentais;

III. Comparação entre os resultados experimentais de deformações últimas do concreto confinado com as deformações últimas do concreto confinado dadas pelos modelos teóricos de confinamento.

\subsubsection{Consideração da flambagem das armaduras longitudinais na capacidade resistente dos pilares}

Após a constatação da ocorrência da flambagem das armaduras longitudinais em todos os pilares estudados, posterior à realização dos ensaios de compressão centrada, decidiu-se considerar esses efeitos na avaliação da capacidade resistente dos pilares estudados. Desse modo, o comportamento do aço de alta resistência utilizado para compor a armadura longitudinal foi simulado em programa de elementos finitos para as relações de espaçamento/diâmetro da armadura longitudinal $\left(L / \phi_{\text {Asl }}\right)$ utilizadas na pesquisa. 
Segundo BAE et al. (2005), quando a relação espaçamento da armadura transversal/diâmetro da armadura longitudinal for menor ou igual a quatro $\left(L / \phi_{\text {Asl }} \leq 4\right)$, o comportamento do aço comprimido é igual ao apresentado em ensaio de tração, atingindo a tensão de escoamento e grandes deformações elásticas, no entanto, quando esta relação apresenta valores superiores, devido à ocorrência do fenômeno da flambagem, as tensões e deformações elásticas correspondentes ao limite de escoamento do aço não são alcançadas. A figura 6.1 ilustra o comportamento dos diagramas tensão-deformação do aço da armadura longitudinal em função da relação L/d.

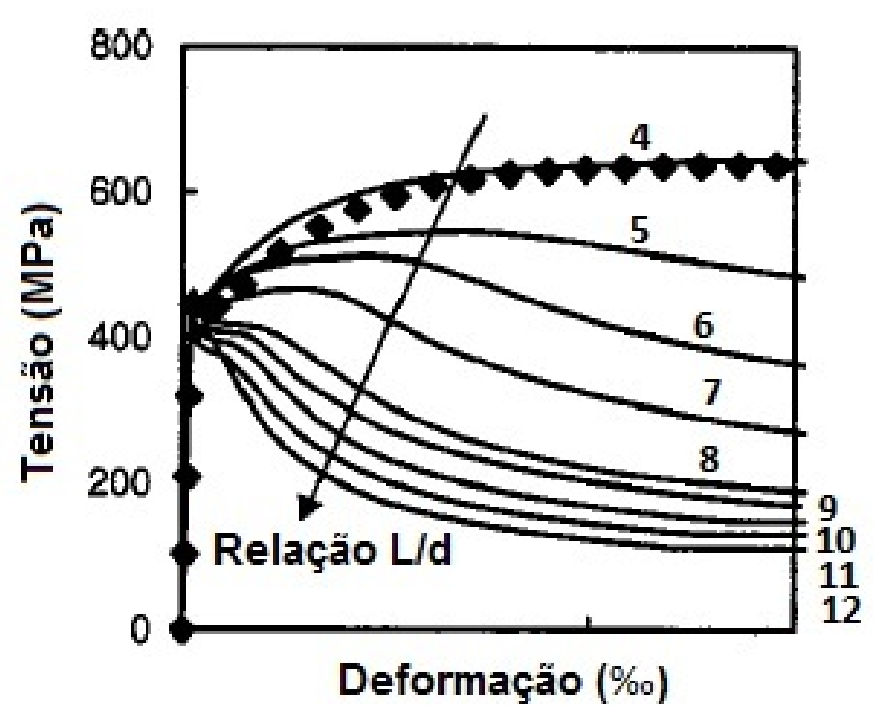

Figura 6.1 - Influência da relação L/d no comportamento do diagrama tensão-deformação do aço da armadura longitudinal (BAE et al., 2005)

\subsubsection{Simulação numérica da flambagem}

Para a consideração dos efeitos da flambagem na capacidade resistente dos pilares, foi realizada uma simulação numérica utilizando o programa ABAQUS, versão CAE-6.13-2, baseado no método dos elementos finitos. A simulação numérica desse fenômeno consistiu na aplicação de um deslocamento lateral muito pequeno no centro do vão (comprimento da barra), para simular uma instabilidade lateral, semelhante ao ocorrido no fenômeno da flambagem. 
Foram utilizados os seguintes parâmetros na simulação numérica:

I. Elemento finito de viga (B32), com aproximação quadrática;

II. Malha formada por dez elementos, apresentando 21 nós;

III. Restrição dos deslocamentos nas três direções na base (condições de contorno);

IV. Restrição dos deslocamentos em duas direções no topo (condições de contorno), livre apenas na direção da aplicação do deslocamento;

V. Fixação da aplicação de deslocamento no topo em 0,5mm;

VI. Aplicação de um deslocamento no centro do vão (comprimento da barra) no valor de $0,005 \mathrm{~mm}$, para simular o efeito da instabilidade lateral;

VII. Propriedades do aço iguais às obtidas no ensaio experimental.

Os passos de carga aplicados na análise foram, respectivamente:

I. $1^{\circ}$ passo de carga: aplicação do deslocamento lateral $0,005 \mathrm{~mm}$ no centro da barra;

II. $\quad 2^{\circ}$ passo de carga: aplicação no topo de um deslocamento inicial no valor de $0,005 \mathrm{~mm}$;

III. $3^{\circ}$ passo de carga: definido automaticamente pelo programa, com as seguintes limitações: passo máximo de $3 \%$ e passo mínimo de $0,005 \%$ do deslocamento fixado para o topo $(0,5 \mathrm{~mm})$.

A figura 6.2 apresenta os resultados dos diagramas tensão-deformação obtidos pela simulação numérica para o comportamento da armadura longitudinal em função dos espaçamentos utilizados na pesquisa e o resultado do ensaio de tração experimental do aço da armadura longitudinal. 


\section{Simulação numérica}

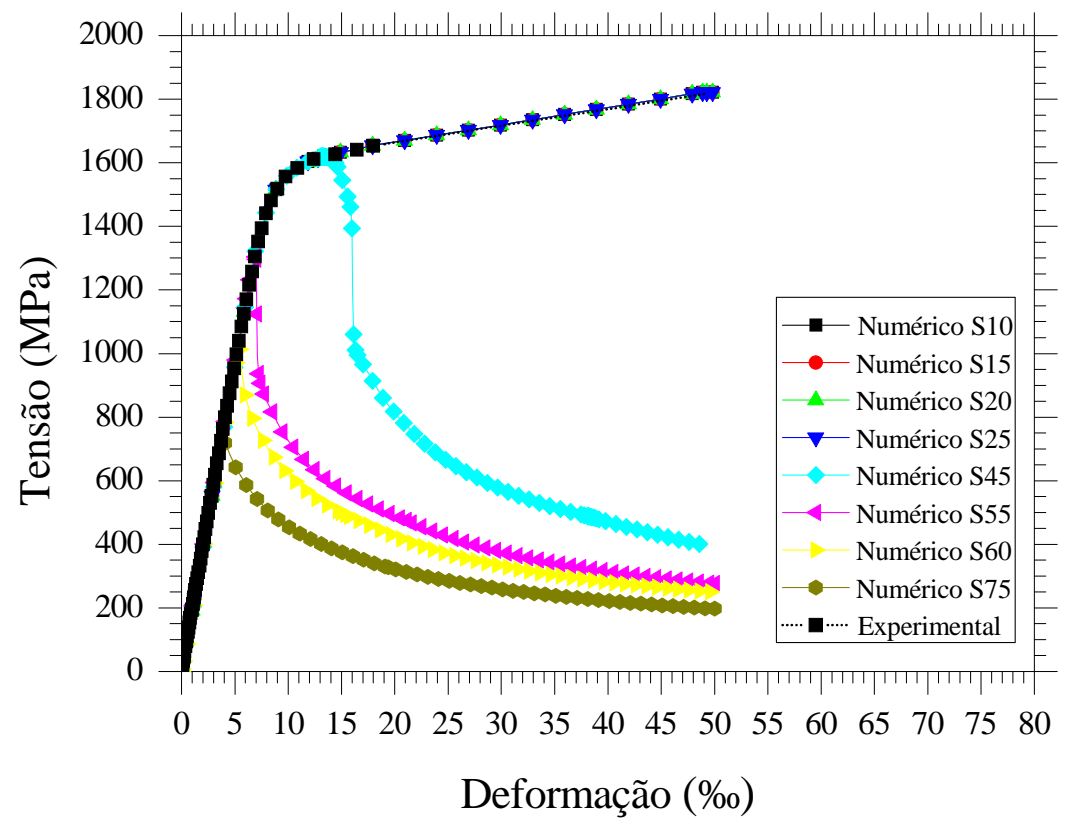

Figura 6.2 - Diagramas tensão-deformação para o aço da armadura longitudinal para os espaçamentos da armadura transversal utilizados na pesquisa

Com base nos resultados obtidos pela simulação numérica, foram determinados os seguintes polinômios, em função da deformação do concreto para a representação do comportamento do aço da armadura longitudinal, em função dos espaçamentos utilizados na pesquisa:

- Polinômios para os espaçamentos S10/S15/S20/S25:

$$
\begin{gathered}
\left(\varepsilon_{c} \leq 10,375\right) \\
\sigma_{A s l, \varepsilon_{c}}=-1,1922 \cdot \varepsilon_{c}{ }^{3}+10,332 \cdot \varepsilon_{c}{ }^{2}+173,28 \cdot \varepsilon_{c} \\
R^{2}=0,999 \\
\left(\varepsilon_{c}>10,375\right) \\
\sigma_{A s l, \varepsilon_{C}}=6,1787 \cdot \varepsilon_{c}+1513 \\
R^{2}=1,000
\end{gathered}
$$


- Polinômios para os espaçamentos S45:

$$
\begin{gathered}
\left(\varepsilon_{c} \leq 13,098\right) \\
\sigma_{A s l, \varepsilon_{c}}=-0,5996 \cdot \varepsilon_{c}{ }^{3}+2,0582 \cdot \varepsilon_{c}{ }^{2}+198,56 \cdot \varepsilon_{c} \\
R^{2}=0,998 \\
\left(\varepsilon_{c}>13,098\right) \\
\sigma_{A s l, \varepsilon_{c}}=31253 \cdot \varepsilon_{c}{ }^{-1,15} \\
R^{2}=0,976
\end{gathered}
$$

- Polinômios para os espaçamentos S55:

$$
\begin{gathered}
\left(\varepsilon_{c} \leq 6,9916\right) \\
\sigma_{A s l, \varepsilon_{c}}=-0,7782 \cdot \varepsilon_{c}^{3}+6,4067 \cdot \varepsilon_{c}^{2}+180,89 \cdot \varepsilon_{c} \\
R^{2}=0,999 \\
\left(\varepsilon_{c}>6,9916\right) \\
\sigma_{A s l, \varepsilon_{c}}=3418,2 \cdot \varepsilon_{c}^{-0,648} \\
R^{2}=0,985
\end{gathered}
$$


- Polinômios para os espaçamentos S60:

$$
\begin{gathered}
\left(\varepsilon_{c} \leq 5,401567\right) \\
\sigma_{A s l, \varepsilon_{C}}=190,2 \cdot \varepsilon_{c}+1,2512 \\
R^{2}=0,999 \\
\left(\varepsilon_{c}>5,401567\right) \\
\sigma_{A s l, \varepsilon_{C}}=2444,2 \cdot \varepsilon_{c}^{-0,586} \\
R^{2}=0,998
\end{gathered}
$$

- Polinômios para os espaçamentos S75:

$$
\begin{gathered}
\left(\varepsilon_{c} \leq 4,089067\right) \\
\sigma_{A s l, \varepsilon_{C}}=184,47 \cdot \varepsilon_{c}+4,358 \\
R^{2}=0,998 \\
\left(\varepsilon_{c}>4,089067\right) \\
\sigma_{A s l, \varepsilon_{C}}=1513,4 \cdot \varepsilon_{3}^{-0,519} \\
R^{2}=0,999
\end{gathered}
$$




\subsection{Estimativa da força normal teórica $\left(F_{1, t e o}\right)$ no ponto $\left(F_{1}, \varepsilon_{1}\right)$, para as séries estudadas}

\subsubsection{Considerações iniciais}

Segundo GUO (2014), a força normal última $\left(F_{u t}\right)$, com concreto e aço atingindo suas resistências máximas, em pilares curtos submetidos à compressão simples é obtida pela equação:

$$
F_{u l t}=A_{c} \cdot f_{c}+A_{A s l} \cdot f_{y}
$$

onde:

$F_{u l t}$ - Força normal última;

$A_{c}$ - Área da seção de concreto;

$f_{c}$ - Resistência à compressão do concreto;

$A_{A s l}$ - Área total de armadura longitudinal na seção;

$f_{y}$ - Tensão de escoamento do aço da armadura longitudinal.

De acordo com o autor citado, quando aços de alta resistência são utilizados em pilares de concreto armado submetidos a esforços de compressão axial, a tensão de escoamento do aço é maior que a deformação axial do concreto, referente ao pico máximo de tensão, $\left(\varepsilon_{y}>\varepsilon_{c}\right)$, a força normal atuante na seção transversal do pilar é diferente da apresentada pela equação 6.1 , sendo recomendada para este caso a seguinte expressão:

$$
F_{\varepsilon_{c}}=A_{c} \cdot f_{c}+\varepsilon_{c} \cdot E_{s} \cdot A_{A s l}
$$

onde:

$F_{\varepsilon_{C}}$ - Força normal no momento que é atingida a deformação do concreto; 
$A_{c}$ - Área da seção de concreto;

$f_{c}$ - Resistência à compressão do concreto;

$\varepsilon_{c}$ - Deformação do concreto, tomada como a deformação registrada na obtenção da máxima tensão de compressão;

$A_{A s l}$ - Área total de armadura longitudinal;

$E_{S}$ - Módulo de elasticidade do aço.

Com base na formulação da equação 6.2 , foram escritas as equações 6.3 e 6.4, alusivas à consideração da força teórica atuante na seção ser: a formada pela seção íntegra de concreto ou pelo núcleo de concreto confinado, definido pelos eixos centrais da armadura transversal, segundo as expressões:

$$
\begin{gathered}
F_{1, \text { teo }, A_{c}}=f_{c m, \text { série }} \cdot A_{c}+A_{A s l} \cdot \sigma_{\text {Asl, } \varepsilon_{C, \text { série }}} \\
F_{1, \text { teo, } A_{\text {cnuc }}}=f_{c m, \text { série }} \cdot A_{c \text { nuc }}+A_{A s l} \cdot \sigma_{A s l, \varepsilon_{C, \text { série }}}
\end{gathered}
$$

onde:

$F_{1, \text { teo, } A c}$ - Força normal no ponto $\left(F_{1}, \varepsilon_{1}\right)$, considerando a área bruta da seção de concreto como resistente;

$F_{1, \text { teo, } \text { Аспис }}$ - Força normal no ponto $\left(F_{1}, \varepsilon_{1}\right)$, considerando a área do núcleo de concreto como resistente;

$A_{c}$ - Área da seção de concreto;

$A_{\text {cnuc }}$ - Área da seção de concreto do núcleo confinado;

$f_{c m, \text { série }}$ - Resistência média à compressão do concreto para a série;

$A_{A s l}$ - Área total de armadura longitudinal;

$\sigma_{A s l, \varepsilon_{c, \text { série }}}$ - Tensão na armadura longitudinal referente à deformação de compressão do concreto da série. 


\subsubsection{Determinação de $\left(F_{1, t e o}\right)$}

Para a avaliação da força normal $\left(F_{1}\right)$, foram utilizados para a determinação da parcela contribuinte da armadura longitudinal os polinômios determinados a partir dos diagramas tensão-deformação, obtidos pela simulação numérica do comportamento da armadura longitudinal, uma vez que os efeitos da flambagem das armaduras longitudinais são considerados na pesquisa. As resistências à compressão e as deformações dos concretos foram tomadas conforme as tabelas 4.9 e 4.10 . A tabela 6.1 apresentam os resultados dos comparativos entre as forças experimentais e teóricas para as séries TCF, TSF, ICF e ISF.

Tabela 6.1 - Estimativas de $F_{1}$ teórica para as séries estudadas

\begin{tabular}{|c|c|c|c|c|c|}
\hline \multirow[b]{2}{*}{ Pilar/Série } & \multirow{2}{*}{$\begin{array}{c}\text { Exp. } \\
F_{1} \\
(\mathrm{kN})\end{array}$} & \multicolumn{2}{|c|}{ Teórico } & \multirow[b]{2}{*}{$\frac{F_{1, \text { teo }, A c}}{F_{1}}$} & \multirow[b]{2}{*}{$\frac{F_{1, \text { teo, }, \text { Аспис }}}{F_{1}}$} \\
\hline & & $\begin{array}{l}F_{1, \text { teo, } A_{c}} \\
(\mathrm{kN})\end{array}$ & $\begin{array}{c}F_{1, \text { teo, } A_{\text {cnuc }}} \\
(\mathrm{kN})\end{array}$ & & \\
\hline MOD10TCF & 785,39 & 1039,51 & 660,57 & 1,32 & 0,84 \\
\hline MOD15TCF & 712,21 & 1039,51 & 660,57 & 1,46 & 0,93 \\
\hline MOD20TCF & 711,37 & 1039,51 & 660,57 & 1,46 & 0,93 \\
\hline MOD45TCF & 703,36 & 1039,88 & 660,94 & 1,48 & 0,94 \\
\hline MOD55TCF & 739,61 & 1048,79 & 669,86 & 1,42 & 0,91 \\
\hline \multirow[t]{2}{*}{ MOD75TCF } & 721,54 & 1031,97 & 653,03 & 1,43 & 0,91 \\
\hline & & & Média & 1,44 & 0,92 \\
\hline MOD10TSF & 574,64 & 923,34 & 589,49 & 1,61 & 1,03 \\
\hline MOD15TSF & 584,71 & 923,34 & 589,49 & 1,58 & 1,01 \\
\hline MOD20TSF & 534,50 & 923,34 & 588,49 & 1,73 & 1,10 \\
\hline MOD45TSF & 508,56 & 924,34 & 590,49 & 1,82 & 1,16 \\
\hline MOD55TSF & 554,80 & 930,76 & 596,91 & 1,68 & 1,08 \\
\hline \multirow[t]{2}{*}{ MOD75TSF } & 473,61 & 916,41 & 582,56 & 1,93 & 1,23 \\
\hline & & & Média & 1,70 & 1,09 \\
\hline MOD10ICF & 618,44 & 816,67 & 527,28 & 1,32 & 0,85 \\
\hline MOD20ICF & 601,88 & 816,67 & 527,28 & 1,36 & 0,88 \\
\hline MOD25ICF & 623,93 & 816,67 & 527,28 & 1,31 & 0,85 \\
\hline MOD55ICF & 590,97 & 823,80 & 534,40 & 1,39 & 0,90 \\
\hline MOD60ICF & 554,88 & 813,24 & 523,85 & 1,47 & 0,94 \\
\hline \multirow[t]{2}{*}{ MOD75ICF } & 588,45 & 809,87 & 520,47 & 1,38 & 0,88 \\
\hline & & & Média & 1,37 & 0,88 \\
\hline MOD10ISF & 525,04 & 765,59 & 492,50 & 1,46 & 0,94 \\
\hline MOD20ISF & 504,29 & 765,59 & 492,50 & 1,52 & 0,98 \\
\hline MOD25ISF & 562,58 & 765,59 & 492,50 & 1,36 & 0,88 \\
\hline MOD60ISF & 447,07 & 762,78 & 489,69 & 1,71 & 1,10 \\
\hline \multirow[t]{3}{*}{ MOD75ISF } & 489,10 & 759,76 & 486,67 & 1,55 & 1,00 \\
\hline & & & Média & 1,52 & 0,98 \\
\hline & & & $\begin{array}{l}\text { Média } \\
\text { Geral }\end{array}$ & 1,51 & 0,97 \\
\hline
\end{tabular}


De modo geral, todas as forças $\left(F_{1, t e o}\right)$, levando em consideração a seção bruta de concreto como seção resistente $\left(F_{1, t e o, A_{C}}\right)$, foram muito superiores às forças experimentais, superestimando as capacidades de força normal atuante no ponto $\left(F_{1}, \varepsilon_{1}\right)$, para as séries nos valores de: $39 \%, 72 \%, 37 \%$ e $51 \%$. No entanto, quando a seção resistente é considerada como a formada pelo núcleo de concreto confinado $\left(F_{1, \text { teo, Аспис }}\right)$, formada pelos eixos centrais da armadura transversal, as forças $\left(F_{1, \text { teo }}\right)$ para as séries TCF, ICF e ISF, foram inferiores às forças experimentais, subestimando as capacidades de força normal atuante no ponto $\left(F_{1}, \varepsilon_{1}\right)$, nos valores de: $8 \%, 12 \%$ e $2 \%$, respectivamente. A série TSF apresentou para esta mesma análise o valor de $9 \%$, superestimando os valores de $\left(F_{1, t e o}\right)$.

Com base na média geral apresentada entre as relações das forças teóricas $\left(F_{1, \text { teo }}\right)$ considerando a seção bruta de concreto $\left(F_{1, \text { teo, } A_{C}}\right)$ e a seção do núcleo de concreto $\left(F_{1, \text { teo, } \text { Аспис }}\right)$, como as resistentes, com as forças experimentais apresentadas pelas séries estudadas, pode-se concluir pelo valor da média geral que a consideração da seção resistente como sendo a formada pelo núcleo de concreto para pilares de concreto de ultra alta resistência, resulta a favor da segurança, semelhante às constatações realizadas por CUSSON \& PAULTRE (1993) e QUEIROGA (1999), de que a seção transversal resistente em pilares com concreto de alta resistência é a formada pelo núcleo de concreto confinado. 


\subsection{Estimativas para $F_{3}, \varepsilon_{3}$}

\subsubsection{Considerações iniciais}

De acordo com GRAYBEAL \& PESSIKI (2000), a resistência à compressão do concreto confinado é dada pela equação:

$$
f_{c c}=\frac{F_{3}-F_{A s l, \varepsilon_{3}}}{A_{c n u c}}
$$

onde:

- $\quad f_{c c}$ - Resistência à compressão do concreto confinado;

- $\quad F_{3}$ - Força normal atuante no ponto $\left(F_{3}, \varepsilon_{3}\right)$;

- $\quad A_{\text {спис }}$ - Área da seção do concreto do núcleo confinado;

- $\quad F_{A s l, \varepsilon_{3}}$ - Força na armadura longitudinal, referente à contribuição da armadura longitudinal na capacidade resistente do pilar, obtida pela multiplicação entre a área da armadura longitudinal e a tensão na armadura longitudinal (referente a deformação a deformação $\varepsilon_{3}$ do diagrama idealizado proposto por GRAYABEAL \& PESSIKI (2000)).

Baseado nos conceitos da equação 6.2 e 6.5, propostas, respectivamente, por GUO (2014) e GRAYBEAL \& PESSIKI (2000), a avaliação da força normal teórica $\left(F_{3, \text { teo }}\right)$, atuante no ponto $\left(F_{3}, \varepsilon_{3}\right)$, pode ser escrita pela expressão:

$$
F_{3, \text { teo }, A_{\text {cnuc }}}=f_{c c, \text { teo }} \cdot A_{\text {cnuc }}+A_{A s l} \cdot \sigma_{A s l, \varepsilon_{3}}
$$

onde:

- $\quad f_{c c, t e o}$ - Resistência à compressão axial do concreto confinado, obtida pelos modelos de previsão teóricos de confinamento; 
- $\sigma_{A s l, \varepsilon_{3}}$ - Tensão na armadura longitudinal correspondente à deformação última do concreto confinado $\left(\varepsilon_{3}\right)$.

A resistência à compressão do concreto confinado foi calculada pela expressão 6.5 , a partir da força normal atuante no ponto $\left(F_{3}, \varepsilon_{3}\right)$ dos diagramas força-deformação dos pilares estudados na pesquisa.

Para a avaliação da força teórica $\left(F_{3, t e o}\right)$, foram utilizados os valores de deformação última do concreto confinado pelos modelos teóricos de confinamento, para a determinação da parcela contribuinte da armadura longitudinal, com base nos diagramas tensão-deformação, obtidos pela simulação numérica, com a ressalva de que para deformações maiores que a deformação de escoamento do aço da armadura longitudinal, foi considerada nesta avaliação a tensão de escoamento do aço, conforme a tabela 4.13. A nomenclatura adotada para descrever os modelos teóricos de confinamento utilizados nas tabelas $6.3,6.5,6,7$ e 6,9 significa: R - Modelo de RICHART et. al. (1929), M - Modelo de MANDER et al. (1988), C\&P - Modelo de CUSSON \& PAULTRE (1995) e R\&S - Modelo de RAZVI \& SAATCIOGLU (2000).

\subsubsection{Série TCF}

A tabela 6.2 mostra os resultados experimentais no ponto $\left(F_{3}, \varepsilon_{3}\right)$, obtidos dos diagramas força-deformação dos pilares da série de: força normal atuante $\left(F_{3}\right)$, deformação do concreto confinado $\left(\varepsilon_{3}\right)$, resistência à compressão do concreto confinado $\left(f_{c c}\right)$ e tensão na armadura longitudinal $\left(\sigma_{A s l, \varepsilon_{3}}\right)$ e a tabela 6.3 , os resultados teóricos, fornecidos pelos modelos de previsão do confinamento com aço para a força normal $F_{3}$. 
Tabela 6.2 - Resultados experimentais série TCF

\begin{tabular}{|c|c|c|c|}
\hline \multicolumn{2}{|c|}{ MOD10TCF } & \multicolumn{2}{|c|}{ MOD15TCF } \\
\hline $\begin{array}{c}F_{3} \\
1221,84(\mathrm{kN}) \\
f_{c c} \\
\mathbf{4 1 8 , 0 7 ( M P a )}\end{array}$ & $\begin{array}{c}\varepsilon_{3} \\
23,21(\%) \\
\sigma_{A s l, \varepsilon_{3}} \\
1656,41(\mathrm{MPa})\end{array}$ & $\begin{array}{c}F_{3} \\
914,34(\mathrm{kN}) \\
f_{c c} \\
308,60(\mathrm{MPa})\end{array}$ & $\begin{array}{c}\varepsilon_{3} \\
6,90(\% \circ) \\
\sigma_{A s l, \varepsilon_{3}} \\
1295,89(\mathrm{MPa})\end{array}$ \\
\hline \multicolumn{2}{|c|}{ MOD20TCF } & \multicolumn{2}{|c|}{ MOD45TCF } \\
\hline $\begin{array}{c}F_{3} \\
832,93(\mathrm{kN}) \\
f_{c c} \\
284,79(\mathrm{MPa})\end{array}$ & $\begin{array}{c}\varepsilon_{3} \\
5,87(\%) \\
\sigma_{A s l, \varepsilon_{3}} \\
1132,03(\mathrm{MPa})\end{array}$ & $\begin{array}{c}F_{3} \\
543,20(\mathrm{kN}) \\
f_{c c} \\
136,23(\mathrm{MPa})\end{array}$ & $\begin{array}{c}\varepsilon_{3} \\
7,83(\%) \\
\sigma_{\text {Asl, } \varepsilon_{3}} \\
1393,07(\mathrm{MPa})\end{array}$ \\
\hline \multicolumn{2}{|c|}{ MOD55TCF } & \multicolumn{2}{|c|}{ MOD75TCF } \\
\hline $\begin{array}{c}F_{3} \\
472,77(\mathrm{kN}) \\
f_{c c} \\
141,43(\mathrm{MPa})\end{array}$ & $\begin{array}{c}\varepsilon_{3} \\
7,71(\%) \\
\sigma_{\text {Asl, } \varepsilon_{3}} \\
909,88(\mathrm{MPa})\end{array}$ & $\begin{array}{c}F_{3} \\
426,76(\mathrm{kN}) \\
f_{c c} \\
151,59(\mathrm{MPa})\end{array}$ & $\begin{array}{c}\varepsilon_{3} \\
8,29(\%) \\
\sigma_{A s l, \varepsilon_{3}} \\
504,92(\mathrm{MPa})\end{array}$ \\
\hline
\end{tabular}

A partir dos resultados, pode-se notar que três pilares da série TCF apresentaram acréscimos de resistência à compressão do concreto do núcleo confinado, sendo estes: MOD10TCF, MOD15TCF e MOD20TCF. Todos os pilares da série apresentaram acréscimos de deformação axial. 
Tabela 6.3 - Previsões de $F_{3}$ para a série TCF

\begin{tabular}{|c|c|c|c|c|c|c|c|c|c|}
\hline Pilar & $\begin{array}{c}\text { Mod. } \\
\text { Teóricos }\end{array}$ & $\begin{array}{c}f_{l} \\
\text { (MPa) }\end{array}$ & $k_{e}$ & $\begin{array}{c}f_{l e} \\
\text { (MPa) }\end{array}$ & $\begin{array}{l}f_{c c, \text { teo }} \\
\text { (MPa) }\end{array}$ & $\begin{array}{c}\varepsilon_{3} \\
(\%)\end{array}$ & $\begin{array}{c}\sigma_{A s l, \varepsilon_{3}} \\
\text { (MPa) }\end{array}$ & $\begin{array}{l}F_{3, \text { teo }} \\
(\mathbf{k N})\end{array}$ & $\frac{F_{3, \text { teo }}}{F_{3, \exp }}$ \\
\hline \multicolumn{10}{|l|}{ MOD10TCF } \\
\hline & $\mathrm{R}$ & 53,18 & 1,00 & 53,18 & 447,43 & 25,03 & 1554,51 & 1270,51 & 1,04 \\
\hline & $\mathrm{M}$ & 53,18 & 1,00 & 53,18 & 477,43 & 27,87 & 1554,51 & 1337,99 & 1,09 \\
\hline & C\&P & 53,18 & 1,00 & 53,18 & 402,53 & 21,85 & 1554,51 & 1169,54 & 0,96 \\
\hline & R\&S & 53,18 & 1,00 & 53,18 & 410,71 & 7,35 & 1358,16 & 1154,56 & 0,94 \\
\hline & & & & & & & Média & 1233,15 & 1,01 \\
\hline \multicolumn{10}{|l|}{ MOD15TCF } \\
\hline & $\mathrm{R}$ & 35,45 & 1,00 & 35,45 & 374,74 & 18,13 & 1554,41 & 1107,05 & 1,21 \\
\hline & $\mathrm{M}$ & 35,45 & 0,97 & 34,39 & 408,78 & 21,36 & 1554,41 & 1183,59 & 1,29 \\
\hline & C\&P & 35,45 & 0,97 & 34,39 & 356,99 & 12,69 & 1554,51 & 1067,13 & 1,16 \\
\hline & R\&S & 35,45 & 0,97 & 34,39 & 355,66 & 6,44 & 1225,69 & 1008,24 & 1,10 \\
\hline & & & & & & & Média & 1091,50 & 1,19 \\
\hline \multicolumn{10}{|l|}{ MOD20TCF } \\
\hline & $\mathrm{R}$ & 26,59 & 1,00 & 26,59 & 338,40 & 14,69 & 1554,41 & 1025,32 & 1,23 \\
\hline & $\mathrm{M}$ & 26,59 & 0,93 & 24,73 & 367,27 & 17,42 & 1554,41 & 1090,23 & 1,31 \\
\hline & C\&P & 26,59 & 0,93 & 24,73 & 330,69 & 9,11 & 1534,78 & 1004,63 & 1,21 \\
\hline & R\&S & 26,59 & 0,93 & 24,73 & 325,42 & 5,94 & 1143,63 & 926,28 & 1,11 \\
\hline & & & & & & & Média & 1011,62 & 1,21 \\
\hline \multicolumn{10}{|l|}{ MOD45TCF } \\
\hline & $\mathrm{R}$ & 11,82 & 1,00 & 11,82 & 277,83 & 8,94 & 1511,62 & 881,82 & 1,62 \\
\hline & $\mathrm{M}$ & 11,82 & 0,68 & 8,04 & 280,81 & 9,23 & 1536,31 & 892,72 & 1,64 \\
\hline & C\&P & 11,82 & 0,68 & 8,04 & 275,50 & 5,05 & 978,77 & 786,00 & 1,44 \\
\hline & R\&S & 11,82 & 0,68 & 8,04 & 267,16 & 4,97 & 964,89 & 764,88 & 1,41 \\
\hline & & & & & & & Média & 831,36 & 1,53 \\
\hline \multicolumn{10}{|l|}{ MOD55TCF } \\
\hline & $\mathrm{R}$ & 9,67 & 1,00 & 9,67 & 269,02 & 8,11 & 880,60 & 754,74 & 1,59 \\
\hline & $\mathrm{M}$ & 9,67 & 0,59 & 5,71 & 266,72 & 7,89 & 896,32 & 752,33 & 1,59 \\
\hline & C\&P & 9,67 & 0,59 & 5,71 & 265,67 & 4,74 & 999,86 & 767,46 & 1,62 \\
\hline & R\&S & 9,67 & 0,59 & 5,71 & 257,81 & 4,82 & 1018,42 & 752,94 & 1,59 \\
\hline & & & & & & & Média & 756,84 & 1,60 \\
\hline \multicolumn{10}{|l|}{ MOD75TCF } \\
\hline & $\mathrm{R}$ & 7,09 & 1,00 & 7,09 & 258,45 & 7,11 & 546,94 & 674,24 & 1,58 \\
\hline & $M$ & 7,09 & 0,39 & 2,77 & 248,03 & 6,12 & 591,14 & 658,31 & 1,54 \\
\hline & C\&P & 7,09 & 0,39 & 2,77 & 251,24 & 4,46 & 696,15 & 683,38 & 1,60 \\
\hline & R\&S & 7,09 & 0,39 & 2,77 & 244,97 & 4,61 & 684,86 & 667,35 & 1,56 \\
\hline & & & & & & & Média & 670,82 & 1,57 \\
\hline
\end{tabular}

De modo geral, pode-se notar que as melhores aproximações teóricas para a resistência do concreto confinado foram obtidas para a situação de alto confinamento, pelos modelos de previsão de confinamento desenvolvidos por CUSSON \& PAULTRE (1995) e RAZVI \& SAATCIOGLU (1999), fornecendo resultados a favor da segurança. Esses modelos também foram os que mais se aproximaram dos resultados experimentais para os pilares com médio confinamento, no entanto, sua consideração resulta contra a segurança. A utilização dos modelos de previsão teóricos para as situações de baixo confinamento superestima a resistência à compressão do concreto confinado, resultando em valores contra a segurança. $A$ 
deformação última do concreto confinado teórica para situações de alto confinamento foi melhor representada pelo modelo de CUSSON \& PAULTRE (1995), a favor da segurança, já para os pilares com médio confinamento o modelo de RAZVI \& SAATCIOGLU (1999) foram os que forneceram resultados a favor da segurança. No caso de pilares com baixo confinamento o modelo de MANDER et al. (1988) foi o que mais se aproximou dos resultados experimentais.

\subsubsection{Série TSF}

A tabela 6.4 mostra os resultados experimentais no ponto $\left(F_{3}, \varepsilon_{3}\right)$, obtidos dos diagramas força-deformação dos pilares da série de: força normal atuante $\left(F_{3}\right)$, deformação do concreto confinado $\left(\varepsilon_{3}\right)$, resistência à compressão do concreto confinado $\left(f_{c c}\right)$ e tensão na armadura longitudinal $\left(\sigma_{A s l, \varepsilon_{3}}\right)$, e a tabela 6.5 , os resultados teóricos, fornecidos pelos modelos de previsão do confinamento com aço para a força normal $F_{3}$.

Tabela 6.4 - Resultados experimentais série TSF

\begin{tabular}{|c|c|c|c|}
\hline \multicolumn{2}{|c|}{ MOD10TSF } & \multicolumn{2}{|c|}{ MOD15TSF } \\
\hline $\begin{array}{c}F_{3} \\
1058,40(\mathrm{kN}) \\
f_{c c} \\
354,36(\mathrm{MPa})\end{array}$ & $\begin{array}{c}\varepsilon_{3} \\
23,29(\% \circ) \\
\sigma_{A s l, \varepsilon_{3}} \\
1656,90(\mathrm{MPa})\end{array}$ & $\begin{array}{c}F_{3} \\
791,88(\mathrm{kN}) \\
f_{c c} \\
249,62(\mathrm{MPa})\end{array}$ & $\begin{array}{c}\varepsilon_{3} \\
7,33(\% \circ) \\
\sigma_{A s l, \varepsilon_{3}} \\
1355,74(\mathrm{MPa})\end{array}$ \\
\hline \multicolumn{2}{|c|}{ MOD20TSF } & \multicolumn{2}{|c|}{ MOD45TSF } \\
\hline $\begin{array}{c}F_{3} \\
514,51(\mathrm{kN}) \\
f_{c c} \\
118,54(\mathrm{MPa})\end{array}$ & $\begin{array}{c}\varepsilon_{3} \\
8,20(\%) \\
\sigma_{A s l, \varepsilon_{3}} \\
1458,28(\mathrm{MPa})\end{array}$ & $\begin{array}{c}F_{3} \\
331,38(\mathrm{kN}) \\
f_{c c} \\
32,04(\mathrm{MPa})\end{array}$ & $\begin{array}{c}\varepsilon_{3} \\
9,10(\% \circ) \\
\sigma_{A s l, \varepsilon_{3}} \\
1525,49(\mathrm{MPa})\end{array}$ \\
\hline \multicolumn{2}{|c|}{ MOD55TSF } & \multicolumn{2}{|c|}{ MOD75TSF } \\
\hline $\begin{array}{c}F_{3} \\
346,80(\mathrm{kN}) \\
f_{c c} \\
86,50(\mathrm{MPa})\end{array}$ & $\begin{array}{c}\varepsilon_{3} \\
7,90(\%) \\
\sigma_{A s l, \varepsilon_{3}} \\
895,64(\mathrm{MPa})\end{array}$ & $\begin{array}{c}F_{3} \\
251,57(\mathrm{kN}) \\
f_{c c} \\
68,86(\mathrm{MPa})\end{array}$ & $\begin{array}{c}\varepsilon_{3} \\
6,59(\%) \\
\sigma_{A s l, \varepsilon_{3}} \\
568,79(\mathrm{MPa})\end{array}$ \\
\hline
\end{tabular}

A partir dos resultados, pode-se notar que dois pilares da série TSF apresentaram acréscimos de resistência à compressão do concreto do núcleo 
confinado, sendo estes: MOD10TSF e MOD15TSF. Todos os pilares da série apresentaram acréscimos de deformação axial.

Tabela 6.5 - Previsões de $F_{3}$ para a série TSF

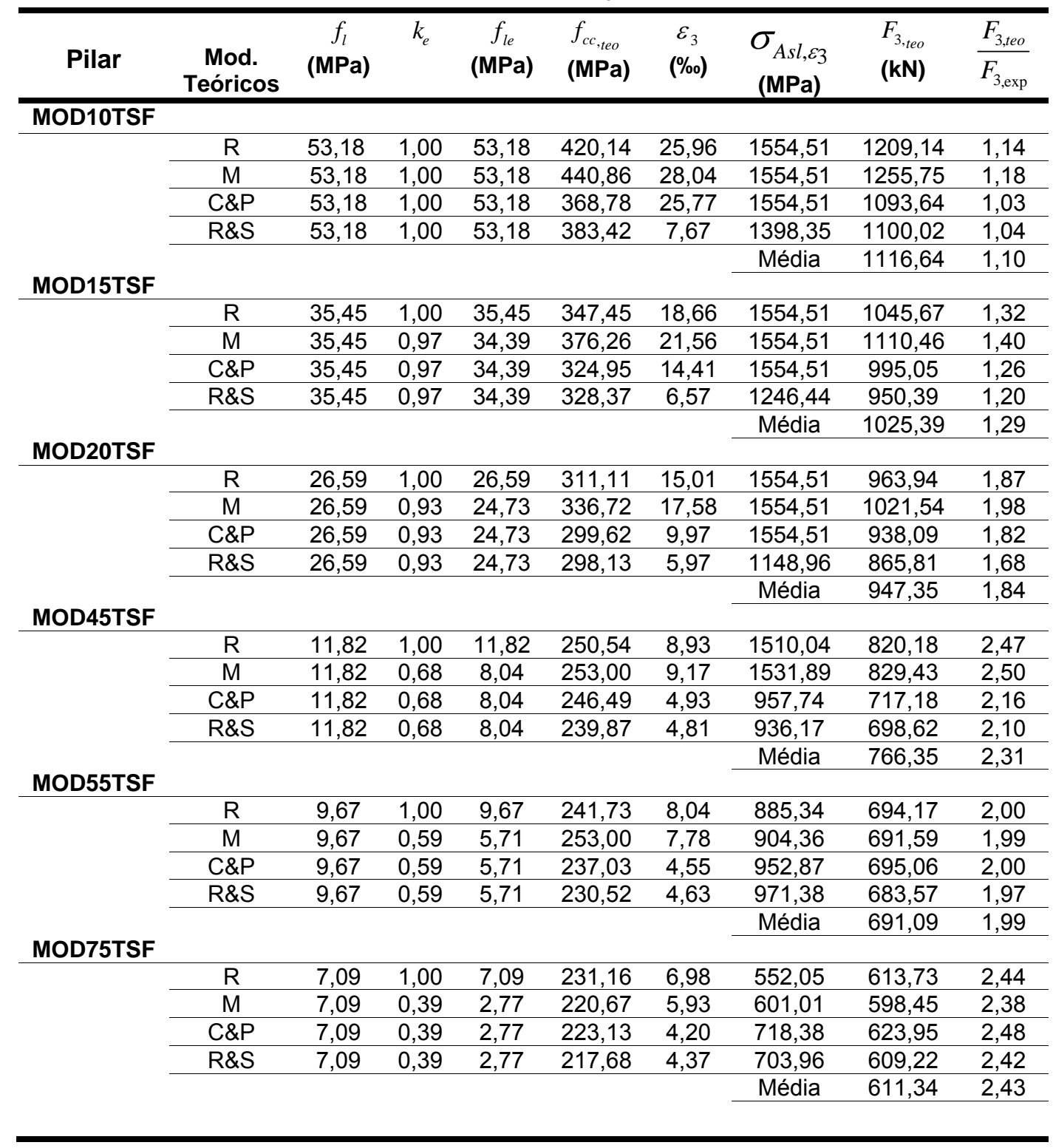

De modo geral, pode-se notar que as melhores aproximações teóricas para a resistência do concreto confinado foram obtidas para a situação de alto confinamento, pelos modelos de previsão de confinamento desenvolvidos por CUSSON \& PAULTRE (1995) e RAZVI \& SAATCIOGLU (1999), fornecendo resultados próximos dos experimentais. Esses modelos também foram os que mais se aproximaram dos resultados experimentais para os pilares com médio confinamento, no entanto, sua consideração resulta contra a segurança, pois 
superestimam os valores de resistência à compressão do concreto confinado. As utilizações dos modelos de previsão teóricos para as situações de baixo confinamento para esta dosagem de concreto são totalmente contra a segurança, pois os valores teóricos são muito aquém dos resultados experimentais. A deformação última teórica do concreto confinado para situações de alto confinamento foi mais bem representada pelos modelos de RICHART et al. (1929) e CUSSON \& PAULTRE (1995), porém, contra a segurança, já para os pilares com médio confinamento o modelo de RAZVI \& SAATCIOGLU (1999) foi o que forneceu resultados a favor da segurança, subestimando as deformações. No caso de pilares com baixo confinamento, o modelo de RICHART et al. (1988) foi o que mais se aproximou dos resultados experimentais.

\subsubsection{Série ICF}

A tabela 6.6 mostra os resultados experimentais no ponto $\left(F_{3}, \varepsilon_{3}\right)$, obtidos dos diagramas força-deformação dos pilares da série de: força normal atuante $\left(F_{3}\right)$, deformação do concreto confinado $\left(\varepsilon_{3}\right)$, resistência à compressão do concreto confinado $\left(f_{c c}\right)$ e tensão na armadura longitudinal $\left(\sigma_{A s, c_{3}}\right)$, e a tabela 6.7 , os resultados teóricos, fornecidos pelos modelos de previsão do confinamento com aço para a força normal $F_{3}$.

A partir dos resultados, pode-se notar que dois pilares MOD10ICF, MOD15ICF e MOD25ICF apresentaram acréscimos de resistência à compressão do concreto do núcleo confinado. Todos os pilares da série apresentaram acréscimos de deformação axial. 
Tabela 6.6 - Resultados experimentais série ICF

\begin{tabular}{|c|c|c|c|}
\hline \multicolumn{2}{|c|}{ MOD10ICF } & \multicolumn{2}{|c|}{ MOD20ICF } \\
\hline $\begin{array}{c}F_{3} \\
1039,01(\mathrm{kN}) \\
f_{c c} \\
333,65(\mathrm{MPa})\end{array}$ & $\begin{array}{c}\varepsilon_{3} \\
29,99(\% \text { o) } \\
\sigma_{A s l, \varepsilon_{3}} \\
1698,30(\mathrm{MPa})\end{array}$ & $\begin{array}{c}F_{3} \\
714,58(\mathrm{kN}) \\
f_{c c} \\
209,44(\mathrm{MPa})\end{array}$ & $\begin{array}{c}\varepsilon_{3} \\
7,96(\% \circ) \\
\sigma_{A s l, \varepsilon_{3}} \\
1432,66(\mathrm{MPa})\end{array}$ \\
\hline \multicolumn{2}{|c|}{ MOD25ICF } & \multicolumn{2}{|c|}{ MOD55ICF } \\
\hline $\begin{array}{c}F_{3} \\
704,89(\mathrm{kN}) \\
f_{c c} \\
201,70(\mathrm{MPa})\end{array}$ & $\begin{array}{c}\varepsilon_{3} \\
8,40(\%) \\
\sigma_{A s l, \varepsilon_{3}} \\
1477,96(\mathrm{MPa})\end{array}$ & $\begin{array}{c}F_{3} \\
501,99(\mathrm{kN}) \\
f_{c c} \\
157,79(\mathrm{MPa})\end{array}$ & $\begin{array}{c}\varepsilon_{3} \\
8,33(\%) \\
\sigma_{A s l, \varepsilon_{3}} \\
865,40(\mathrm{MPa})\end{array}$ \\
\hline \multicolumn{2}{|c|}{ MOD60ICF } & \multicolumn{2}{|c|}{ MOD75ICF } \\
\hline $\begin{array}{c}F_{3} \\
558,01(\mathrm{kN}) \\
f_{c c} \\
182,88(\mathrm{MPa})\end{array}$ & $\begin{array}{c}\varepsilon_{3} \\
5,91(\%) \\
\sigma_{A s l, \varepsilon_{3}} \\
862,95(\mathrm{MPa})\end{array}$ & $\begin{array}{c}F_{3} \\
619,51(\mathrm{kN}) \\
f_{c c} \\
230,04(\mathrm{MPa})\end{array}$ & $\begin{array}{c}\varepsilon_{3} \\
5,93(\% 0) \\
\sigma_{A s l, \varepsilon_{3}} \\
600,81(\mathrm{MPa})\end{array}$ \\
\hline
\end{tabular}

De modo geral, as melhores aproximações teóricas para a resistência do concreto confinado foram obtidas para a situação de alto confinamento, pelos modelos de previsão de confinamento desenvolvidos por CUSSON \& PAULTRE (1995) e RAZVI \& SAATCIOGLU (1999), fornecendo resultados próximos dos experimentais, com os resultados do modelo de CUSSON \& PAULTRE (1995), a favor da segurança. Esses modelos também foram os que mais se aproximaram dos resultados experimentais para os pilares com médio confinamento. No entanto, sua consideração resulta contra a segurança, pois superestimam os valores de resistência à compressão do concreto confinado. As utilizações dos modelos de previsão teóricos para as situações de baixo confinamento para esta dosagem de concreto se mostraram diferentes das apresentadas pelos pilares das séries anteriormente descritas, com os modelos de MANDER et al. (1988) e RAZVI \& SAATCIOGLU (1999), fornecendo resultados teóricos próximos dos experimentais. 
Tabela 6.7 - Previsões de $F_{3}$ para a série ICF

\begin{tabular}{|c|c|c|c|c|c|c|c|c|c|}
\hline Pilar & $\begin{array}{c}\text { Mod. } \\
\text { Teóricos }\end{array}$ & $\begin{array}{c}f_{l} \\
(\mathrm{MPa})\end{array}$ & $k_{e}$ & $\begin{array}{c}f_{l e} \\
\text { (MPa) }\end{array}$ & $\begin{array}{l}f_{c c, \text { teo }} \\
\text { (MPa) }\end{array}$ & $\begin{array}{c}\varepsilon_{3} \\
(\%)\end{array}$ & $\begin{array}{c}\sigma_{A s l, \varepsilon_{3}} \\
(\mathrm{MPa})\end{array}$ & $\begin{array}{l}F_{3, \text { teo }} \\
(\mathbf{k N})\end{array}$ & $\frac{F_{3, \text { teo }}}{F_{3, \text { exp }}}$ \\
\hline \multicolumn{10}{|l|}{ MOD10ICF } \\
\hline & $\mathrm{R}$ & 53,18 & 1,00 & 53,18 & 393,23 & 28,87 & 1554,41 & 1148,62 & 1,10 \\
\hline & M & 53,18 & 1,00 & 53,18 & 403,16 & 30,10 & 1554,41 & 1170,95 & 1,13 \\
\hline & C\&P & 53,18 & 1,00 & 53,18 & 334,88 & 31,69 & 1554,41 & 1017,39 & 0,97 \\
\hline & $R \& S$ & 53,18 & 1,00 & 53,18 & 356,51 & 8,75 & 1508,46 & 1058,22 & 1,02 \\
\hline & & & & & & & Média & 1098,79 & 1,05 \\
\hline \multicolumn{10}{|l|}{ MOD20ICF } \\
\hline & $\mathrm{R}$ & 26,59 & 1,00 & 26,59 & 284,20 & 16,49 & 1554,41 & 903,42 & 1,26 \\
\hline & M & 26,59 & 0,93 & 24,73 & 305,90 & 18,97 & 1554,41 & 952,22 & 1,33 \\
\hline & C\&P & 26,59 & 0,93 & 24,73 & 268,62 & 11,54 & 1554,41 & 868,37 & 1,21 \\
\hline & $R \& S$ & 26,59 & 0,93 & 24,73 & 271,22 & 6,52 & 1238,54 & 820,52 & 1,14 \\
\hline & & & & & & & Média & 886,13 & 1,24 \\
\hline \multicolumn{10}{|l|}{ MOD25ICF } \\
\hline & $\mathrm{R}$ & 21,27 & 1,00 & 21,27 & 262,40 & 13,99 & 1554,41 & 854,38 & 1,21 \\
\hline & M & 21,27 & 0,88 & 18,72 & 279,73 & 15,98 & 1554,51 & 893,35 & 1,26 \\
\hline & C\&P & 21,27 & 0,88 & 18,72 & 252,07 & 8,70 & 1504,54 & 822,68 & 1,16 \\
\hline & $R \& S$ & 21,27 & 0,88 & 18,72 & 251,40 & 6,00 & 1154,46 & 761,66 & 1,08 \\
\hline \multirow{2}{*}{\multicolumn{10}{|c|}{ MOD55ICF }} \\
\hline & & & & & & & & & \\
\hline & $\mathrm{R}$ & 9,67 & 1,00 & 11,82 & 214,82 & 8,55 & 851,07 & 627,82 & 1,25 \\
\hline & M & 9,67 & 0,59 & 5,71 & 211,89 & 8,21 & 873,48 & 625,03 & 1,24 \\
\hline & C\&P & 9,67 & 0,59 & 5,71 & 208,65 & 4,63 & 973,05 & 634,67 & 1,26 \\
\hline & $R \& S$ & 9,67 & 0,59 & 5,71 & 203,61 & 4,75 & 1002,16 & 628,28 & 1,25 \\
\hline & & & & & & & Média & 628,95 & 1,25 \\
\hline \multicolumn{10}{|l|}{ MOD60ICF } \\
\hline & $\mathrm{R}$ & 8,86 & 1,00 & 8,86 & 211,52 & 8,17 & 876,39 & 624,69 & 1,12 \\
\hline & M & 8,86 & 0,54 & 4,79 & 206,34 & 7,58 & 920,39 & 620,49 & 1,11 \\
\hline & C\&P & 8,86 & 0,54 & 4,79 & 204,78 & 4,47 & 934,64 & 619,43 & 1,11 \\
\hline & R\&S & 8,86 & 0,54 & 4,79 & 199,75 & 4,65 & 977,86 & 615,48 & 1,10 \\
\hline & & & & & & & Média & 620,03 & 1,11 \\
\hline \multicolumn{10}{|l|}{ MOD75ICF } \\
\hline & $\mathrm{R}$ & 7,09 & 1,00 & 7,09 & 204,25 & 7,34 & 573,94 & 550,81 & 0,88 \\
\hline & M & 7,09 & 0,39 & 2,77 & 193,67 & 6,13 & 590,77 & 535,98 & 0,86 \\
\hline & C\&P & 7,09 & 0,39 & 2,77 & 195,34 & 4,19 & 719,34 & 561,61 & 0,90 \\
\hline & R\&S & 7,09 & 0,39 & 2,77 & 190,77 & 4,42 & 700,03 & 548,04 & 0,88 \\
\hline & & & & & & & Média & 549,11 & 0,88 \\
\hline
\end{tabular}

A deformação última teórica do concreto confinado para situações de alto confinamento foi melhor representada pelo modelo de RICHART et al. (1929), a favor da segurança, com os resultados dos modelos de MANDER et al. (1988) e CUSSON \& PAULTRE (1995) apresentando valores próximos dos experimentais. Já para os pilares com médio confinamento, o modelo de RAZVI \& SAATCIOGLU (1999) foi o que forneceu resultados a favor da segurança, subestimando as deformações. No caso de pilares com baixo confinamento o modelo de MANDER et al. (1988), foi o que mais se aproximou dos resultados experimentais. 


\subsubsection{Série ISF}

A tabela 6.8 mostra os resultados experimentais no ponto $\left(F_{3}, \varepsilon_{3}\right)$, obtidos dos diagramas força-deformação dos pilares da série de: força normal atuante $\left(F_{3}\right)$, deformação do concreto confinado $\left(\varepsilon_{3}\right)$, resistência à compressão do concreto confinado $\left(f_{c c}\right)$ e tensão na armadura longitudinal $\left(\sigma_{A s l, \varepsilon_{3}}\right)$, e a tabela 6.9, os resultados teóricos, fornecidos pelos modelos de previsão do confinamento com aço.

Tabela 6.8 - Resultados experimentais série ISF

\begin{tabular}{|c|c|c|c|}
\hline \multicolumn{2}{|c|}{ MOD10ISF } & \multicolumn{2}{|c|}{ MOD20ISF } \\
\hline $\begin{array}{c}F_{3} \\
916,02(\mathrm{kN}) \\
f_{c c} \\
281,87(\mathrm{MPa})\end{array}$ & $\begin{array}{c}\varepsilon_{3} \\
23,69(\%) \\
\sigma_{A s l, \varepsilon_{3}} \\
1698,30(\mathrm{MPa})\end{array}$ & $\begin{array}{c}F_{3} \\
471,32(\mathrm{kN}) \\
f_{c c} \\
89,92(\mathrm{MPa})\end{array}$ & $\begin{array}{c}\varepsilon_{3} \\
11,31(\%) \\
\sigma_{A s l, \varepsilon_{3}} \\
1432,66(\mathrm{MPa})\end{array}$ \\
\hline \multicolumn{2}{|c|}{ MOD25ISF } & \multicolumn{2}{|c|}{ MOD60ISF } \\
\hline $\begin{array}{c}F_{3} \\
423,56(\mathrm{kN}) \\
f_{c c} \\
84,47(\mathrm{MPa})\end{array}$ & $\begin{array}{c}\varepsilon_{3} \\
7,43(\%) \\
\sigma_{A s l, \varepsilon_{3}} \\
865,40(\mathrm{MPa})\end{array}$ & $\begin{array}{c}F_{3} \\
298,96(\mathrm{kN}) \\
f_{c c} \\
79,51(\mathrm{MPa})\end{array}$ & $\begin{array}{c}\varepsilon_{3} \\
8,31(\%) \\
\sigma_{A s l, \varepsilon_{3}} \\
865,40(\mathrm{MPa})\end{array}$ \\
\hline \multicolumn{4}{|c|}{ MOD75ISF } \\
\hline $\begin{array}{c}F_{3} \\
232,88(\mathrm{kN})\end{array}$ & $\begin{array}{c}f_{c c} \\
52,97(\mathrm{MPa})\end{array}$ & $\begin{array}{c}\varepsilon_{3} \\
4,82(\% \circ)\end{array}$ & $\begin{array}{c}\sigma_{A s l, \varepsilon_{3}} \\
600,81(\mathrm{MPa})\end{array}$ \\
\hline
\end{tabular}

A partir dos resultados, pode-se notar que apenas o pilar MOD10ISF apresentou acréscimo de resistência à compressão do concreto do núcleo confinado. Todos os pilares da série apresentaram acréscimos de deformação axial. 
Tabela 6.9 - Previsões de $F_{3}$ para a série ISF

\begin{tabular}{|c|c|c|c|c|c|c|c|c|c|}
\hline Pilar & $\begin{array}{l}\text { Mod. } \\
\text { Teóricos }\end{array}$ & $\begin{array}{c}f_{l} \\
(\mathrm{MPa})\end{array}$ & $k_{e}$ & $\begin{array}{c}f_{l e} \\
(\mathrm{MPa})\end{array}$ & $\begin{array}{l}f_{c c, t e o} \\
\text { (MPa) }\end{array}$ & $\begin{array}{c}\varepsilon_{3} \\
(\% \circ)\end{array}$ & $\begin{array}{c}\sigma_{A s l, \varepsilon 3} \\
(\mathrm{MPa})\end{array}$ & $\begin{array}{l}F_{3, \text { teo }} \\
(\mathbf{k N})\end{array}$ & $\frac{F_{3, \text { teo }}}{F_{3, \exp }}$ \\
\hline \multicolumn{10}{|c|}{ MOD10ISF } \\
\hline & $\mathrm{R}$ & 53,18 & 1,00 & 53,18 & 383,36 & 27,65 & 1554,41 & 1126,42 & 1,23 \\
\hline & $M$ & 53,18 & 1,00 & 53,18 & 388,82 & 28,25 & 1554,41 & 1138,70 & 1,24 \\
\hline & C\&P & 53,18 & 1,00 & 53,18 & 322,25 & 34,18 & 1554,41 & 988,99 & 1,08 \\
\hline & R\&S & 53,18 & 1,00 & 53,18 & 346,64 & 8,47 & 1484,52 & 1031,95 & 1,12 \\
\hline & & & & & & & Média & 1071,52 & 1,17 \\
\hline \multicolumn{10}{|c|}{ MOD20ISF } \\
\hline & $\mathrm{R}$ & 26,59 & 1,00 & 26,59 & 274,33 & 15,64 & 1554,41 & 881,22 & 1,87 \\
\hline & $M$ & 26,59 & 0,93 & 24,73 & 294,37 & 17,85 & 1554,41 & 926,29 & 1,96 \\
\hline & C\&P & 26,59 & 0,93 & 24,73 & 257,14 & 11,95 & 1554,41 & 842,54 & 1,78 \\
\hline & R\&S & 26,59 & 0,93 & 24,73 & 261,35 & 6,20 & 1187,11 & 789,58 & 1,67 \\
\hline & & & & & & & Média & 859,91 & 1,82 \\
\hline \multicolumn{10}{|c|}{ MOD25ISF } \\
\hline & $\mathrm{R}$ & 21,27 & 1,00 & 21,27 & 252,53 & 13,24 & 1554,41 & 832,18 & 1,96 \\
\hline & $\mathrm{M}$ & 21,27 & 0,88 & 18,72 & 268,75 & 15,03 & 1554,41 & 868,67 & 2,05 \\
\hline & C\&P & 21,27 & 0,88 & 18,72 & 240,88 & 8,82 & 1513,81 & 799,08 & 1,88 \\
\hline & R\&S & 21,27 & 0,88 & 18,72 & 241,53 & 5,67 & 1097,45 & 729,77 & 1,72 \\
\hline & & & & & & & Média & 807,42 & 1,90 \\
\hline \multicolumn{10}{|c|}{ MOD60ISF } \\
\hline & $\mathrm{R}$ & 8,86 & 1,00 & 8,86 & 201,65 & 7,64 & 915,19 & 609,09 & 2,03 \\
\hline & $M$ & 8,86 & 0,54 & 4,79 & 196,35 & 7,06 & 963,51 & 605,39 & 2,02 \\
\hline & $C \& P$ & 8,86 & 0,54 & 4,79 & 194,40 & 4,15 & 858,57 & 583,16 & 1,95 \\
\hline & R\&S & 8,86 & 0,54 & 4,79 & 189,88 & 4,29 & 892,69 & 578,81 & 1,93 \\
\hline & & & & & & & Média & 594,11 & 1,98 \\
\hline \multicolumn{10}{|c|}{ MOD75ISF } \\
\hline & $\mathrm{R}$ & 7,09 & 1,00 & 7,09 & 194,38 & 6,84 & 557,87 & 532,00 & 2,28 \\
\hline & $\mathrm{M}$ & 7,09 & 0,39 & 2,77 & 183,75 & 5,67 & 614,92 & 517,79 & 2,22 \\
\hline & $C \& P$ & 7,09 & 0,39 & 2,77 & 185,12 & 3,84 & 712,81 & 537,52 & 2,30 \\
\hline & R\&S & 7,09 & 0,39 & 2,77 & 180,90 & 4,06 & 752,42 & 534,75 & 2,29 \\
\hline & & & & & & & Média & 530,52 & 2,27 \\
\hline
\end{tabular}

De modo geral, pode-se notar que as melhores aproximações teóricas para a resistência do concreto confinado foram obtidas para a situação de alto confinamento, pelos modelos de previsão de confinamento desenvolvidos por CUSSON \& PAULTRE (1995) e RAZVI \& SAATCIOGLU (1999), fornecendo resultados próximos dos experimentais, porém contra a segurança. Esses modelos também foram os que mais se aproximaram dos resultados experimentais para os pilares com médio confinamento, no entanto, sua consideração resulta contra a segurança, pois superestimam os valores de resistência à compressão do concreto confinado. As utilizações dos modelos de previsão teóricos para as situações de baixo confinamento para esta dosagem de concreto são totalmente contra a segurança, pois os valores teóricos são muito aquém dos resultados experimentais. A deformação 
última teórica do concreto confinado para situações de alto confinamento foi melhor representada pelos modelos de RICHART et al. (1929) e MANDER et al. (1988), porém contra a segurança, já para os pilares com médio confinamento o modelo de RAZVI \& SAATCIOGLU (1999) foi o que forneceu resultados a favor da segurança, subestimando as deformações. No caso de pilares com baixo confinamento o modelo de MANDER et al. (1988) foi o que mais se aproximou dos resultados experimentais. 


\section{Conclusão}

Constatou-se que o CPR sem adição de fibras metálicas apresenta comportamento frágil e que a adição de fibras metálicas utilizada neste trabalho aumentou a ductilidade, com as fibras evitando a fragmentação do concreto.

Observou-se que quanto maior a resistência à compressão do concreto, maiores taxas de armadura transversal tiveram que ser utilizadas para que os efeitos do confinamento fossem significativos.

Com base na média geral apresentada entre as relações das forças teóricas $\left(F_{1, \text { teo }}\right)$, considerando a seção bruta de concreto $\left(F_{1, t e o, A_{C}}\right)$, e a seção do núcleo de concreto $\left(F_{1, \text { teo, Асnuc }}\right)$, como as resistentes, com as forças experimentais apresentadas pelas séries estudadas, pode-se concluir que a seção resistente é a formada pelo núcleo de concreto confinado para pilares de CUAR, semelhante às constatações realizadas por CUSSON \&PAULTRE (1993) e QUEIROGA (1999), de que a seção transversal resistente em pilares com concreto de alta resistência é a formada pelo núcleo de concreto confinado.

Observou-se pela média dos valores de $I D_{1}$ das séries TCF, TSF, ICF e ISF que a perda do concreto do cobrimento (spalling) ocorre quando é atingido $0,81 \%$ da deformação do concreto não confinado.

Os índices de ductilidade $\left(I D_{2}\right)$, que relacionam a deformação do concreto confinado com a deformação do concreto não confinado, obtidos na pesquisa, ficaram situados entre 1,32 a 7,47, valores compatíveis com os obtidos por SHIN et al. (2014) em sua pesquisa.

Constatou-se pelos valores de $I D_{3}$ que os pilares com as dosagens com adição de fibras metálicas (TCF e TSF) apresentaram maior ductilidade no trecho descendente do diagrama força-deformação do concreto confinado em relação aos pilares dosados sem adição de fibras metálicas (TSF e ISF). 
Os resultados experimentais indicam que quanto menor o espaçamento da armadura transversal $\left(A_{s w}\right)$ maiores os ganhos de resistência e deformação axial do CUAR confinado.

Notou-se em alguns pilares com baixo confinamento uma significativa queda de capacidade resistente do pilar a um nível de deformação axial relativamente baixo. Isto indicou que a taxa de armadura transversal $\left(\rho_{w}\right)$ utilizada nesses pilares foi insuficiente para evitar o modo de ruptura frágil, apresentado pelo CUAR.

Notou-se nos pilares com alto confinamento, MOD10TCF, MOD10TSF, MOD10ICF e MOD10ISF, que foram gerados ao concreto do núcleo confinado significativos acréscimos de resistência e deformação, aumentando a resistência do concreto confinado em relação à resistência do concreto não confinado em: $82,26 \%$, $75,34 \%, 90,46 \%$ e $70,51 \%$, respectivamente, e as deformações do concreto confinado em relação à deformação do concreto não confinado em: 433\%, 474\%, 647\% e 550\%.

Observou-se nos pilares com médio confinamento que apenas os pilares que tinham dosagens com fibras metálicas (MOD20TCF e MOD20ICF) apresentaram acréscimos de resistência à compressão do concreto confinado.

A utilização do aço de alta resistência para a armadura longitudinal se mostrou vantajosa, pois a deformação de escoamento do aço é superior à deformação do concreto não confinado. Dessa forma, na obtenção da força normal $F_{1}$, no ponto ( $\left.F_{1}, \varepsilon_{1}\right)$, trecho praticamente linear do diagrama força-deformação, o aço não atinge sua tensão de escoamento, situação mais vantajosa que a apresentada nos ensaios de SHIN et al. (2014), que utilizaram aços com tensão de escoamento de 489 MPa e deformação de escoamento igual a 2,45\%, e constataram que a armadura longitudinal atingia seu limite de escoamento antes da ocorrência do spalling (destacamento do concreto do cobrimento), ou seja, antes da obtenção da força normal $F_{1}$, a armadura longitudinal já se encontrava em escoamento. 
A utilização de aço de alta resistência para compor a armadura transversal mostrou-se mais vantajosa para as situações de alto confinamento, onde significativas pressões laterais foram aplicadas ao núcleo de concreto, proporcionando ganhos de resistência e ductilidade, com alguns modelos apresentando a ruptura da espiral, indicando que a armadura transversal estava trabalhando com altos níveis de tensão.

Observou-se que os modelos teóricos avaliados em geral superestimaram a capacidade resistente dos pilares, exceto para a situação de alto confinamento, apresentada pelos pilares MOD10TCF, MOD10TSF, MOD10ICF e MOD10ISF. Os modelos de previsão teórica que mais se aproximaram da força normal experimental $\left(F_{3, \text { exp }}\right)$, no ponto $\left(F_{3}, \varepsilon_{3}\right)$, para as situações de alto confinamento e médio confinamento, foram os modelos de CUSSON \& PAULTRE (1995) e RAZVI \& SAATCIOGLU (1999). Já para a situação de baixo confinamento, não ficou muito claro qual dos modelos de previsão forneceram os melhores resultados, pois os resultados oscilaram muito.

O reforço por encamisamento com compósito de fibra de carbono, utilizado nas extremidades dos pilares de concreto armado, mostrou-se eficaz em todos os modelos, evitando a ruptura prematura das extremidades.

\subsection{Sugestão para continuação da pesquisa}

As sugestões para continuidade da pesquisa são:

I. Estudar outras taxas de armadura longitudinal, bem como, outras disposições no perímetro da seção transversal;

II. O desenvolvimento de um modelo teórico de confinamento com aço para o concreto de ultra alta resistência. Esta sugestão justifica-se pelo fato de não existir no meio técnico nenhum modelo de previsão de confinamento para resistências à compressão do concreto não confinado acima de $130 \mathrm{MPa}$, como as obtidas na presente pesquisa; 
III. Estudar a influência da resistência do aço da armadura transversal para as situações de médio e baixo confinamento, utilizando aços de diferentes resistências;

IV. Estudar através de simulações numéricas, em programa de elementos finitos, o comportamento dos pilares da pesquisa em escalas usuais utilizadas em projetos de estruturas e verificar como esses elementos estruturais se comportam. Esta sugestão comprova-se devido às limitações de carga apresentadas pelos laboratórios, uma vez que qualquer seção típica as utilizadas em projetos de estruturas teriam capacidade de força normal altíssima, proporcionada pela alta resistência à compressão do CUAR;

V. Estudar os pilares da pesquisa em situações cíclicas de carregamento. 


\section{Referências Bibliográficas}

AGUIAR, E. A. B. (2000). Projeto de pilares de concreto de alto desempenho. Dissertação (Mestrado) - Escola de Engenharia de São Carlos, Universidade de São Paulo, São Carlos, SP.

ASSOCIAÇÃO BRASILEIRA DE NORMAS TÉCNICAS. (1983). NBR 7211: Agregado para Concreto. Rio de Janeiro, 1983.

ASSOCIAÇÃO BRASILEIRA DE NORMAS TÉCNICAS. (1990). NBR 11414: Arame redondo de aço-carbono para molas - Especificação. Rio de Janeiro, 1990.

ASSOCIAÇÃO BRASILEIRA DE NORMAS TÉCNICAS. (1991). NBR 5733: Cimento Portland de alta resistência inicial. Rio de Janeiro, 1991.

ASSOCIAÇÃO BRASILEIRA DE NORMAS TÉCNICAS. (1991). NBR 7482: Fios de aço para concreto protendido. Rio de Janeiro, 1991.

ASSOCIAÇÃO BRASILEIRA DE NORMAS TÉCNICAS. (1993). NBR 5738: Moldagem e cura de corpos-de-prova cilíndricos ou prismáticos de concreto. Rio de Janeiro, 1993.

ASSOCIAÇÃO BRASILEIRA DE NORMAS TÉCNICAS. (1994). NBR 5739: Ensaio de compressão de corpos-de-prova cilíndricos de concreto. Rio de Janeiro, 1994.

ASSOCIAÇÃO BRASILEIRA DE NORMAS TÉCNICAS. (2008). NBR 8522: Concreto - Determinação dos módulos estáticos de elasticidade e de deformação e da curva tensão- deformação. Rio de Janeiro, 2008.

ASSOCIAÇÃO BRASILEIRA DE NORMAS TÉCNICAS. (2014). NBR 6118: Projeto de estruturas de concreto - Procedimento. Rio de Janeiro, 2014.

BAE, S.; MIESES, A. M.; BAYRAK, O. Inelastic buckling of reinforcing bars. Journal of Structural Engineering, v. 131, n. 2, p. 314-321, 2005.

BING, L.; PARK, R.; TANAKA, H. Stress-strain behavior of high-strength concrete confined by ultra-high-and normal-strength transverse reinforcements. ACI Structural Journal, v. 98, n. 3, 2001.

BLAIS, P. Y.; COUTURE, M. Precast, prestressed pedestrian bridge-world's first reactive powder concrete structure. ACI Structural Journal, v. 44, p. 60-71, 1999.

BONNEAU, O.et al. Reactive powder concretes: from theory to practice. Concrete International, v. 18, n. 4, p. 47-49, 1996. 
CARRAZEDO, R. (2002). Mecanismos de confinamento e suas implicações no reforço de pilares de concreto por encamisamento com compósito de fibras de carbono. Dissertação (Mestrado) - Escola de Engenharia de São Carlos, Universidade de São Paulo, São Carlos, SP.

CHEYREZY, M.; MARET, V.; FROUIN, L. Microstructural analysis of RPC (reactive powder concrete). Cement and Concrete Research, v. 25, n. 7, p. 1491-1500, 1995.

CUSSON, D.; PAUTRE, P. Confinement model for high-strength concrete tie columns. Internal report of Department of Civil Engineering, University of Sherbrooke, SMS-93/2, 1993, p.54

CUSSON, D.; PAULTRE, P. Prediction of effective confinement pressure in highstrength concrete columns. 2008.

CUSSON, D.; PAULTRE, P. High-strength concrete columns confined by rectangular ties. Journal of Structural Engineering, v. 120, n. 3, p. 783-804, 1994.

CUSSON, D.; PAULTRE, P. Stress-strain model for confined high-strength concrete. Journal of Structural Engineering, v. 121, n. 3, p. 468-477, 1995.

DUGAT, J.; ROUX, N.; BERNIER, G. Mechanical properties of reactive powder concretes. Materials and structures, v. 29, n. 4, p. 233-240, 1996.

FEHLING, E. et al. Ultra-High Performance Concrete UHPC: Fundamentals, Design, Examples. John Wiley \& Sons, 2014.

GRASS, L.; SEIDLER, N. Avaliação da resistência à compressão de concretos dosados com pós reativos. In: $52^{\circ}$ Congresso Brasileiro do Concreto, 2010, Fortaleza. Anais: CBC2010. IBRACON.

GRAYBEAL, B. A. Material property characterization of ultra-high performance concrete. 2006.

GUO, Z. Principles of reinforced concrete. Butterworth-Heinemann, 2014.

JUNGWIRTH, J.; MUTTONI, A. Underspanned bridge structures in reactive powder concrete (RPC). In: 4th International PhD Symposium in Civil Engineering. 4th International PhD Symposium in Civil Engineering, 2002.

LEONHARDT, F.; MÖNNIG, E. Construções de concreto-Princípios básicos do dimensionamento de estruturas de concreto armado. Rio de Janeiro: Interciência, v. 1, 1977.

LI, B.; PARK, R.; TANAKA, H. Stress-strain behavior of high-strength concrete confined. ACI Structural Journal, v. 98, n. 3, p. 395-406, 2000. 
LIU, S.; LI, L.; FENG, J. Study on Mechanical Properties of Reactive Powder Concrete. Journal of Civil Engineering, v. 1, n. 1, 2012.

MANDER, J. B.; PRIESTLEY, M. J. N.; PARK, R. Observed stress-strain behavior of confined concrete. Journal of structural engineering, v. 114, n. 8, p. 1827-1849, 1988.

MANDER, J. B.; PRIESTLEY, M. J. N; PARK, R. Theoretical stress-strain model for confined concrete. Journal of structural engineering, v. 114, n. 8, p. 1804-1826, 1988.

MAROLIYA, M. K. State of Art-on Development of Reactive Powder Concrete. International Journal of Innovative Research and Development, v. 1, n. 8, p. 493503, 2012.

MEHTA, P.K.; MONTEIRO, P. J. M. Concreto: Estrutura, Propriedades e Materiais. 3a ed. New York: McGraw-Hil, 2008.

MENDES, H. O. (1993). Dutilidade de elementos de concreto de alta resistência. Dissertação (Mestrado) - Universidade Federal do Rio de Janeiro, COPPE, Rio de Janeiro, RJ.

PARK, J. J.et al. Influence of the ingredients on the compressive strength of UHPC as a fundamental study to optimize the mixing proportion. In: Proceedings of the international symposium on ultra-high performance concrete, structural materials and engineering series. 2008. p. 105-12.

PESSIKI, S.; GRAYBEAL, B. A. Axial Load Tests of Concrete Compression Members with High Strength Spiral Reinforcement. ACI Structural Journal, v. 45, n. 2, p. 6483, 2000.

QUEIROGA, M. V. M. (1999). Análise experimental de pilares de concreto de alto desempenho submetidos à compressão simples. Dissertação (Mestrado) - Escola de Engenharia de São Carlos, Universidade de São Paulo, São Carlos, SP.

RAZVI, S.; SAATCIOGLU, M. Confinement model for high-strength concrete. Journal of Structural Engineering, v. 125, n. 3, p. 281-289, 1999.

RESPLENDINO, J. First recommendations for Ultra-High-Performance Concretes and examples of application. In: International Symposium on Ultra High Performance Concrete. 2004. p. 79-90.

RICHARD, P.; CHEYREZY, M. Composition of reactive powder concretes. Cement and concrete research, v. 25, n. 7, p. 1501-1511, 1995. 
RICHART, F. E.; BRANDTZAEG, A.; BROWN, R. L. Failure of plain and spirally reinforced concrete in compression. University of Illinois. Engineering Experiment Station. Bulletin; no. 190, 1929.

RUSSELL, H. G.; GRAYBEAL, B. A. Ultra-high performance concrete: A state-ofthe-art report for the bridge community. Georgetown, Office of Infrastructure Research \& Development Federal Highway Consultant, 2013.

SAATCIOGLU, M.; RAZVI, S. R. Strength and ductility of confined concrete. Journal of Structural Engineering, v. 118, n. 8, p. 1590 - 1607, 1992.

SHAH, S. P.; WEISS, W. J. Ultra-high performance concrete: a look to the future. In: Zia Symposium. ACI Spring Convention 1998. 1998.

SHIN, H. O. et al.Effect of Confinement on the Axial Load Response of UltrahighStrength Concrete Columns. Journal of Structural Engineering, v. 141, n. 6, p. 1-12, 2014.Disponível em:<http://ascelibrary.org/doi/abs/10.1061/(ASCE)ST.1943541X.0001106>. Acesso em: 15/12/2014.

VANDERLEI, R. D. (2004). Análise experimental do concreto de pós reativos: dosagem e propriedades mecânicas. Tese (Doutorado) - Escola de Engenharia de São Carlos, Universidade de São Paulo, São Carlos, SP.

WELDON, Brad D. et al. Feasibility Analysis of Ultra High Performance Concrete for Prestressed Concrete Bridge Applications. Albuquerque, NMDOT Research Bureau, 2010. 


\section{Apêndice A - Fotos dos ensaios definitivos}

Apresentam-se fotos dos ensaios de alguns pilares da série definitiva para as situações de alto, médio e baixo confinamento.

\subsection{Alto confinamento}

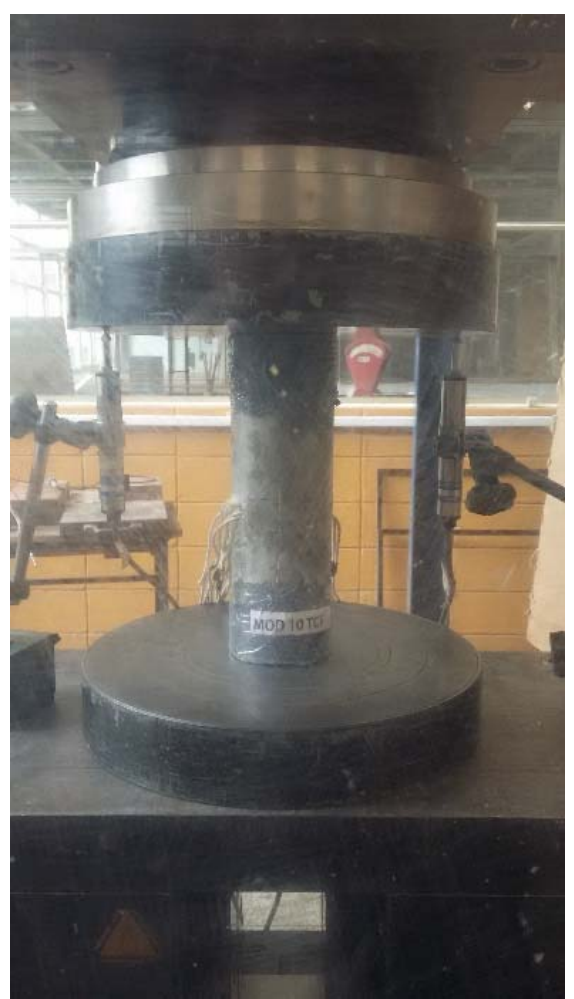

Figura 9.1 -Ensaio de compressão centrada do pilar MOD10TCF 


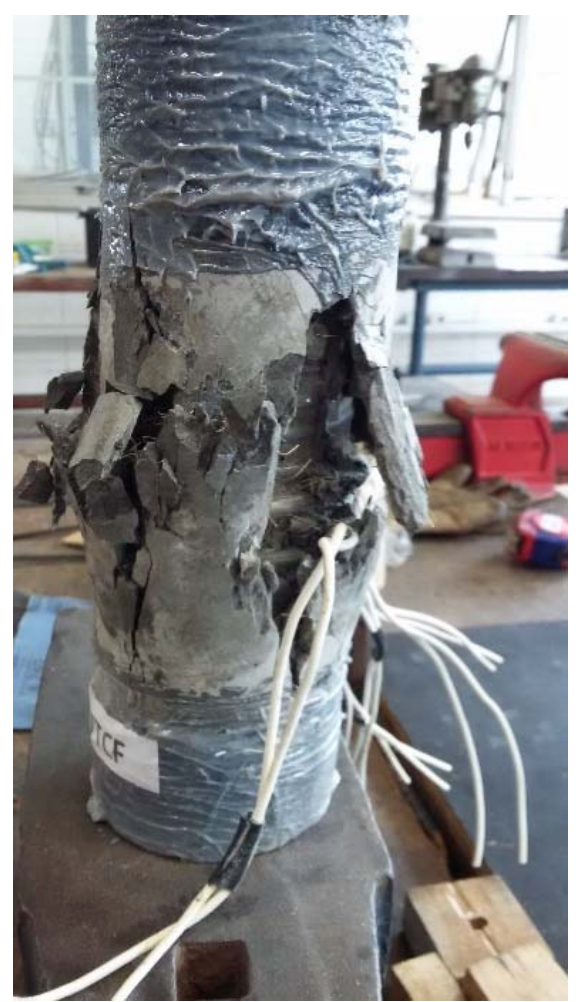

Figura 9.2 - Final do ensaio de compressão centrada do pilar MOD10TCF

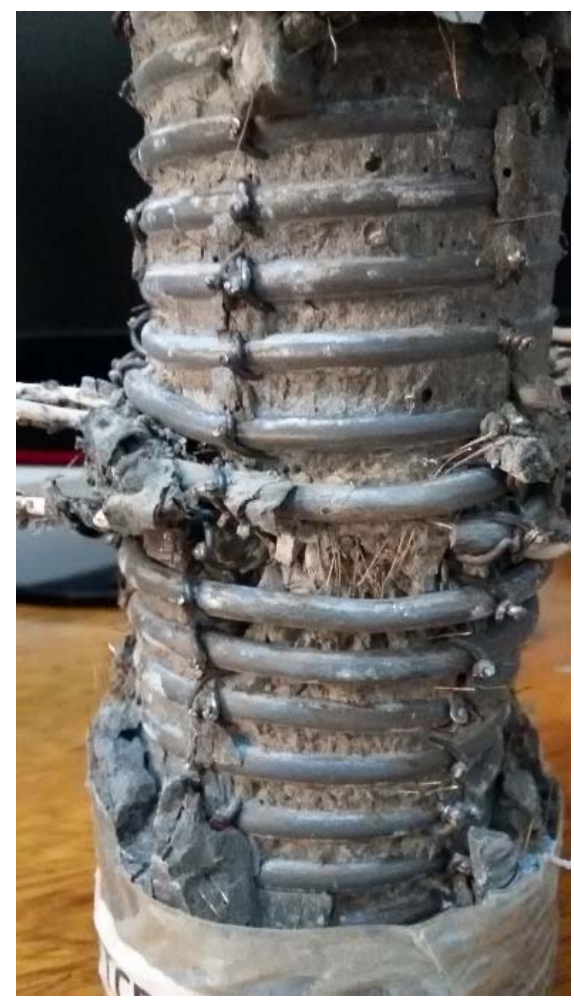

Figura 9.3 - Ruptura da espiral e flambagem da armadura longitudinal 


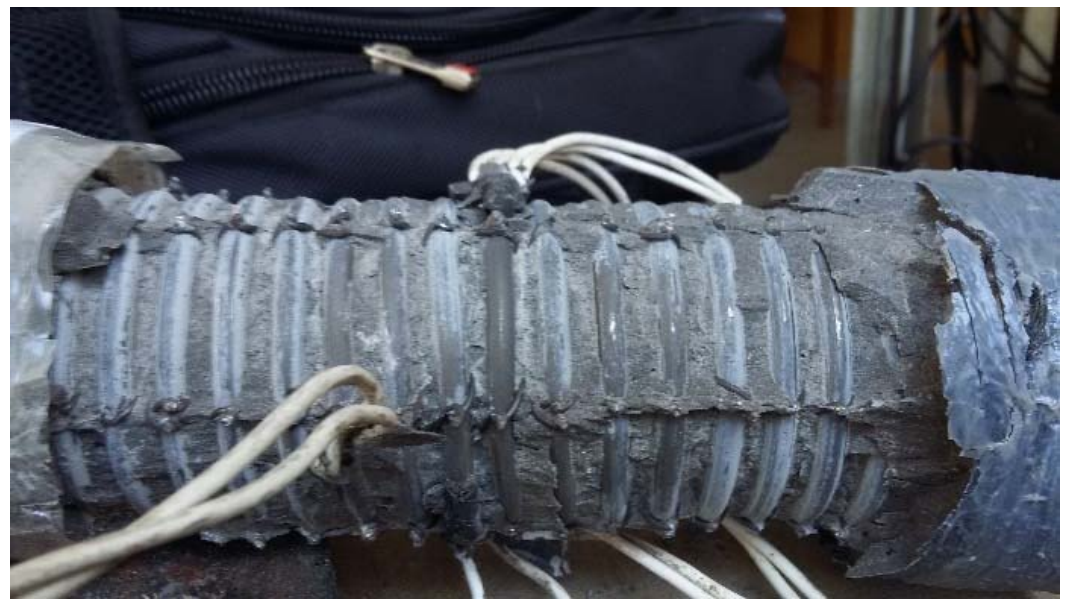

Figura 9.4 - Final do ensaio de compressão centrada do pilar MOD10TSF

\subsection{Médio confinamento}

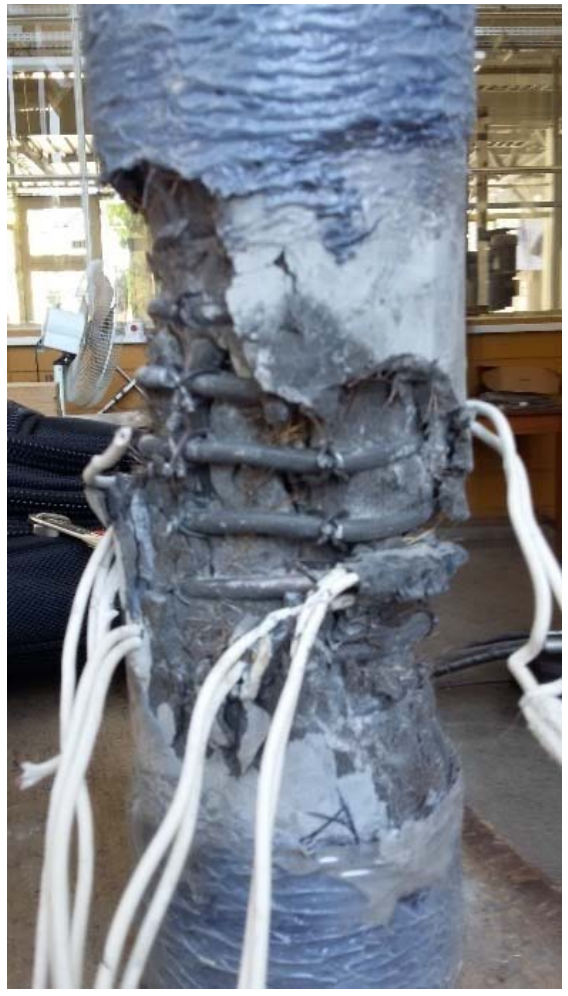

Figura 9.5 - Pilar MOD15TCF após término do ensaio de compressão centrada 


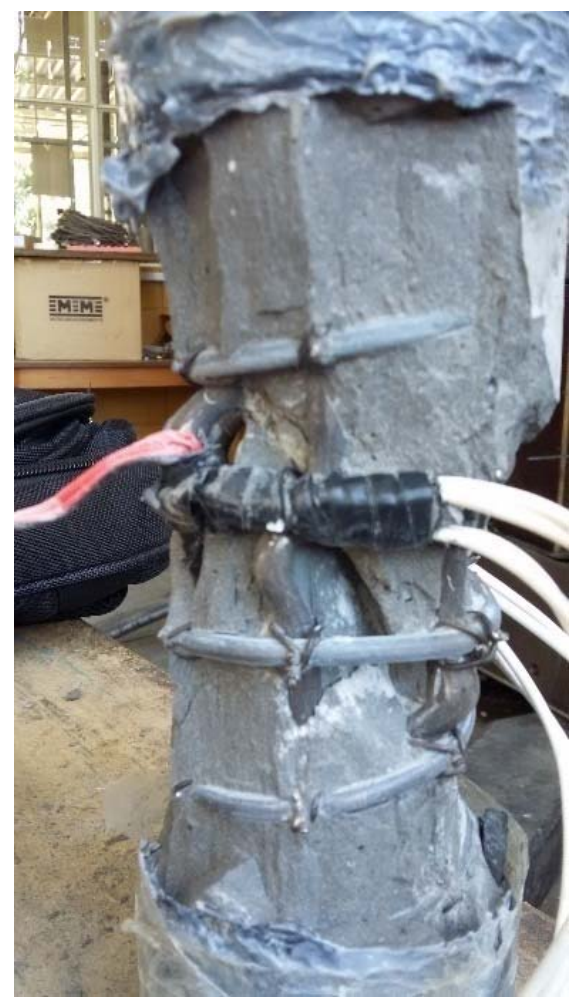

Figura 9.6 - Pilar MOD20ISF após a ruptura

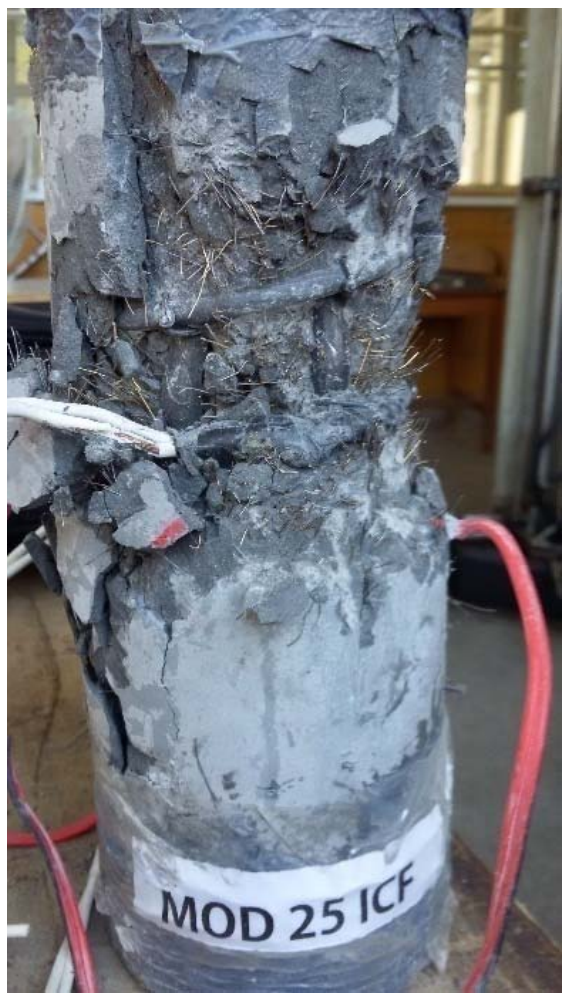

Figura 9.7 -Flambagem das armaduras longitudinais do pilar MOD25ICF 


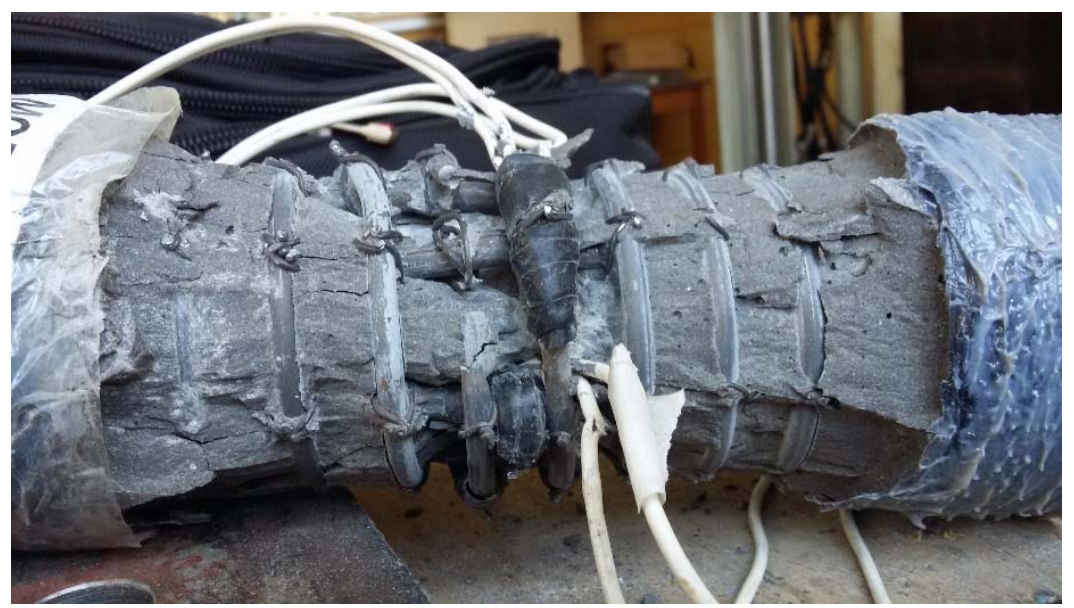

Figura 9.8 - Ruptura da espiral e flambagem das armaduras longitudinais do pilar MOD15TSF

\subsection{Baixo confinamento}

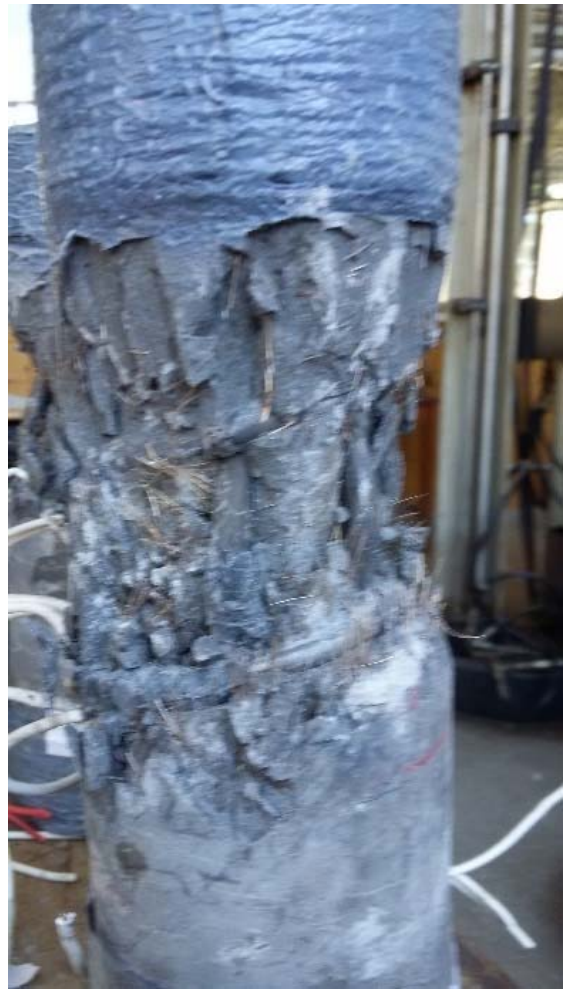

Figura 9.9 - Flambagem das armaduras longitudinais pilar MOD45TCF 


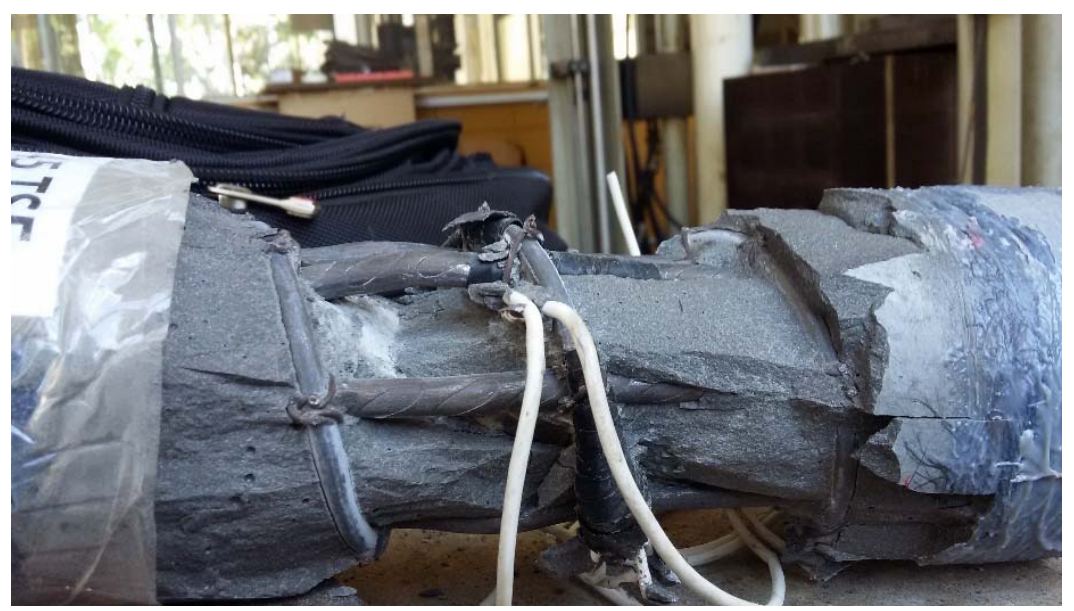

Figura 9.10 - Flambagem das armaduras longitudinais pilar MOD45TSF

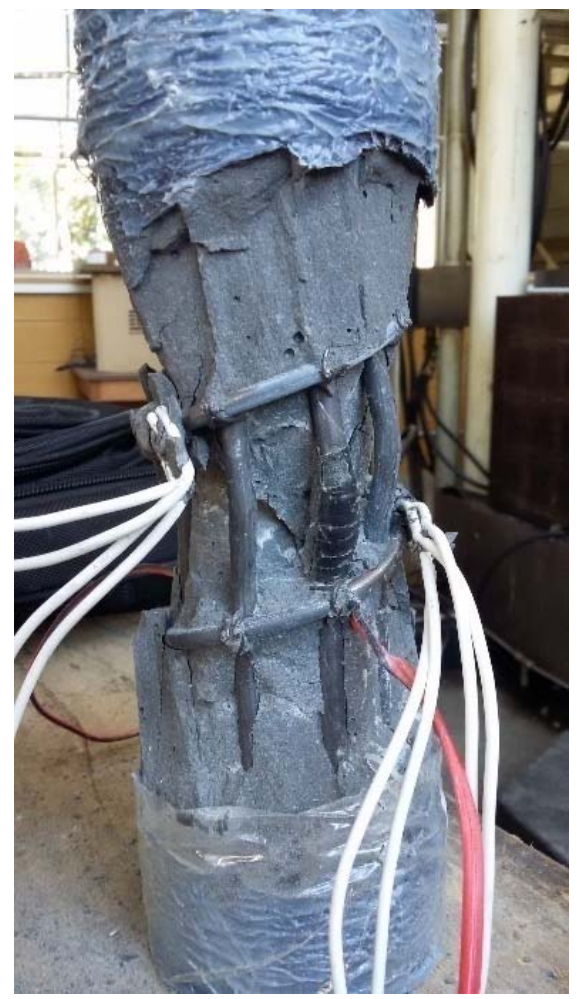

Figura 9.11 - Pilar MOD55TSF após a ruptura 


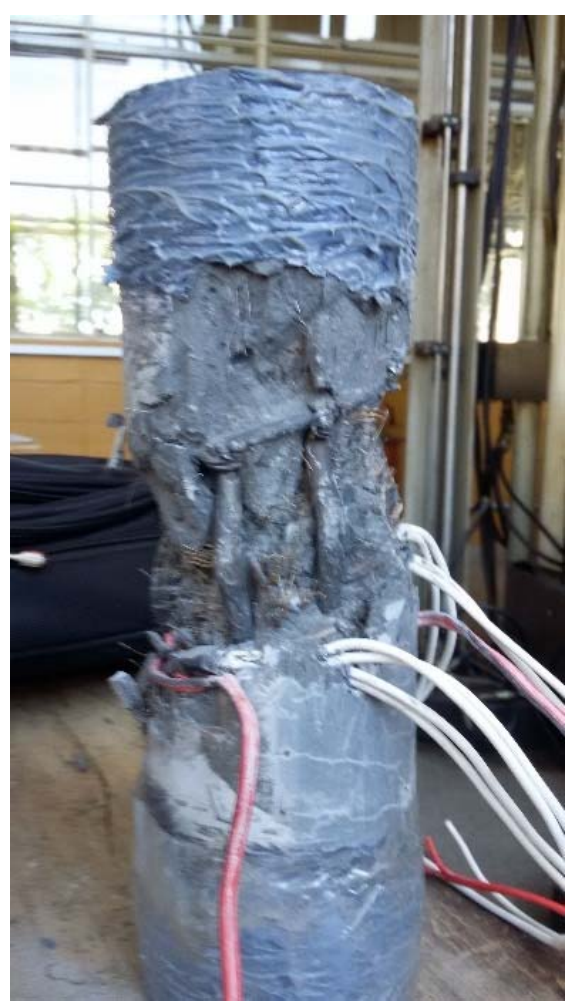

Figura 9.12 - Pilar MOD60ICF após a ruptura

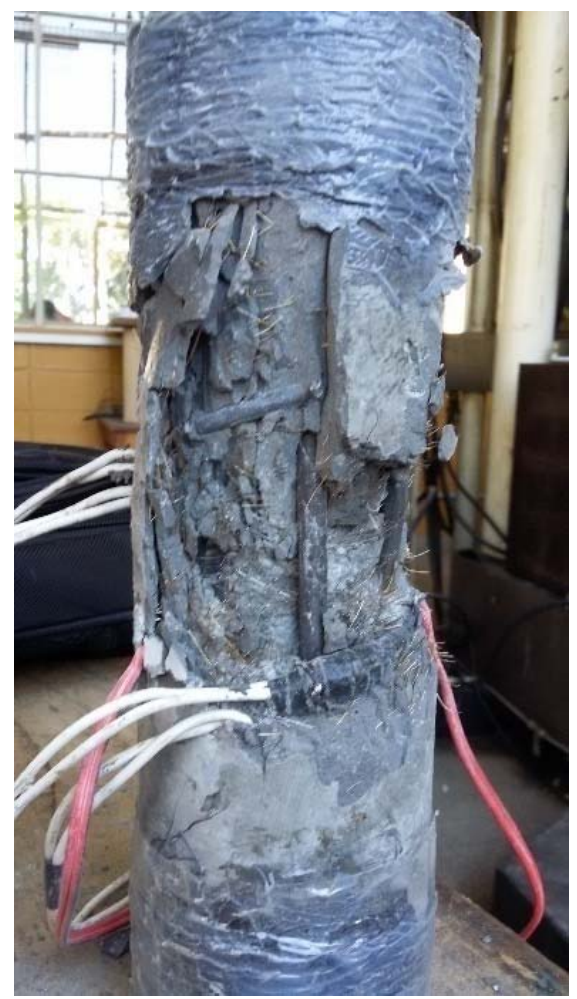

Figura 9.13 - Flambagem das armaduras longitudinais Pilar MOD75ICF 


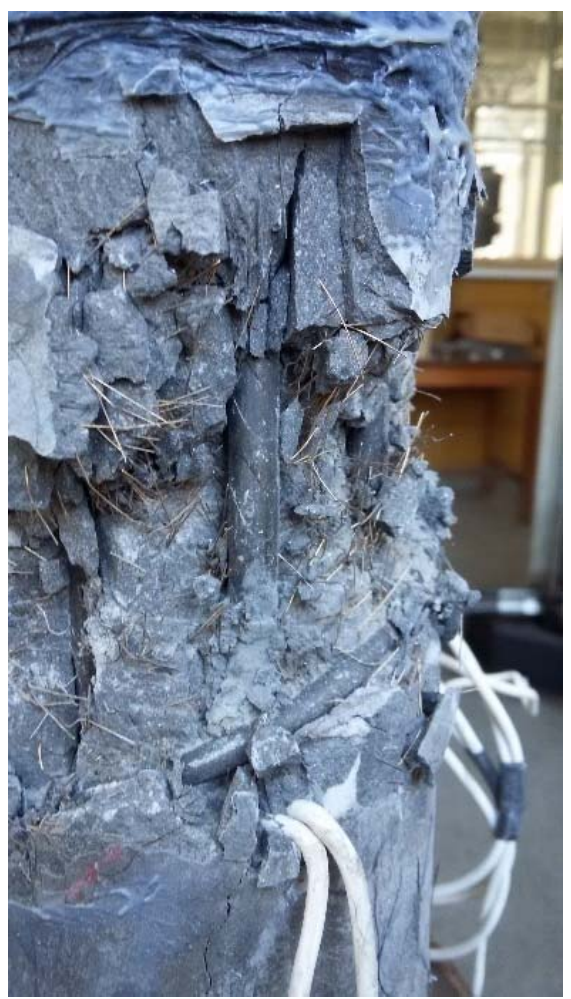

Figura 9.14 - Pilar MOD75TCF após a ruptura 


\section{Apêndice B - Diagramas força- deformação dos ensaios definitivos}

Neste anexo são apresentados os diagramas força-deformação dos pilares da série definitiva estudada na pesquisa. Os diagramas força-deformação são apresentados tendo como base o deslocamento axial do pilar e as deformações máximas registradas nas armaduras longitudinal e transversais.

\subsection{Série TCF}

Tabela 10.1 - Deformações máximas nas armaduras longitudinais e transversais apresentadas pelos pilares da série TCF

\begin{tabular}{|c|c|c|c|c|c|c|c|}
\hline Pilar & Pontos & $\begin{array}{l}\varepsilon_{\text {Asl }} \\
(\% \circ)\end{array}$ & $\begin{array}{l}\varepsilon_{\text {Asw }} \\
(\% 0)\end{array}$ & Pilar & Pontos & $\begin{array}{l}\varepsilon_{\text {Asl }} \\
(\% \circ)\end{array}$ & $\begin{array}{c}\varepsilon_{\text {Asw }} \\
(\% 0)\end{array}$ \\
\hline \multirow{4}{*}{ MOD10TCF } & $F_{1}, \varepsilon_{1}$ & $-4,37$ & 0,28 & \multirow{4}{*}{ MOD15TCF } & $F_{1}, \varepsilon_{1}$ & $-3,61$ & 0,14 \\
\hline & $F_{2}, \varepsilon_{2}$ & $-5,11$ & 0,38 & & $F_{2}, \varepsilon_{2}$ & $-3,68$ & 0,26 \\
\hline & $F_{3}, \varepsilon_{3}$ & $-18,41$ & - & & $F_{3}, \varepsilon_{3}$ & $-6,31$ & - \\
\hline & $F_{4}, \varepsilon_{4}$ & - & - & & $F_{4}, \varepsilon_{4}$ & - & - \\
\hline \multirow{4}{*}{ MOD20TCF } & $F_{1}, \varepsilon_{1}$ & $-3,74$ & 0,18 & \multirow{4}{*}{ MOD45TCF } & $F_{1}, \varepsilon_{1}$ & $-2,50$ & 0,36 \\
\hline & $F_{2}, \varepsilon_{2}$ & $-3,99$ & 0,20 & & $F_{2}, \varepsilon_{2}$ & $-1,62$ & 3,32 \\
\hline & $F_{3}, \varepsilon_{3}$ & $-6,81$ & 1,65 & & $F_{3}, \varepsilon_{3}$ & $-1,91$ & 10,55 \\
\hline & $F_{4}, \varepsilon_{4}$ & $-3,05$ & 5,69 & & $F_{4}, \varepsilon_{4}$ & - & 22,77 \\
\hline \multirow{4}{*}{ MOD55TCF } & $F_{1}, \varepsilon_{1}$ & $-5,34$ & 1,13 & \multirow{4}{*}{ MOD75TCF } & $F_{1}, \varepsilon_{1}$ & $-5,81$ & 0,62 \\
\hline & $F_{2}, \varepsilon_{2}$ & $-9,88$ & 7,07 & & $F_{2}, \varepsilon_{2}$ & $-9,67$ & 2,85 \\
\hline & $F_{3}, \varepsilon_{3}$ & $-11,63$ & 7,59 & & $F_{3}, \varepsilon_{3}$ & $-11,83$ & - \\
\hline & $F_{4}, \varepsilon_{4}$ & $-15,94$ & - & & $F_{4}, \varepsilon_{4}$ & $-10,27$ & - \\
\hline
\end{tabular}


MOD10TCF

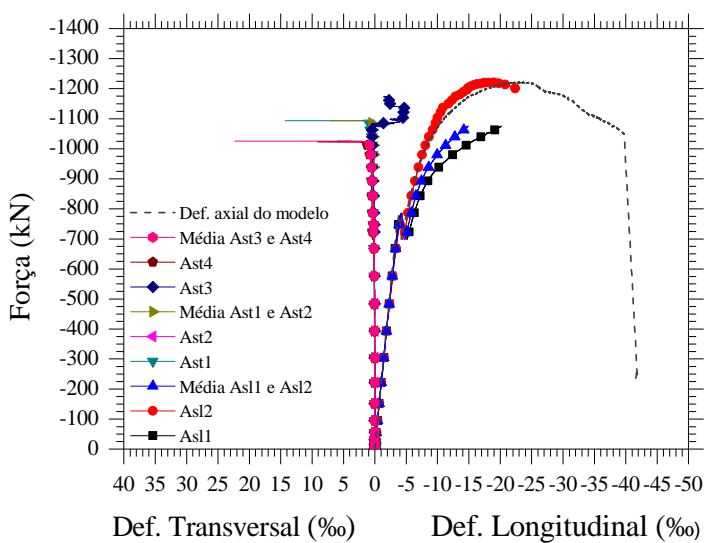

MOD15TCF

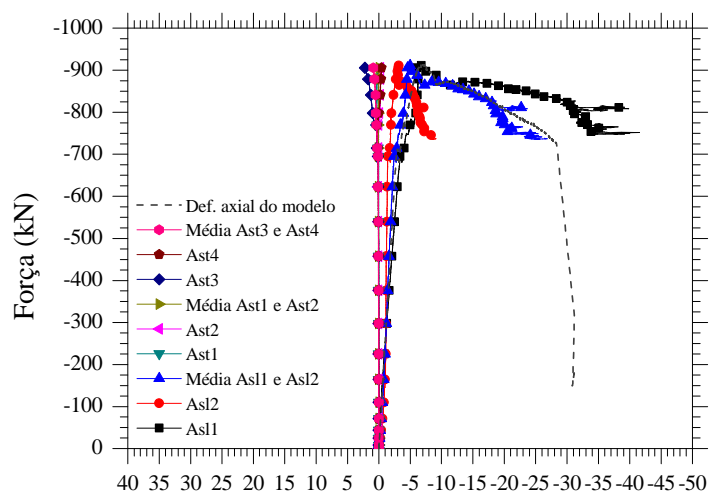

Def. Transversal (\%) Def. Longitudinal (\%)

\section{MOD20TCF}

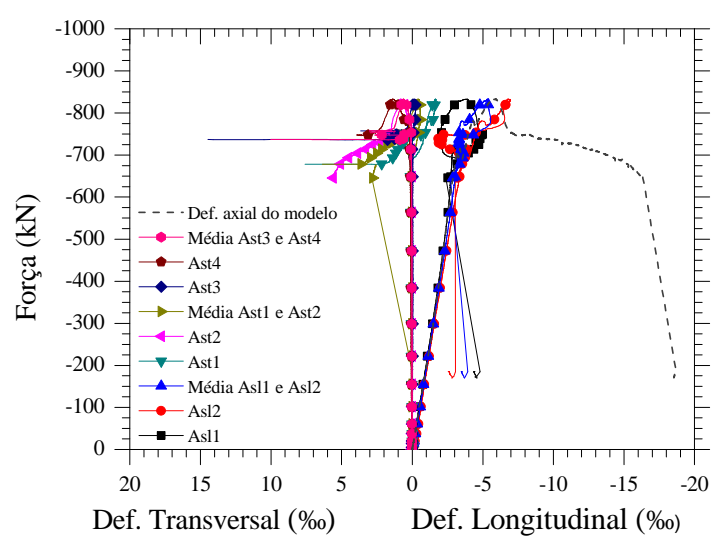

MOD45TCF

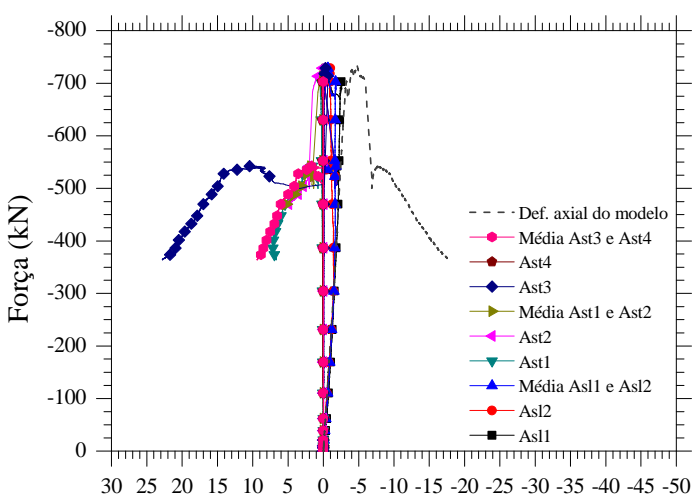

Def. Transversal (\%)

Def. Longitudinal (\%o)

\section{MOD55TCF}

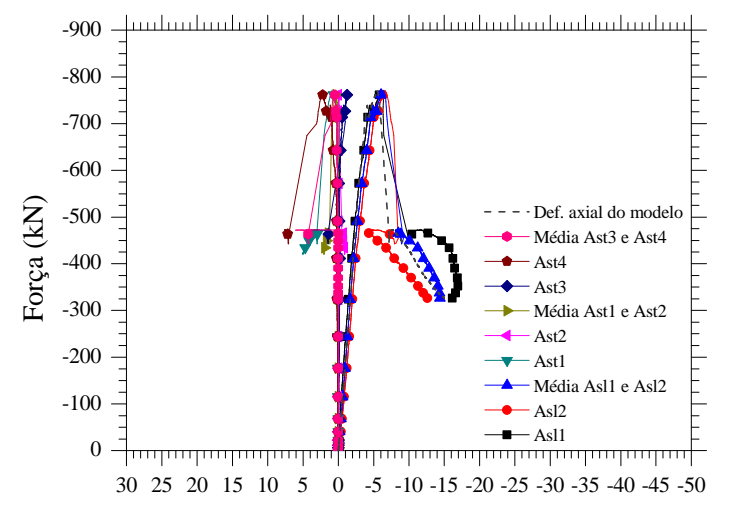

Def. Transversal (\%) Def. Longitudinal (\%o) MOD75TCF

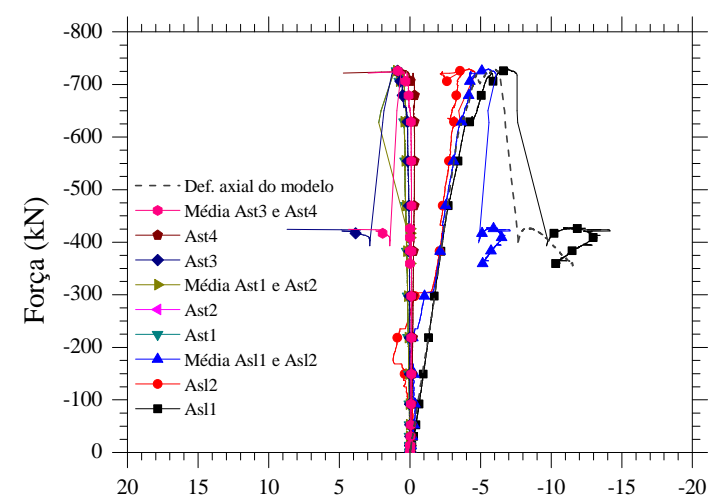

Def. Transversal (\%) Def. Longitudinal (\%)

Figura 10.1- Deformações nas armaduras longitudinais e transversais série TCF 


\subsection{Série TSF}

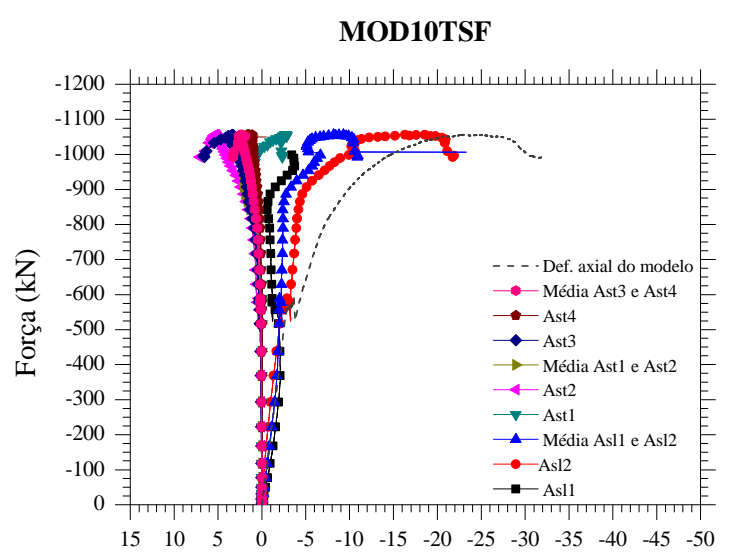

Def. Transversal (\%)

Def. Longitudinal (\%)

MOD15TSF

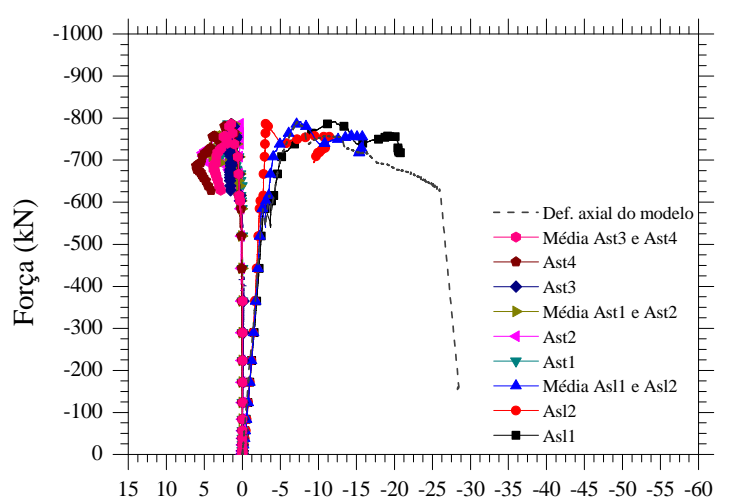

Def. Transversal (\%) Def. Longitudinal (\%)

MOD20TSF

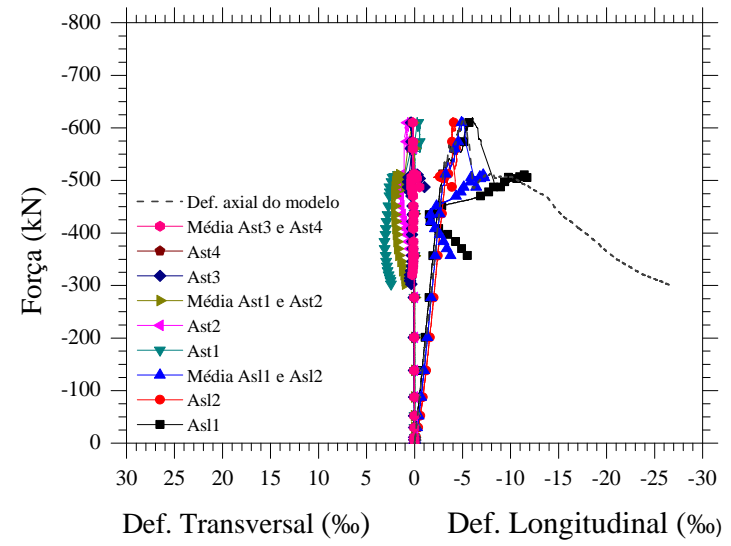

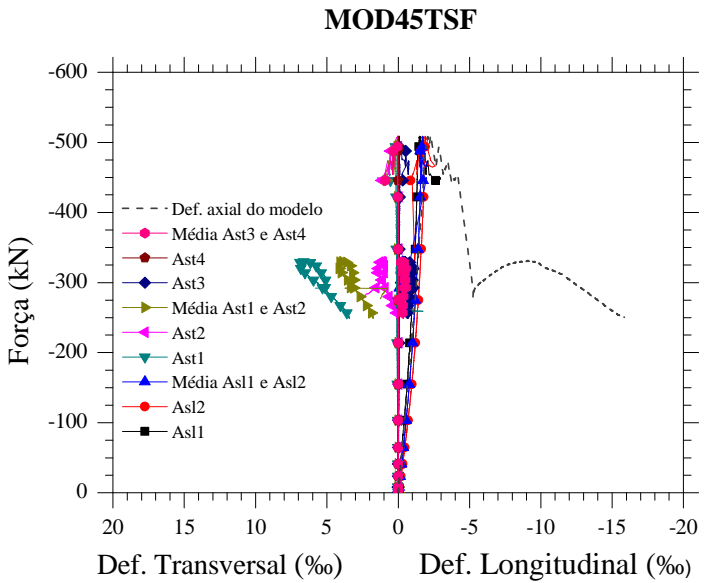

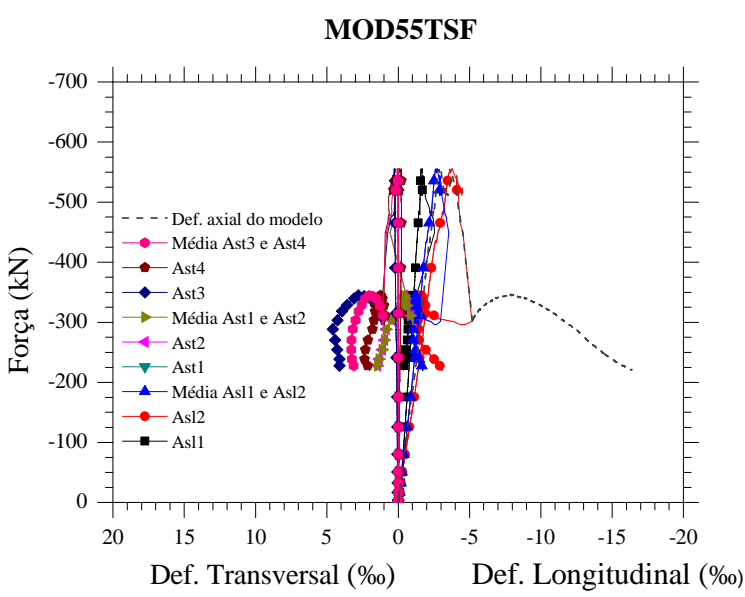

MOD75TSF

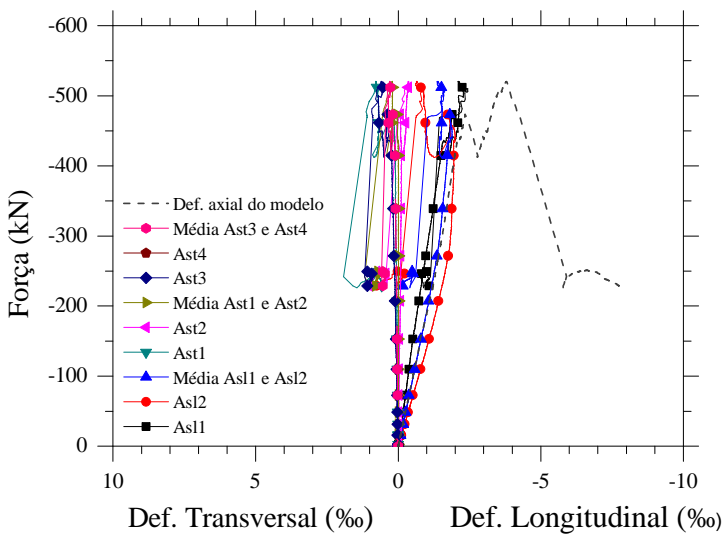

Figura 10.2 - Deformações nas armaduras longitudinais e transversais série TSF 
Tabela 10.2 - Deformações máximas nas armaduras longitudinais e transversais apresentadas pelos pilares da série TSF

\begin{tabular}{|c|c|c|c|c|c|c|c|}
\hline Pilar & Pontos & $\begin{array}{l}\varepsilon_{\text {Asl }} \\
(\% \circ)\end{array}$ & $\begin{array}{l}\varepsilon_{\text {Asw }} \\
(\% 0)\end{array}$ & Pilar & Pontos & $\begin{array}{l}\varepsilon_{\text {Asl }} \\
(\% 0)\end{array}$ & $\begin{array}{l}\varepsilon_{\text {Asw }} \\
(\% 0)\end{array}$ \\
\hline \multirow{4}{*}{ MOD10TSF } & $F_{1}, \varepsilon_{1}$ & $-2,33$ & 0,24 & \multirow{4}{*}{ M0D15TSF } & $F_{1}, \varepsilon_{1}$ & $-3,00$ & 0,20 \\
\hline & $F_{2}, \varepsilon_{2}$ & $-3,24$ & 0,39 & & $F_{2}, \varepsilon_{2}$ & $-3,76$ & 0,32 \\
\hline & $F_{3}, \varepsilon_{3}$ & $-16,45$ & 5,19 & & $F_{3}, \varepsilon_{3}$ & $-12,10$ & 1,94 \\
\hline & $F_{4}, \varepsilon_{4}$ & $-21,72$ & 7,22 & & $F_{4}, \varepsilon_{4}$ & - & 4,07 \\
\hline \multirow{4}{*}{ MOD20TSF } & $F_{1}, \varepsilon_{1}$ & $-3,75$ & 0,14 & \multirow{4}{*}{ MOD45TSF } & $F_{1}, \varepsilon_{1}$ & $-1,90$ & 0,08 \\
\hline & $F_{2}, \varepsilon_{2}$ & $-8,43$ & 1,00 & & $F_{2}, \varepsilon_{2}$ & $-0,69$ & 2,34 \\
\hline & $F_{3}, \varepsilon_{3}$ & $-11,38$ & 1,81 & & $F_{3}, \varepsilon_{3}$ & $-0,34$ & 6,71 \\
\hline & $F_{4}, \varepsilon_{4}$ & - & 2,44 & & $F_{4}, \varepsilon_{4}$ & - & 3,42 \\
\hline \multirow{4}{*}{ MOD55TSF } & $F_{1}, \varepsilon_{1}$ & $-3,61$ & 0,27 & \multirow{4}{*}{ MOD75TSF } & $F_{1}, \varepsilon_{1}$ & $-1,90$ & 0,37 \\
\hline & $F_{2}, \varepsilon_{2}$ & $-4,39$ & 1,03 & & $F_{2}, \varepsilon_{2}$ & $-0,88$ & 1,45 \\
\hline & $F_{3}, \varepsilon_{3}$ & $-1,62$ & 2,57 & & $F_{3}, \varepsilon_{3}$ & $-0,99$ & 1,02 \\
\hline & $F_{4}, \varepsilon_{4}$ & $-3,05$ & 4,17 & & $F_{4}, \varepsilon_{4}$ & $-1,21$ & 1,14 \\
\hline
\end{tabular}




\subsection{Série ICF}

MOD10ICF

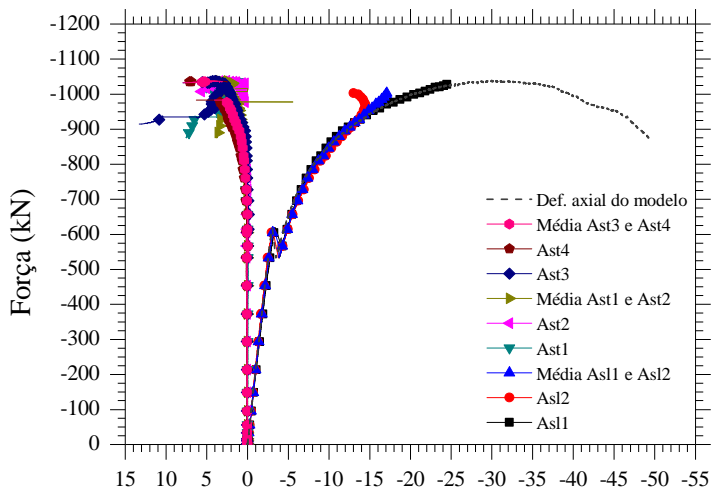

Def. Transversal (\%) Def. Longitudinal (\%o)

MOD20ICF

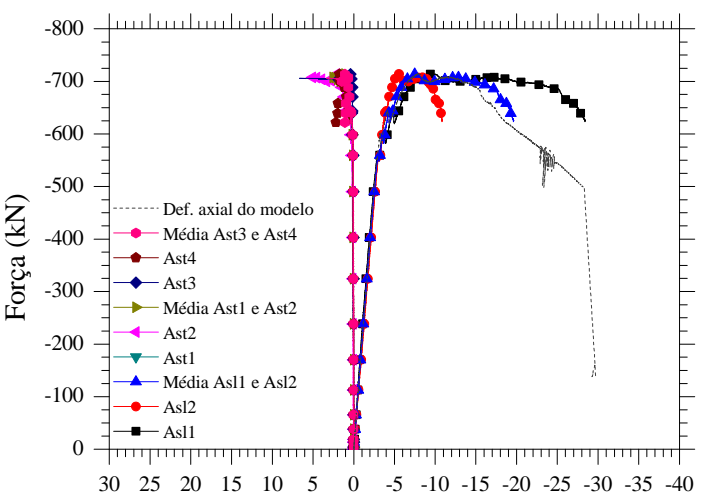

Def. Transversal (\%) Def. Longitudinal (\%)

MOD25ICF

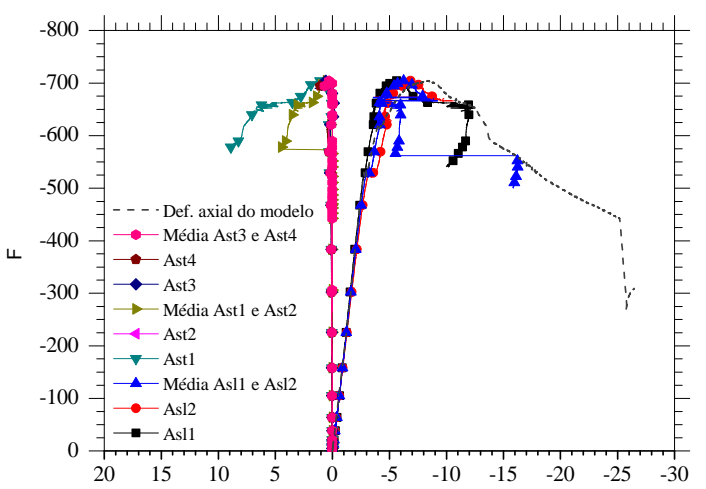

Def. Transversal (\%) Def. Longitudinal (\%)
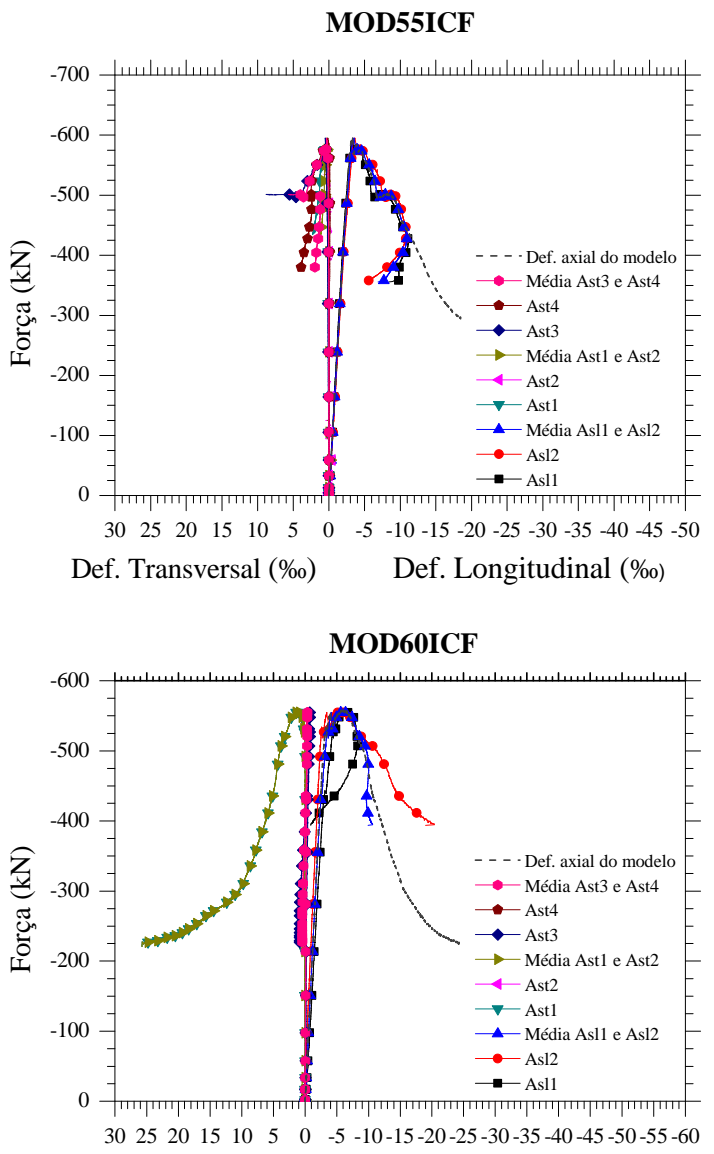

Def. Transversal (\%) Def. Longitudinal (\%o)

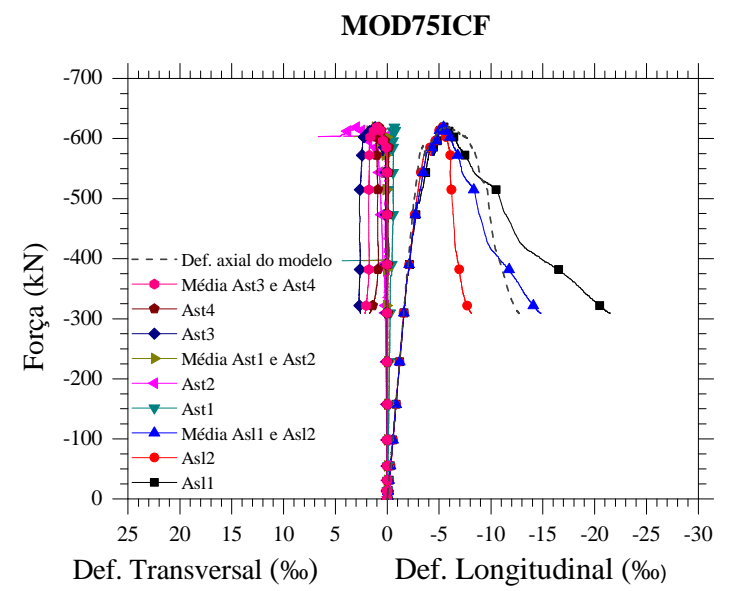

Figura 10.3 - Deformações nas armaduras longitudinais e transversais série ICF 
Tabela 10.3 - Deformações máximas nas armaduras longitudinais e transversais apresentadas pelos pilares da série ICF

\begin{tabular}{|c|c|c|c|c|c|c|c|}
\hline Pilar & Pontos & $\begin{array}{l}\varepsilon_{\text {Asl }} \\
(\% 0)\end{array}$ & $\begin{array}{c}\varepsilon_{\text {Asw }} \\
(\% 0) \\
\end{array}$ & Pilar & Pontos & $\begin{array}{l}\mathcal{E}_{\text {Asl }} \\
(\% \circ)\end{array}$ & $\begin{array}{c}\mathcal{E}_{\text {Asw }} \\
(\% 0)\end{array}$ \\
\hline \multirow{4}{*}{ MOD10ICF } & $F_{1}, \varepsilon_{1}$ & $-3,37$ & 0,10 & \multirow{4}{*}{ MOD20ICF } & $F_{1}, \varepsilon_{1}$ & $-3,60$ & 0,29 \\
\hline & $F_{2}, \varepsilon_{2}$ & $-3,91$ & 0,08 & & $F_{2}, \varepsilon_{2}$ & $-3,91$ & 0,34 \\
\hline & $F_{3}, \varepsilon_{3}$ & - & 4,46 & & $F_{3}, \varepsilon_{3}$ & $-9,74$ & 2,24 \\
\hline & $F_{4}, \varepsilon_{4}$ & - & 7,51 & & $F_{4}, \varepsilon_{4}$ & - & - \\
\hline \multirow{4}{*}{ MOD25ICF } & $F_{1}, \varepsilon_{1}$ & $-4,83$ & 0,30 & \multirow{4}{*}{ MOD55ICF } & $F_{1}, \varepsilon_{1}$ & $-3,42$ & 0,39 \\
\hline & $F_{2}, \varepsilon_{2}$ & $-4,84$ & 0,34 & & $F_{2}, \varepsilon_{2}$ & $-7,77$ & 4,18 \\
\hline & $F_{3}, \varepsilon_{3}$ & $-6,85$ & 1,09 & & $F_{3}, \varepsilon_{3}$ & $-8,99$ & 2,45 \\
\hline & $F_{4}, \varepsilon_{4}$ & - & - & & $F_{4}, \varepsilon_{4}$ & - & - \\
\hline \multirow{4}{*}{ MOD60ICF } & $F_{1}, \varepsilon_{1}$ & $-4,80$ & 0,53 & \multirow{4}{*}{ MOD75ICF } & $F_{1}, \varepsilon_{1}$ & $-4,34$ & 1,07 \\
\hline & $F_{2}, \varepsilon_{2}$ & $-4,84$ & 0,62 & & $F_{2}, \varepsilon_{2}$ & $-4,49$ & 1,17 \\
\hline & $F_{3}, \varepsilon_{3}$ & $-6,36$ & 1,08 & & $F_{3}, \varepsilon_{3}$ & $-5,53$ & 3,03 \\
\hline & $F_{4}, \varepsilon_{4}$ & - & 25,77 & & $F_{4}, \varepsilon_{4}$ & $-21,44$ & 2,59 \\
\hline
\end{tabular}




\subsection{Série ISF}

MOD10ISF

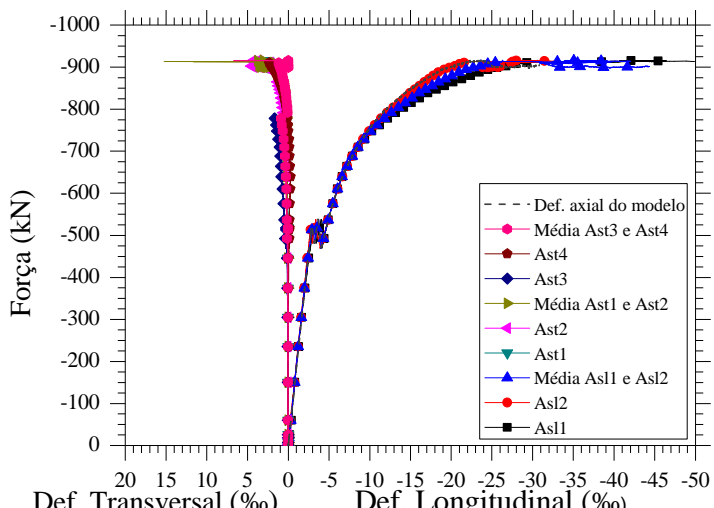

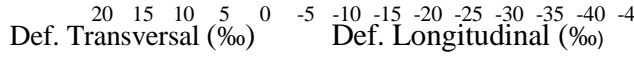

MOD20ISF

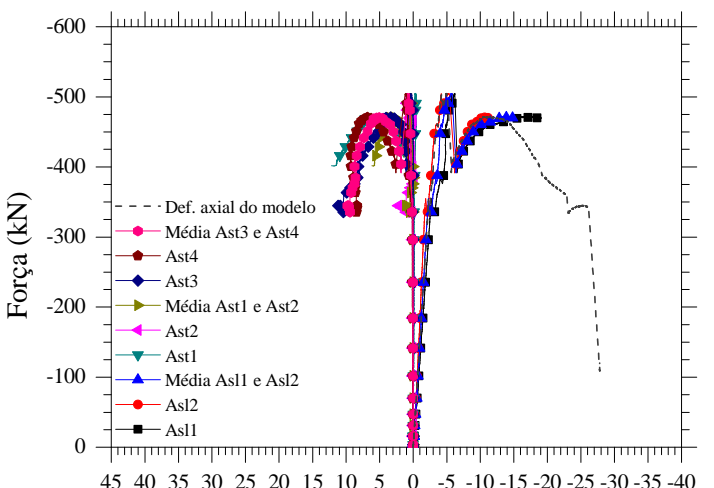

Def. Transversal (\%) Def. Longitudinal (\%)

MOD25ISF

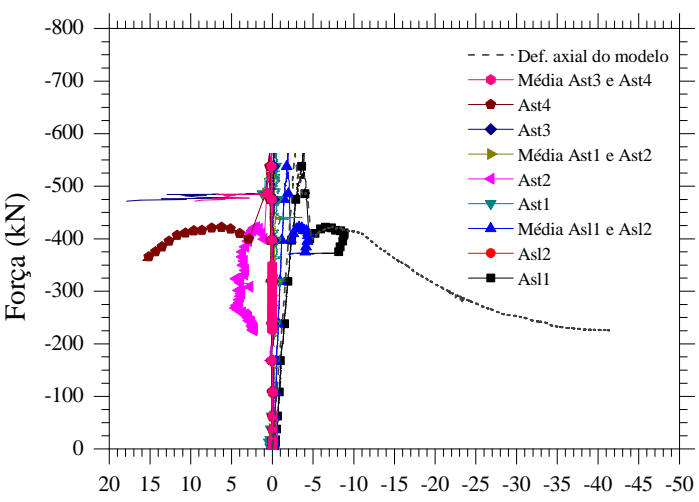

Def. Transversal (\%) Def. Longitudinal (\%)
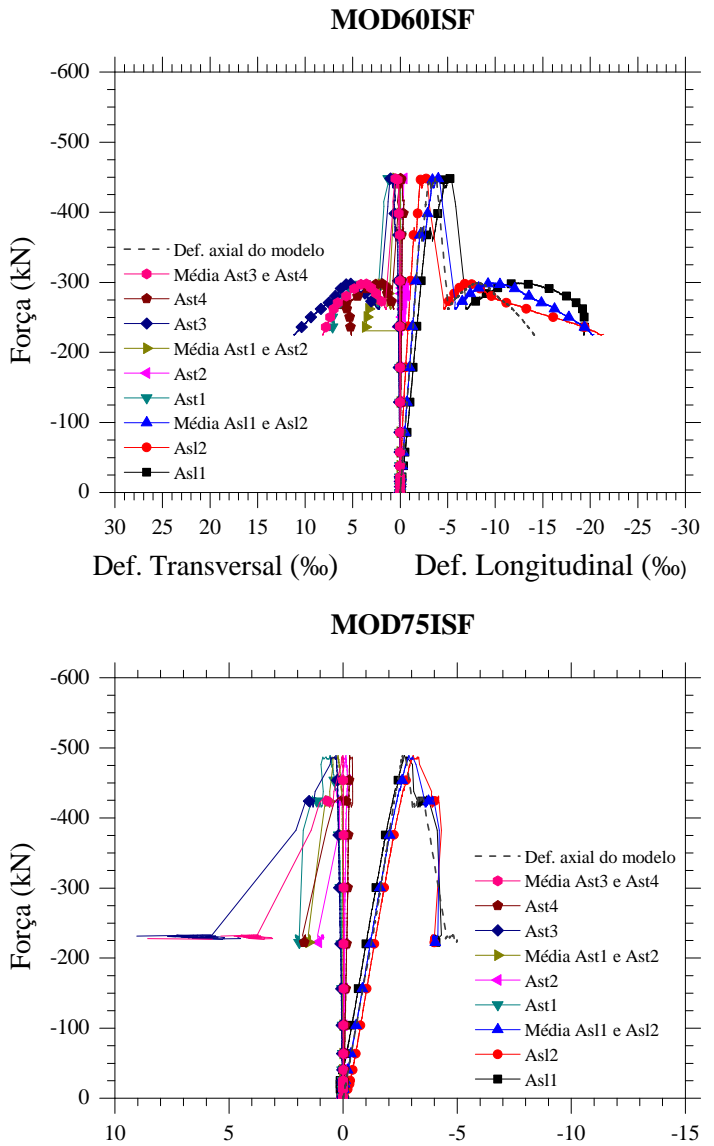

Def. Transversal (\%) Def. Longitudinal (\%)

Figura 10.4 - Deformações nas armaduras longitudinais e transversais série ISF 
Tabela 10.4 - Deformações máximas nas armaduras longitudinais e transversais apresentadas pelos pilares da série ISF

\begin{tabular}{|c|c|c|c|c|c|c|c|}
\hline Pilar & Pontos & $\begin{array}{l}\varepsilon_{\text {Asl }} \\
(\% \circ)\end{array}$ & $\begin{array}{c}\varepsilon_{\text {Asw }} \\
(\% \circ)\end{array}$ & Pilar & Pontos & $\begin{array}{l}\varepsilon_{\text {Asl }} \\
(\% 0)\end{array}$ & $\begin{array}{c}\mathcal{E}_{\text {Asw }} \\
(\% 0)\end{array}$ \\
\hline \multirow{4}{*}{ MOD10ISF } & $F_{1}, \varepsilon_{1}$ & $-3,17$ & 0,27 & \multirow{4}{*}{ MOD20ISF } & $F_{1}, \varepsilon_{1}$ & $-5,76$ & 0,39 \\
\hline & $F_{2}, \varepsilon_{2}$ & $-4,11$ & 0,34 & & $F_{2}, \varepsilon_{2}$ & $-6,52$ & 2,58 \\
\hline & $F_{3}, \varepsilon_{3}$ & $-42,48$ & 3,82 & & $F_{3}, \varepsilon_{3}$ & $-17,67$ & 6,96 \\
\hline & $F_{4}, \varepsilon_{4}$ & $-26,37$ & 4,75 & & $F_{4}, \varepsilon_{4}$ & - & 11,46 \\
\hline \multirow{4}{*}{ MOD25ISF } & $F_{1}, \varepsilon_{1}$ & $-3,79$ & 0,34 & \multirow{4}{*}{ MOD55ISF } & $F_{1}, \varepsilon_{1}$ & - & - \\
\hline & $F_{2}, \varepsilon_{2}$ & $-4,59$ & 2,91 & & $F_{2}, \varepsilon_{2}$ & - & - \\
\hline & $F_{3}, \varepsilon_{3}$ & $-6,79$ & 6,58 & & $F_{3}, \varepsilon_{3}$ & - & - \\
\hline & $F_{4}, \varepsilon_{4}$ & - & 2,31 & & $F_{4}, \varepsilon_{4}$ & - & - \\
\hline \multirow{4}{*}{ MOD60ISF } & $F_{1}, \varepsilon_{1}$ & $-4,62$ & 0,65 & \multirow{4}{*}{ MOD75ISF } & $F_{1}, \varepsilon_{1}$ & $-3,07$ & 0,57 \\
\hline & $F_{2}, \varepsilon_{2}$ & $-6,90$ & 2,22 & & $F_{2}, \varepsilon_{2}$ & $-4,13$ & 5,21 \\
\hline & $F_{3}, \varepsilon_{3}$ & $-12,81$ & 5,49 & & $F_{3}, \varepsilon_{3}$ & $-4,02$ & 5,79 \\
\hline & $F_{4}, \varepsilon_{4}$ & $-21,20$ & 11,18 & & $F_{4}, \varepsilon_{4}$ & $-4,07$ & 1,92 \\
\hline
\end{tabular}

